\title{
1 Genome size evolution in the diverse insect order Trichoptera
}

2

3

4

5

6

7

\section{Authors}

Jacqueline Heckenhauer (jacqueline.heckenhauer@senckenberg.de) ${ }^{1,2^{*}}, \quad$ Paul B. Frandsen (paul_frandsen@byu.edu) $^{1,3,4}, \quad$ John $\quad$ S. $\quad$ Sproul $\quad$ (johnssproul@gmail.com) $^{5}, \quad$ Zheng $\quad$ Li (zheng.li@austin.utexas.edu) ${ }^{6}$, Juraj Paule (juraj.paule@senckenberg.de) ${ }^{7}$, Amanda M. Larracuente (alarracu@ur.rochester.edu) $)^{5}$, Peter J. Maughan (jeff_maughan@byu.edu) ${ }^{3}$, Michael S. Barker (msbarker@arizona.edu) $^{6}$, Julio V. Schneider (julio.schneider@senckenberg.de) ${ }^{2}$, Russell J. Stewart (russell.stewart@utah.edu) ${ }^{8}$, Steffen U. Pauls (steffen.pauls@ senckenberg.de) $^{1,2,9}$

\section{Affiliations}

*corresponding author

${ }^{1}$ LOEWE Centre for Translational Biodiversity Genomics (LOEWE-TBG), Frankfurt, Germany,

${ }^{2}$ Department of Terrestrial Zoology, Senckenberg Research Institute and Natural History Museum Frankfurt, Frankfurt, Germany

${ }^{3}$ Department of Plant \& Wildlife Sciences, Brigham Young University, Provo, UT

${ }^{4}$ Data Science Lab, Smithsonian Institution, Washington, DC

${ }^{5}$ Department of Biology, University of Rochester, Rochester, NY, USA

${ }^{6}$ Department of Ecology and Evolutionary Biology, University of Arizona, Tucson, USA

${ }^{7}$ Department of Botany and Molecular Evolution, Senckenberg Research Institute and Natural History Museum Frankfurt, Frankfurt, Germany

${ }^{8}$ Department of Biomedical Engineering, University of Utah, Salt Lake City, UT ${ }^{9}$ Institute for Insect Biotechnology, Justus-Liebig-University, Gießen, Germany 


\section{Abstract}

Background: Genome size is implicated in form, function, and ecological success of a species. Two principally different mechanisms are proposed as major drivers of eukaryotic genome evolution and diversity: Polyploidy (i.e. whole genome duplication: WGD) or smaller duplication events and bursts in the activity of repetitive elements (RE). Here, we generated de novo genome assemblies of 17 caddisflies covering all major lineages of Trichoptera. Using these and previously sequenced genomes, we use caddisflies as a model for understanding genome size evolution in diverse insect lineages.

Results: We detect a $\sim 14$-fold variation in genome size across the order Trichoptera. While gene age distribution analyses found no evidence that ancient WGD played a major role in genome size variation in this group, we find strong evidence that transposable element (TE) expansions are the primary drivers of large caddisfly genome sizes. Using an innovative method to examine TEs associated with BUSCO genes, we find that TE expansions have a major impact on protein-coding gene regions with TE-gene associations showing a linear relationship with increasing genome size. Intriguingly, we find that expanded genomes and TE-gene associations preferentially evolved in caddisfly clades with a higher ecological diversity (i.e. various feeding modes, diversification in variable, less stable environments).

Conclusion: Our findings provide a platform to test hypotheses about the potential evolutionary roles of TE activity and TE-gene associations, particularly in groups with high species, ecological, and functional diversities.

\section{Key words:}

biodiversity, de novo genome assembly, genomics, genomic diversity, genome duplication, genome size evolution, insects, repetitive elements, transposable elements, Trichoptera 


\section{Background}

Genome size can vary widely among closely and distantly related species, though our knowledge is still scarce for many non-model groups. This is especially true for insects, which account for much of the earth's species diversity. To date 1,345 insect genome size estimates have been published, representing less than $0.15 \%$ of all described insect species (Gregory, 2005: Animal Genome Size Database: http://www.genomesize.com, last accessed 2021-04-30).

Genome size in insects ranges 240-fold from $69 \mathrm{Mb}$ in chironomid midges [1] to $16.5 \mathrm{~Gb}$ in the mountain grasshopper Podisma pedestris [2].

Genome size variation relates poorly to the number of coding genes or the complexity of the organism (C-value enigma, [3],[4],[5],[6]) and evolutionary drivers of genome size variation remain a topic of ongoing debate (e.g. [7], [8], [9], [10]). Two principally different mechanisms are proposed as primary drivers of eukaryotic genome size evolution: Whole genome duplication (WGD, i.e. polyploidy) or smaller duplication events and expansion of repetitive elements (REs, [5]). While WGD is ubiquitous in plant evolution, it has been regarded as the exception in animals [11], [12]. However, ancient WGD has been hypothesized to be an important driver of evolution of mollusks (e.g. [13]) amphibians (e.g. [14], [15], fish (e.g. [16], [17], [18]) and arthropods (e.g. [19], [20], [21]), including multiple putative ancient large-scale gene duplications within Trichoptera [22].

REs are the primary driver of genome size variation in many eukaryotic genomes [23], [24]. The two major categories of REs are tandem repeats (satellite DNA) and mobile transposable elements (TEs). TEs are classified into class I [retrotransposons: endogenous retroviruses (ERVs), related long terminal repeat (LTR) and non-LTR retrotransposons: SINEs (Short Interspersed Nuclear Elements), LINEs (Long Interspersed Nuclear Elements)] and class II elements (DNA transposons, [25]). In insects, the genomic proportion of TEs ranges from 1\% in the antarctic midge Belgica antarctica [26] to $65 \%$ in the migratory locust Locusta migratoria [27]. Broad-scale analysis of TE abundance in insects suggests that some order- 
specific signatures are present, however, major shifts in TE abundance are also common at shallow taxonomic levels [28], [29], including in Trichoptera [30]. The movement and proliferation of REs can have deleterious consequences on gene function and genome stability [31], [32], [33], [34], [35]. Moreover, repeat content and abundance can turn over rapidly even over short evolutionary time scales (reviewed in [36]). This rapid evolution has consequences for genome evolution and speciation, e.g. repeat divergence causes genetic incompatibilities between even closely related species [37]. However, TEs can also be sources of genomic innovation with selective advantages for the host [38], [39], [40], [41], [42], [43] and they can contribute to global changes in gene regulatory networks [44], [45], [46]. Investigating RE dynamics in diverse clades provides a powerful lens for understanding their capacity for contributing to genome function and evolution. In addition, studying REs in species-rich groups may be critical for understanding how environmental factors are linked to genome evolution in natural populations (see [47]).

With more than 16,500 species, caddisflies (Trichoptera) are among the most diverse of all aquatic insects [48]. Their species richness is reflective of their ecological diversity, including, e.g. microhabitat specialization, full array of feeding modes, and diverse use of underwater silk secretions [49], [50]. An initial comparison of six caddisfly species found wide genome size variation in Trichoptera (ranging from $230 \mathrm{Mbp}$ to $1.4 \mathrm{Gbp}$ ). In that study, we hypothesized that the observed variation was correlated with caddisfly phylogeny and that TEs contributed to a suborder-specific increase of genome size [30].

Here, we present a multi-faceted analysis to investigate genome size evolution in the order Trichoptera, as an example for highly diversified non-model organisms. Specifically, we (i) estimated genome size for species across the order to explore phylogenetic patterns in the distribution of genome size variation in Trichoptera and (ii) generated 17 new Trichoptera genomes to analyze, in conjunction with 9 existing genomes, the causes (WGD, TE expansions) 
of genome size variation in the evolution of caddisflies. Studying the genomic diversity of this highly diversified insect order adds new insights into drivers of genome size evolution with potential to shed light on how genome size is linked to form, function, and ecology.

\section{Data Description}

\section{Genomic resources}

Non-model insect clades are largely underrepresented in genomic research, especially aquatic insects [51], [52]. This makes studying broad trends of genome evolution, such as the evolution of genome size and the links between ecological diversification and genome evolution, very difficult. Only nine genomes were available for the order Trichoptera prior to this study. With this in mind, we combined long- and short-read sequencing technologies to generate 17 new de novo genome assemblies across a wide taxonomic range, covering all major lineages of Trichoptera. Details on sequencing coverage and assembly strategies are given in Data S1 and supplementary notes 1-4. To assess quality, we calculated assembly statistics with QUAST v5.0.2 [53], examined completeness with BUSCO v3.0.2 [54], [55] and screened for potential contamination with taxon-annotated GC-coverage (TAGC) plots using BlobTools v1.0 (94, supplementary Figs. S31-S47). The new genomes are of comparable or better quality than other Trichoptera genomes previously reported in terms of BUSCO completeness and contiguity (Table 1, Data S1). This study increases the number of assemblies in this order from nine to 26, nearly tripling the number of available caddisfly genomes and thus providing a valuable resource for studying genomic diversity across this ecologically diverse insect order. The annotation of these genomes predicted 6,413 to 12,927 proteins (Table 1). Most of the annotated proteins $(94.4 \%-98.8 \%)$ showed significant sequence similarity to entries in the NCBI nr database. GO Distributions were similar to previously annotated caddisfly genomes, i.e. the major biological processes were cellular and metabolic processes. Catalytic activity was the largest subcategory in molecular function and the cell membrane subcategories were the largest 
cellular component (supplementary Figs. S1-S30). This project has been deposited at NCBI under BioProject ID: PRJNA558902. For accession numbers of individual assemblies see Table 1.

We downloaded existing Trichoptera genomes from GenBank (https://www.ncbi.nlm.nih.gov/genome/) or Lepbase (http://download.lepbase.org/v4/) and used these in conjunction with our newly generated genomes to analyze genome size evolution as explained in the following sections of this manuscript.

\section{Flow cytometry}

In addition to genomic resources, we used flow cytometry to detect genome size variation across the order. Our study increased the number of species with available flow cytometrybased genome size estimates from 4 [57] to 31. Estimates were submitted to the Animal Genome Size Database (http://www.genomesize.com).

\section{Analysis}

\section{Genome size evolution in Trichoptera}

Based on the genomes of six trichopteran species, Olsen et al. [30] found a 3-fold suborderspecific increase of genome size and hypothesized that genome size variation is correlated with their phylogeny. To test this hypothesis, we first reconstructed phylogenetic relationships by analyzing 2,000 single-copy BUSCO genes from the 26 study species (Fig. $1 \&$ Fig. 2, Fig. S48). We obtained a robust molecular phylogeny that was in agreement with recent phylogenetic hypotheses ([58], see supplementary note 6) and which showed that Trichoptera is divided into two suborders: Annulipalpia (Figs. $1 \& 2$ : Clade A, blue) and Integripalpia [consisting of basal Integripalpia (Fig. 1: Clade B1-3, light green) and infraorder Phryganides (Fig. 1: clade B4, dark green)]. Trichopterans use silk to build diverse underwater structures (see illustrations Fig.1; supplementary note 6, supplementary Fig. S48). Thus, we refer to 
Annulipalpia as 'fixed retreat- and net-spinners', to Phryganides (Integripalpia) as 'tube casebuilders', and to basal Integripalpia as 'cocoon-builders'.

We used three approaches for estimating genome size across Trichoptera: $k$-mer distributionestimates, backmapping of sequence data to available draft genomes (as described in [59]), and flow cytometry (FCM, supplementary note 7, supplementary figures S49-S72, Data S1). FCM estimates can be affected by chromatin condensation, the proportion of cells in $\mathrm{G} 0$ to $\mathrm{G} 1$ phases [60], [61] and endoreplication in insect cells and tissues [62] while kmer-based estimates can be affected by repetitive elements in the genome resulting in smaller genome size estimates (e.g. [63], [57], [64]). Bland-Altman plots (supplementary note 8, Fig. S73) revealed general agreement of all three methods in our study. However, the FCM estimates were generally higher compared to the sequence-based estimates (Fig. 1, Data S1) and, among all three approaches, this measure is expected to be the most accurate [8]. We observe that variation among the methods increased with genome size, indicating issues potentially caused by repeat content (see Results Repeat dynamics).

We observed large variation in genome size across the order. Genome size tends to be lower in 'fixed retreat- and net-spinners' and 'cocoon-builders' compared to 'tube case-builders' (Fig. 1). Specifically, we observe that genome size varies $\sim 14$-fold ranging from $1 \mathrm{C}=154 \mathrm{Mb}$ in 'cocoon-builders' (Fig. 1, B1: Hydroptilidae) to 1C $=2129 \mathrm{Mb}$ in 'tube case-builders' (Fig. 1, clade B4: Limnephilidae). Of the 29 species analyzed by FCM, Halesus digitatus (Fig. 1, clade B4: Limnephilidae, Intergripalpia) possessed the largest genome $(1 \mathrm{C}=2129 \mathrm{Mb})$, while the genome of Hydropsyche saxonica (Fig. 1, clade A: Hydropsychidae, 'fixed retreat- and netspinners') was the smallest $(1 \mathrm{C}=242 \mathrm{Mb})$. Genome size estimates based on sequence-based methods (kmer-based and back-mapping) range from 1C $=154-160 \mathrm{Mb}$ in Agraylea sexmaculata (Fig. 1, clade B1: Hydroptilidae, 'cocoon-builders') to $1 \mathrm{C}=1238-1400 \mathrm{Mb}$ in Sericostoma sp. (Fig. 1, clade B4: Sericostomatidae, 'tube case-builders').

\section{Repeat Dynamics}




\section{Repetitive element abundance and classification}

To understand the structural basis of genome size variation across the order Trichoptera we explored repetitive element (RE) content. We found that major expansions of transposable elements (TEs) contribute to larger genomes in 'tube case-' and some 'cocoon-builders', but particularly in 'tube case-builders' with an average of $\sim 600 \mathrm{Mb}$ of REs compared to $\sim 138 \mathrm{Mb}$ in 'fixed retreat- and net-spinners' (Fig. 2 A, B). LINEs are the most abundant classified TEs in 'cocoon-' and 'tube case-builders' and comprise $>154 \mathrm{Mb}$ on average in 'tube case-builders', or an average genome proportion of $16.9 \%$ (range $=5.6-34.7 \%$ ). This represents a $1.8-$ and 2.8 fold increase in genome proportion relative to 'cocoon-builders' and 'fixed retreat- and netspinners', respectively. The LINE abundance of $>312 \mathrm{Mb}$ in Odontocerum albicorne exceeds the entire assembly lengths (152-282 $\mathrm{Mb})$ of the three smallest genome assemblies (Hydropsyche tenuis, Parapsyche elsis, and Agraylea sexmaculata) (Fig. 2 A, B). DNA transposons also comprise large genomic fractions in both 'cocoon-' and 'tube case-builders' (averages of $54.4 \mathrm{Mb}$ and $32.8 \mathrm{Mb}$, respectively). However, despite containing a large number of bps, they make up a smaller fraction of total bps in the genomes of 'cocoon-' and 'tube casebuilders' than in 'fixed retreat- and net-spinners' (average genome proportion $=5.9 \%, 4.5 \%$, and $11.1 \%$ in 'tube case-builders', 'cocoon-builders', and 'fixed retreat- and net-spinners', respectively) (Fig. 2 B), and thus cannot explain the larger genome sizes. SINEs, LTRs, Penelope (grouped with "other" repeats in Fig. 2), and satDNAs show a disproportionate increase in 'cocoon-' and 'tube case-builders', however, all categories combined make up a relatively small proportion of their genomes (all less than 3\% on average in Integripalpia) (Fig.

2, B). Unclassified repeats are the most abundant repeat category across all Trichoptera but also show disproportionate expansions in both 'cocoon-' and 'case-builders' relative to 'fixed retreat- and net-spinners' (Fig. 2 A, B). The general trends noted in our assembly-based analysis of REs were corroborated by our reference-free analysis of repeat abundance (Fig. S74, supplementary note 9 ). 
To test whether the observed abundance patterns of specific TEs are driven by shared ancient proliferation events or more recent/ongoing activity of the respective TEs, we analyzed TE age distributions. TE age distributions showed a high abundance of recently diverged TE sequences in 'cocoon-' and 'tube case-builders', particularly in LINEs, DNA transposons, and LTRs in which the majority of TEs for a given class show $0-10 \%$ sequence divergence within copies of a given repeat (Fig. 3). This trend was particularly pronounced among 'tube case-builders' with several species showing high abundance of LINEs and DNA transposons with 0-5\% sequence divergence (Fig. 3). This pattern suggests that the observed TE expansion is due primarily to ongoing TE activity within lineages rather than a few shared bursts of activity in ancestral lineages. This is further supported by our analysis of repeat sub-classes with landscape plots (Fig. S75). For example, in our study, LINE abundance is often due to the expansion of different LINE subclasses even between species in the same sub-clade (e.g., compare Lepidostoma with Micrasema, Himalopsyche with Glossosoma; Fig. S75). We also find evidence of shared ancient bursts of SINE activity in 'cocoon-' and 'tube case-builders', although SINEs are not an abundant repeat class in any species (avg. genomic proportion=1.9\% stdev=1.7\%) (Fig. to these putative gene fragments discovered by BUSCO as 'repetitive BUSCOs' BUSCO gene fragments in 'cocoon-' and 'tube case-builders' (Fig. 4A) that are significantly correlated with total repeat abundance, as well as the genomic proportion of LINEs and DNA 
transposons (supplementary Fig. S77). To test whether repetitive fragments were due to TE insertions near or in the BUSCO genes or, conversely, due to the proliferation of "true" BUSCO protein-coding gene fragments throughout the genome, we examined patterns of BUSCO gene structure in pairwise alignments of three species pairs in which one species has a repetitive fragment (i.e., the "inflated" species) and its counterpart does not (i.e., the "reference" species). 73 of 75 randomly sampled alignments were consistently missing or non-contiguous in inflated regions in the reference sequence (Fig. 4B). The number of BLAST hits in the genome assembly of an "inflated species" when using the BUSCO sequence from the "reference species" as a query was significantly fewer than when using the BUSCO sequence from the "inflated species" as a query (Fig. 4C, Data S2). Our intersect analysis aimed at (I) quantifying shifts in associations between TEs and genic regions across Trichoptera lineages with varying repeat abundance and (II) determining if repetitive fragments were annotated as TEs. It showed that large fractions of BLAST hits for repetitive BUSCOs (when BLASTed to their own assembly) are in fact annotated transposable element sequences, especially LINEs and DNA transposons (Fig. 4D). We further validated the insertion of TEs by mapping Nanopore reads to subsets of repetitive BUSCOs, thus ensuring that junctions between repetitive BUSCOs and non-repetitive regions were embedded in full reads and do not occur disproportionately at ends of reads as would be expected in chimeric reads (see supplementary note 11, supplementary Figs. S76S87). Taken together, these findings provide strong evidence that the repetitive fragments we observe in BUSCO genes are derived from TE sequences. These sequences may represent remnants left behind following historical insertion events, or TE sequences with open reading frames that are immediately adjacent to protein-coding genes and inadvertently classified as BUSCO fragments. Given the large fraction of BUSCO genes shown to have TE fragments (averages of $11.2 \%$ and $21.4 \%$ in 'cocoon-' and 'tube case-builders', respectively, compared to $0.062 \%$ in annulipalipans), this finding highlights the impact of TEs on the composition of protein-coding genes in species with repeat-rich genomes. 


\section{Gene and genome duplications}

Recently, a transcriptome-based study found evidence for putative ancient gene and genome duplications in hexapods, including potential WGD events in caddisflies [22], suggesting that duplication events could be responsible for some genome size variation in Trichoptera. We investigated whether this pattern persists with whole genome data and found that the age distribution of duplications in 18 genomes were significantly different compared to the background rate of gene duplication (Figs. $88 \& 89$ ). To identify if any significant peak is consistent with a potential WGD, we used mixture modeling to identify peaks in these gene age distributions. We found no obvious peak consistent with an ancient WGD suggesting that WGD did not play a major role in genome size variation in Trichoptera.

\section{Discussion}

The drivers and evolutionary consequences of genome size evolution are a topic of ongoing debate. Several models have been proposed [8]. Some hypothesize genome size to be a (mal)adaptive trait by impacting phenotypic traits such as developmental/life history, body size neutral theories suggest that DNA accumulation occurs only by genetic drift without selective pressures playing a major role in the accumulation or loss of DNA [the mutational hazard hypothesis (MHH, [23] and the mutational equilibrium hypothesis ( $\mathrm{MEH}$, [24]]. The MHH only allows for small deleterious effects for the accumulation of extra DNA which is accompanied by higher mutation rates in larger genomes [23], while the MEH focuses on the balance between insertions and deletions. It suggests that genome expansions arise by 'bursts' of duplication 
In this study, we observe that genome size varies $\sim 14$-fold across the order Trichoptera, with lower genome size estimates in 'fixed retreat- and net-spinners' and 'cocoon-builders' compared to 'tube case-builders' and explore potential drivers of genome size evolution. Although, recent genomic studies have shown evidence of bursts of gene duplication and gene family expansion during the evolution of hexapods [22], [69] the presence of ancient genome duplication events are still in debate [70], [71], [72]. We found no evidence of ancient WGD in the gene age distribution in our Trichoptera genomes, although we recognize that our current genome assemblies might be too fragmented to infer synteny. Future studies using chromosome-level genome assemblies are needed to allow a deeper exploration of putative ancient duplications observed by Li et al. [22].

We find evidence that TE expansions (especially LINEs) are the primary driver of genome size evolution in Trichoptera (Fig. 2, Fig. S3), which is consistent with the MEH explained above. Our TE age distribution analysis suggests that the high abundance of LINEs is due to ongoing/recent activity occurring independently across 'cocoon-' and particularly 'tube casebuilders' (Fig. 3, Fig. S4). Thus, the shift to large genomes in these lineages does not appear to be due to a single (or few) shared ancient events, they rather maintain dynamic turnover in composition in their large genomes. Mutational bias affecting pathways tied to TE-regulation may affect insertion/deletion ratios and subsequently lead to lineage-specific shifts in genome size equilibrium [73]. Such changes may be stochastic (e.g., due to drift), or linked to traits that evolve on independent trajectories as lineages diverge and are thereby constrained by phylogeny. Ecological factors, demographic history and effective population size can further impact mutation rates. For example, environmental stress can trigger bursts of TE activity and elevated mutation rates [74], [75], [76] driving lineages that occupy niche space with frequent exposure to environmental stress toward increased TE loads and larger genomes. Similarly, lineages with small effective population sizes or which are prone to population bottlenecks may 
have higher mutation rates and/or reduced efficacy of natural selection which would otherwise purge mildly deleterious TE load.

Although our study is not designed to pinpoint specific forces maintaining large genomes in some lineages, the pattern we observe in the distribution of genome size (i.e. lower genome size estimates in 'fixed retreat- and net-spinners' and 'cocoon-builders' compared to 'tube casebuilders') leads us to hypothesize that ecological factors may play a role in genome size evolution in the order. The three focal groups discussed here exhibit markedly different ecological strategies. Larvae of 'fixed retreat- and net-spinners' generally occupy relatively narrow niche space in oxygen-rich flowing-water (mostly stream/river) environments where they rely on water currents to bring food materials to their filter nets. The evolutionary innovation of tube-case making is thought to have enabled 'tube case-builders' to occupy a much greater diversity of ecological niche space by allowing them to obtain oxygen in lentic (e.g., pond, lake, marsh) environments which are much more variable in temperature and oxygen availability than lotic environments [77], [78]. This environmental instability is greater over short (daily, seasonal) and long time scales (centuries, millennia) [79]. It is thus plausible these tube case-building lineages experience greater environmental stress and less stable population demographics that could lead to both more frequent TE bursts and reduced efficacy of natural selection in purging deleterious effects of TE expansions as described above [23], [24].

We show that TE expansions (especially LINEs and DNA transposons) in 'cocoon-' and 'tube case-builders' have a major impact on protein-coding gene regions (Fig. 4). These TE-gene associations show a linear relationship with increasing genome size. This trend is particularly pronounced among 'tube case-builders' in which an average of $21.4 \%$ of BUSCO genes that have internal or adjacent repetitive sequences (compared to $6.2 \%$ in annulipalpians). This finding corroborates other studies highlighting the role of TEs as drivers of rapid genome evolution [80], [81], [82], [83] and highlights their impact on genomic regions that have 
potential effects on phenotypes. Questions remain as to what evolutionary roles such changes in genic regions may play. In general, TE insertions are considered to have deleterious effects on their host's fitness activity [84], [85]. They are known to "interrupt" genes [33], pose a risk of ectopic recombination that can lead to genome rearrangements [34], [31], [86], and have epigenetic effects on neighboring sequences [87], [88]. Therefore, purifying selection keeps TEs at low frequencies [33]. However, there is growing evidence that TE activity can also be a critical source of new genetic variation driving diversification via chromosomal rearrangements and transposition events which can result in mutations [89], including examples, of co-option [90], e.g. recent research in mammals has shown that DNA transposon fragments can be coopted to form regulatory networks with genome-wide effects on gene expression [44].

Ecological correlates with genome size are widely discussed in other taxa [91], [92], [93], [94], [95]. Caddisflies and other diverse insect lineages that feature various microhabitat specializations, feeding modes, and/or the use of silk represent evolutionary replicates with contrasting traits and dynamic genome size evolution. They thus have high potential as models for understanding links between ecology and the evolution of REs, genomes, and phenotypes. Our study lays a foundation for future work in caddisflies that investigates the potential impact of TE expansions on phenotypes and tests for evidence of co-option/adaptive impacts of TErich genomes against a null of neutral or slightly deleterious effects.

\section{Potential implications}

Many open questions remain as to the causes and consequences of genome size evolution. As we move forward in an era where genome assemblies are attainable for historically intractable organisms (e.g. due to constraints given large genome sizes, tissue limitations, no close reference available) we can leverage new model systems spanning a greater diversity of life to understand how genomes evolve. Here, we provide genomic resources and new genome size estimates across lineages of an underrepresented insect order that spans major variation in 
genome size. These data allowed us to study genome size evolution in a phylogenetic framework to reveal lineage-specific patterns in which genome size correlates strongly with phylogeny and ecological characteristics within lineages. We find that large genomes dominate lineages that occupy unstable environments, and that ongoing recent TE activity appears to maintain large genomes in these lineages. This leads us to hypothesize that ecological factors may play a predictable role in genome size evolution in this group. The future directions spawned by our findings highlight the potential for using Trichoptera and other diverse insect groups to understand the link between ecological and genomic diversity, a link that has been challenging to study with past models [8].

We also show that TE expansions are associated with increasing genome size and have an impact on protein-coding regions. These impacts have been greatest in the most species-rich and ecologically diverse caddisfly clades. While TEs are generally considered to have deleterious effects on their host's fitness activity, their roles can also be neutral or even adaptive. TE activity can be a critical source of new genetic variation and thus an important driver for diversification. Caddisflies and potentially other non-model insect groups are excellent models to test these contrasting hypotheses, as well as the potential impact of TEs on phenotypes. Using these models, especially with respect to the increasing emergence of high-quality insect genomes [52], will allow researchers to identify recurring patterns in TE dynamics and investigate their evolutionary implications across diverse clades.

\section{Methods}

\section{DNA extraction, library preparation, sequencing, and sequence read processing}

We extracted high molecular weight genomic DNA (gDNA) from 17 individuals (15 species) of caddisfly larvae (for sampling information, see Data S1) after removing the intestinal tracts using a salting-out protocol adapted from [96] as described in supplementary note 3 . We 
generated gDNA libraries for a low-cost high-contiguity sequencing strategy, i.e. employing a combination of short (Illumina) and long read (Nanopore or PacBio) technologies as described in supplementary notes 1-2. For details on sequencing coverage for each specimen see Data S1.

\section{De novo genome assembly, annotaion and quality assessment}

We applied different assembly strategies for different datasets. First, we applied a long-read assembly method with subsequent short-read polishing as this method revealed good results in previous de novo assemblies in caddisflies [57]. In cases where this pipeline did not meet the expected quality regarding contiguity and BUSCO completeness, we applied de novo hybrid assembly approaches supplementary note 5. Illumina-only data was assembled with SPAdes [97] explained in supplementary note3).

Prior to annotating the individual genomes with MAKER2 v2.31.10 [98], [99] we used RepeatModeler v1.0.11 and RepeatMasker v4.0.7, to identify species-specific repetitive elements in each of the assemblies, relative to RepBase libraries v20181026; www.girinst.org). Transcriptome evidence for the annotation of the individual genomes included their speciesspecific or closely related de novo transcriptome provided by 1KITE (http://www.1kite.org/; last accessed November 11, 2019, Data S1) or downloaded from Genbank as well as the cDNA and protein models from Stenopsyche tienmushanensis [100] and Bombyx mori (AR102, GenBank accession ID\# GCF_000151625.1). Additional protein evidence included the uniprotsprot database (downloaded September 25, 2018). We masked repeats based on species-specific files produced by RepeatModeler. For $a b$ initio gene prediction, species specific AUGUSTUS gene prediction models as well as Bombyx mori SNAP gene models were provided to MAKER. The EvidenceModeler [101] and tRNAscan [102] options in MAKER were employed to produce a weighted consensus gene structure and to identify tRNAs genes. MAKER default options were utilized for BLASTN, BLASTX, TBLASTX searches. Two assemblies (Agapetus fuscipens GL3 and Micrasema longulum ML1) were not annotated because of their low 
contiguity. All protein sequences were assigned putative names by BlastP Protein-Protein BLAST 2.2.30+ searches [103] and were functionally annotated using command line Blast2Go v1.3.3 [104], see supplementary note 4, Figs. S1-S31).

We calculated assembly statistics with QUAST v5.0.2 [53] and examined completeness with BUSCO v3.0.2 [54], [55] using the Endopterygota odb9 dataset with the options --long, $-m=$ genome and $-s p=f l y$. A summary of the assembly statistics and BUSCO completeness is given in Data S1. The final genome assemblies and annotations were screened and filtered for potential contaminations with taxon-annotated GC-coverage (TAGC) plots using BlobTools v1.0 [56]. Details and blobplots are given in supplementary note 5 \& supplementary Figs. S31S47.

\section{Species tree reconstruction}

We used the single-copy orthologs resulting from the BUSCO analyses to generate a species tree. We first combined single-copy ortholog amino acid files from each species into a single FASTA for each ortholog. We then aligned them with the MAFFT L-INS-i algorithm [105]. We selected amino acid substitution models for each ortholog using ModelFinder (option -m mfp,[106] in IQtree v.2.0.6 [107] and estimated a maximum likelihood tree with 1000 ultrafast bootstrap replicates [108] with the BNNI correction (option -bb 1000 -bnni). We combined the best maximum likelihood tree from each gene for species tree analysis in ASTRAL-III [109]. We visualized the trees using FigTree v.1.4.4 (http://tree.bio.ed.ac.uk/software/figtree/).

\section{Genome size estimations and genome profiling}

Genome size estimates of 27 species were conducted using flow cytometry (FCM) according to Otto [110] using Lycopersicon esculentum cv. Stupické polnítyčkové rané $(2 \mathrm{C}=1.96 \mathrm{pg} ;[111])$ as internal standard and propidium iodine as stain. Additionally, we used the short-read data sequenced in this study, to conduct genome profiling (estimation of major genome characteristics such as size, heterozygosity, and repetitiveness) using a $k$-mer 
distribution-based method (GenomeScope 2.0, [112]. Genome scope profiles are available online (see links to Genomescope 2 in Data S1). In addition, we applied a second sequencingbased method for genome size estimates, which uses the backmapping rate of sequenced reads to the assembly and coverage distribution (backmap.pl v0.1, [59]. Details of all three methods are described in supplementary note 7 . Coverage distribution per position and genome size estimate from backmap.pl are shown in Figs. S49-72). We assessed the congruence among the three quantitative methods of measurement (Genomescope2, Backmap.pl and FCM) with Bland-Altman-Plots using the function BlandAltmanLeh::bland.altman.plot in ggplot2 [113] in RStudio (RStudio Team (2020). RStudio: Integrated Development for R. RStudio, PBC, Boston, MA URL http://www.rstudio.com/; supplementary note 8, Fig. S73).

\section{Repeat dynamics}

\section{Repeat abundance and classification}

We identified and classified repetitive elements in the genome assemblies of each species using RepeatModeler2.0 [114]. We annotated repeats in the contamination filtered assemblies with RepeatMasker 4.1.0 (http://www.repeatmasker.org) using the custom repeat libraries generated from RepeatModeler2 for each respective assembly with the search engine set to "ncbi" and using the -xsmall option. We converted the softmasked assembly resulting from the first RepeatMasker round into a hardmasked assembly using the lc2n.py script (https://github.com/PdomGenomeProject/repeat-masking). Finally, we re-ran RepeatMasker on the hard-masked genome with RepeatMasker's internal arthropod repeat library using species "Arthropoda". We then merged RepeatMasker output tables from both runs to summarize the abundance of repeat categories.

\section{We also estimated repetitive element abundance and composition using RepeatExplorer2 [115],} [116]. This reference-free approach quantifies repeats directly from unassembled short-read 
data using clustering-based methods. This analysis allowed us to test for general consistency of patterns with our assembly-based approach described above, and to test for the presence of abundant repeat categories such as satellite DNAs which can comprise large fractions of genomes yet can be prone to poor representation in the genome assembly. Prior to analysis in RepeatExplorer2 we normalized input data sets to $0.5 \mathrm{x}$ coverage using RepeatProfiler [117] and seqtk (https://github.com/lh3/seqtk), and then ran RepeatExplorer2 clustering with the Metazoa 3.0 database specified for annotation (supplementary Fig. S74).

\section{TE age distribution analysis}

We further characterized repetitive element dynamics in Trichoptera by analyzing TE landscapes, which show relative age differences among TE sequences and their genomic abundance. We used these analyses to test whether abundance patterns of specific TEs are driven by shared ancient proliferation events or more recent/ongoing activity of the respective TEs. For example, if shared ancient proliferation is driving abundance patterns of a given TE, the majority of its copies would show moderate to high sequence divergence (e.g., >10\% pairwise divergence). In contrast, if abundance patterns are driven by recent/ongoing activity of a given TE, we would expect the majority of its sequences to show low sequence divergence (e.g., 0-10\%). We generated TE landscape plots using dnaPipeTE v1.3.1 [118] with genomic coverage for each species sampled to $0.5 \mathrm{X}$ prior to analysis and the -RM_lib flag set to the Repbase v20170127 repeat library (supplementary Fig. S75).

\section{TE sequence associations with protein-coding genes}

During the early exploration of our sequence data we noted that copy number profiles of some BUSCO genes showed regions of unexpected high copy number with the frequency of such genes varying widely across species. Following this observation, we analyzed all BUSCO genes for all species to quantify the abundance of repetitive BUSCOs across samples and test two hypotheses that could account for the observed patterns: (I) inflated copy-number of BUSCO 
gene fragments occur when sequences of repetitive elements (e.g. TEs) are inserted into (or immediately adjacent to genes; (II) inflated regions are BUSCO gene fragments that have proliferated throughout the genome (e.g., by hitch-hiking with TEs). We investigated associations between TEs and genic sequences in Trichoptera lineages by quantifying the abundance of repetitive sequences found within or adjacent to BUSCO genes (for presence and absence of repetitive BUSCOs see Fig. S5, Data S2). This analysis also allowed us to quantify shifts in associations between TEs and genic regions across Trichoptera lineages with varying repeat abundance. We used copy number profiles to identify BUSCO genes with repetitive sequences based on coverage profiles and quantified their genomic abundance by using each repetitive BUSCO as a query in a BLAST search against their respective genome assembly. We then conducted intersect analysis for all unique BUSCO hits from repetitive sequences to determine if repetitive fragments were annotated as TEs. We calculated the total number of bases in filtered BLAST after subtracting the number of bases at the locus belonging to all 'complete' BUSCO genes and categorize BUSCO repeats based on their annotation status and repeat classification using custom scripts (available at https://app.box.com/folder/136985262731?v=trich-genomes). We plotted the number of BUSCO repeats belonging to repetitive element categories (i.e., classes and subclasses) alongside plots of the relative genomic abundance of each respective category. For details of this method readers are directed to supplementary note 10 . To validate that the insertion of TEs are not an artefact of poor assembly quality, we mapped Nanopore reads back to repetitive BUSCO sequences and showed that junctions between repetitive BUSCOs and non-repetitive regions are embedded in full reads (see supplementary note 11, supplementary Table S1, supplementary Figs.78-87). In addition, we investigated BUSCO genes with repetitive sequences by pairwise alignments. Specifically, we visualized alignments of BUSCOs with repetitive fragments alongside orthologous BUSCOS that lack repetitive fragments taken from closely related species. To test whether repetitive fragments are due to TE insertions or to 
proliferation of true BUSCO gene fragments we examined patterns of BUSCO gene structure in pairwise alignments of species in which one species has a repetitive fragment (i.e., the "inflated" species) and its counterpart does not (i.e., the "reference" species). To reduce the likelihood that indels due to sequence divergence (i.e., not due to REs) would complicate the analysis we conducted this test with three pairs of closely related species: Micrasema longulum and Micrasema minimum; Rhyacophila brunnea and Rhyacophila evoluta; and Hesperophylax magnus and Halesus radiatus. We predicted that if repetitive regions were due to RE sequence insertion (i.e., Hyp1 above) that inflated species would show indels at coordinates of repetitive fragments relative to reference species. If repetitive regions were due to proliferation of true BUSCO sequence (i.g., Hyp2 above) we predicted that alignments would be contiguous over the repetitive region. We further tested this prediction by taking the set of BUSCOs that are only repetitive in the inflated species and contrasted results of two BLAST searches followed by an intersect analysis. A detailed description of this method is provided in supplementary note 9.

\section{Gene and Genome duplications}

\section{Inference of WGDs from gene age distributions}

To recover signal from potential WGDs, for each genome, we used the DupPipe pipeline to construct gene families and estimate the age distribution of gene duplications [119], https://bitbucket.org/barkerlab/evopipes/src/master/). We translated DNA sequences and identified ORFs by comparing the Genewise [120] alignment to the best-hit protein from a collection of proteins from 24 metazoan genomes from Metazome v3.0. For all DupPipe runs, we used protein-guided DNA alignments to align our nucleic acid sequences while maintaining the ORFs. We estimated synonymous divergence $\left(\mathrm{K}_{\mathrm{s}}\right)$ using PAML with the F3X4 model [121] for each node in the gene family phylogenies. We first identified taxa with potential WGDs by comparing their paralog ages to a simulated null distribution without ancient WGDs using a K- 
S goodness-of-fit test [122]. We then used mixture modeling to identify if any significant peaks consistent with a potential WGD and to estimate their median paralog $\mathrm{K}_{\mathrm{s}}$ values. Significant peaks were identified using a likelihood ratio test in the boot.comp function of the package mixtools in R [123].

\section{Figures Legends:}
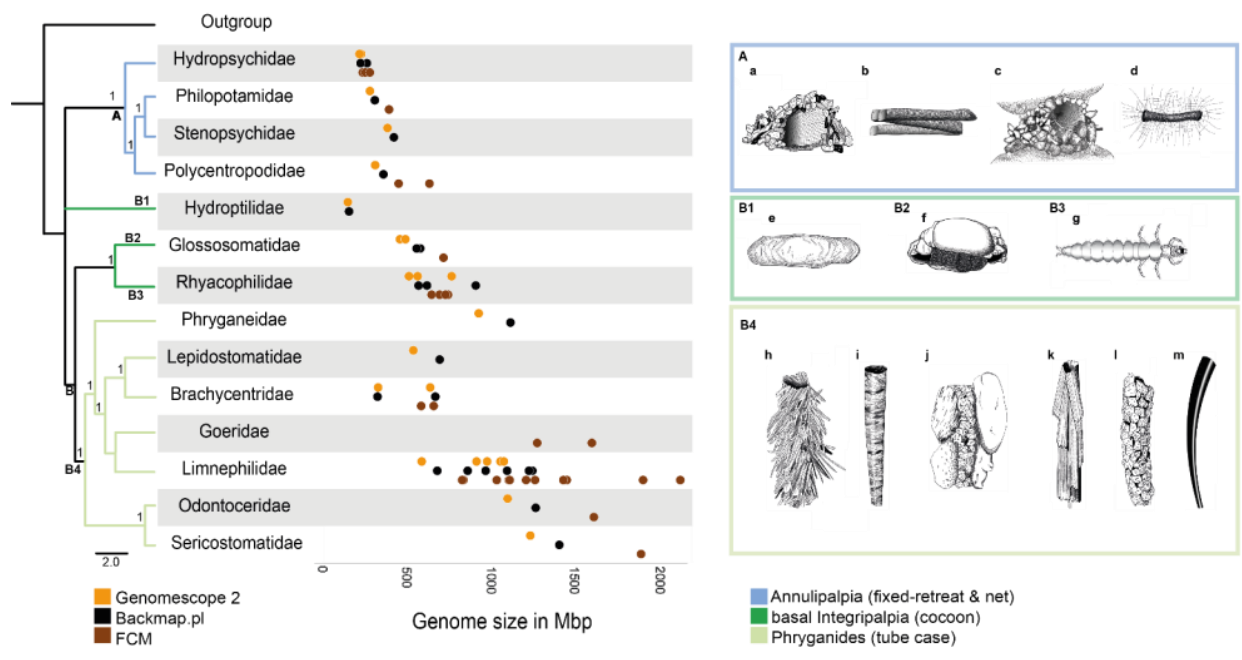

Fig. 1: Ecological diversity (right) and genome size (left) in caddisflies. Phylogenetic relationships derived from ASTRAL-III analyses using single BUSCO genes. Goeridae, which was not included in the BUSCO gene set, was placed according to [58]. ASTRAL support values (local posterior probabilities) higher than 0.9 are given for each node. Nodes with less than 0.9 support were collapsed. Taxa were collapsed to family level. Trichoptera are divided into two suborders: Annulipalpia ('fixed retreat- and net-spinners', clade A: blue) and Intergripalpia (clade B: green) which includes basal Integripalpia ('cocoon-builders', clades B1-B3, dark green) and Phryganides or 'tube case-builders' (clade B4: light green). 'Cocoonbuilders' are divided into 'purse case' - (clade B1), 'tortoise case-building' (clade B2) and 'freeliving' (clade B3) families. Genome size estimates based on different methods (Genomescope2: orange, Backmap.pl: black, Flow Cytometry (FCM): brown) are given for various caddisfly 
families. Each dot corresponds to a mean estimate of a species. For detailed information on the species and number of individuals used in each method see Data S1. Colors and clade numbers in the phylogenetic tree refer to colored boxes with illustrations. The following species are illustrated by Ralph Holzenthal: a: Hydropsyche sp. (Hydropsychidae); b: Chimarra sp. (Philopotamidae); c: Stenopsyche sp. (Stenopsychidae);

d: Polycentropus sp.

(Polycentropodidae); e: Agraylea sp. (Hydroptilidae); f: Glossosoma sp. (Glossosomatidae); g:

Rhyacophila sp. (Rhyacophilidae); h: Fabria inornata (Phryganeidae); i: Micrasema sp.

Psilotreta sp. (Odontoceridae), m: Grumicha grumicha (Sericostomatidae). 
A

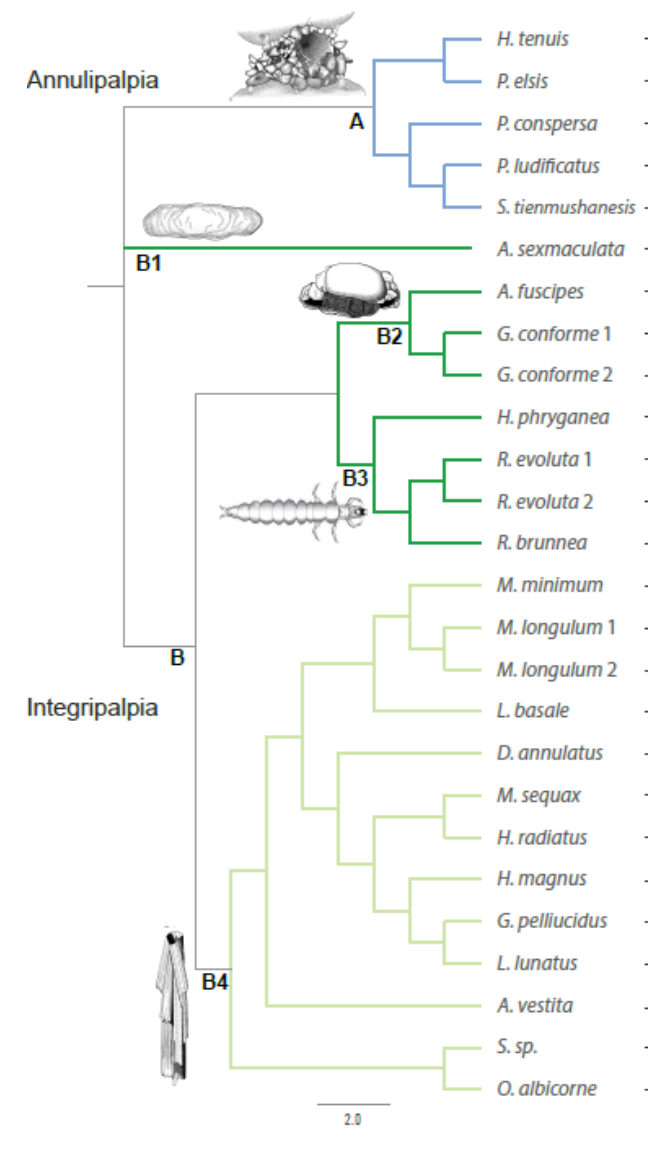

Repetitive Element Abundance

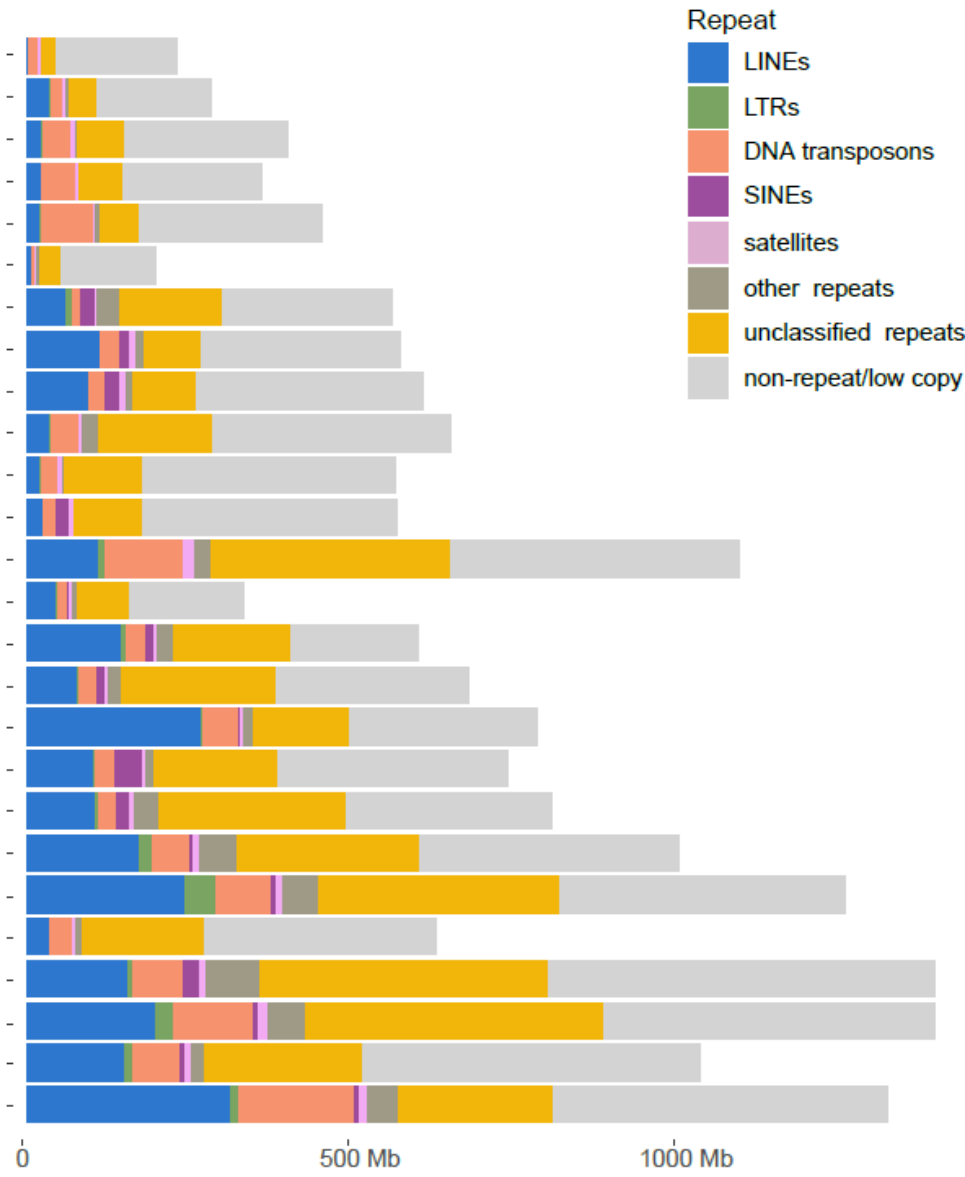

B

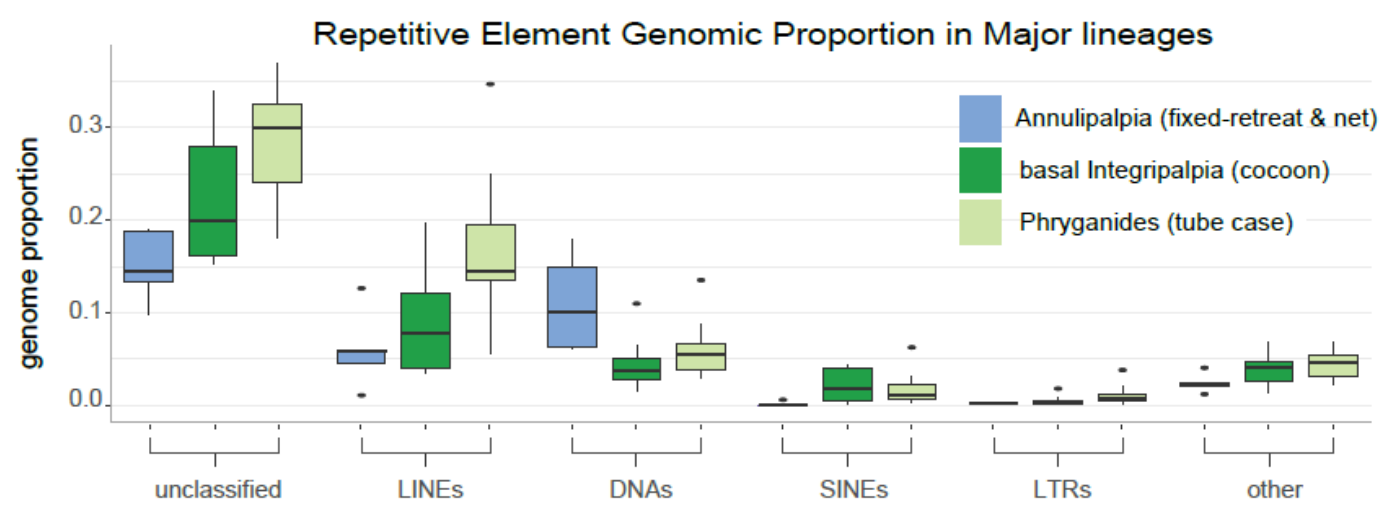

Fig. 2: Repeat abundance and classification in $\mathbf{2 6}$ caddisfly genomes. Number of bp for each

repeat type is given for each caddisfly genome. A: Repeat abundance and classification.

Phylogenetic tree was reconstructed with ASTRAL-III using single BUSCO genes from the genome assemblies. Nodes with ASTRAL support below 0.9 were collapsed. Species names corresponding to the abbreviations in the tree can be found in Table 1. Trichoptera are divided into two suborders: Annulipalpia ('fixed retreat- and net-spinners', clade A: blue) and Intergripalpia (clade B: green) which includes basal Integripalpia ('cocoon-builders', clades 
bioRxiv preprint doi: https://doi. org/10.1101/2021.05.10.443368; this version posted July 18, 2021. The copyright holder for this preprint (which was not certified by peer review) is the author/funder, who has granted bioRxiv a license to display the preprint in perpetuity. It is made available under aCC-BY-NC-ND 4.0 International license.

B1-B3, dark green) and Phryganides or 'tube case-builders' (clade B4: light green). 'Cocoonbuilders' are divided into 'purse case'- (clade B1), 'tortoise case-building' (clade B2) and 'freeliving' (clade B3) families. An illustration of a representative of each clade is given. The “other_repeats” category includes: rolling-circles, Penelope, low-complexity, simple repeats, and small RNAs. B: Boxplots summarizing shifts in the genomic proportion of RE categories in major Trichoptera lineages.

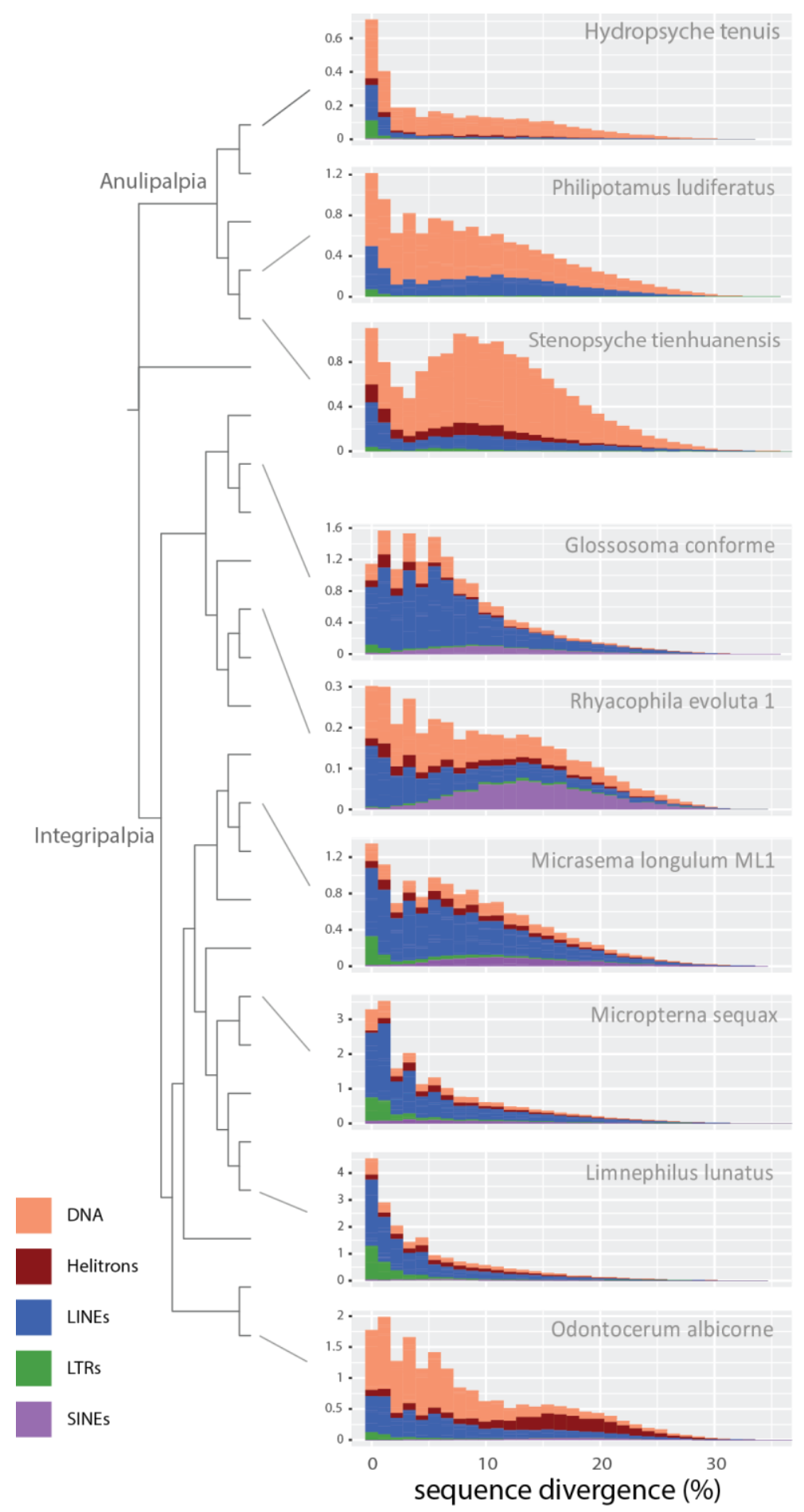


Fig. 3: Transposable element age distribution landscapes. Representative examples are chosen from major Trichoptera lineages. The y-axis shows TE abundance as a proportion of the genome (e.g., $1.0=1 \%$ of the genome). The $\mathrm{x}$-axis shows sequence divergence relative to TE consensus sequences for major TE classes. TE classes with abundance skewed toward the left (i.e., low sequence divergence) are inferred to have a recent history of diversification relative species are shown in supplementary Fig. 4. For tip labels of the phylogenetic tree see Fig. 2.

A

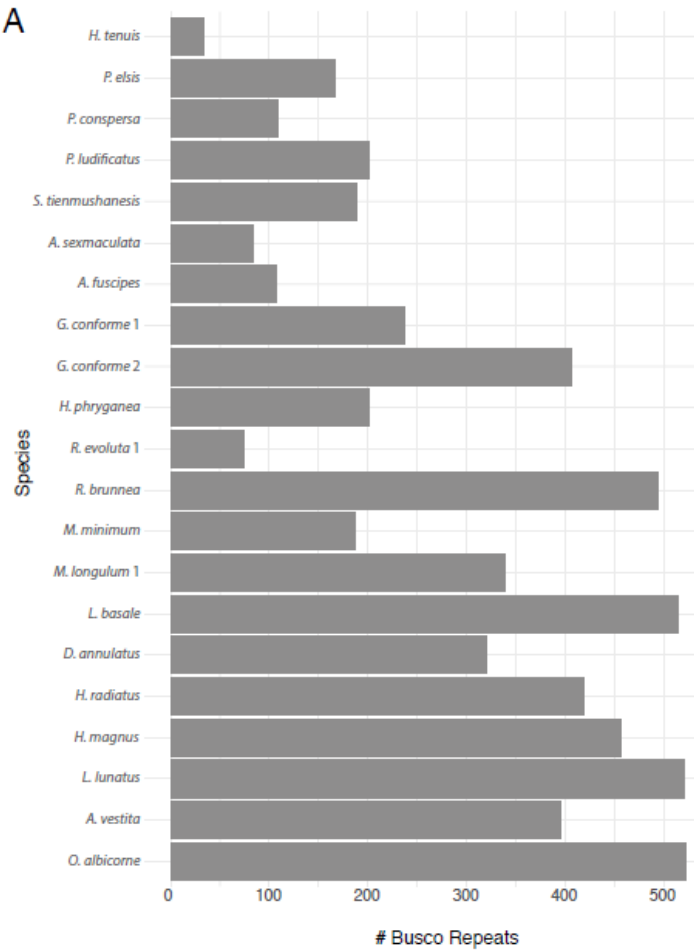

B

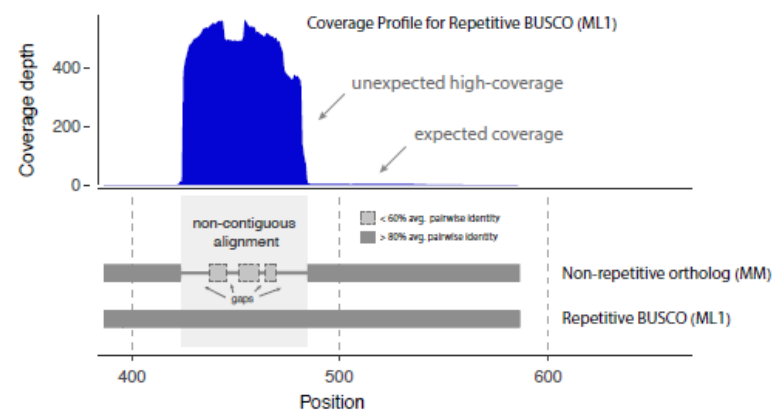

C

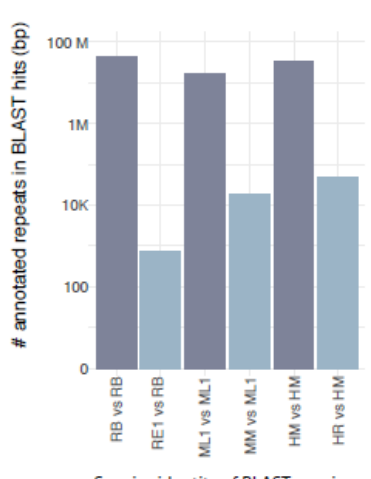

D

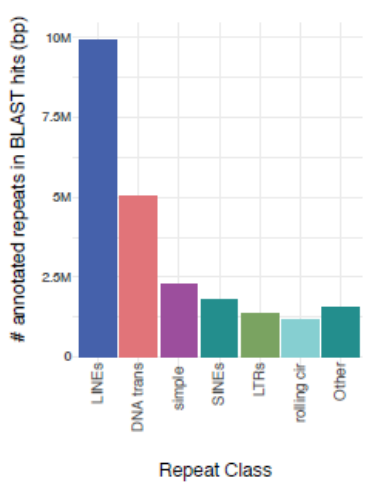

Fig. 4: TE-BUSCO-gene associations in Trichoptera species. (A) Raw abundance of

BUSCO with repetitive fragments present in the assembly out of a total of 2442BUSCOs studied in the OrthoDB 9 Endopterygota dataset. (B) Upper plot: An example of a copy number profile of a repetitive BUSCO gene (BUSCO EOG090R02Q9 from ML1 ('inflated species')) which shows unexpected high coverage in the second exon putatively due to the presence of a TE-derived sequence fragment. Lower plot: alignments of repetitive BUSCOs to non-repetitive orthologs taken from a closely related species ('reference species') are consistently non- 
contiguous in regions of inflated coverage in the repetitive BUSCO, consistent with the presence of a TE-derived sequence fragment in the repetitive BUSCO which is absent in the reference species. (C) Summary of total bases annotated as REs obtained from each of two BLAST searches. First, when repetitive BUSCOs are BLASTed against an assembly for the same species BLAST hits included megabases of annotated repeats (dark plots). Second, when non-repetitive orthologs of the repetitive BUSCOs in the first search are taken from a close relative and BLASTed against the inflated species, there is a dramatic drop in BLAST hits annotated as REs. Note log scale on the y-axis. (D) Summary of annotations for BLAST hits for classified REs when repetitive BUSCOs are BLASTed against an assembly of the same species.

Table 1. Comparison of assembly and annotation statistics of all available Trichoptera Genomes. $*$ Assemblies produced in this study. $* * \mathrm{~N}_{\text {Arthropoda }}=2442, \%$ of present BUSCOS $=$ complete + fragmented.

\begin{tabular}{|l|l|l|l|l|l|l|}
\hline Species & $\begin{array}{l}\text { Abbre- } \\
\text { viation }\end{array}$ & Accession number & Length (bp) & $\begin{array}{l}\text { N50 } \\
(\mathbf{k b p})\end{array}$ & $\begin{array}{l}\text { No. of } \\
\text { contigs }\end{array}$ & $\begin{array}{l}\text { BUSCOS } \\
\text { \%** }\end{array}$ \\
\hline Agapetus fuscipes* & AF & JAGTXP000000000 & $552,637,417$ & 2.8 & 291,536 & 75.5 \\
\hline Agraylea sexmaculata* & AS & JAGTTH000000000 & $196,044,125$ & 86 & 7,050 & 96.5 \\
\hline Agrypnia vestita [30] & AV & JADDOH000000000 & $1,352,945,503$ & 111.8 & 25,541 & 92.8 \\
\hline Drusus annulatus* & DA & JAGWCC000000000 & $727,941,535$ & $1,043.7$ & 2,401 & 96.8 \\
\hline Glossosoma conforme* & GC1 & JAGTXR000000000 & $568,249,599$ & $2,212.1$ & 653 & 91.8 \\
\hline Glossosoma conforme [124] & GC2 & GCA_003347265.1 & $604,293,666$ & 17.1 & 119,821 & 92.1 \\
\hline Glyphotaelius pellucidula [125] & GP & Glyphotaelius_pelluci & $623,431,006$ & 1.6 & 461,749 & 68.6 \\
\hline Halesus radiatus* & & dus_k51_scaffolds & & & & \\
\hline Himalopsyche phryganea* & HP & JAGVSL000000000 & $633,785,554$ & 4,634 & 710 & 97.8 \\
\hline Hesperophylax magnus [30] & HM & JADDOG000000000 & $1,275,967,528$ & 768.2 & 6,877 & 95.2 \\
\hline
\end{tabular}


bioRxiv preprint doi: https://doi org/10.1101/2021.05.10.443368: this version posted July 18,2021 The copyright holder for this preprint (which was not certified by peer review) is the author/funder, who has granted bioRxiv a license to display the preprint in perpetuity. It is made available under aCC-BY-NC-ND 4.0 International license.

\begin{tabular}{|c|c|c|c|c|c|c|}
\hline Hydropsyche tenuis [57] & HT & GCA_009617725.1 & $229,663,394$ & $2,190.1$ & 403 & 97.6 \\
\hline Lepidostoma basale $^{*}$ & LB & JAGTTH000000000 & $769,208,668$ & 1,052 & 1,621 & 97.0 \\
\hline Limnephilus lunatus [69] & LL & GCA_000648945.2 & $1,369,180,260$ & 69.1 & 58,718 & 91 \\
\hline Micrasema longulum* & ML2 & JAGXCS000000000 & $668,600,304$ & 2.5 & 368,330 & 69.8 \\
\hline Micrasema longulum* & ML1 & JAGVSM000000000 & $585,245,295$ & 170.5 & 5,451 & 84.5 \\
\hline Micrasema minimum* & MM & JAGVSQ000000000 & $329,257,313$ & 69.5 & 7,561 & 67.1 \\
\hline Micropterna sequax* & MS & JAGUCF000000000 & $778,692,278$ & 7.9 & 144,286 & 68.9 \\
\hline Odontocerum albicorne* & $\mathrm{OA}$ & JAGTXQ000000000 & $1,305,984,461$ & 266.4 & 9,303 & 95.9 \\
\hline Parapysche elsis* & $\mathrm{PE}$ & JAGVSN000000000 & $282,185,525$ & $5,591.7$ & 159 & 97.4 \\
\hline Philopotamus ludificatus* & PL & JAGXCT000000000 & $360,300,449$ & 67.5 & 37,274 & 92.6 \\
\hline Plectrocnemia conspersa [57] & $\mathrm{PC}$ & GCA_009617715.1 & $396,695,105$ & 869 & 1,614 & 97.8 \\
\hline Rhyacophila brunnea* & RB & JAGYXB000000000 & $1,086,872,538$ & $1,030.6$ & 2,125 & 97.3 \\
\hline Rhyacophila evoluta* & RE2 & JAGVSQ000000000 & $565,830,460$ & 9.9 & 114,057 & 91.7 \\
\hline Rhyacophila evoluta* & RE1 & JAGVSO000000000 & $562,550,625$ & 9.7 & 111,706 & 91.7 \\
\hline Sericostoma sp.[126] & SS & GCA_003003475.1 & $1,015,727,762$ & 3.2 & 561,698 & 60.3 \\
\hline Stenopsyche tienhuanesis [100] & ST & GCA_008973525.1 & $451,494,475$ & $1,296.7$ & 552 & 97.6 \\
\hline
\end{tabular}

617

618

619

Data and materials availability: This project has been deposited at NCBI under BioProject

ID: PRJNA558902. The data sets supporting the results of this article are available in the Supplementary, Data files S1 and S2 and at https://app.box.com/folder/136985262731?v=trich-genomes. The data available at the link will be uploaded to GigaDB when the paper is sent out for review.

\section{Declarations}

Consent for publication: Not applicable

Competing interests: Authors declare that they have no competing interests. 


\section{Funding}

This work is a result of the LOEWE-Centre for Translational Biodiversity Genomics funded by the Hessen State Ministry of Higher Education, Research and the Arts (HMWK) that supported JH and SUP, as well as internal funds of Senckenberg Research Institute provided to JP. JSS was supported by an NSF Postdoctoral Research Fellowship in Biology (DBI-1811930) and an NIH General Medical Sciences award (R35GM119515) to AML. Sequencing was, in part, supported by BYU start-up funds to PBF and funds from the Army Research Office, Life Science Division (Award no. W911NF-13-1-0319) to RJS.

\section{Author's contributions:}

Conceptualization -JH, JSS, PBF, SUP

Data curation - JH

Formal Analysis - JH, JM, JP, JSS, PBF, ZL

Funding acquisition - AML, PBF, SUP, RJS, RJS

Investigation - JH, JP, JSS, PBF, ZL

Methodology - AML, JSS, JP, JVS, PBF

Project administration - SUP

Resources - JP, MB, PBF, SUP

Visualization - JH, JSS

Writing - original draft - JH, JSS, PBF, ZL

Writing - review \& editing - AML, JH, JM, JP, JSS, JVS, MB, PBF, RJS, ,RJS, SUP, ZL

\section{Acknowledgments}

The authors thank Ralph Holzenthal for providing illustrations of larval Trichoptera and the structures they build. We thank Bob Wisseman for collecting Himalopsyche phryganeae. 


\section{References}

1. Cornette R, Gusev O, Nakahara Y, Shimura S, Kikawada T, Okuda T. Chironomid midges (Diptera, chironomidae) show extremely small genome sizes. Zoolog Sci. 2015; doi: 10.2108/zs140166.

2. Westerman M, Barton NH, Hewitt GM. Differences in DNA content between two chromosomal races of the grasshopper Podisma pedestris. Heredity. Nature Publishing Group; 1987; doi: 10.1038/hdy.1987.36.

3. Thomas CA. The genetic organization of chromosomes. Annu Rev Genet. Annual Reviews; 1971; doi: 10.1146/annurev.ge.05.120171.001321.

4. Bernard J. The Eukaryote Genome in Development and Evolution. Springer Netherlands;

5. Gregory TR. The C-value Enigma in Plants and Animals: A Review of Parallels and an Appeal for Partnership. Ann Bot. 2005; doi: 10.1093/aob/mci009.

6. Elliott TA, Gregory TR. What's in a genome? The C-value enigma and the evolution of eukaryotic genome content. Philos Trans R Soc B Biol Sci. Royal Society; 2015; doi: 10.1098/rstb.2014.0331.

7. Abdel-Haleem H. The Origins of Genome Architecture. J Hered. 2007; doi: 10.1093/jhered/esm073.

8. Blommaert J. Genome size evolution: towards new model systems for old questions. Proc R Soc B Biol Sci. Royal Society; 2020; doi: 10.1098/rspb.2020.1441.

9. Canapa A, Barucca M, Biscotti MA, Forconi M, Olmo E. Transposons, Genome Size, and Evolutionary Insights in Animals. Cytogenet Genome Res. 2015; doi: 10.1159/000444429.

10. Petrov DA. Evolution of genome size: new approaches to an old problem. Trends Genet TIG. 2001; doi: 10.1016/s0168-9525(00)02157-0.

11. Orr HA. "Why Polyploidy is Rarer in Animals Than in Plants" Revisited. Am Nat. The University of Chicago Press; 1990; doi: 10.1086/285130.

12. Otto SP, Whitton J. Polyploid Incidence and Evolution. Annu Rev Genet. 2000; doi: 10.1146/annurev.genet.34.1.401.

13. Hallinan NM, Lindberg DR. Comparative analysis of chromosome counts infers three paleopolyploidies in the mollusca. Genome Biol Evol. 2011; doi: 10.1093/gbe/evr087.

14. Alexandrou MA, Swartz BA, Matzke NJ, Oakley TH. Genome duplication and multiple evolutionary origins of complex migratory behavior in Salmonidae. Mol Phylogenet Evol. 2013; doi: 10.1016/j.ympev.2013.07.026.

15. Campbell MA, Hale MC, McKinney GJ, Nichols KM, Pearse DE. Long-Term Conservation of Ohnologs Through Partial Tetrasomy Following Whole-Genome Duplication in Salmonidae. G3 GenesGenomesGenetics. 2019; doi: 10.1534/g3.119.400070. 
16. Woods IG, Wilson C, Friedlander B, Chang P, Reyes DK, Nix R, et al.. The zebrafish gene map defines ancestral vertebrate chromosomes. Genome Res. 2005; doi: 10.1101/gr.4134305.

17. Berthelot C, Brunet F, Chalopin D, Juanchich A, Bernard M, Noël B, et al.. The rainbow trout genome provides novel insights into evolution after whole-genome duplication in vertebrates. Nat Commun. Nature Publishing Group; 2014; doi: 10.1038/ncomms4657.

18. Glasauer SMK, Neuhauss SCF. Whole-genome duplication in teleost fishes and its evolutionary consequences. Mol Genet Genomics MGG. 2014; doi: 10.1007/s00438-0140889-2.

19. Clarke TH, Garb JE, Hayashi CY, Arensburger P, Ayoub NA. Spider Transcriptomes Identify Ancient Large-Scale Gene Duplication Event Potentially Important in Silk Gland Evolution. Genome Biol Evol. 2015; doi: 10.1093/gbe/evv110.

20. Kenny NJ, Chan KW, Nong W, Qu Z, Maeso I, Yip HY, et al.. Ancestral whole-genome duplication in the marine chelicerate horseshoe crabs. Heredity. Nature Publishing Group; 2016; doi: 10.1038/hdy.2015.89.

21. Schwager EE, Sharma PP, Clarke T, Leite DJ, Wierschin T, Pechmann M, et al.. The house spider genome reveals an ancient whole-genome duplication during arachnid evolution. BMC Biol. 2017; doi: 10.1186/s12915-017-0399-x.

22. Li Z, Tiley GP, Galuska SR, Reardon CR, Kidder TI, Rundell RJ, et al.. Multiple largescale gene and genome duplications during the evolution of hexapods. Proc Natl Acad Sci. National Academy of Sciences; 2018; doi: 10.1073/pnas.1710791115.

23. Lynch M, Conery JS. The Origins of Genome Complexity. Science. American Association for the Advancement of Science; 2003; doi: 10.1126/science.1089370.

24. Petrov DA. Mutational Equilibrium Model of Genome Size Evolution. Theor Popul Biol. 2002; doi: 10.1006/tpbi.2002.1605.

25. Wicker T, Sabot F, Hua-Van A, Bennetzen JL, Capy P, Chalhoub B, et al.. A unified classification system for eukaryotic transposable elements. Nat Rev Genet. Nature Publishing Group; 2007; doi: 10.1038/nrg2165.

26. Kelley JL, Peyton JT, Fiston-Lavier A-S, Teets NM, Yee M-C, Johnston JS, et al.. Compact genome of the Antarctic midge is likely an adaptation to an extreme environment. Nat Commun. Nature Publishing Group; 2014; doi: 10.1038/ncomms5611.

27. Wang X, Fang X, Yang P, Jiang X, Jiang F, Zhao D, et al.. The locust genome provides insight into swarm formation and long-distance flight. Nat Commun. Nature Publishing Group; 2014; doi: 10.1038/ncomms3957.

28. Petersen M, Armisén D, Gibbs RA, Hering L, Khila A, Mayer G, et al.. Diversity and evolution of the transposable element repertoire in arthropods with particular reference to insects. BMC Ecol Evol. 2019; doi: 10.1186/s12862-018-1324-9.

29. Gilbert C, Peccoud J, Cordaux R. Transposable Elements and the Evolution of Insects. Annu Rev Entomol. Annual Reviews; 2021; doi: 10.1146/annurev-ento-070720-074650. 
30. Olsen LK, Heckenhauer J, Sproul JS, Dikow RB, Gonzalesz VL, Kweskin MP, et al.. De novo whole genome assemblies of Agrypnia vestita Walker, and Hesperophlax magnus Banks reveal substantial repetitive element expansion in tube case-making caddisflies (Insecta: Trichoptera). Genome Biol Evol. 2021; doi: 10.1093/gbe/evab013.

31. Montgomery E, Charlesworth B, Langley $\mathrm{CH}$. A test for the role of natural selection in the stabilization of transposable element copy number in a population of Drosophila melanogaster. Genet Res. Cambridge University Press; 1987; doi: 10.1017/S0016672300026707.

32. Charlesworth B, Langley CH. Transposition of copia elements in Drosophila. Nature. Nature Publishing Group; 1988; doi: 10.1038/332021b0.

33. Charlesworth B, Langley CH. The Population Genetics of Drosophila Transposable Elements. Annu Rev Genet. 1989; doi: 10.1146/annurev.ge.23.120189.001343.

34. Montgomery EA, Huang SM, Langley CH, Judd BH. Chromosome rearrangement by ectopic recombination in Drosophila melanogaster: genome structure and evolution. Genetics. 1991; doi: 10.1093/genetics/129.4.1085.

35. Mieczkowski PA, Lemoine FJ, Petes TD. Recombination between retrotransposons as a source of chromosome rearrangements in the yeast Saccharomyces cerevisiae. DNA Repair. 2006; doi: 10.1016/j.dnarep.2006.05.027.

36. Ugarković Đ, Plohl M. Variation in satellite DNA profiles-causes and effects. EMBO J. John Wiley \& Sons, Ltd; 2002; doi: 10.1093/emboj/cdf612.

37. Ferree PM, Barbash DA. Species-Specific Heterochromatin Prevents Mitotic Chromosome Segregation to Cause Hybrid Lethality in Drosophila. PLOS Biol. Public Library of Science; 2009; doi: 10.1371/journal.pbio.1000234.

38. Gahan LJ, Gould F, Heckel DG. Identification of a Gene Associated with Bt Resistance in Heliothis virescens. Science. American Association for the Advancement of Science; 2001; doi: 10.1126/science.1060949.

39. Chen $\mathrm{S}$, Li X. Transposable elements are enriched within or in close proximity to xenobiotic-metabolizing cytochrome P450 genes. BMC Evol Biol. 2007; doi: 10.1186/14712148-7-46.

40. González J, Lenkov K, Lipatov M, Macpherson JM, Petrov DA. High Rate of Recent Transposable Element-Induced Adaptation in Drosophila melanogaster. PLOS Biol. Public Library of Science; 2008; doi: 10.1371/journal.pbio.0060251.

41. González J, Karasov TL, Messer PW, Petrov DA. Genome-Wide Patterns of Adaptation to Temperate Environments Associated with Transposable Elements in Drosophila. PLOS Genet. Public Library of Science; 2010; doi: 10.1371/journal.pgen.1000905.

42. Itokawa K, Komagata O, Kasai S, Okamura Y, Masada M, Tomita T. Genomic structures of Cyp9m10 in pyrethroid resistant and susceptible strains of Culex quinquefasciatus. Insect Biochem Mol Biol. 2010; doi: 10.1016/j.ibmb.2010.06.001. 
43. Hof AE van't, Campagne P, Rigden DJ, Yung CJ, Lingley J, Quail MA, et al.. The industrial melanism mutation in British peppered moths is a transposable element. Nature. Nature Publishing Group; 2016; doi: 10.1038/nature17951.

44. Feschotte C. Transposable elements and the evolution of regulatory networks. Nat Rev Genet. Nature Publishing Group; 2008; doi: 10.1038/nrg2337.

45. Ellison CE, Bachtrog D. Dosage Compensation via Transposable Element Mediated Rewiring of a Regulatory Network. Science. American Association for the Advancement of Science; 2013; doi: 10.1126/science.1239552.

46. Santos ME, Braasch I, Boileau N, Meyer BS, Sauteur L, Böhne A, et al.. The evolution of cichlid fish egg-spots is linked with a cis -regulatory change. Nat Commun. Nature Publishing Group; 2014; doi: 10.1038/ncomms6149.

47. Alfsnes K, Leinaas HP, Hessen DO. Genome size in arthropods; different roles of phylogeny, habitat and life history in insects and crustaceans. Ecol Evol. 2017; doi: https://doi.org/10.1002/ece3.3163.

48. : Trichoptera World Checklist. https://entweb.sites.clemson.edu/database/trichopt/ Accessed 2021 May 8.

49. Wiggins GB, Mackay RJ. Some Relationships between Systematics and Trophic Ecology in Nearctic Aquatic Insects, with Special Reference to Trichoptera. Ecology. 1978; doi: https://doi.org/10.2307/1938234.

50. Mackay RJ, Wiggins GB. Ecological Diversity in Trichoptera. Annu Rev Entomol. 1979; doi: 10.1146/annurev.en.24.010179.001153.

51. Hotaling S, Kelley JL, Frandsen PB. Aquatic Insects Are Dramatically Underrepresented in Genomic Research. Insects. Multidisciplinary Digital Publishing Institute; 2020; doi: 10.3390/insects 11090601 .

52. Hotaling S, Sproul JS, Heckenhauer J, Powell A, Larracuente AM, Pauls SU, et al.. Longreads are revolutionizing 20 years of insect genome sequencing. Genome Biol Evol. 2021; doi: 10.1093/gbe/evab138.

53. Gurevich A, Saveliev V, Vyahhi N, Tesler G. QUAST: Quality assessment tool for genome assemblies. Bioinforma Oxf Engl. 2013; doi: 10.1093/bioinformatics/btt086.

54. Simão F, Waterhouse R, Ioannidis P, Zdobnov E. BUSCO: Assessing genome assembly and annotation completeness with single-copy orthologs. Bioinforma Oxf Engl. 2015; doi: 10.1093/bioinformatics/btv351.

55. Waterhouse RM, Seppey M, Simão FA, Manni M, Ioannidis P, Klioutchnikov G, et al.. BUSCO Applications from Quality Assessments to Gene Prediction and Phylogenomics. Mol Biol Evol. 2018; doi: 10.1093/molbev/msx319.

56. Laetsch DR, Blaxter ML. BlobTools: Interrogation of genome assemblies.

F1000Research. 2017; doi: 10.12688/f1000research.12232.1. 
57. Heckenhauer J, Frandsen PB, Gupta DK, Paule J, Prost S, Schell T, et al.. Annotated Draft Genomes of Two Caddisfly Species Plectrocnemia conspersa CURTIS and Hydropsyche tenuis NAVAS (Insecta: Trichoptera). Genome Biol Evol. 2019; doi: 10.1093/gbe/evz264.

58. Thomas JA, Frandsen PB, Prendini E, Zhou X, Holzenthal RW. A multigene phylogeny and timeline for Trichoptera (Insecta). Syst Entomol. 2020; doi: https://doi.org/10.1111/syen.12422.

59. Schell T, Feldmeyer B, Schmidt H, Greshake B, Tills O, Truebano M, et al.. An Annotated Draft Genome for Radix auricularia (Gastropoda, Mollusca). Genome Biol Evol. 2017; doi: 10.1093/gbe/evx032.

60. Hanrahan SJ, Johnston JS. New genome size estimates of 134 species of arthropods. Chromosome Res Int J Mol Supramol Evol Asp Chromosome Biol. 2011; doi: 10.1007/s10577-011-9231-6.

61. Yu Y-S, Jin S, Cho N, Lim J, Kim C-H, Lee S-G, et al.. Genome Size Estimation of Callipogon relictus Semenov (Coleoptera: Cerambycidae), an Endangered Species and a Korea Natural Monument. Insects. Multidisciplinary Digital Publishing Institute; 2021; doi: 10.3390/insects 12020111 .

62. Hare EE, Johnston JS. Genome size determination using flow cytometry of propidium iodide-stained nuclei. Methods Mol Biol Clifton NJ. 2011; doi: 10.1007/978-1-61779-228$1 \_1$.

63. Austin CM, Tan MH, Harrisson KA, Lee YP, Croft LJ, Sunnucks P, et al.. De novo genome assembly and annotation of Australia's largest freshwater fish, the Murray cod (Maccullochella peelii), from Illumina and Nanopore sequencing read. GigaScience. 2017; doi: 10.1093/gigascience/gix063.

64. Pflug JM, Holmes VR, Burrus C, Johnston JS, Maddison DR. Measuring Genome Sizes Using Read-Depth, k-mers, and Flow Cytometry: Methodological Comparisons in Beetles (Coleoptera). G3 GenesGenomesGenetics. 2020; doi: 10.1534/g3.120.401028.

65. Bennett MD, Riley R. The duration of meiosis. Proc R Soc Lond B Biol Sci. Royal Society; 1971; doi: 10.1098/rspb.1971.0066.

66. Cavalier-Smith T. Nuclear volume control by nucleoskeletal DNA, selection for cell volume and cell growth rate, and the solution of the DNA C-value paradox. J Cell Sci. 1978; doi: $10.1242 /$ jcs.34.1.247.

67. Gregory TR, Hebert PDN. The Modulation of DNA Content: Proximate Causes and Ultimate Consequences. Genome Res. 1999; doi: 10.1101/gr.9.4.317.

68. CAVALIER-SMITH T. Economy, Speed and Size Matter: Evolutionary Forces Driving Nuclear Genome Miniaturization and Expansion. Ann Bot. 2005; doi: 10.1093/aob/mci010.

69. Thomas GWC, Dohmen E, Hughes DST, Murali SC, Poelchau M, Glastad K, et al.. Gene content evolution in the arthropods. Genome Biol. 2020; doi: 10.1186/s13059-019-1925-7.

70. Nakatani Y, McLysaght A. Macrosynteny analysis shows the absence of ancient wholegenome duplication in lepidopteran insects. Proc Natl Acad Sci U S A. 2019; doi: 10.1073/pnas.1817937116. 
71. Li Z, Tiley GP, Rundell RJ, Barker MS. Reply to Nakatani and McLysaght: Analyzing deep duplication events. Proc Natl Acad Sci. National Academy of Sciences; 2019; doi: 10.1073/pnas.1819227116.

72. Roelofs D, Zwaenepoel A, Sistermans T, Nap J, Kampfraath AA, Van de Peer Y, et al.. Multi-faceted analysis provides little evidence for recurrent whole-genome duplications during hexapod evolution. BMC Biol. 2020; doi: 10.1186/s12915-020-00789-1.

73. Lamichhaney S, Catullo R, Keogh JS, Clulow S, Edwards SV, Ezaz T. A bird-like genome from a frog: Mechanisms of genome size reduction in the ornate burrowing frog, Platyplectrum ornatum. Proc Natl Acad Sci. National Academy of Sciences; 2021; doi: 10.1073/pnas.2011649118.

74. Capy P, Gasperi G, Biémont C, Bazin C. Stress and transposable elements: co-evolution or useful parasites? Heredity. 2000; doi: 10.1046/j.1365-2540.2000.00751.x.

75. Pecinka A, Dinh HQ, Baubec T, Rosa M, Lettner N, Scheid OM. Epigenetic Regulation of Repetitive Elements Is Attenuated by Prolonged Heat Stress in Arabidopsis. Plant Cell. 2010; doi: $10.1105 /$ tpc.110.078493.

76. Tittel-Elmer M, Bucher E, Broger L, Mathieu O, Paszkowski J, Vaillant I. Stress-Induced Activation of Heterochromatic Transcription. PLOS Genet. Public Library of Science; 2010; doi: 10.1371/journal.pgen.1001175.

77. Wiggins G. Larvae of the North American Caddisfly Genera (Trichoptera). Larvae North Am. Caddisfly Genera Trichoptera. University of Toronto Press;

78. Wiggins GB, Information CI for S and T, Museum RO. Caddisflies: The Underwater Architects. University of Toronto Press;

79. Dijkstra K-DB, Monaghan MT, Pauls SU. Freshwater biodiversity and aquatic insect diversification. Annu Rev Entomol. 2014; doi: 10.1146/annurev-ento-011613-161958.

80. Kordiš D, Lovšin N, Gubenšek F. Phylogenomic Analysis of the L1 Retrotransposons in Deuterostomia. Syst Biol. 2006; doi: 10.1080/10635150601052637.

81. Warren IA, Naville M, Chalopin D, Levin P, Berger CS, Galiana D, et al.. Evolutionary impact of transposable elements on genomic diversity and lineage-specific innovation in vertebrates. Chromosome Res. 2015; doi: 10.1007/s10577-015-9493-5.

82. Suh A, Churakov G, Ramakodi MP, Platt RN II, Jurka J, Kojima KK, et al.. Multiple Lineages of Ancient CR1 Retroposons Shaped the Early Genome Evolution of Amniotes. Genome Biol Evol. 2015; doi: 10.1093/gbe/evu256.

83. Grandi FC, An W. Non-LTR retrotransposons and microsatellites. Mob Genet Elem. Taylor \& Francis; 2013; doi: 10.4161/mge.25674.

84. Mackay TFC. Transposable elements and fitness in Drosophila melanogaster. Genome. NRC Research Press Ottawa, Canada; 2011; doi: 10.1139/g89-046.

85. Pasyukova EG, Nuzhdin SV, Morozova TV, Mackay TFC. Accumulation of Transposable Elements in the Genome of Drosophila melanogaster is Associated with a Decrease in Fitness. J Hered. 2004; doi: 10.1093/jhered/esh050. 
86. Langley CH, Montgomery E, Hudson R, Kaplan N, Charlesworth B. On the role of unequal exchange in the containment of transposable element copy number. Genet Res. Cambridge University Press; 1988; doi: 10.1017/S0016672300027695.

87. Hollister JD, Gaut BS. Epigenetic silencing of transposable elements: A trade-off between reduced transposition and deleterious effects on neighboring gene expression. Genome Res. 2009; doi: 10.1101/gr.091678.109.

88. Lee YCG, Karpen GH. Pervasive epigenetic effects of Drosophila euchromatic transposable elements impact their evolution. Nordborg M, editor. eLife. eLife Sciences Publications, Ltd; 2017; doi: 10.7554/eLife.25762.

89. Kraaijeveld K. Genome Size and Species Diversification. Evol Biol. 2010; doi: 10.1007/s11692-010-9093-4.

90. Cosby RL, Chang N-C, Feschotte C. Host-transposon interactions: conflict, cooperation, and cooption. Genes Dev. 2019; doi: 10.1101/gad.327312.119.

91. Hardie DC, Hebert PD. Genome-size evolution in fishes. Can J Fish Aquat Sci. NRC Research Press Ottawa, Canada; 2011; doi: 10.1139/f04-106.

92. Rees DJRJ, Dufresne FD, Glémet HG, Belzile CB. Amphipod genome sizes: first estimates for Arctic species reveal genomic giants. Genome. 2007; doi: 10.1139/G06-155.

93. Dufresne F, Jeffery N. A guided tour of large genome size in animals: what we know and where we are heading. Chromosome Res. 2011; doi: 10.1007/s10577-011-9248-x.

94. Lertzman-Lepofsky G, Mooers AØ, Greenberg DA. Ecological constraints associated with genome size across salamander lineages. Proc R Soc B Biol Sci. Royal Society; 2019; doi: 10.1098/rspb.2019.1780.

95. Vinogradov AE. Larger genomes for molluskan land pioneers. Genome. 2000; doi: 10.1139/g99-063.

96. Miller SA, Dykes DD, Polesky HF. A simple salting out procedure for extracting DNA from human nucleated cells. Nucleic Acids Res. 16:12151988;

97. Bankevich A, Nurk S, Antipov D, Gurevich AA, Dvorkin M, Kulikov AS, et al.. SPAdes: A New Genome Assembly Algorithm and Its Applications to Single-Cell Sequencing. $J$ Comput Biol. 2012; doi: 10.1089/cmb.2012.0021.

98. Cantarel BL, Korf I, Robb SMC, Parra G, Ross E, Moore B, et al.. MAKER: an easy-touse annotation pipeline designed for emerging model organism genomes. Genome Res. 2008; doi: 10.1101/gr.6743907.

99. Holt C, Yandell M. MAKER2: an annotation pipeline and genome-database management tool for second-generation genome projects. BMC Bioinformatics. 2011; doi: 10.1186/14712105-12-491.

100. Luo S, Tang M, Frandsen PB, Stewart RJ, Zhou X. The genome of an underwater architect, the caddisfly Stenopsyche tienmushanensis Hwang (Insecta: Trichoptera). GigaScience. 2018; doi: 10.1093/gigascience/giy143. 
101. Haas BJ, Salzberg SL, Zhu W, Pertea M, Allen JE, Orvis J, et al.. Automated eukaryotic gene structure annotation using EVidenceModeler and the Program to Assemble Spliced Alignments. Genome Biol. 2008; doi: 10.1186/gb-2008-9-1-r7.

102. Lowe TM, Chan PP. tRNAscan-SE On-line: integrating search and context for analysis of transfer RNA genes. Nucleic Acids Res. 2016; doi: 10.1093/nar/gkw413.

103. Camacho C, Coulouris G, Avagyan V, Ma N, Papadopoulos J, Bealer K, et al.. BLAST+: architecture and applications. BMC Bioinformatics. 2009; doi: 10.1186/1471-2105-10-421.

104. Götz S, García-Gómez JM, Terol J, Williams TD, Nagaraj SH, Nueda MJ, et al.. Highthroughput functional annotation and data mining with the Blast2GO suite. Nucleic Acids Res. 2008; doi: 10.1093/nar/gkn176.

105. Katoh K, Kuma K, Toh H, Miyata T. MAFFT version 5: improvement in accuracy of multiple sequence alignment. Nucleic Acids Res. 2005; doi: 10.1093/nar/gki198.

106. Kalyaanamoorthy S, Minh BQ, Wong TKF, von Haeseler A, Jermiin LS. ModelFinder: fast model selection for accurate phylogenetic estimates. Nat Methods. Nature Publishing Group; 2017; doi: 10.1038/nmeth.4285.

107. Minh BQ, Schmidt HA, Chernomor O, Schrempf D, Woodhams MD, von Haeseler A, et al.. IQ-TREE 2: New Models and Efficient Methods for Phylogenetic Inference in the Genomic Era. Mol Biol Evol. 2020; doi: 10.1093/molbev/msaa015.

108. Hoang DT, Chernomor O, von Haeseler A, Minh BQ, Vinh LS. UFBoot2: Improving the Ultrafast Bootstrap Approximation. Mol Biol Evol. 2018; doi: 10.1093/molbev/msx281.

109. Zhang C, Rabiee M, Sayyari E, Mirarab S. ASTRAL-III: polynomial time species tree reconstruction from partially resolved gene trees. BMC Bioinformatics. 2018; doi: 10.1186/s12859-018-2129-y.

110. Otto F. DAPI staining of fixed cells for high-resolution flow cytometry of nuclear DNA. Methods Cell Biol. 1990; doi: 10.1016/s0091-679x(08)60516-6.

111. Dolezel J, Binarova P, Lucretti S. Analysis of Nuclear DNA content in plant cells by Flow cytometry. Biol Plant. 1989; doi: 10.1007/BF02907241.

112. Ranallo-Benavidez TR, Jaron KS, Schatz MC. GenomeScope 2.0 and Smudgeplot for reference-free profiling of polyploid genomes. Nat Commun. 2020; doi: 10.1038/s41467-02014998-3.

113. Wickham H. ggplot2: Elegant Graphics for Data Analysis. 2nd ed. Springer International Publishing;

114. Flynn JM, Hubley R, Goubert C, Rosen J, Clark AG, Feschotte C, et al.. RepeatModeler 2 for automated genomic discovery of transposable element families. Proc Natl Acad Sci. National Academy of Sciences; 2020; doi: 10.1073/pnas.1921046117.

115. Novák P, Neumann P, Pech J, Steinhaisl J, Macas J. RepeatExplorer: a Galaxy-based web server for genome-wide characterization of eukaryotic repetitive elements from nextgeneration sequence reads. Bioinformatics. 2013; doi: 10.1093/bioinformatics/btt054. 
116. Novák P, Ávila Robledillo L, Koblížková A, Vrbová I, Neumann P, Macas J. TAREAN: a computational tool for identification and characterization of satellite DNA from unassembled short reads. Nucleic Acids Res. 2017; doi: 10.1093/nar/gkx257.

117. Negm S, Greenberg A, Larracuente AM, Sproul JS. RepeatProfiler: a pipeline for visualization and comparative analysis of repetitive DNA profiles. bioRxiv. Cold Spring Harbor Laboratory; 2020; doi: 10.1101/2020.05.22.111252.

118. Goubert C, Modolo L, Vieira C, ValienteMoro C, Mavingui P, Boulesteix M. De Novo Assembly and Annotation of the Asian Tiger Mosquito (Aedes albopictus) Repeatome with dnaPipeTE from Raw Genomic Reads and Comparative Analysis with the Yellow Fever Mosquito (Aedes aegypti). Genome Biol Evol. 2015; doi: 10.1093/gbe/evv050.

119. Barker MS, Dlugosch KM, Dinh L, Challa RS, Kane NC, King MG, et al.. EvoPipes.net: Bioinformatic Tools for Ecological and Evolutionary Genomics. Evol Bioinforma. SAGE Publications Ltd STM; 2010; doi: 10.4137/EBO.S5861.

120. Birney E, Clamp M, Durbin R. GeneWise and Genomewise. Genome Res. 2004; doi: 10.1101/gr.1865504.

121. Yang Z. PAML 4: Phylogenetic Analysis by Maximum Likelihood. Mol Biol Evol. 2007; doi: 10.1093/molbev/msm088.

122. Cui L, Wall PK, Leebens-Mack JH, Lindsay BG, Soltis DE, Doyle JJ, et al.. Widespread genome duplications throughout the history of flowering plants. Genome Res. 2006; doi: $10.1101 /$ gr.4825606.

123. Benaglia T, Chauveau D, Hunter DR, Young DS. mixtools: An R Package for Analyzing Mixture Models. J Stat Softw. 2009; doi: 10.18637/jss.v032.i06.

124. Weigand H, Weiss M, Cai H, Li Y, Yu L, Zhang C, et al.. Fishing in troubled waters: Revealing genomic signatures of local adaptation in response to freshwater pollutants in two macroinvertebrates. Sci Total Environ. 2018; doi: 10.1016/j.scitotenv.2018.03.109.

125. Ferguson L, Marlétaz F, Carter J-M, Taylor WR, Gibbs M, Breuker CJ, et al.. Ancient Expansion of the Hox Cluster in Lepidoptera Generated Four Homeobox Genes Implicated in Extra-Embryonic Tissue Formation. PLOS Genet. Public Library of Science; 2014; doi: 10.1371/journal.pgen.1004698.

126. Weigand H, Weiss M, Cai H, Li Y, Yu L, Zhang C, et al.. Deciphering the origin of mito-nuclear discordance in two sibling caddisfly species. Mol Ecol. 2017; doi:

10.1111/mec.14292. 


\section{Supplementary Material}

\section{Supplementary note 1: DNA extraction}

For extraction of high molecular weight genomic DNA (gDNA) from 17 individuals (15 species) of caddisfly larvae, we used a salting-out protocol adapted from [1]. After removing the intestinal tracts, tissue lysis was done in $600 \mu \mathrm{l}$ lysis buffer $(10 \mathrm{mM}$ Tris-Hcl, $400 \mathrm{mM}$ $\mathrm{NaCl}$, and $100 \mathrm{mM}$ EDTA, pH 8.0), $40 \mu \mathrm{l} 10 \%$ SDS and $5 \mu 1$ Proteinase K (20 mg/ml) on a MKR23 thermoshaker (Hettich Benelux, Geldermalsen, Netherlands) overnight at $37^{\circ} \mathrm{C}$. After adding $20 \mu \mathrm{l}$ RNAse A $(10 \mathrm{mg} / \mathrm{ml})$, we incubated the samples for another $30 \mathrm{~min}$ at $37^{\circ} \mathrm{C}$. Then, we added $240 \mu \mathrm{l} 5 \mathrm{M} \mathrm{NaCl}$ and inverted the tube 5-10 times. To pellet the precipitate, we centrifuged the tube at $10000 \mathrm{rpm}$ at $4^{\circ} \mathrm{C}$ for $10 \mathrm{~min}$ in a $\mathrm{Z} 300 \mathrm{~K}$ centrifuge (Hermle, Gosheim, Germany) and transferred the supernatant to a new tube. After adding 1 volume of chloroform-isoamylalcohol (24:1), we carefully inverted the tube 20-30 times and centrifuged again as above. To pellet the precipitated DNA, we mixed the supernatant with $1.2 \mathrm{ml} \mathrm{100 \%} \mathrm{ethanol} \mathrm{in} \mathrm{a} \mathrm{new} \mathrm{tube} \mathrm{and} \mathrm{centrifuged} \mathrm{again} \mathrm{for} 10 \mathrm{~min}$. After washing the DNA two times with freshly prepared $70 \%$ ethanol and subsequent air-drying for $20 \mathrm{~min}$, we resuspended the DNA pellet in 1X TE buffer. We quantified the DNA using a Qubit 4.0 fluorometer with the dsDNA Broad Range Kit (ThermoFisher Scientific, Waltham, USA), checked its purity with a DS11 spectrophotometer (DeNovix, Wilmington, DE, USA) and verified DNA integrity on a 2200 TapeStation (Agilent Technologies, Santa Clara, USA) with a Genomic Tape.

\section{Supplementary note 2: Sequencing strategies}

\section{Short read (Illumina) sequencing}

All 17 individuals (15 species) were subject to Illumina paired-end sequencing. We prepared genomic libraries for Illumina sequencing from 400-500 ng gDNA using the NEBNext Ultra II FS DNA Library Preparation Kit (New England Biolabs, Ipswich, MA, USA) following the manufacturer's manual. To achieve a mean insert size of 400-500 bp, we conducted enzymatic fragmentation with subsequent size selection. We chose a combinatorial dual indexing approach using the NEBNext Multiplex Oligos for Illumina (Dual Index Set 1) and amplified libraries with five PCR cycles. We quantified each library on a Qubit 4.0 fluorometer with the 1x dsDNA HS Assay Kit and checked the fragment size distribution on a 2200 TapeStation using a High Sensitivity D1000 Tape. Illumina paired-end (150 bp) sequencing was done on a HiSeq 2000 sequencer at Novogene. After checking the quality of 
$\begin{array}{llll}\text { Illumina } & \text { reads } & \text { using } & \text { FastQC }\end{array}$ (http://www.bioinformatics.babraham.ac.uk/projects/fastqc), we trimmed of overrepresented k-mers using autotrim.pl v0.6.1 [2] with Trimmomatic v0.38 [3] and a custom adapter file (ILLUMINACLIP: >adapter_combined.fa>:2:30:10), SLIDINGWINDOW:4:20 and MINLEN:50 and further processed reads with Cutadapt v2.23 [4] using the following parameters:-- pair-filter=any $-1=140$, --max-n=0 for sample which showed a warning flag at per base sequence content in FastQC. To filter out potentially contaminated reads, we used Kraken 2 v2.0.8-beta [5], [6] with the standard Kraken 2 database and only kept unclassified reads for further analyses.

\section{Long-read sequencing}

In addition to Illumina sequencing, we sequenced 14 individuals (14 species) with Oxford Nanopore or PacBio long-read technologies.

\section{Oxford Nanopore sequencing}

To generate Oxford Nanopore long-reads we sheared high-molecular-weight gDNA (2.0-3.2 $\mu \mathrm{g} ;>60 \mathrm{~kb}$ ) to a mean fragment size of about $10 \mathrm{~kb}$ using g-TUBES (Covaris, Woburn, MA, USA), centrifuging the samples at $6000 \mathrm{rpm}$ for $1 \mathrm{~min}$ in an Eppendorf 5424 Centrifuge. Libraries were prepared with the SQK-LSK109 kit (Oxford Nanopore, Oxford, UK) according to the manufacturer's manual (version: GDE_9063_v109_revB_23May2018) with the following modifications: (1.) During DNA repair and end-prep, we used nuclease-free water instead of DNA CS; (2.) the incubation time of the end-prep reaction was 15 min (instead of $5 \mathrm{~min}$ ) at $65^{\circ} \mathrm{C}$; (3.) mixing was always done by pipetting; (4.) we used $80 \%$ ethanol (instead of 70\%) for magnetic bead-based cleanup; (5.) we increased the time for DNA-binding to the magnetic beads to $15-20 \mathrm{~min}$; (6.) the magnetic beads were air-dried for 1-2 min; (7.) after the adapter ligation, we carried out the clean-up with $45 \mu 1$ Ampure XP beads (instead of $40 \mu \mathrm{l}$; Beckman Coulter, Brea, CA, USA); (8.) when preparing the library for loading onto the flow cell, we used $14 \mu 1$ (instead of $12 \mu \mathrm{l}$ ) of the DNA library. To enrich for long fragments after adapter ligation, we used the L Fragment Buffer (LFB). After both the end-prep and adapter ligation steps, we quantified DNA using a Qubit 4.0 fluorometer.

\section{Oxford Nanopore whole genome amplification}

For the small species Agapetus fuscipes and Agraylea sexmaculata, gDNA obtained from a single individual was insufficient for direct library preparation for Nanopore sequencing. 
Therefore, we performed whole genome amplification (WGA) following the "Premium whole genome amplification protocol (SQK-LSK109), version 23 May 2018”. First, we diluted gDNA samples with $1 \mathrm{x}$ TE buffer to obtain a DNA input of ca. 2 ng. We mixed $5 \mu 1$ normalized gDNA with $5 \mu 1$ reconstituted DLB buffer (from the Repli-g Mini Kit, Qiagen, Hilden, Germany) and incubated for $3 \mathrm{~min}$ at room temperature. Then, $10 \mu 1$ of reconstituted Stop Solution were added and mixed by pipetting. We added this DNA reaction mixture to a $0.2 \mathrm{ml}$ PCR tube that contained $29 \mu \mathrm{l}$ Repli-g Reaction buffer and $1 \mu \mathrm{l}$ Repli-g DNA Polymerase. After mixing by pipetting, the reaction was incubated for $16 \mathrm{~h}$ at $30^{\circ} \mathrm{C}$, followed by $3 \mathrm{~min}$ at $65^{\circ} \mathrm{C}$ in a Master Cycler (Eppendorf, Hamburg, Germany). We purified the reactions using $90 \mu \mathrm{l}$ Ampure XP beads (Beckman and Coulter, Brea, U.S.A.). The beads were washed only once with $80 \%$ freshly prepared ethanol. We resuspended the DNA in $50 \mu 1$ nuclease-free water and quantified it with the Qubit BR kit. Afterwards, we mixed $1.5 \mu \mathrm{g}$ of the amplified DNA with $3 \mu \mathrm{l}$ NEBuffer 2, $1.5 \mu 1$ T7 endonuclease I (New England Biolabs, Ipswich, U.S.A.) and water to achieve a reaction volume of $30 \mu$ l. This reaction mixture was incubated for $15 \mathrm{~min}$ at $37^{\circ} \mathrm{C}$. We cleaned up reactions using $35 \mu \mathrm{l}$ of the pre-made custom bead suspension (made from Ampure XP beads following the protocol). The beads were washed twice with $80 \%$ ethanol and the DNA resuspended in $50 \mu 1$ nuclease-free water. The DNA was quantified with the Qubit BR kit. Subsequently, the library preparation continued with the end-prep and FFPE repair following the protocol for the SQK-LSK109 library preparation with the addition of a barcoding step for multiplexed sequencing using the EXPNBD104 Native Barcoding Expansion kit (Oxford Nanopore).

We sequenced each Oxford Nanopore library on a single flow cell using the MinION portable DNA sequencer. For basecalling Nanopore reads from their raw .fast5 files, we used Poretools v0.6.0 [7] or Guppy Basecalling Software v2.3.1. Reads resulting from the whole genome amplification protocol were demultiplexed using guppy_barcoder (Guppy Basecalling Software v2.3.1: https://nanoporetech.com/nanopore-sequencing-data-analysis) with --barcode_kits "EXP-NBD104". After trimming adapters with Porechop v.2.0.4 (https://github.com/rrwick/Porechop) using default parameters, we used FASTQ Screen like tools (https://github.com/schellt/fqs-tools) to filter out potential contaminants. For this purpose, we mapped the long reads to a custom-made database with minimap $2-\mathrm{x}$ map-ont. The database contains viral, bacteria and human sequences, as well as potential parasites of Trichoptera (Ascogregaria, Gregarina, Mermithidae) and Trichoptera genomes (as positive control). We created an ID list with awk and extracted the screening info with the paf $2 \mathrm{fqs} . \mathrm{pl}$ script of FASTQ Screen like tools (https://github.com/schellt/fqs-tools). Screening info was 
extracted with the paf2fqs.pl script from FastQ Screen like tools using the paf. file obtained from minimap2 and the previously created ID list. We kept reads without hits and reads that mapped to Trichoptera genomes with subseq command of seqtk 1.3-r106 (https://github.com/lh3/seqtk).

\section{PacBio sequencing}

Two species, Micrasema minimum and Agraylea sexmaculata, were sequenced with PacBio. We constructed a SMRTbell library following the instructions of the SMRTbell Express Prep kit v2.0 with low DNA Input Protocol (Pacific Biosciences, Menlo Park, CA). Following ligation with T-overhang SMRTbell adapters at $20^{\circ} \mathrm{C}$ overnight, we purified the SMRTbell library with an AMPure PB bead clean up step with $0.45 \mathrm{X}$ volume of AMPure PB beads. To remove short SMRTbell templates < $3 \mathrm{~kb}$, we performed a size-selection step with AMPure PB Beads. For this purpose, we diluted the AMPure PB beads with elution buffer (40\% volume/volume) and added a 2.2X volume to the DNA sample. We performed one SMRT cell sequencing run each on the Sequel System II with Sequel II Sequencing Kit 2.0. CLR mode was run for 30 hour movie time with NO pre-extension and Software SMRTLINK 8.0. After obtaining a subreads.bam file containing automatically trimmed reads, we used bam2fastq (https://github.com/jts/bam2fastq) to extract and save reads in fastq format. To filter out contaminations, we mapped reads to our custom database with minimap2 -x map-pb and followed the steps described above.

\section{Supplementary note 3: Assembly strategies}

\section{Long-read assembly with subsequent short-read polishing}

In detail, we first conducted a long-read assembly of the Oxford Nanopore Technology sequencing reads using a fuzzy Bruijn graph approach with wtdbg2 v2.4 [8], following a correction with long-reads by re-mapping these to the assembly with Minimap2 v14 [9] and polishing with Racon v1.3.1 [10]. We then used nanopolish 0.11.1 [11] to further improve the consensus accuracy of the assembly. For this purpose, we used nanopolish index to create an index readdb file that links read ids with their signal-level data in the FAST5 files. To compute a new consensus sequence of our draft assembly, we first aligned the long-reads to the draft assembly with minimap and sorted alignments with samtools. Subsequently, we ran a consensus algorithm with nanopolish variants (--consensus --min-candidate-frequency 0.1) on our draft assembly. We used nanopolish_makerange.py to split our draft genome assembly into $50 \mathrm{~kb}$ segments, to run this step on several parts of the assembly in parallel. We generated 
the polished genome in fasta format with nanopolish vcf2fasta. To obtain an improved representation of the genome based on the short-read data, we used Pilon v1.22 (Walker et al., 2014) to further improve the assembly. Therefore, we mapped the preprocessed Illumina reads to the „nanopolished“" assembly with bwa mem and sorted the read alignments by leftmost coordinates using sort options of SAMtools v1.9 [12]. We used Pilon v1.22 [13], option --fix indels) to identify inconsistencies between the input genome and the evidence in the reads. We used purge_dups 1.2.3 [14] to purge haplotigs and overlaps in an assembly based on read depth.

Hybrid assemblies

DeBruijn graph and overlap-layout-consensus assembly using MaSuRCA

We conducted a de novo hybrid assembly with the raw Illumina data together with the longreads using MaSuRCA v.3.1.1 (137-138). In the config file for each run, we specified the insert size and a standard deviation (10\% of insert size) for the Illumina reads, as well as jellyfish hash size (estimated_genome_size* ${ }^{*}$ long-read coverage). All other parameters were left as defaults. We used purge_dups 1.2.3 to purge haplotigs and overlaps in an assembly based on read depth.

\section{SPAdes hybrid assembly}

For datasets with low long-read coverage, we conducted a hybrid assembly using SPAdes v3.12.0 [15] with the preprocessed Illumina and Oxford Nanopore reads. The option --covcutoff auto was applied. SPAdes contigs $\geq 500 \mathrm{bp}$ were further scaffolded with the long-reads using SLR (https://github.com/luojunwei/SLR) and gaps were closed with TGS-Gapcloser (https://github.com/BGI-Qingdao/TGS-GapCloser).

\section{Short-read assembly}

For Illumina only datasets, we conducted short-read assembly with the preprocessed Illumina reads using SPAdes v3.13.1 [16] with the option --cov-cutoff auto.

\section{Supplementary note 4: Functional annotation of protein coding genes}

The annotation of the genomes resulted in the prediction of 6,413 to 12,927 proteins. Most of the annotated proteins $(94.4 \%$ - 98.8\%) showed significant sequence similarity to entries in the NCBI nr database. GO Distributions were similar to previously annotated caddisfly genomes. Specifically, the major biological processes were cellular and metabolic processes. 
bioRxiv preprint doi: https://doi.org/10.1101/2021.05.10.443368; this version posted July 18, 2021. The copyright holder for this preprint (which was not certified by peer review) is the author/funder, who has granted bioRxiv a license to display the preprint in perpetuity. It is made available under aCC-BY-NC-ND 4.0 International license.

Catalytic activity was the largest subcategory in molecular function. Regarding the cellular component category, most genes were assigned to the cell subcategory or to the membrane subcategory. 
bioRxiv preprint doi: https://doi org/10.1101/2021.05 10.443368; this version posted July 18, 2021. The copyright holder for this preprint (which was not certified by peer review) is the author/funder, who has granted bioRxiv a license to display the preprint in perpetuity. It is made available under aCC-BY-NC-ND 4.0 International license.

Data Distribution Pie Chart [cli_project]

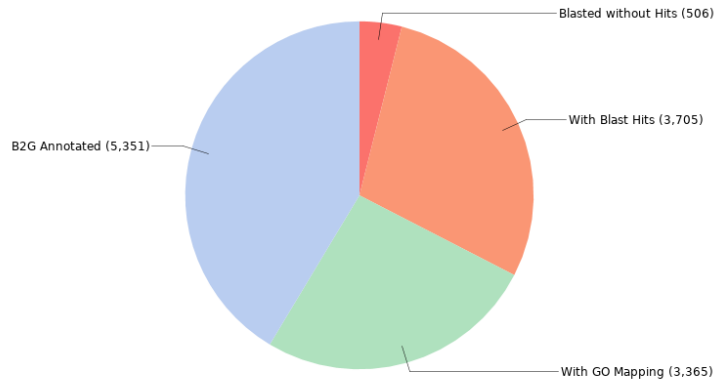

Fig. S1. Blast2GO Annotation Results of Drusus annulatus. Pie charts showing the percentage of proteins with functional Blast2GO annotations, verified by BLAST and mapped to GO terms.

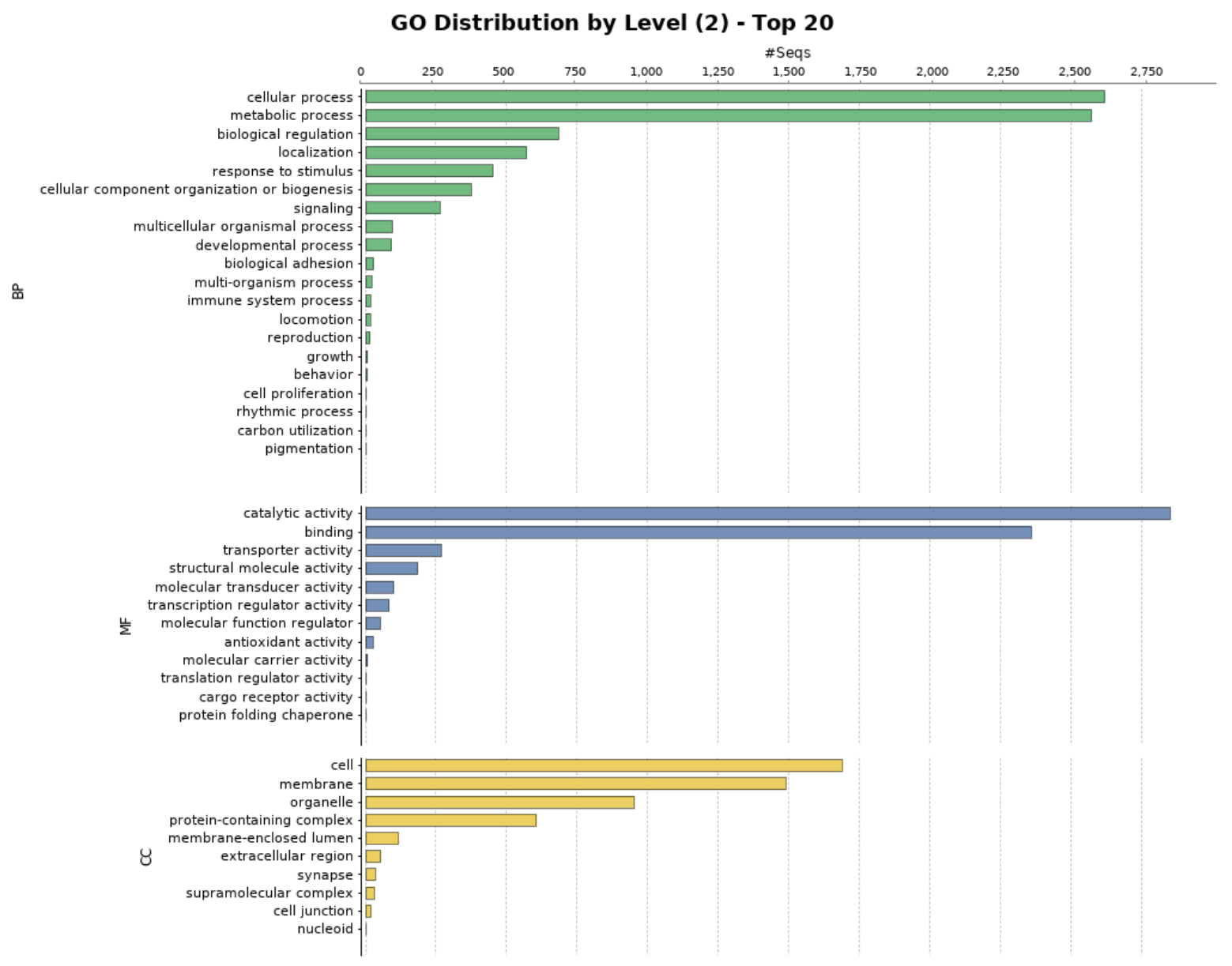

Fig. S2. Blast2GO Functional Annotation for Drusus annulatus. Barplot showing GO terms characterized by biological process, molecular function, and cellular component. Barplots are grouped by biological process (BP), molecular function (MF), and cellular component (CC). 
bioRxiv preprint doi: https://doi. org/10.1101/2021.05.10.443368; this version posted July 18, 2021. The copyright holder for this preprint (which was not certified by peer review) is the author/funder, who has granted bioRxiv a license to display the preprint in perpetuity. It is made available under aCC-BY-NC-ND 4.0 International license.

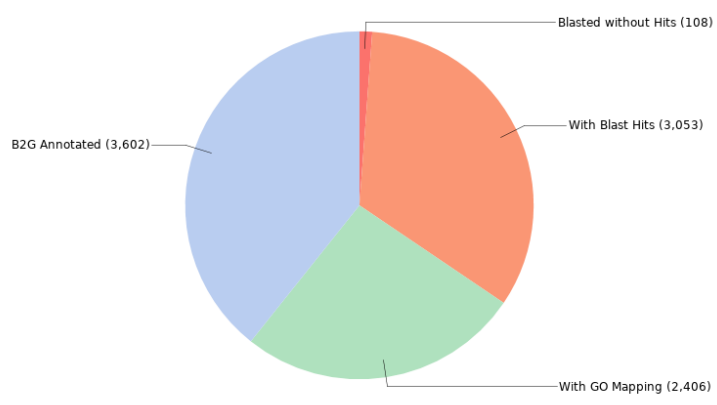

Fig. S3. Blast2GO Annotation Results of Agraylea sexmaculata. Pie charts showing the percentage of proteins with functional Blast2GO annotations, verified by BLAST and mapped to GO terms.

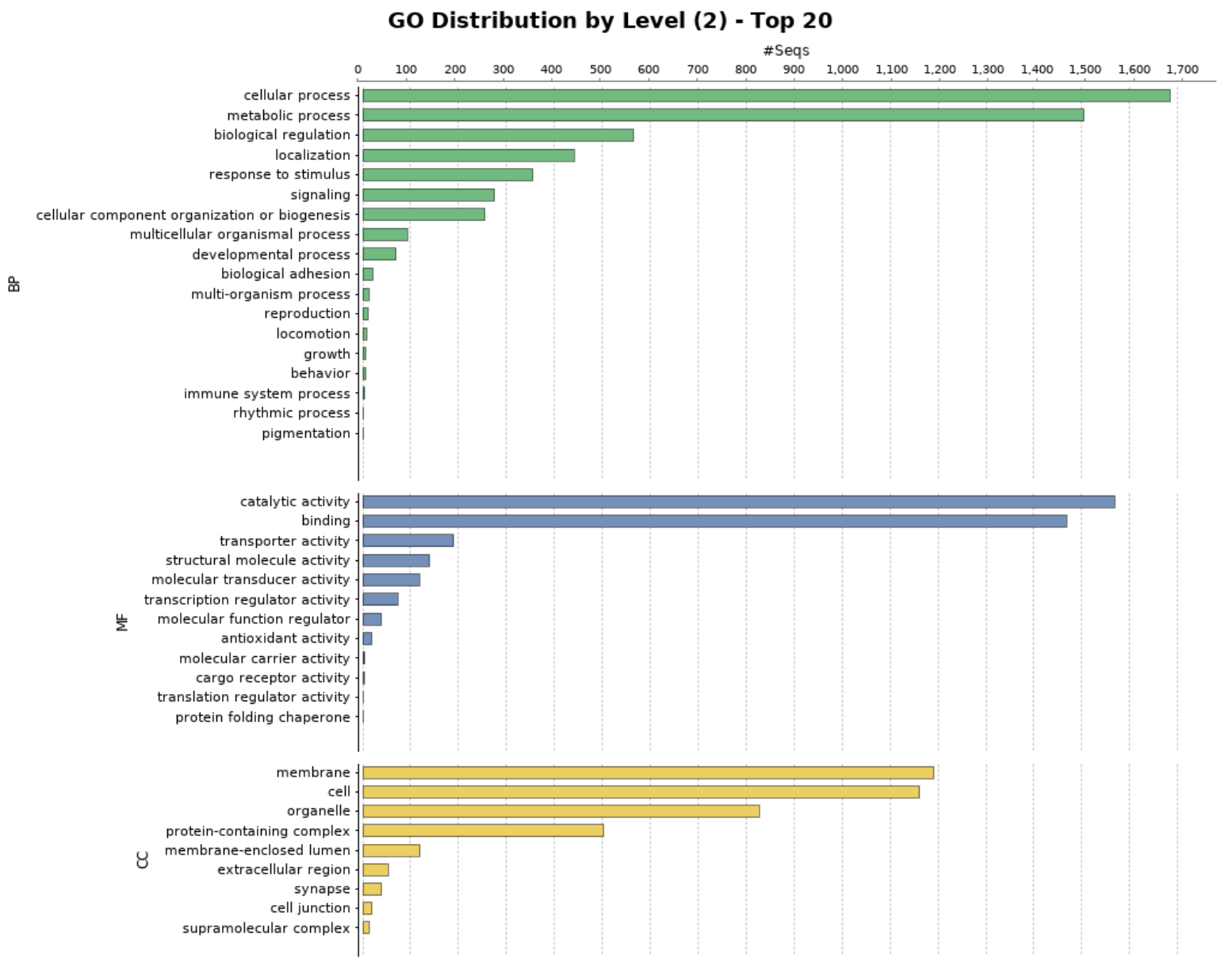

Fig. S4. Blast2GO Functional Annotation for Agraylea sexmaculata. Barplot showing GO terms characterized by biological process, molecular function, and cellular component. Barplots are grouped by biological process (BP), molecular function (MF), and cellular component (CC). 
bioRxiv preprint doi: $h$ ttps://doi. org/10.1101/2021 05.10.443368; this version posted July 18,2021 . The copyright holder for this preprint (which was not certified by peer review) is the author/funder, who has granted bioRxiv a license to display the preprint in perpetuity. It is made available under aCC-BY-NC-ND 4.0 International license.

Data Distribution Pie Chart [cli_project]

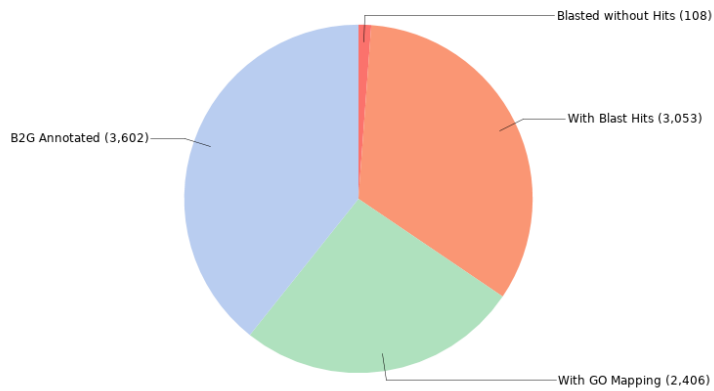

Fig. S5. Blast2GO Annotation Results of Glossosoma conforme. Pie charts showing the percentage of proteins with functional Blast2GO annotations, verified by BLAST and mapped to GO terms.

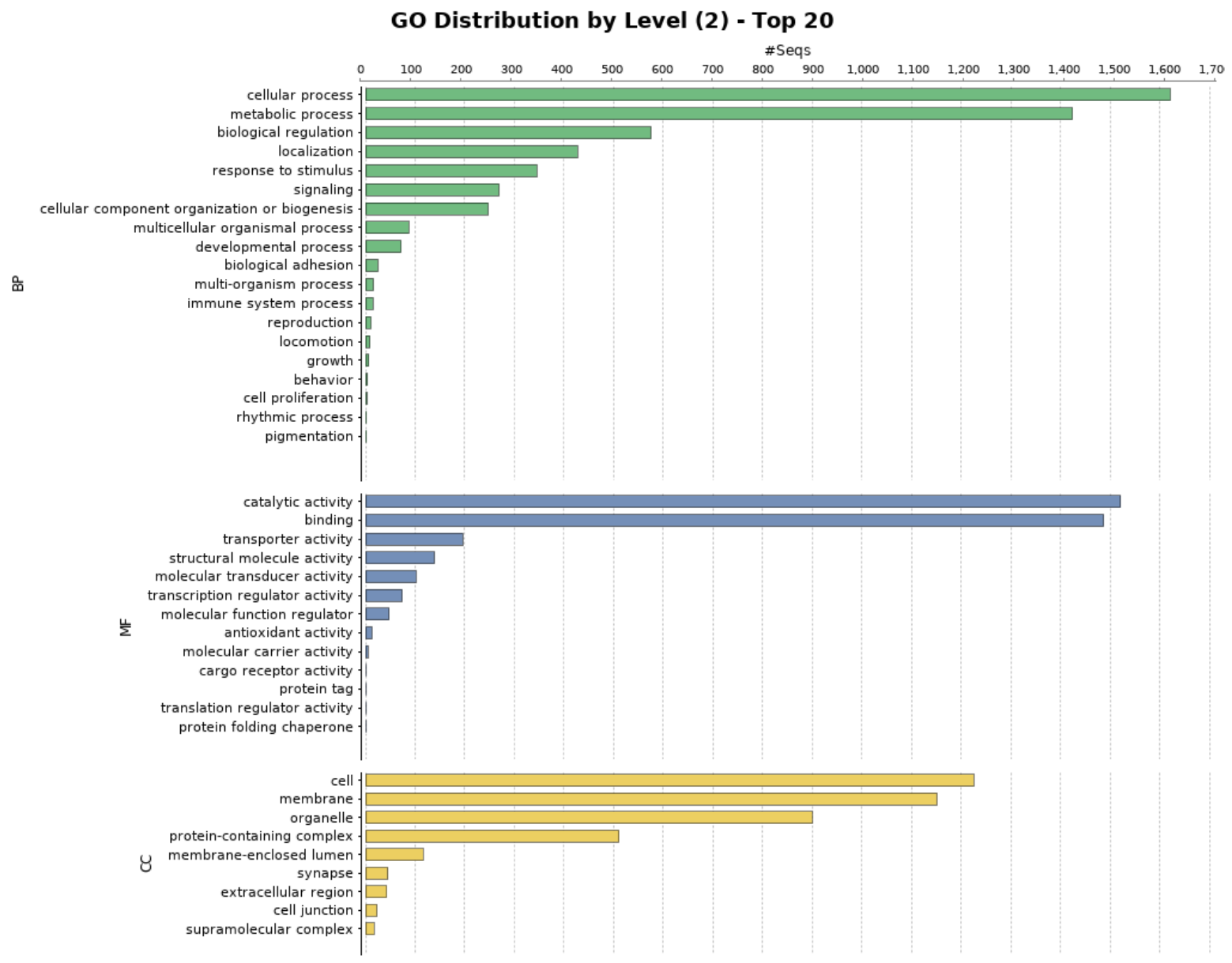

Fig. S6. Blast2GO Functional Annotation for Glossosoma conforme. Barplot showing GO terms characterized by biological process, molecular function, and cellular component. Barplots are grouped by biological process (BP), molecular function (MF), and cellular component (CC). 
bioRxiv preprint doi: $h$ ttps://doi. org/10.1101/2021 05 10.443368; this version posted July 18,2021 . The copyright holder for this preprint (which was not certified by peer review) is the author/funder, who has granted bioRxiv a license to display the preprint in perpetuity. It is made available under aCC-BY-NC-ND 4.0 International license.

Data Distribution Pie Chart [cli_project]

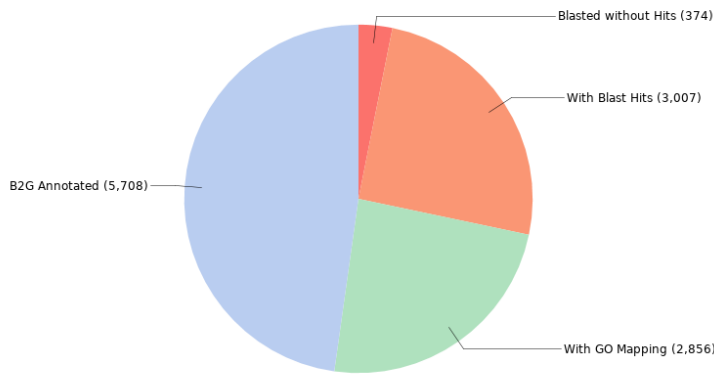

Fig. S7. Blast2GO Annotation Results of Halesus radiatus. Pie charts showing the percentage of proteins with functional Blast2GO annotations, verified by BLAST and mapped to GO terms. GO Distribution by Level (2) - Top 20

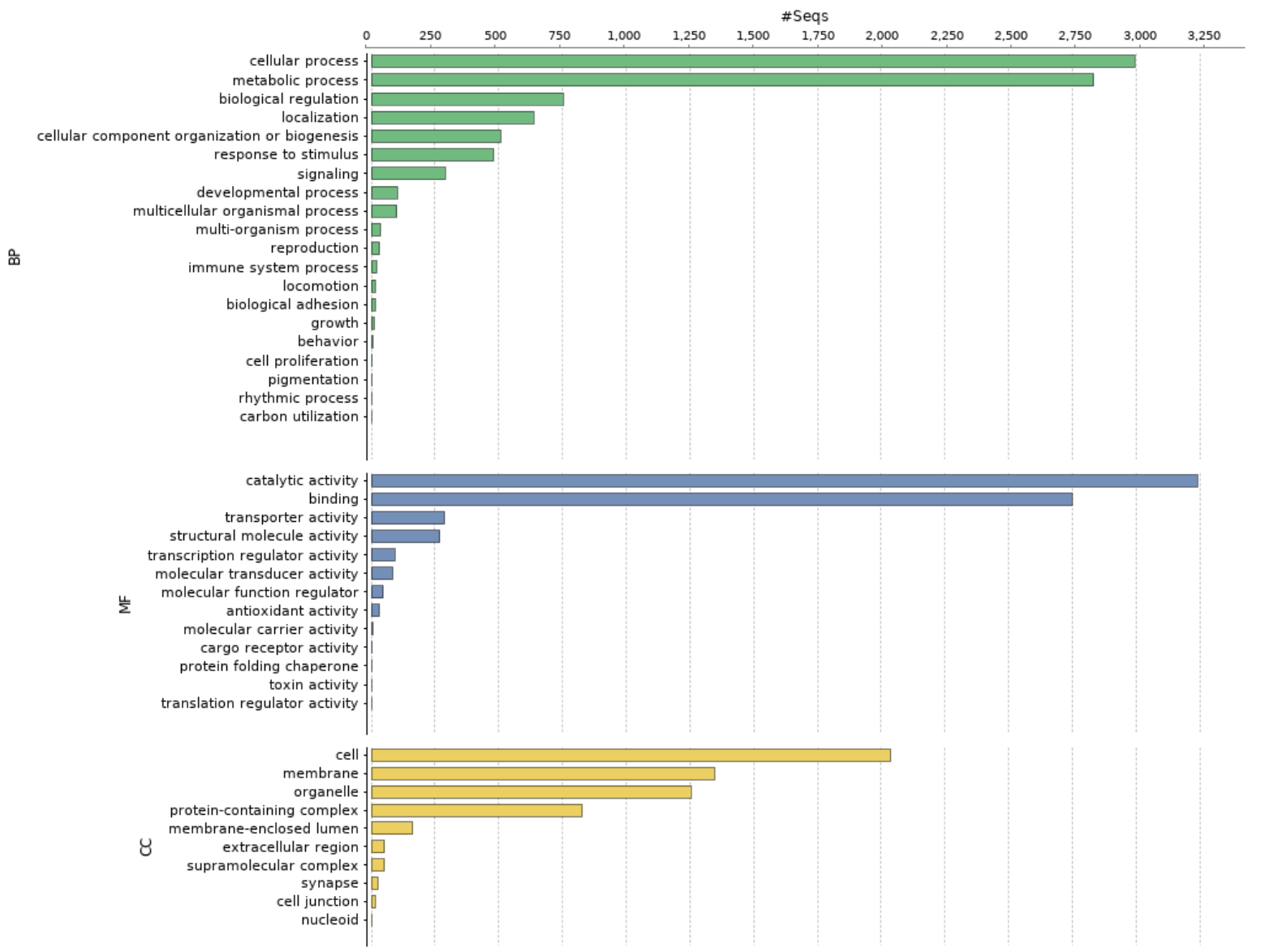

Fig. S8. Blast2GO Functional Annotation for Halesus radiatus. Barplot showing GO terms characterized by biological process, molecular function, and cellular component. Barplots are grouped by biological process (BP), molecular function (MF), and cellular component (CC). 
bioRxiv preprint doi: $\mathrm{https}$ ://doi. org/10.1101/2021.05.10.443368; this version posted July 18,2021 . The copyright holder for this preprint (which was not certified by peer review) is the author/funder, who has granted bioRxiv a license to display the preprint in perpetuity. It is made available under aCC-BY-NC-ND 4.0 International license.

Data Distribution Pie Chart [cli_project]

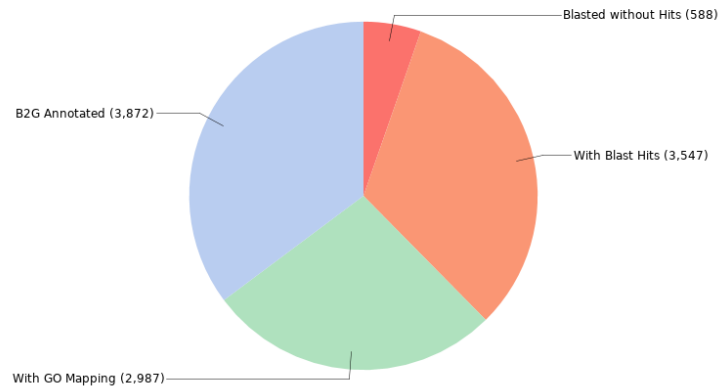

Fig. S9. Blast2GO Annotation Results of Himalopsyche phryganeae. Pie charts showing the percentage of proteins with functional Blast2GO annotations, verified by BLAST and mapped to GO terms.

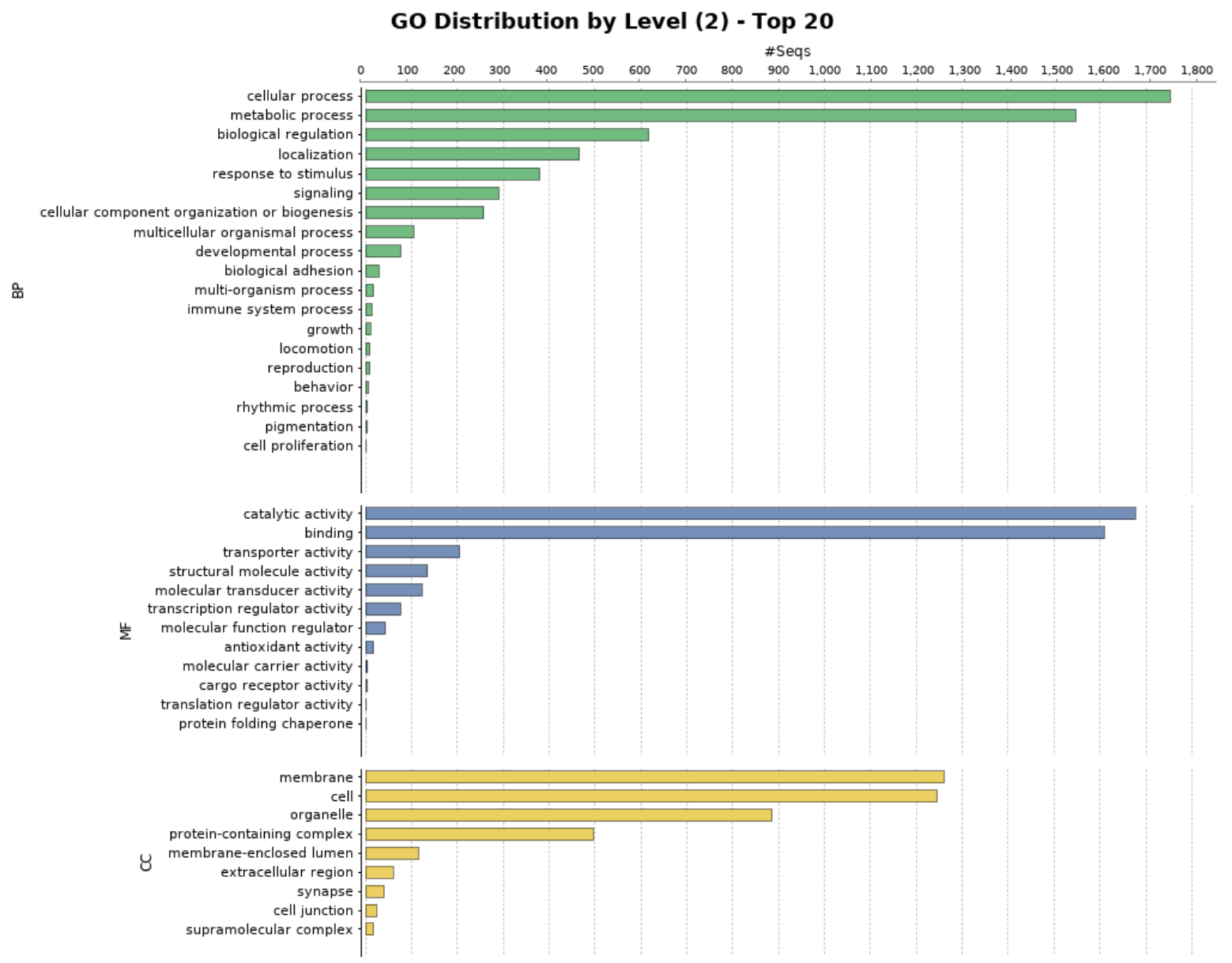

Fig. S10. Blast2GO Functional Annotation for Himalopsyche phryganeae. Barplot showing GO terms characterized by biological process, molecular function, and cellular component. Barplots are grouped by biological process (BP), molecular function (MF), and cellular component (CC). 
bioRxiv preprint doi: https://doi. org/10.1101/2021.05.10.443368; this version posted July 18, 2021. The copyright holder for this preprint (which was not certified by peer review) is the author/funder, who has granted bioRxiv a license to display the preprint in perpetuity. It is made available under aCC-BY-NC-ND 4.0 International license.

Data Distribution Pie Chart [cli_project]

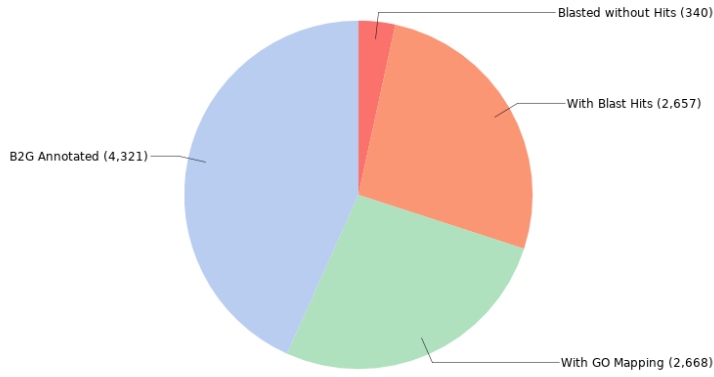

Fig. S11. Blast2GO Annotation Results of Lepidostoma basale. Pie charts showing the percentage of proteins functional Blast2GO annotations, verified by BLAST and mapped to GO terms.

GO Distribution by Level (2) - Top 20

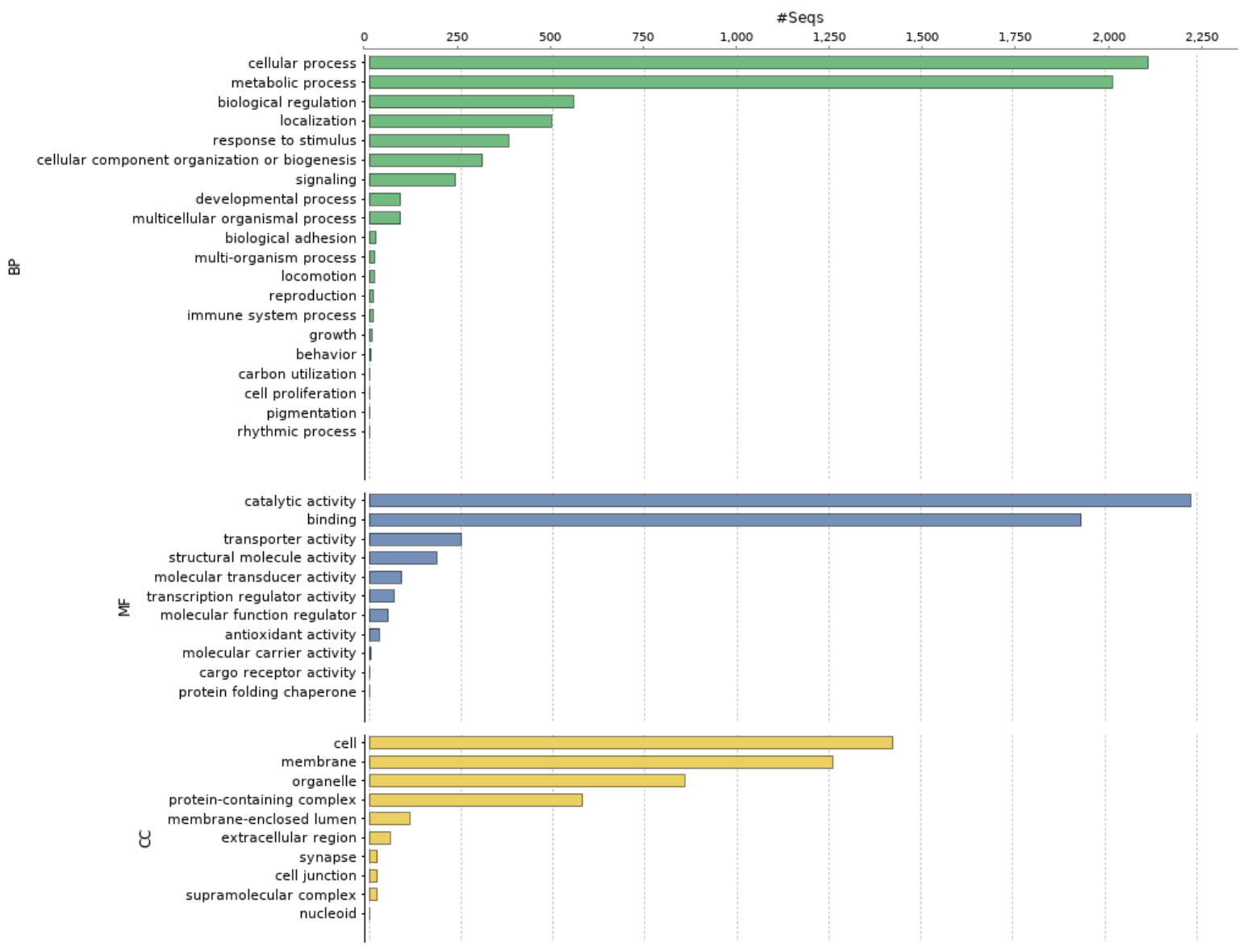

Fig. S12. Blast2GO Functional Annotation for Lepidostoma basale. Barplot showing GO terms characterized by biological process, molecular function, and cellular component. Barplots are grouped by biological process (BP), molecular function (MF), and cellular component (CC). 
bioRxiv preprint doi: $\mathrm{https}$ ://doi. org/10.1101/2021.05.10.443368; this version posted July 18,2021 . The copyright holder for this preprint (which was not certified by peer review) is the author/funder, who has granted bioRxiv a license to display the preprint in perpetuity. It is made available under aCC-BY-NC-ND 4.0 International license.

Data Distribution Pie Chart [cli_project]

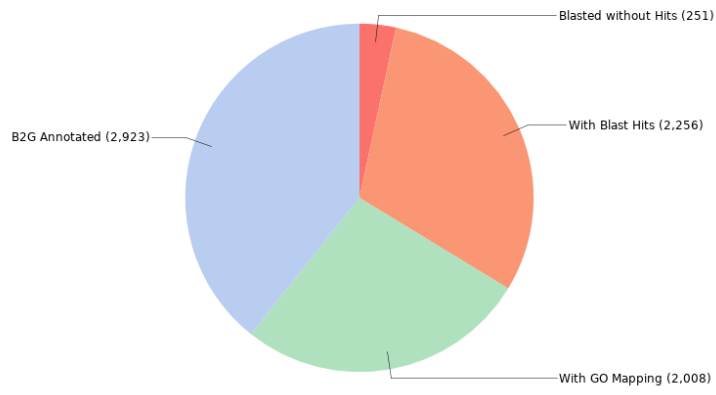

Fig. S13. Blast2GO Annotation Results of Micrasema longulum ML3. Pie charts showing the percentage of proteins with functional Blast2GO annotations, verified by BLAST and mapped to GO terms.

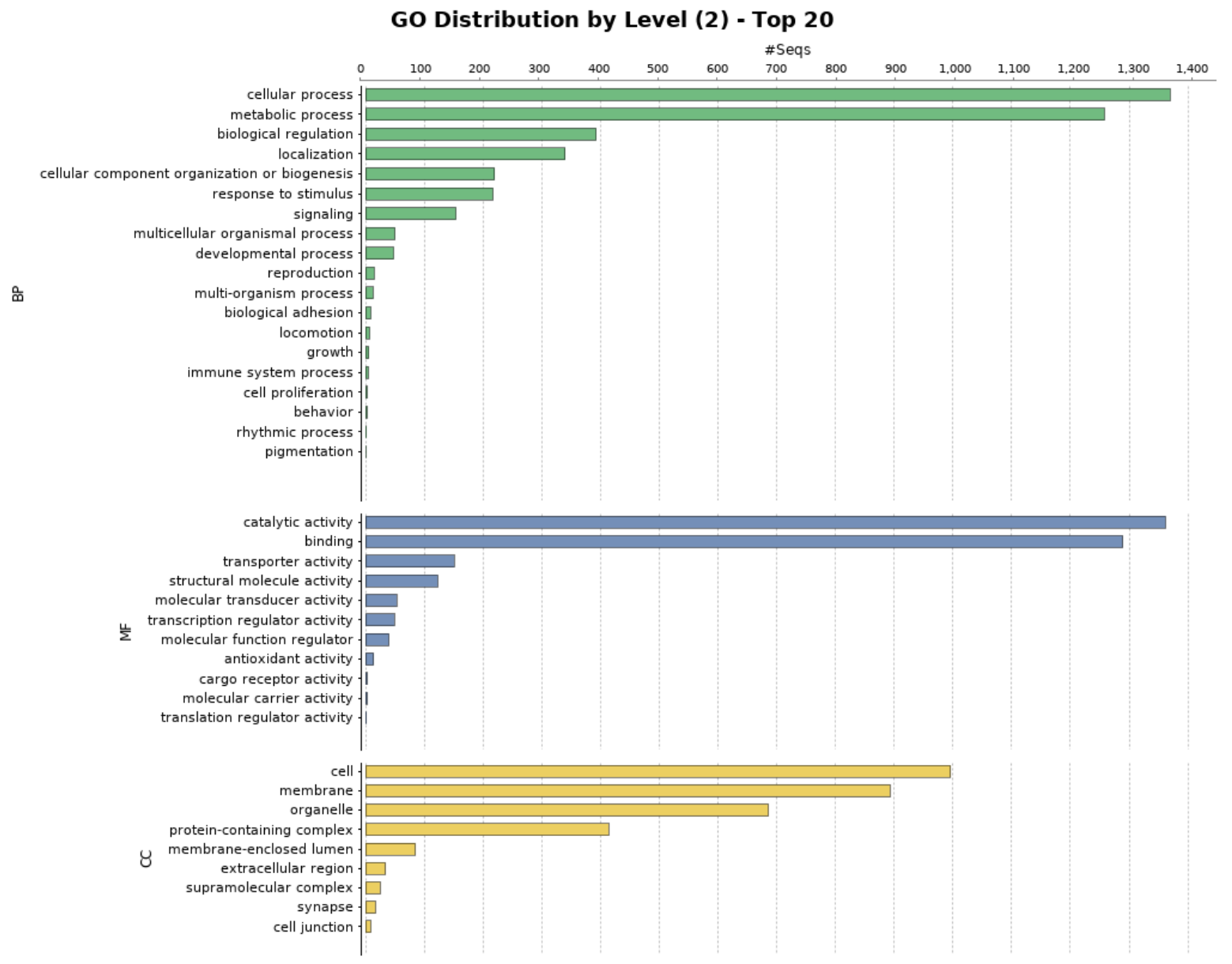

Fig. S14. Blast2GO Functional Annotation for Micrasema longulum ML3. Barplot showing GO terms characterized by biological process, molecular function, and cellular component. Barplots are grouped by biological process (BP), molecular function (MF), and cellular component (CC). 
bioRxiv preprint doi: https://doi org/10.1101/2021 05 10.443368; this version posted July 18, 2021. The copyright holder for this preprint (which was not certified by peer review) is the author/funder, who has granted bioRxiv a license to display the preprint in perpetuity. It is made available under aCC-BY-NC-ND 4.0 International license.

Data Distribution Pie Chart [cli_project]

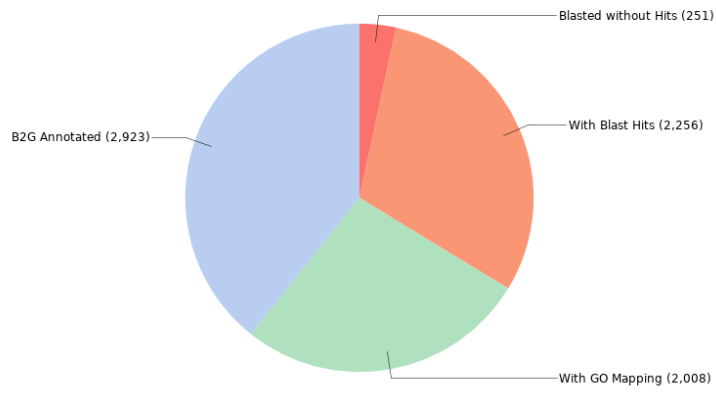

Fig. S15. Blast2GO Annotation Results of Micrasema minimum. Pie charts showing the percentage of proteins with functional Blast2GO annotations, verified by BLAST and mapped to GO terms.

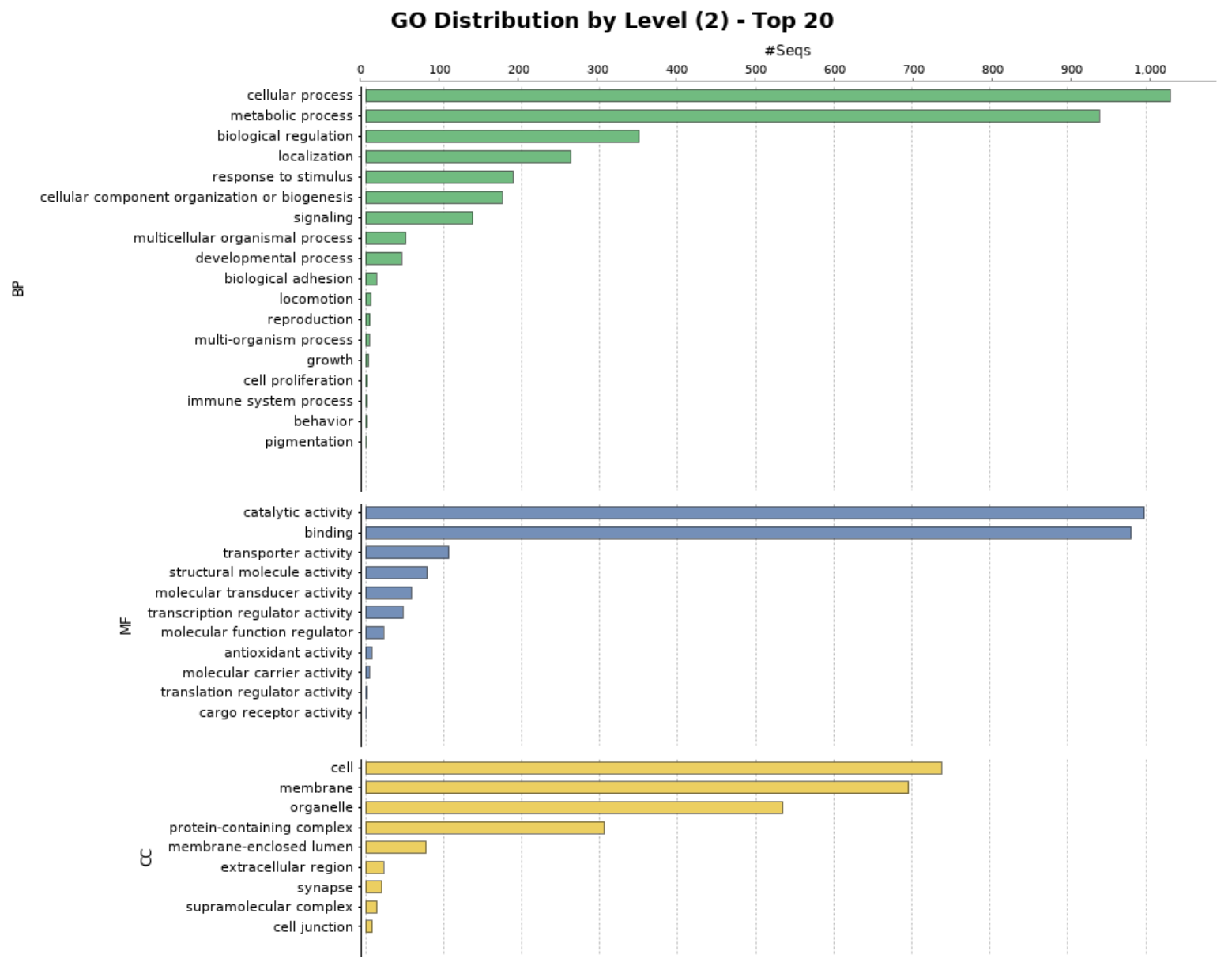

Fig. S16. Blast2GO Functional Annotation for Micrasema minimum. Barplot showing GO terms characterized by biological process, molecular function, and cellular component. Barplots are grouped by biological process (BP), molecular function (MF), and cellular component (CC). 
bioRxiv preprint doi: https://doi. org/10.1101/2021.05.10.443368; this version posted July 18, 2021. The copyright holder for this preprint (which was not certified by peer review) is the author/funder, who has granted bioRxiv a license to display the preprint in perpetuity. It is made available under aCC-BY-NC-ND 4.0 International license.

Data Distribution Pie Chart [cli_project]

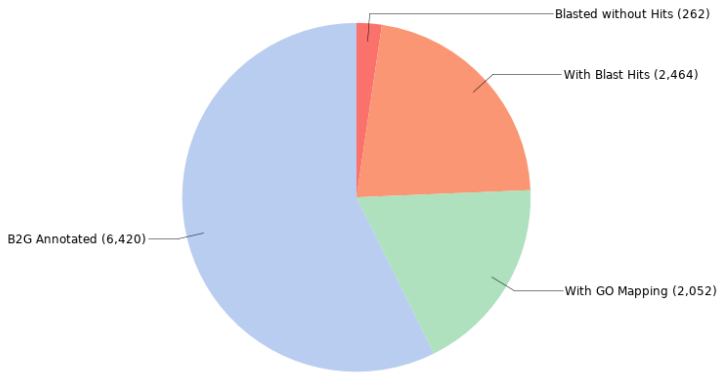

Fig. S17. Blast2GO Annotation Results of Micropterna sequax. Pie charts showing the percentage of proteins in Micropterna sequax with functional Blast2GO annotations, verified by BLAST and mapped to GO terms.

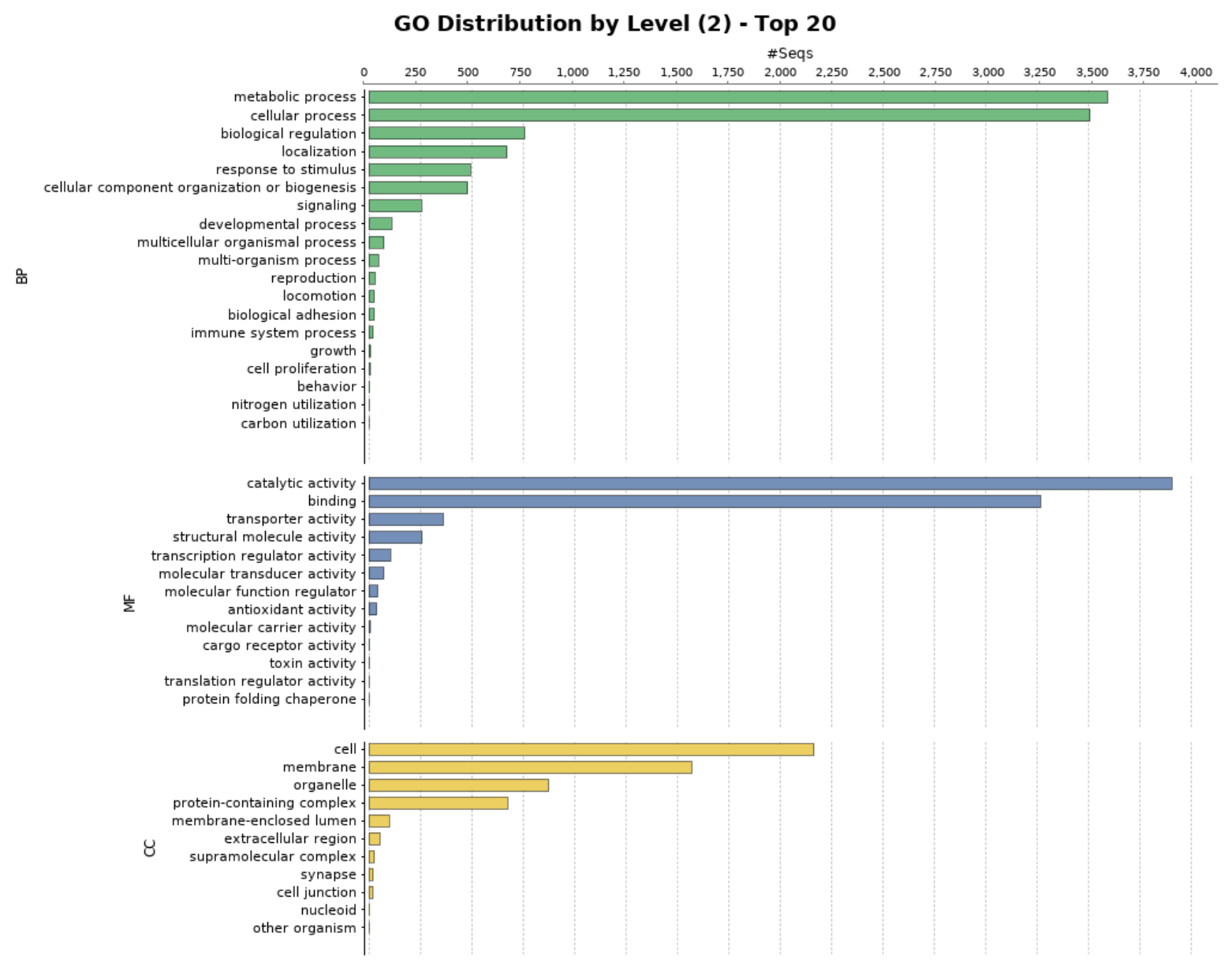

Fig. S18. Blast2GO Functional Annotation for Micropterna sequax. Barplot showing GO terms characterized by biological process, molecular function, and cellular component. Barplots are grouped by biological process (BP), molecular function (MF), and cellular component (CC). 
bioRxiv preprint doi: $h t t p s: / / d o i . o r g / 10.1101 / 2021.05 .10 .443368$; this version posted July 18,2021 . The copyright holder for this preprint (which was not certified by peer review) is the author/funder, who has granted bioRxiv a license to display the preprint in perpetuity. It is made available under aCC-BY-NC-ND 4.0 International license.

Data Distribution Pie Chart [cli_project]

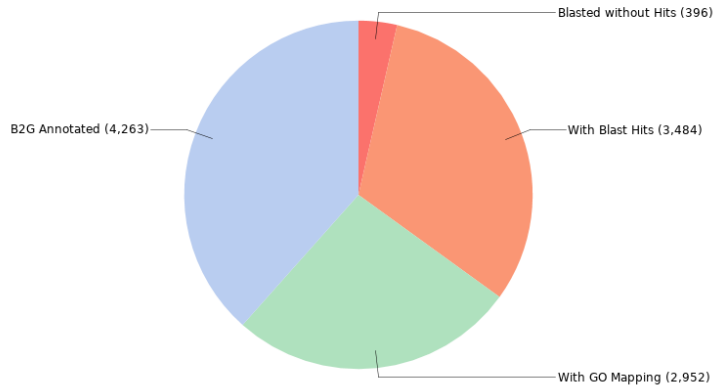

Fig. S19. Blast2GO Annotation Results of Odontocerum albicorne. Pie charts showing the percentage of proteins with functional Blast2GO annotations, verified by BLAST and mapped to GO terms.

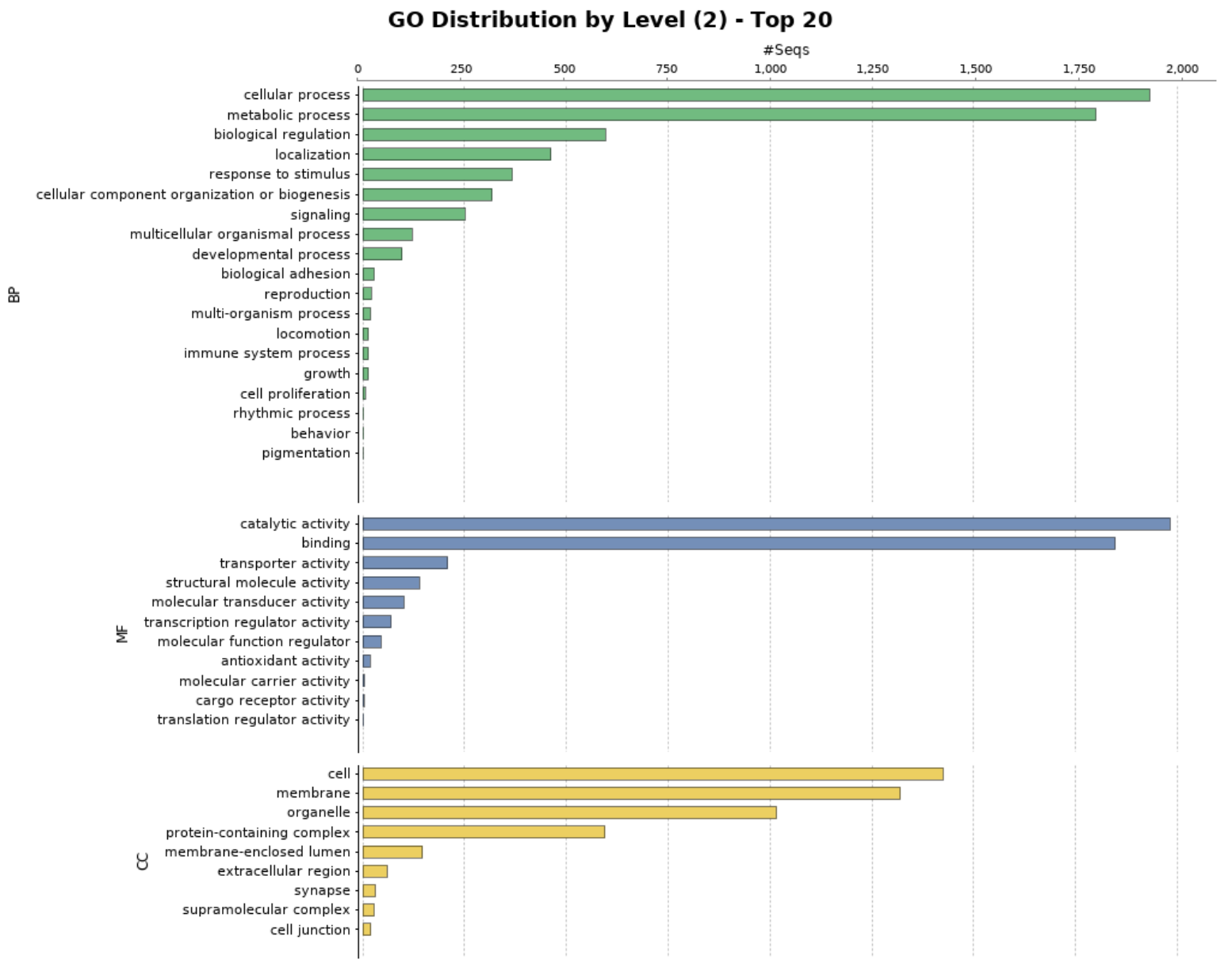

Fig. S20. Blast2GO Functional Annotation for Odontocerum albicorne. Barplot showing GO terms characterized by biological process, molecular function, and cellular component. Barplots are grouped by biological process (BP), molecular function (MF), and cellular component (CC). 
bioRxiv preprint doi: $\mathrm{https}$ ://doi. org/10.1101/2021.05.10.443368; this version posted July 18,2021 . The copyright holder for this preprint (which was not certified by peer review) is the author/funder, who has granted bioRxiv a license to display the preprint in perpetuity. It is made available under aCC-BY-NC-ND 4.0 International license.

Data Distribution Pie Chart [cli_project]

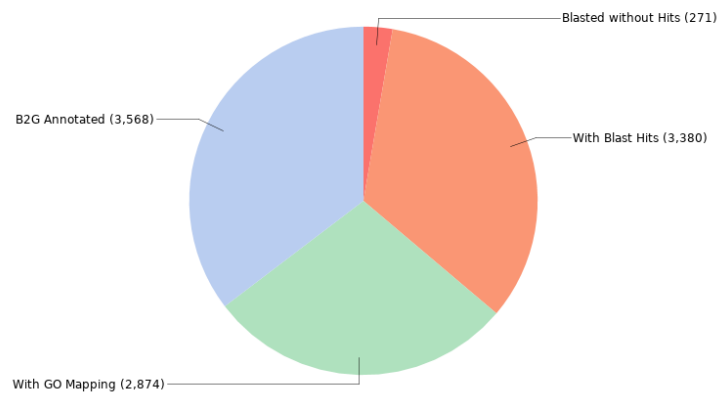

Fig. S21. Blast2GO Annotation Results of Parapsyche elsis. Pie charts showing the percentage of proteins with functional Blast2GO annotations, verified by BLAST and mapped to GO terms.

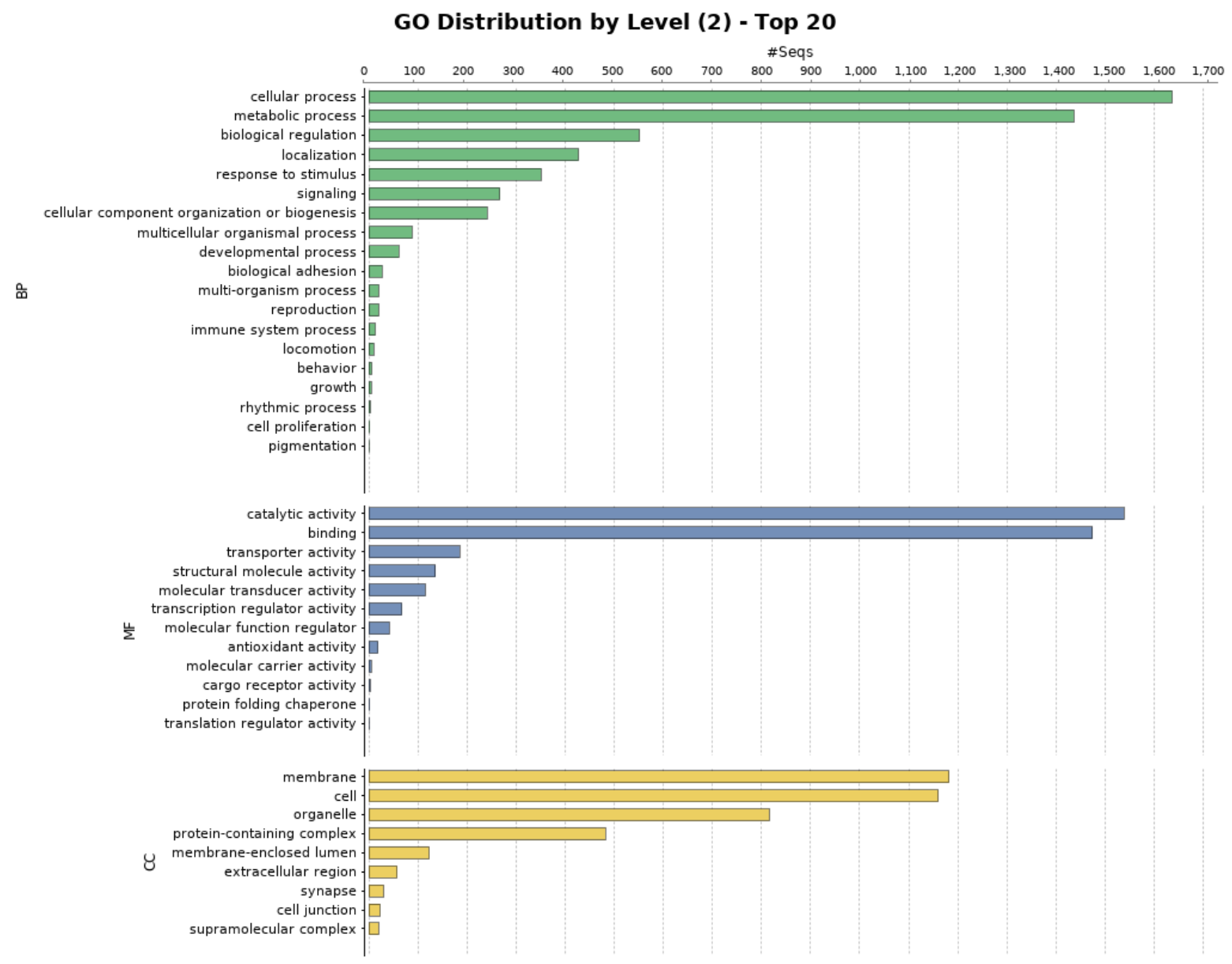

Fig. S22. Blast2GO Functional Annotation for Parapsyche elsis. Barplot showing GO terms characterized by biological process, molecular function, and cellular component. Barplots are grouped by biological process (BP), molecular function (MF), and cellular component (CC). 
bioRxiv preprint doi: $\mathrm{https}$ ://doi. org/10.1101/2021.05.10.443368; this version posted July 18,2021 . The copyright holder for this preprint (which was not certified by peer review) is the author/funder, who has granted bioRxiv a license to display the preprint in perpetuity. It is made available under aCC-BY-NC-ND 4.0 International license.

Data Distribution Pie Chart [cli_project]

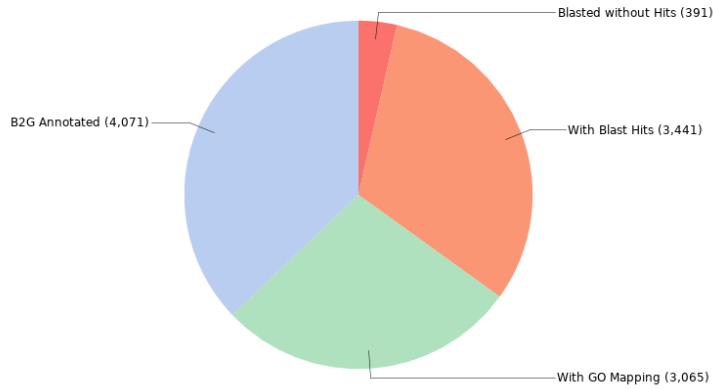

Fig. S23. Blast2GO Annotation Results of Philopotamus ludiferatus. Pie charts showing the percentage of proteins with functional Blast2GO annotations, verified by BLAST and mapped to GO terms.

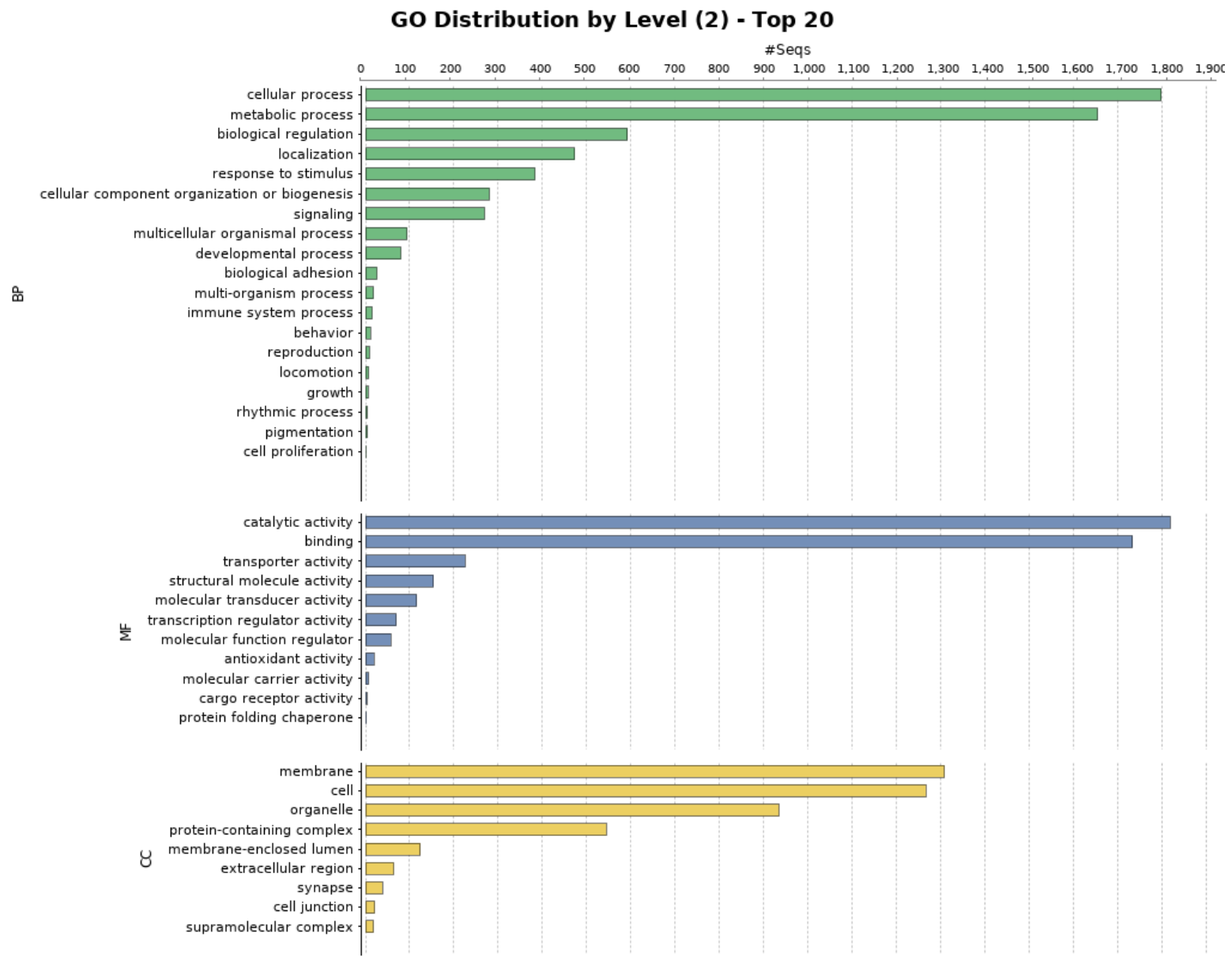

Fig. S24. Blast2GO Functional Annotation for Philopotamus ludiferatus. Barplot showing GO terms characterized by biological process, molecular function, and cellular component. Barplots are grouped by biological process (BP), molecular function (MF), and cellular component (CC). 
bioRxiv preprint doi: $h$ ttps://doi. org/10.1101/2021 05 10.443368; this version posted July 18, 2021. The copyright holder for this preprint (which was not certified by peer review) is the author/funder, who has granted bioRxiv a license to display the preprint in perpetuity. It is made available under aCC-BY-NC-ND 4.0 International license.

Data Distribution Pie Chart [cli_project]

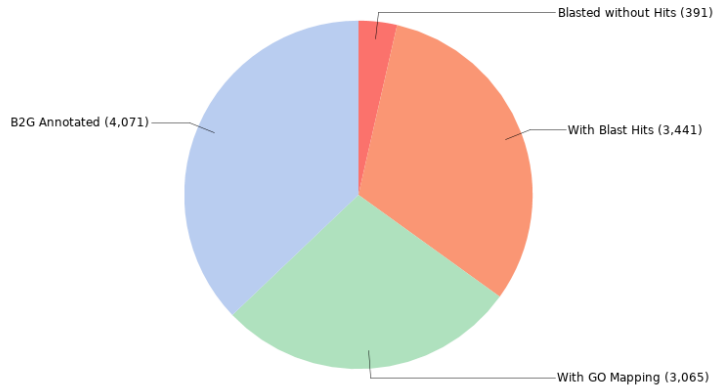

Fig. S25. Blast2GO Annotation Results of Rhyacophila brunneae. Pie charts showing the percentage of proteins with functional Blast2GO annotations, verified by BLAST and mapped to GO terms.

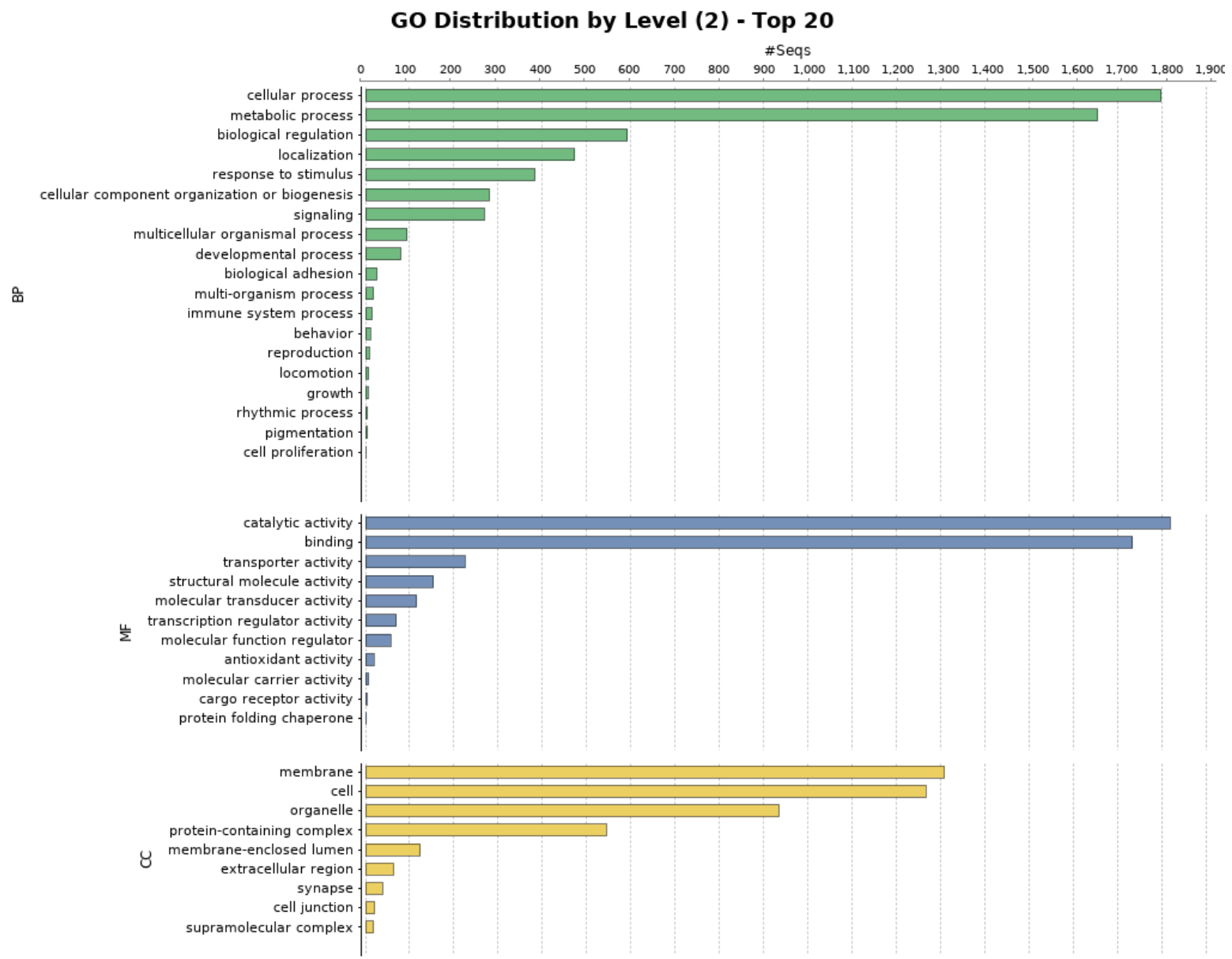

Fig. S26. Blast2GO Functional Annotation for Rhyacophila brunneae. Barplot showing GO terms characterized by biological process, molecular function, and cellular component. Barplots are grouped by biological process (BP), molecular function (MF), and cellular component (CC). 
bioRxiv preprint doi: $\mathrm{https}$ ://doi. org/10.1101/2021.05.10.443368; this version posted July 18,2021 . The copyright holder for this preprint (which was not certified by peer review) is the author/funder, who has granted bioRxiv a license to display the preprint in perpetuity. It is made available under aCC-BY-NC-ND 4.0 International license.

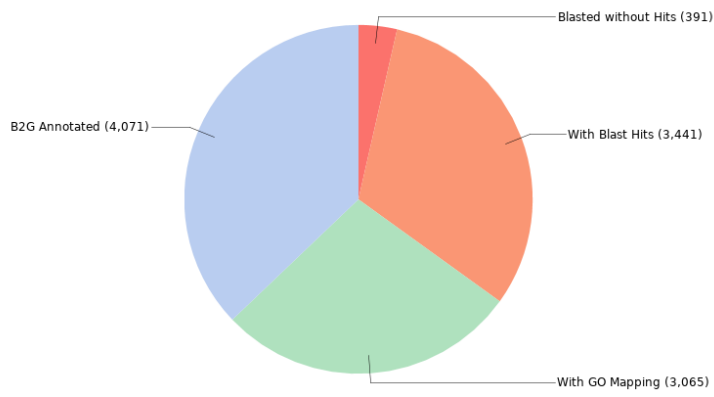

Fig. S27. Blast2GO Annotation Results of Rhyacophila evoluta HR1. Pie charts showing the percentage of proteins with functional Blast2GO annotations, verified by BLAST and mapped to GO terms.

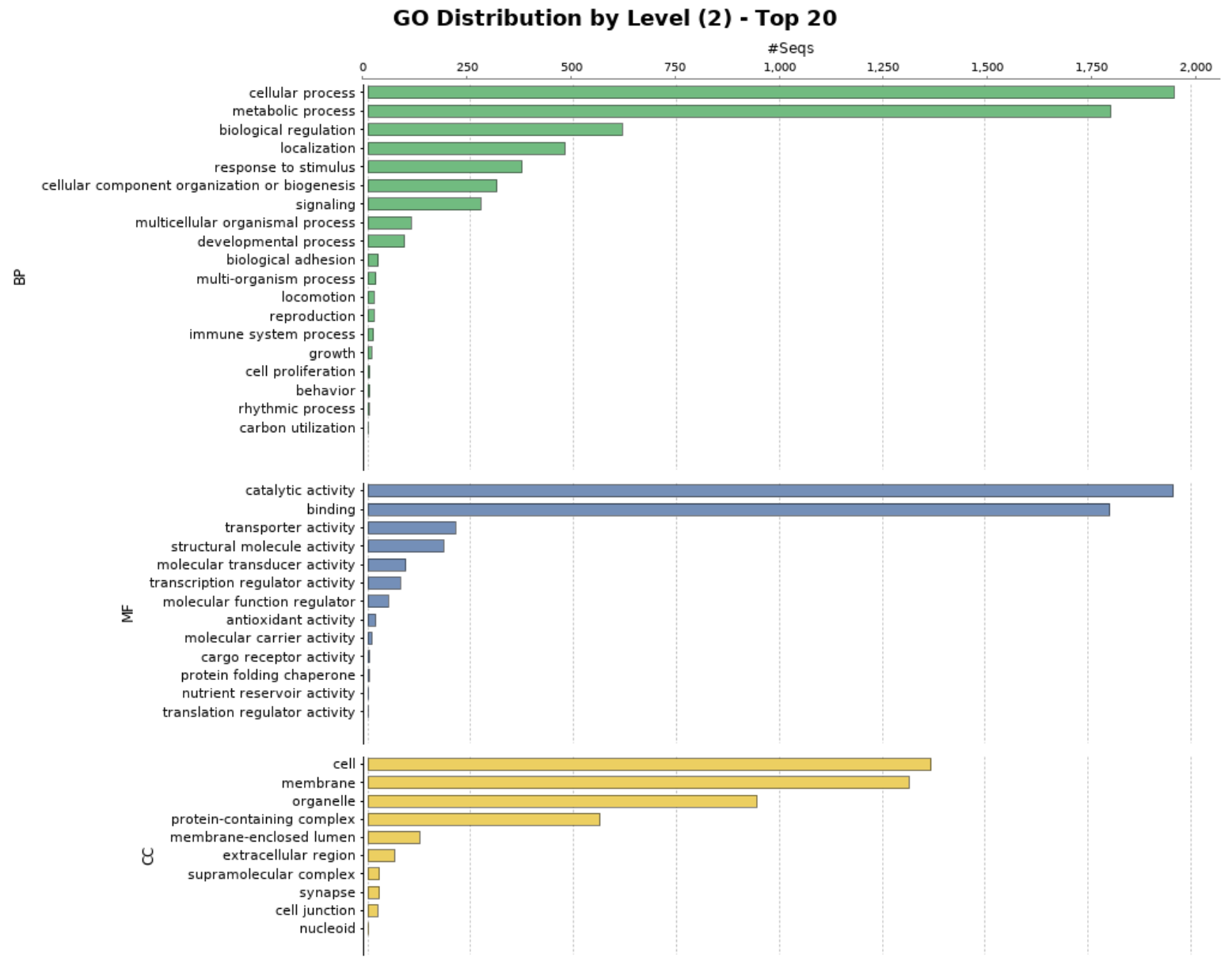

Fig. S28. Blast2GO Functional Annotation for Rhyacophila evoluta HR1. Barplot showing GO terms characterized by biological process, molecular function, and cellular component. Barplots are grouped by biological process (BP), molecular function (MF), and cellular component (CC). 
bioRxiv preprint doi: https://doi. org/10.1101/2021.05.10.443368; this version posted July 18, 2021. The copyright holder for this preprint (which was not certified by peer review) is the author/funder, who has granted bioRxiv a license to display the preprint in perpetuity. It is made available under aCC-BY-NC-ND 4.0 International license.

Data Distribution Pie Chart [cli_project]

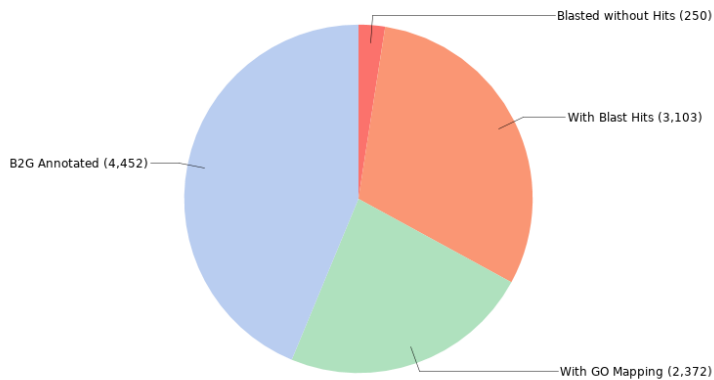

Fig. S29. Blast2GO Annotation Results of Rhyacophila evoluta RSS1. Pie charts showing the percentage of proteins with functional Blast2GO annotations, verified by BLAST and mapped to GO terms.

\section{GO Distribution by Level (2) - Top 20}

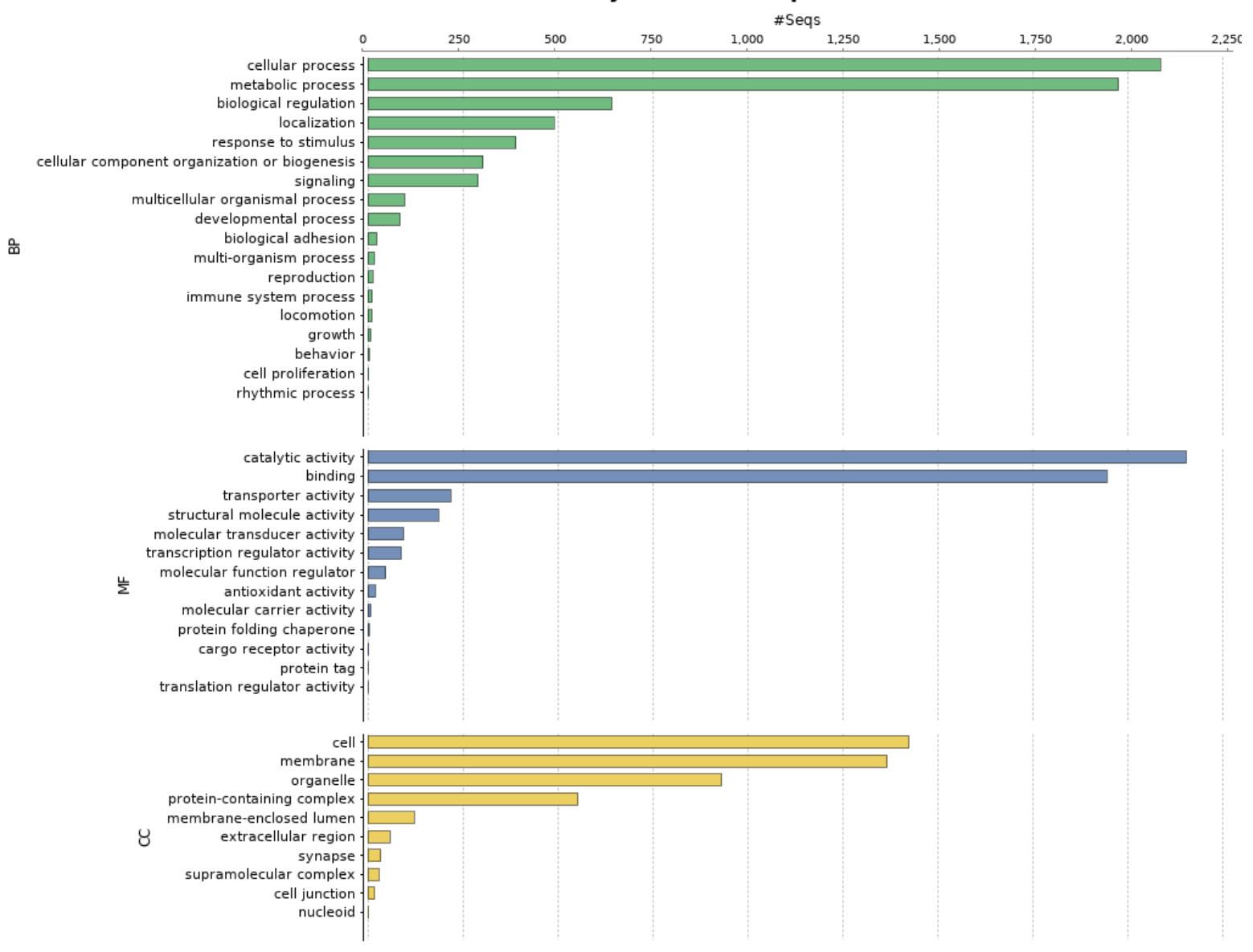

Fig. S30. Blast2GO Functional Annotation for Rhyacophila evoluta RSS1. Barplot showing GO terms characterized by biological process, molecular function, and cellular component. 


\section{Supplementary note 5: Contamination filtering}

The final genome assemblies were screened and filtered for potential contaminations with taxon-annotated GC-coverage (TAGC) plots using BlobTools v1.0 [17]. For this purpose, all preprocessed Illumina reads were mapped against the final genome assemblies using BWAMEM v0.7.17-r1188 [18]. Taxonomic assignment for BlobTools was done with blastn using the following parameters:

-task megablast, max_target_seqs 1, and -max_hsps 1. Contaminations were detected in some assemblies. To filter out contigs based on the Blobplots, a table containing the information on coverage, GC content and taxonomic assignment was produced with the option view of BlobTools. We filtered contigs with potential contaminations from the assemblies using (xargs samtools faidx >contaminated assembly> 〈contaminationfree_contigs.txt> > $<$ filtered_assembly>) and annotations (using python filter_gffs.py <contaminated_contigs.txt> <contaminated.gff>) after criteria outlined in legends of Figs. S31 to S47. Moreover, during uploading the genomes to NCBI, the NCBI genome assembly processing pipeline detected contamination in few assemblies which were further filtered out by manually or by NCBI directly as follows below. When the contamination was not the whole contig but only parts of it, the contingency was broken where the contamination sequences were. We filtered out the contigs which contained contaminations from the MAKER annotations as described above, re-annotated the contamination filtered contigs and combined the results with the previous MAKER runs.

Micrasema longulum ML1:

ctg163846, ctg19699, ctg248737, ctg325643, ctg333503, ctg53726, $\operatorname{ctg} 54533, \operatorname{ctg} 10643$, ctg125325, ctg14195, ctg180425, ctg21916, ctg340516, ctg34404, ctg60979

Micropterna sequax AB08: scf7180000362978: 811..1199, scf7180000455877: 11989..12080

Philopotamus ludificatus Ph2: contig25005

Lepidostoma basale LB1: scf1713:1059388..1059813

Halesus radiates L2: $\operatorname{scf} 3403: 246974 . .252200$

Rhyacophila brunneae Rhy_bru:

scf1041: 163140..163728

scf1110:551504..551909

scf1128:33014..33597

scf1184:1536502..1536986 
bioRxiv preprint doi: https://doi.org/10.1101/2021 05.10.443368; this version posted July 18, 2021. The copyright holder for this preprint (which was not certified by peer review) is the author/funder, who has granted bioRxiv a license to display the preprint in perpetuity. It is made available under aCC-BY-NC-ND 4.0 International license.

scf1270:1559810..1559871,1560071..1560361

scf1305:1032669..1033098,1034246..1034303

scf138:267360..267733

scf1417:192623..193022

scf1512:1368136..1368538

scf1588:293425..293830

scf1905:2898967..2899621

scf2084:985175..985580

scf418:215063..215545

scf541:247440..247517,251355..251805

scf651:112771..113167

scf713:77993..78081,78612..78966

scf79:2533756..2533988,2534216..2534291 
bioRxiv preprint doi: https://doi org/10.1101/2021.05 10.443368; this version posted July 18, 2021. The copyright holder for this preprint (which was not certified by peer review) is the author/funder, who has granted bioRxiv a license to display the preprint in perpetuity. It is made available under aCC-BY-NC-ND 4.0 International license.

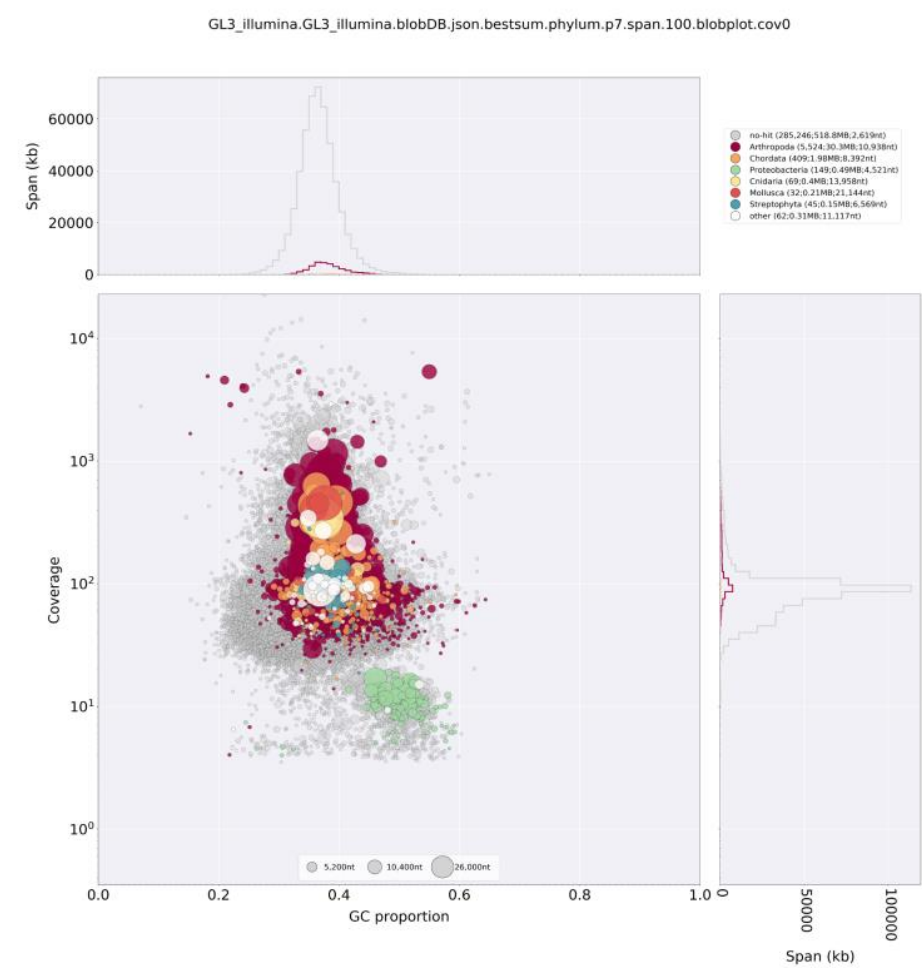

Fig. S31. Taxon-annotated GC-coverage (TAGC) plots of Agapetus fuscipens GL3 genome assembly. Circles indicate contigs and the color indicates the best match to taxon annotation. The upper and right hand panel show the total span of contigs (kb) given GC proportion.

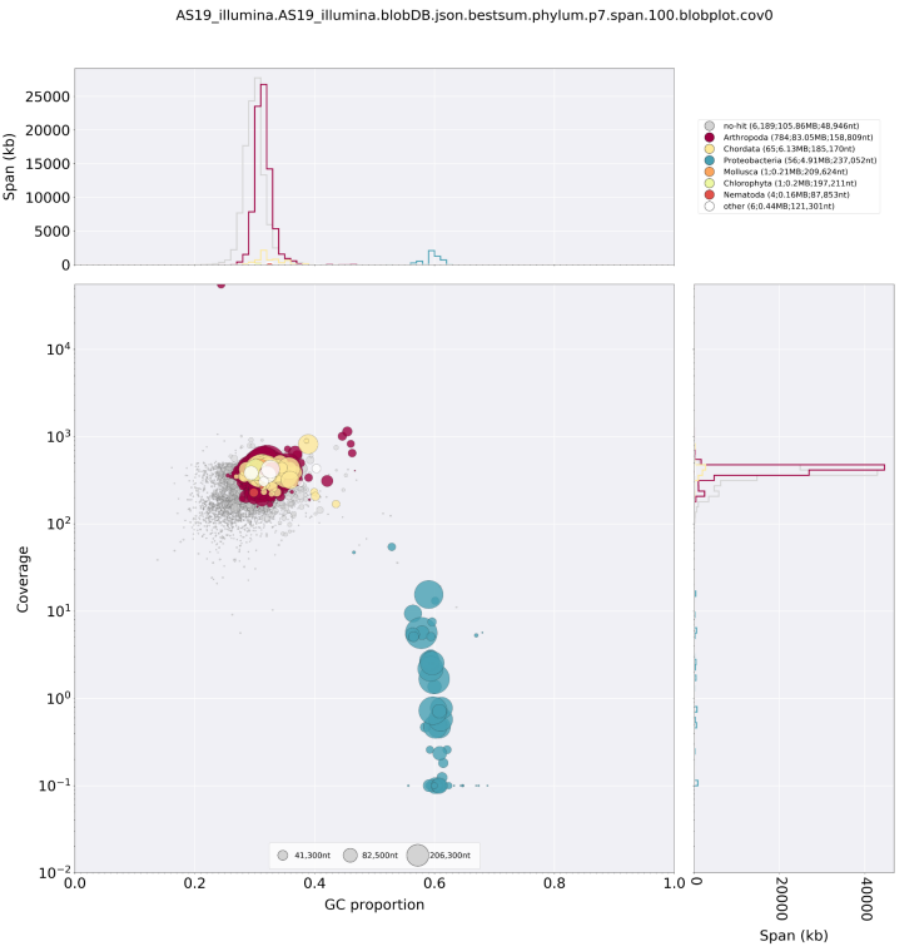

Fig. S32. Taxon-annotated GC-coverage (TAGC) plots of Agraylea sexmaculata AS19 genome assembly. Circles indicate contigs and the color indicates the best match to taxon annotation. The upper and right hand panel show the total span of contigs $(\mathrm{kb})$ given GC proportion. We removed all contigs assigned to Proteobacteria. 
bioRxiv preprint doi: https://doi org/10.1101/2021 05 10.443368; this version posted July 18, 2021. The copyright holder for this preprint (which was not certified by peer review) is the author/funder, who has granted bioRxiv a license to display the preprint in perpetuity. It is made available under aCC-BY-NC-ND 4.0 International license.

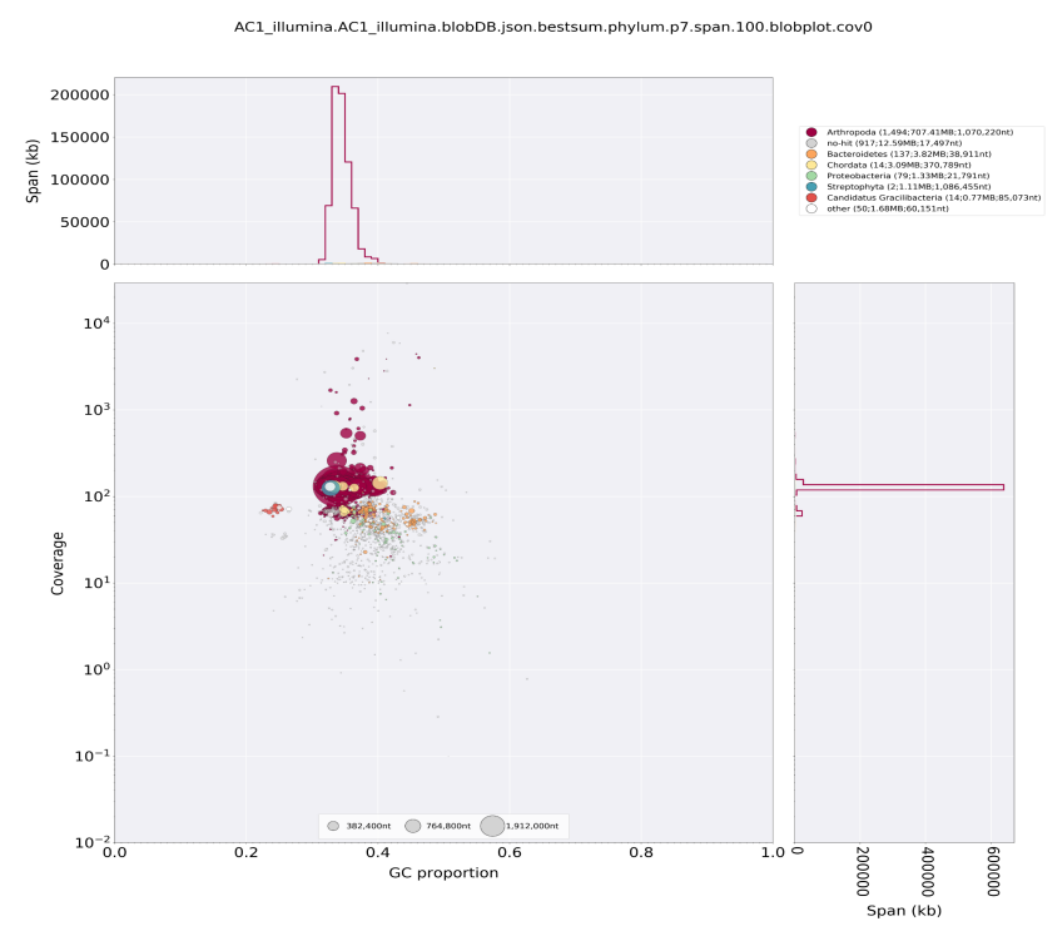

Fig. S32. Taxon-annotated GC-coverage (TAGC) plots of Drusus annulatus AC1 genome assembly. Circles indicate contigs and the color indicates the best match to taxon annotation. The upper and right hand panel show the total span of contigs $(\mathrm{kb})$ given GC proportion. We removed contigs with a coverage $\leq$ the lowest coverage in "Arthropod" contigs (20.363) and contigs which were out of the GC content range of "Arthropod" contigs (0.3042-0.4621).

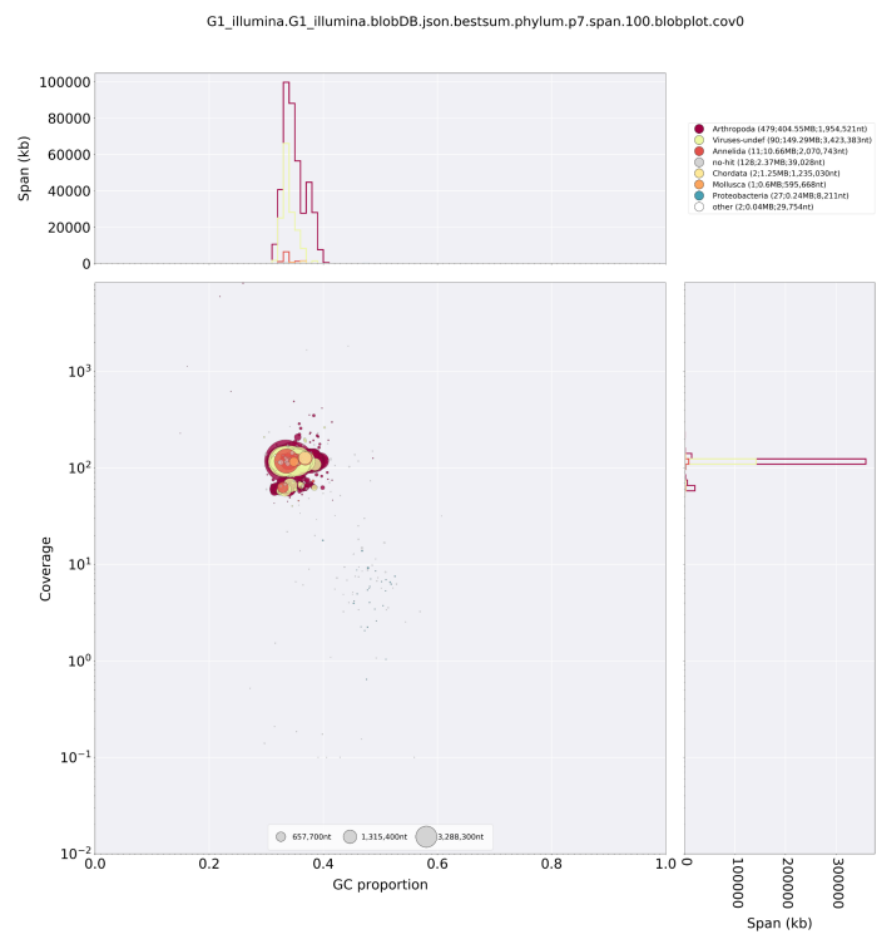

Fig. S34. Taxon-annotated GC-coverage (TAGC) plots of Glossosoma conforme G1. Circles indicate contigs and the color indicates the best match to taxon annotation. The upper and right hand panel show the total span of contigs $(\mathrm{kb})$ given GC proportion. We removed contigs with coverage $\leq$ the lowest coverage in "Arthropod" contigs (43.031) and contigs with GC content $\geq$ highest GC content in "Arthropod" contigs (0.487). 
bioRxiv preprint doi: https://doi org/10.1101/2021.05 10.443368; this version posted July 18, 2021. The copyright holder for this preprint (which was not certified by peer review) is the author/funder, who has granted bioRxiv a license to display the preprint in perpetuity. It is made available under aCC-BY-NC-ND 4.0 International license.

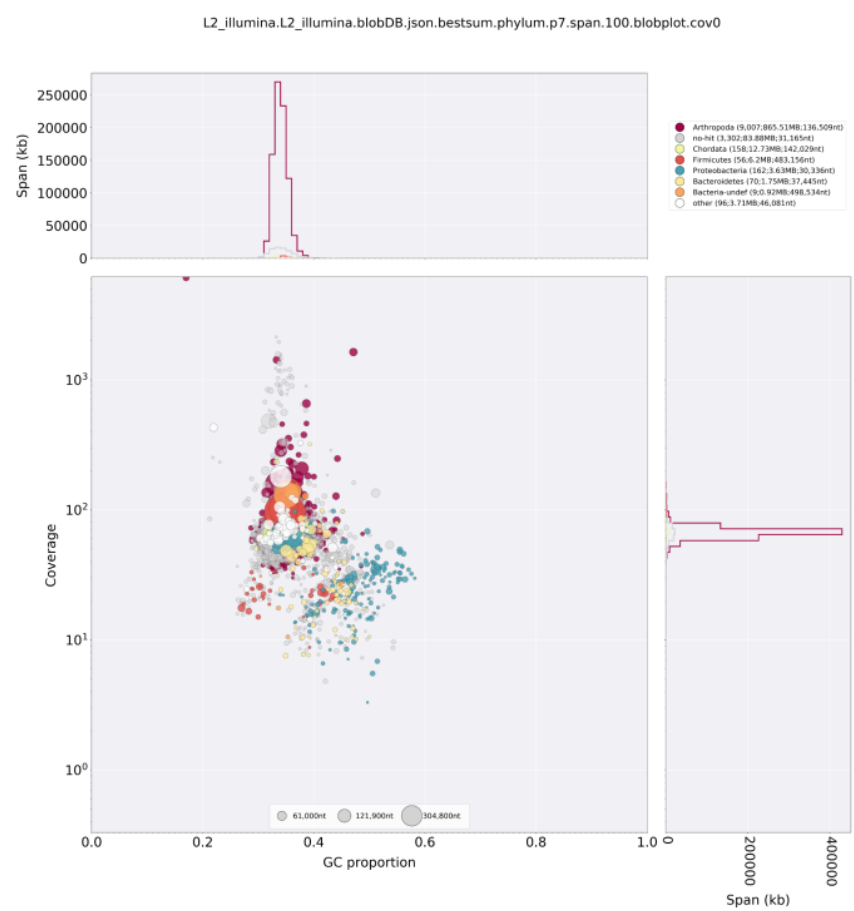

Fig. S35. Taxon-annotated GC-coverage (TAGC) plots of Halesus radiatus. Circles indicate contigs and the color indicates the best match to taxon annotation. The upper and right hand panel show the total span of contigs $(\mathrm{kb})$ given GC proportion. We removed contigs with coverage $\leq$ the lowest coverage in "Arthropod" contigs (30.06) and contigs with GC content $\geq$ highest GC content in "Arthropod" contigs (0.4876).

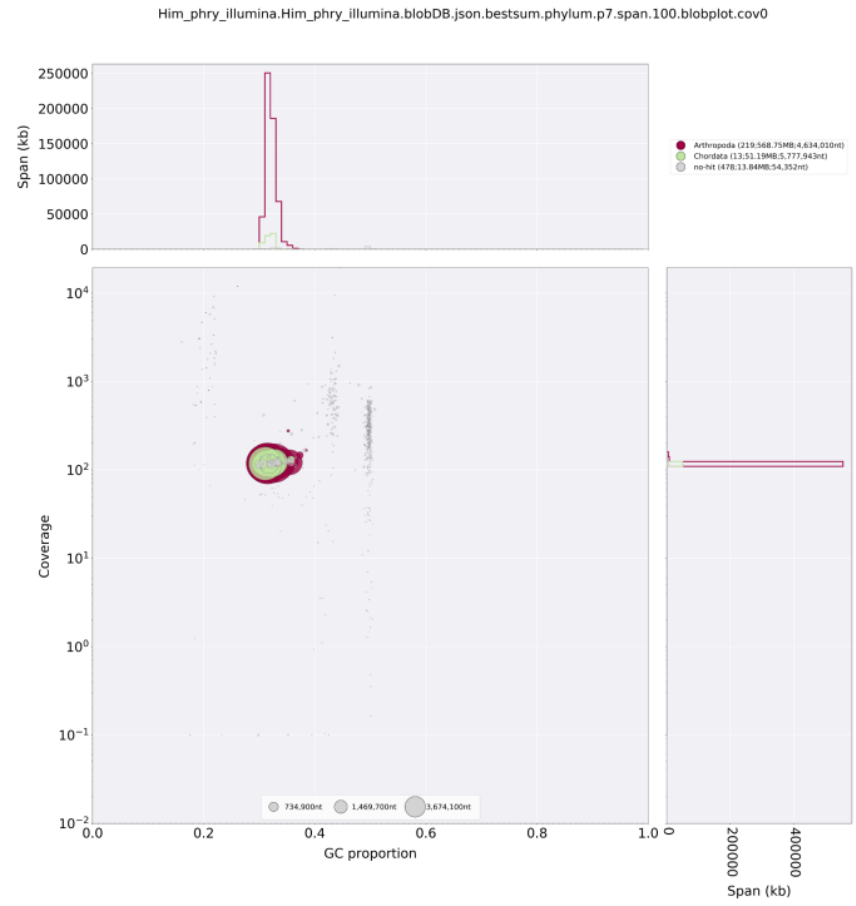

Fig. S36. Taxon-annotated GC-coverage (TAGC) plots of Himalopsyche phryganeae. Circles indicate contigs and the color indicates the best match to taxon annotation. The upper and right hand panel show the total span of contigs $(\mathrm{kb})$ given GC proportion. 
bioRxiv preprint doi: https://doi org/10.1101/2021.05 10.443368; this version posted July 18, 2021. The copyright holder for this preprint (which was not certified by peer review) is the author/funder, who has granted bioRxiv a license to display the preprint in perpetuity. It is made available under aCC-BY-NC-ND 4.0 International license.

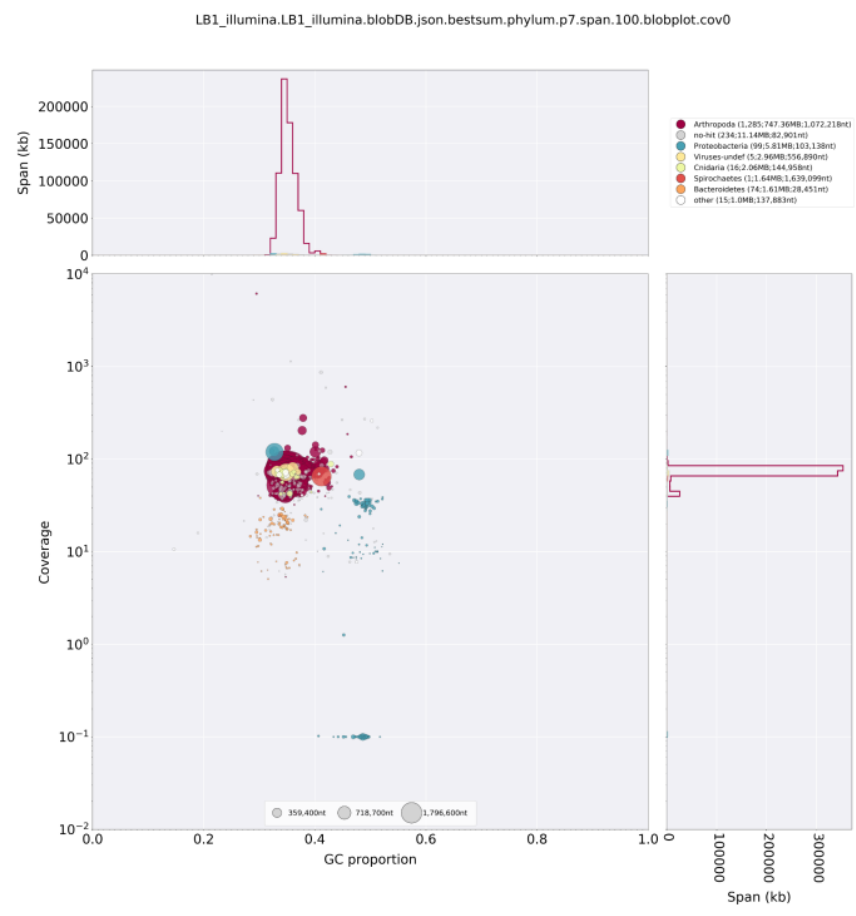

Fig. S37. Taxon-annotated GC-coverage (TAGC) plots of Lepidostoma basale. Circles indicate contigs and the color indicates the best match to taxon annotation. The upper and right hand panel show the total span of contigs $(\mathrm{kb})$ given GC proportion. We removed contigs with a coverage $\leq$ the lowest coverage in "Arthropod" contigs (5.336) and contigs which were out of the GC content range of "Arthropod" contigs (0.295 - 0.4657).

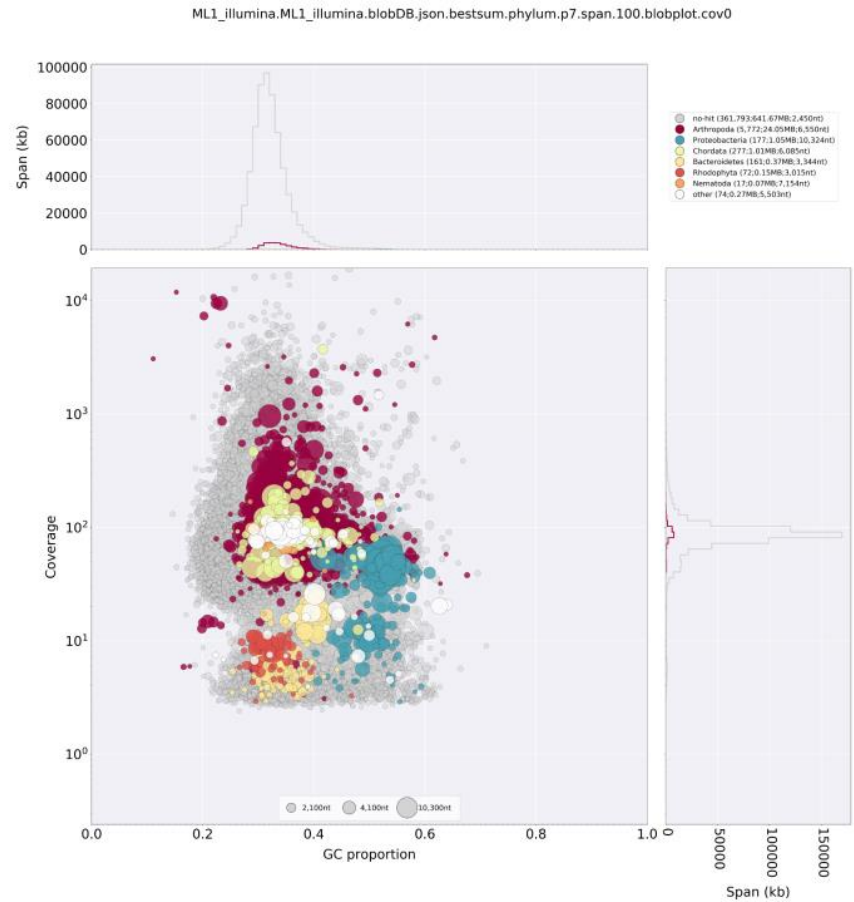

Fig. S38. Taxon-annotated GC-coverage (TAGC) plots of Micrasema longulum ML1. Circles indicate contigs and the color indicates the best match to taxon annotation. The upper and right hand panel show the total span of contigs $(\mathrm{kb})$ given GC proportion. 
bioRxiv preprint doi: https://doi org/10.1101/2021.05 10.443368; this version posted July 18, 2021. The copyright holder for this preprint (which was not certified by peer review) is the author/funder, who has granted bioRxiv a license to display the preprint in perpetuity. It is made available under aCC-BY-NC-ND 4.0 International license.

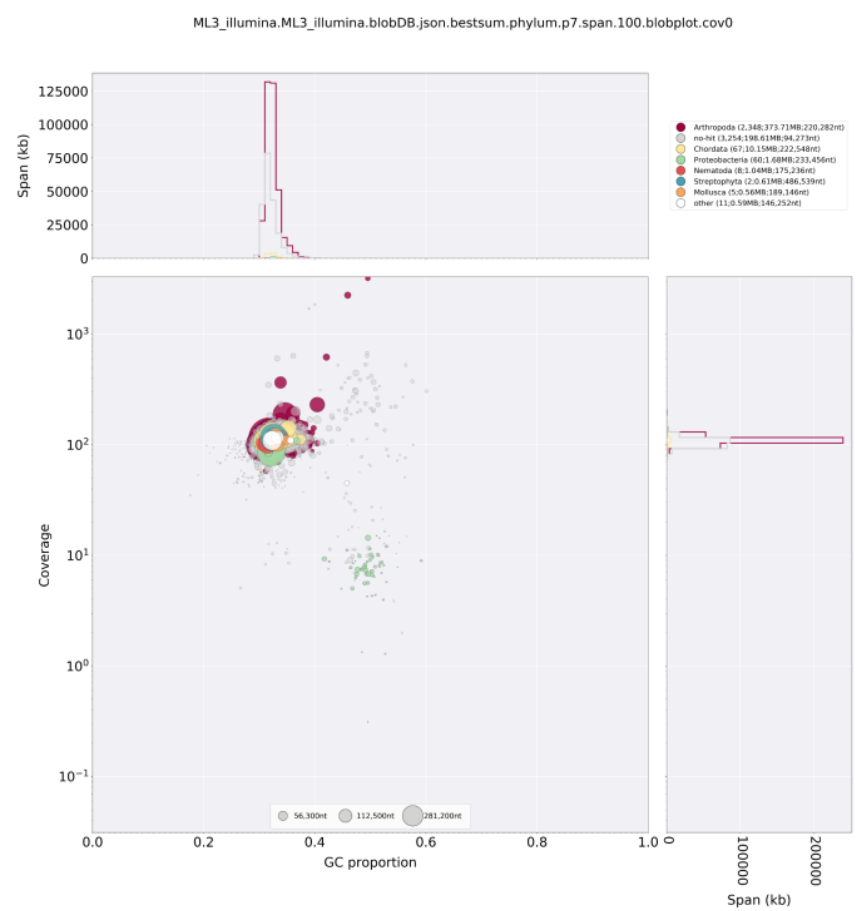

Fig. S39.Taxon-annotated GC-coverage (TAGC) plots of Micrasema longulum ML3. Circles indicate contigs and the color indicates the best match to taxon annotation. The upper and right hand panel show the total span of contigs $(\mathrm{kb})$ given GC proportion. We removed contigs with a coverage $\leq$ the lowest coverage in "Arthropod" contigs (56.642) and contigs which were out of the GC content range of "Arthropod" contigs (0.2962 - 0.4954).

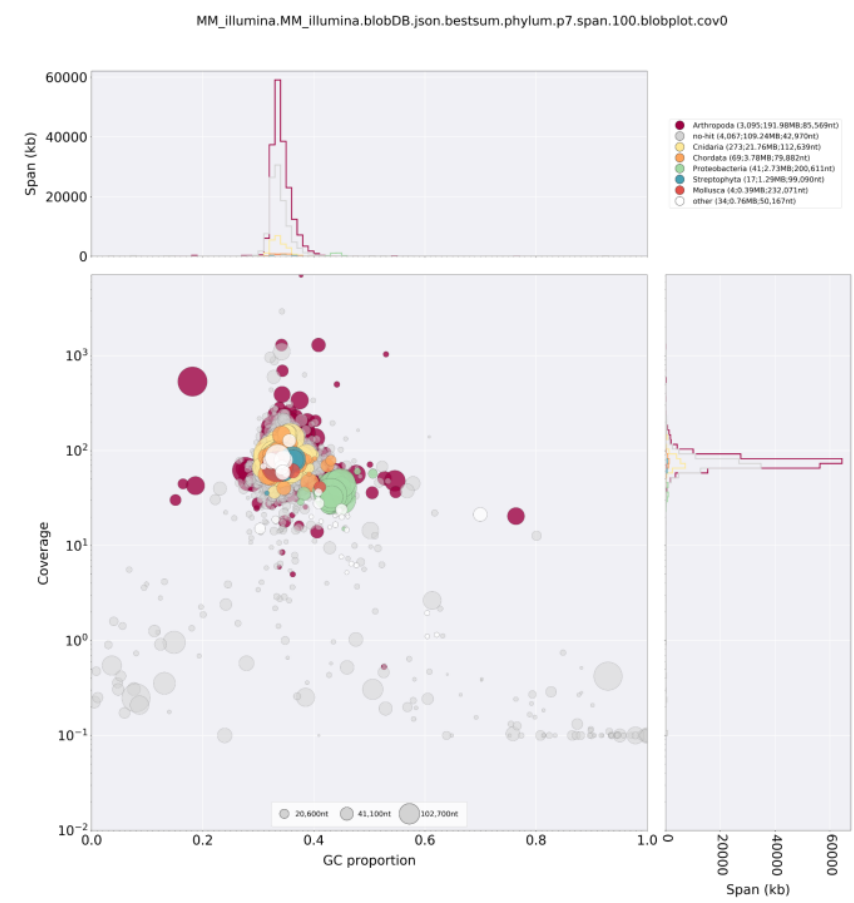

Fig. S40. Taxon-annotated GC-coverage (TAGC) plots of Micrasema minimum. Circles indicate contigs and the color indicates the best match to taxon annotation. The upper and right hand panel show the total span of contigs $(\mathrm{kb})$ given GC proportion. We removed contigs to Proteobacteria with a GC content of $\geq 0.4$. 


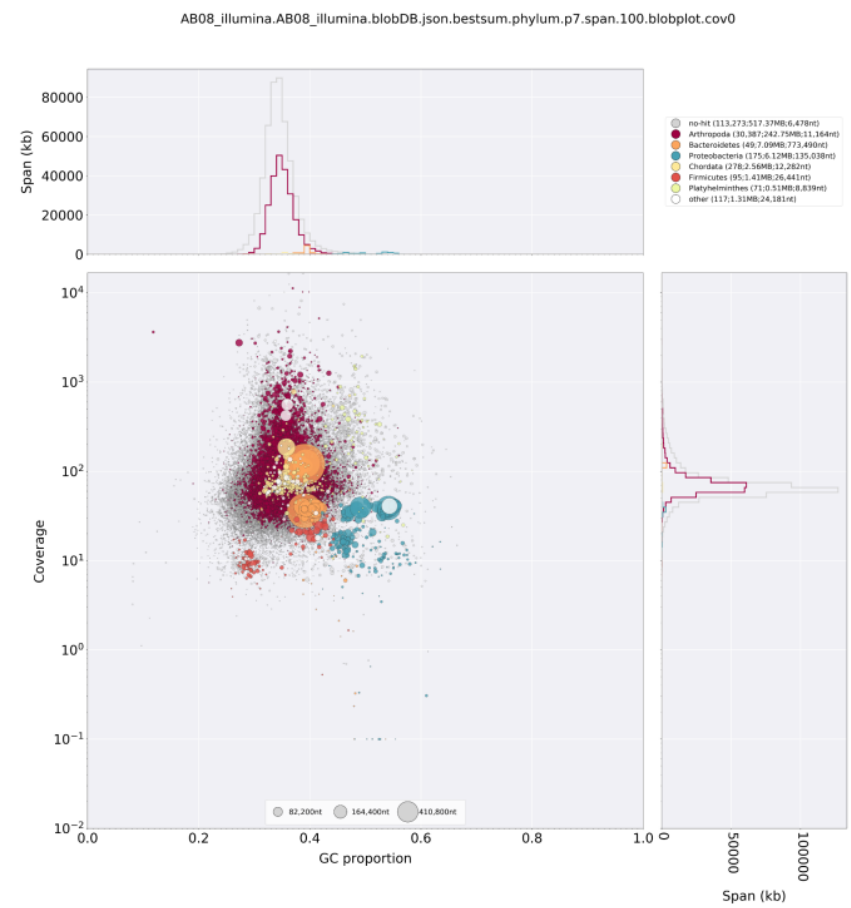

Fig. S41. Taxon-annotated GC-coverage (TAGC) plots of Micropterna sequax. Circles indicate contigs and the color indicates the best match to taxon annotation. The upper and right hand panel show the total span of contigs $(\mathrm{kb})$ given GC proportion. We removed contigs with a coverage $\leq$ the lowest coverage in "Arthropod" contigs (5.665) and contigs which were out of the GC content range of "Arthropod" contigs (0.1182 - 0.5602).

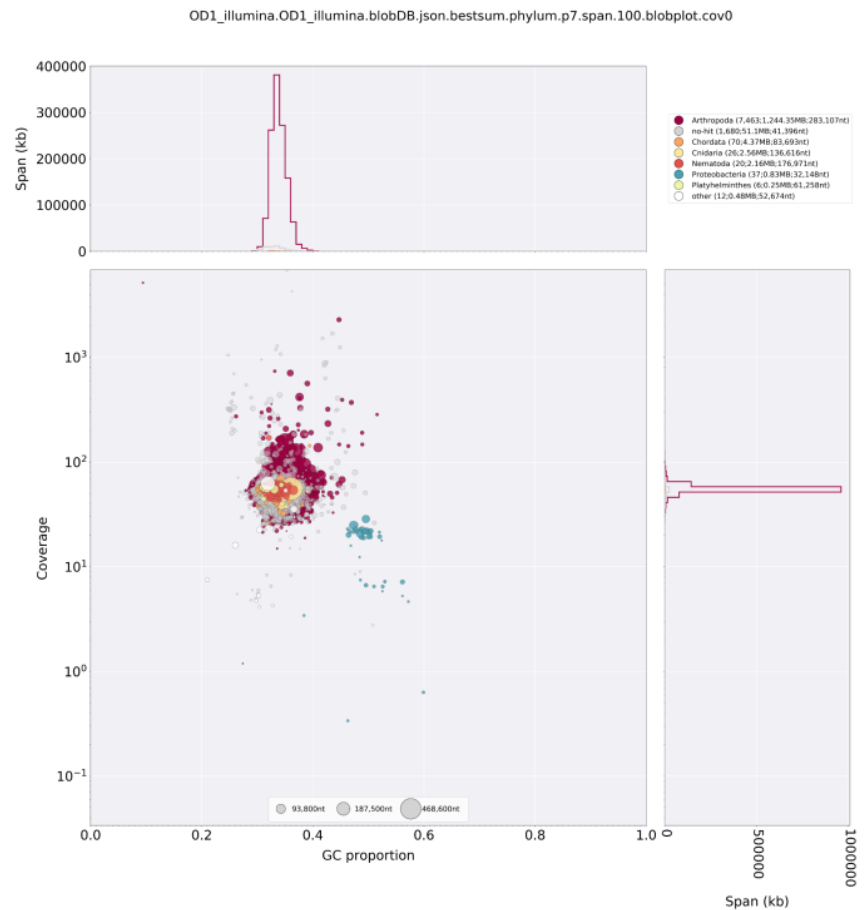

Fig. S42. Taxon-annotated GC-coverage (TAGC) plots of Odontocerum albicorne. Circles indicate contigs and the color indicates the best match to taxon annotation. The upper and right hand panel show the total span of contigs (kb) given GC proportion. We removed contigs with coverage $\leq 1$ and contigs with GC content $\geq$ highest GC content in "Arthropod" contigs ( 0.5157$)$. 
bioRxiv preprint doi: https://doi.org/10.1101/2021.05.10.443368; this version posted July 18, 2021. The copyright holder for this preprint (which was not certified by peer review) is the author/funder, who has granted bioRxiv a license to display the preprint in perpetuity. It is made available under aCC-BY-NC-ND 4.0 International license.

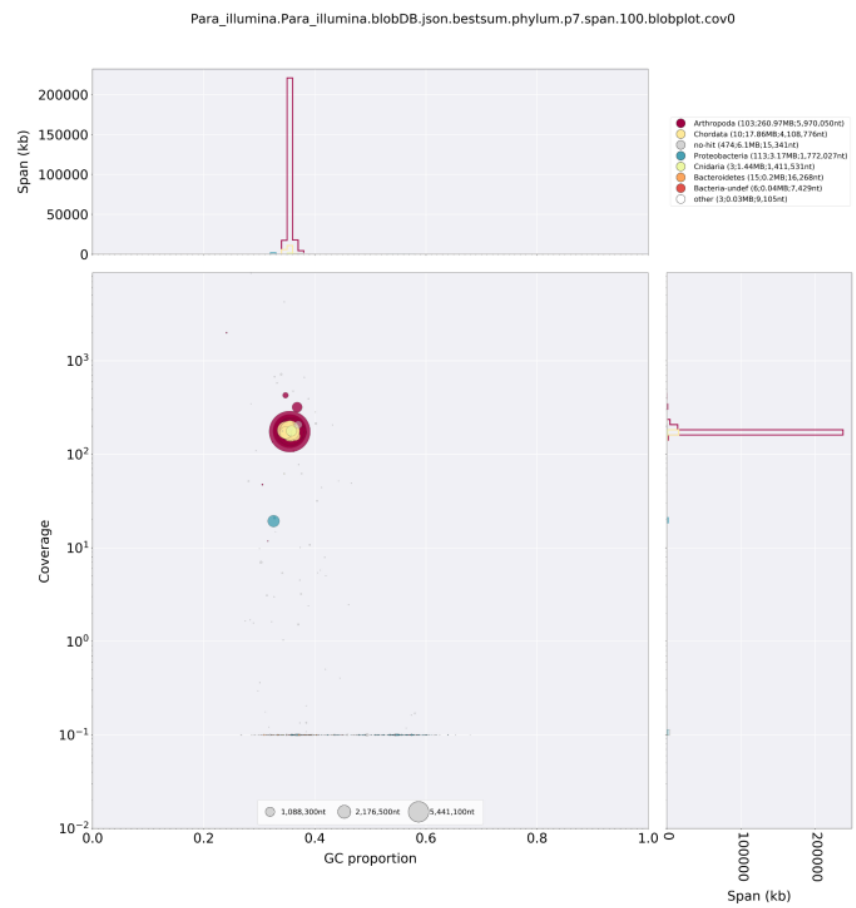

Fig. S43. Taxon-annotated GC-coverage (TAGC) plots of Parapsyche elsis. Circles indicate contigs and the color indicates the best match to taxon annotation. The upper and right hand panel show the total span of contigs $(\mathrm{kb})$ given GC proportion. We removed all contigs assigned to Proteobacteria and contigs with coverage $\leq 1$.

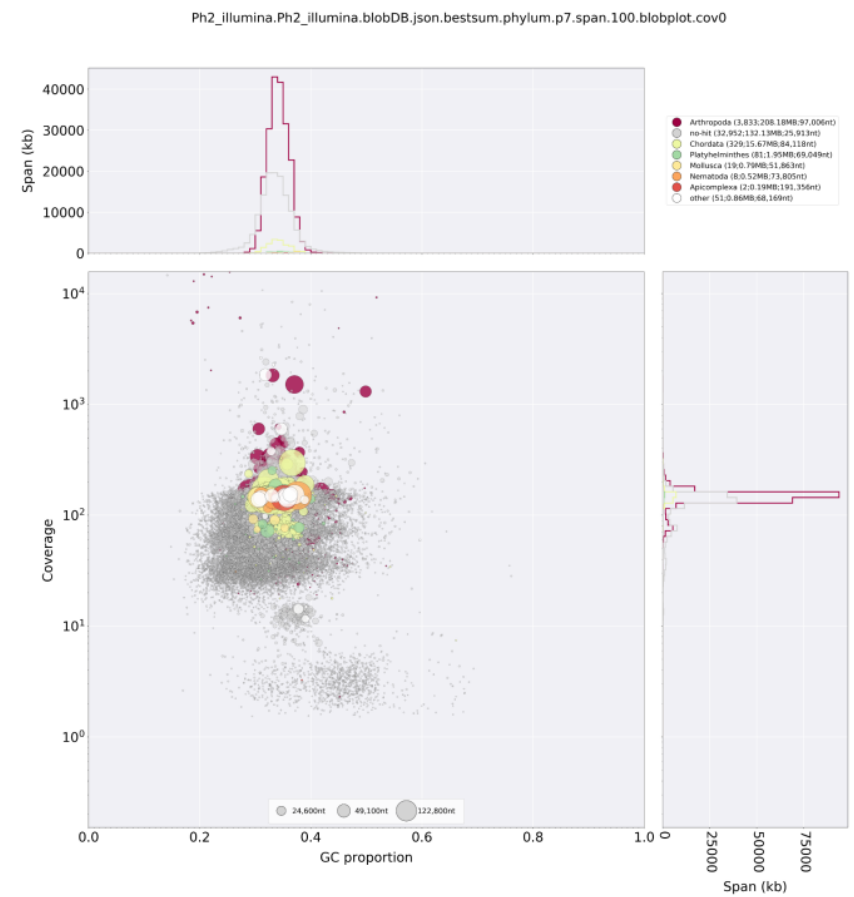

Fig. S44.Taxon-annotated GC-coverage (TAGC) plots of Philopotamus ludiferatus. Circles indicate contigs and the color indicates the best match to taxon annotation. The upper and right hand panel show the total span of contigs $(\mathrm{kb})$ given $\mathrm{GC}$ proportion. 
bioRxiv preprint doi: https://doi org/10.1101/2021.05.10.443368; this version posted July 18, 2021. The copyright holder for this preprint (which was not certified by peer review) is the author/funder, who has granted bioRxiv a license to display the preprint in perpetuity. It is made available under aCC-BY-NC-ND 4.0 International license.

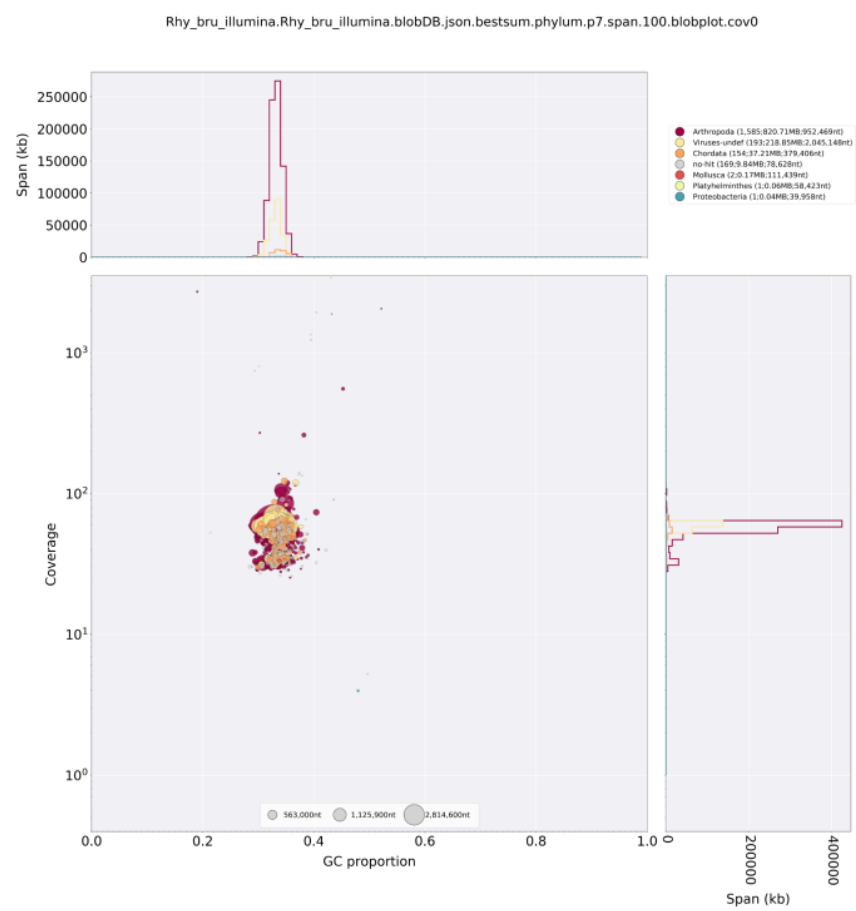

Fig. S45. Taxon-annotated GC-coverage (TAGC) plots of Rhyacophila brunneae. Circles indicate contigs and the color indicates the best match to taxon annotation. The upper and right hand panel show the total span of contigs $(\mathrm{kb})$ given GC proportion.

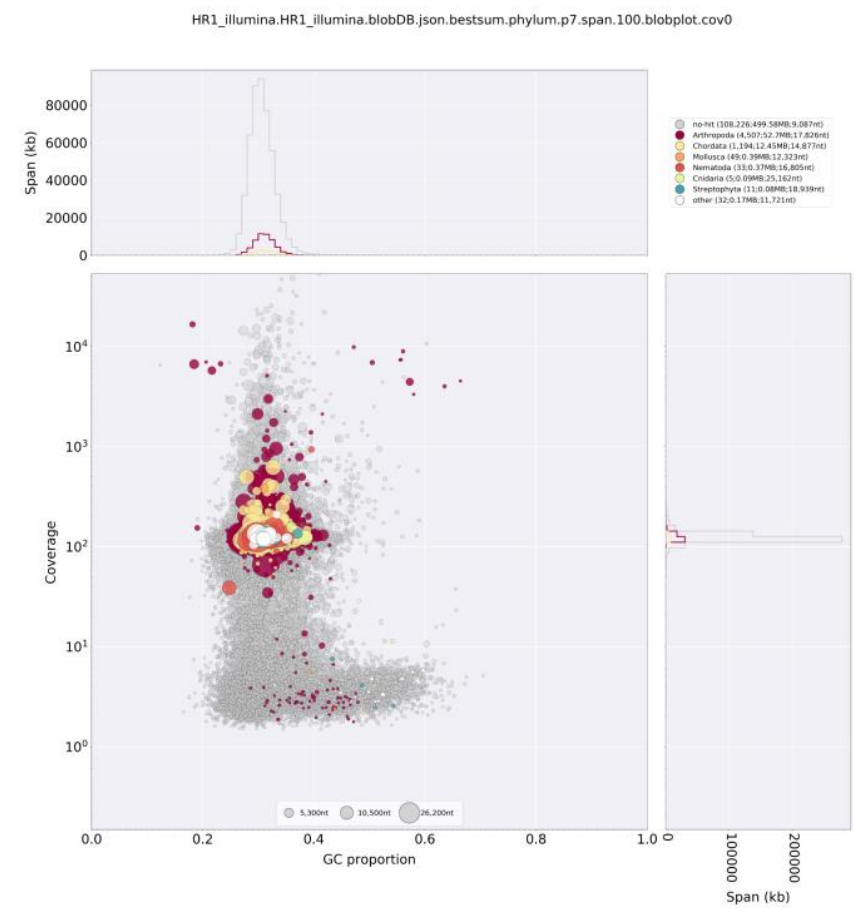

Fig. S46. Taxon-annotated GC-coverage (TAGC) plots of Rhyacophila evoluta HR1. Circles indicate contigs and the color indicates the best match to taxon annotation. The upper and right hand panel show the total span of contigs $(\mathrm{kb})$ given $\mathrm{GC}$ proportion. 


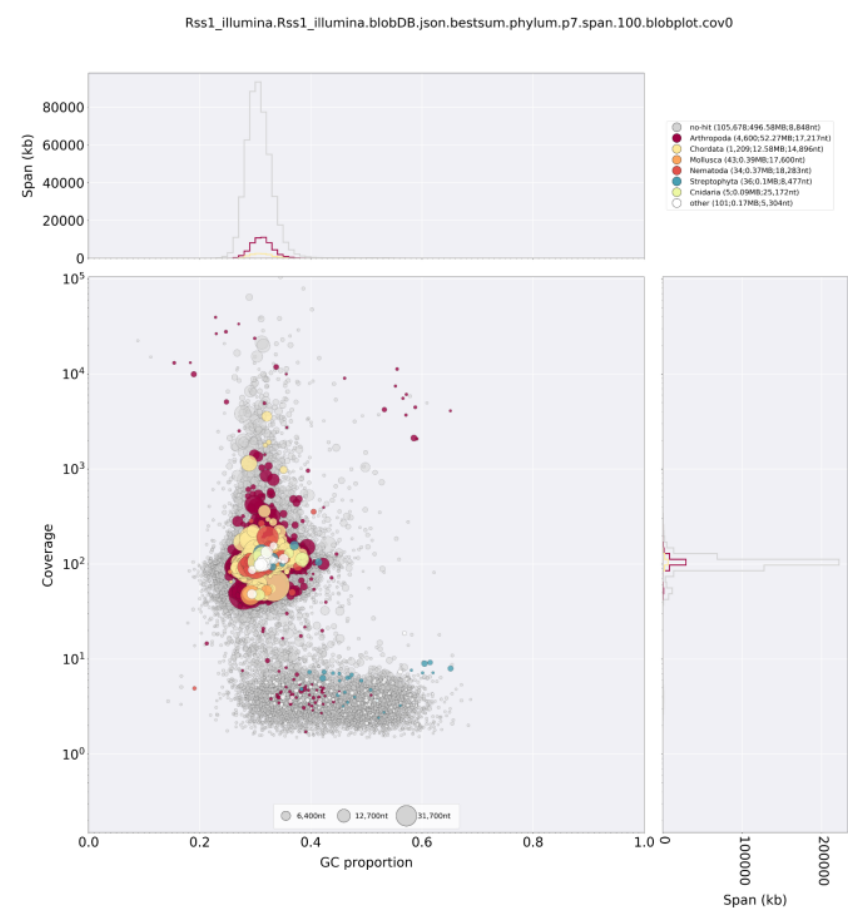

Fig. S47. Taxon-annotated GC-coverage (TAGC) plots of Rhyacophila evoluta RSS1. Circles indicate contigs and the color indicates the best match to taxon annotation. The upper and right hand panel show the total span of contigs $(\mathrm{kb})$ given GC proportion.

\section{Supplementary note 6: Caddislfy silk usage}

Trichoptera use silk produced in their salivary glands to build diverse underwater structures. While Annulipalpia is represented by fixed retreat- and net-making species, Integripalpia consists of 'tube case'- and 'cocoon'-making species. Larvae of most families in suborder Integripalpia create portable, tubular cases made from diverse materials encountered in their habitats, such as small stones or plant material or made purely from silk. These larvae then pupate in their final case, by encapsulating themselves within the portable structure and fixing this to the substrate. Basal integripalpian families which show diverse case-making behaviors ('free-living', 'tortoise case'-making, 'purse case'-making), are referred to as cocoon-makers because they pupate in a silken pupal cocoon with an internal osmotic environment [19]. Previously, cocoon-making caddisflies were recognized as their own suborder 'Spicipalpia' [20]. However, recent studies [21] rejected 'Spicipalpia' as a third suborder and defined Integripalpia to include both the tube-case (Phryganides) and cocoon-makers (basal Integripapia) as previously suggested by [22]. Our results support this classification (Fig. 1, main text, supplementary Fig. 1), though more data is needed to assess the phylogenetic 
position of Agraylea sexmaculata (Hydroptilidae, see polytomy in supplementary Fig. 1) as the only 'purse-case' maker in this study.

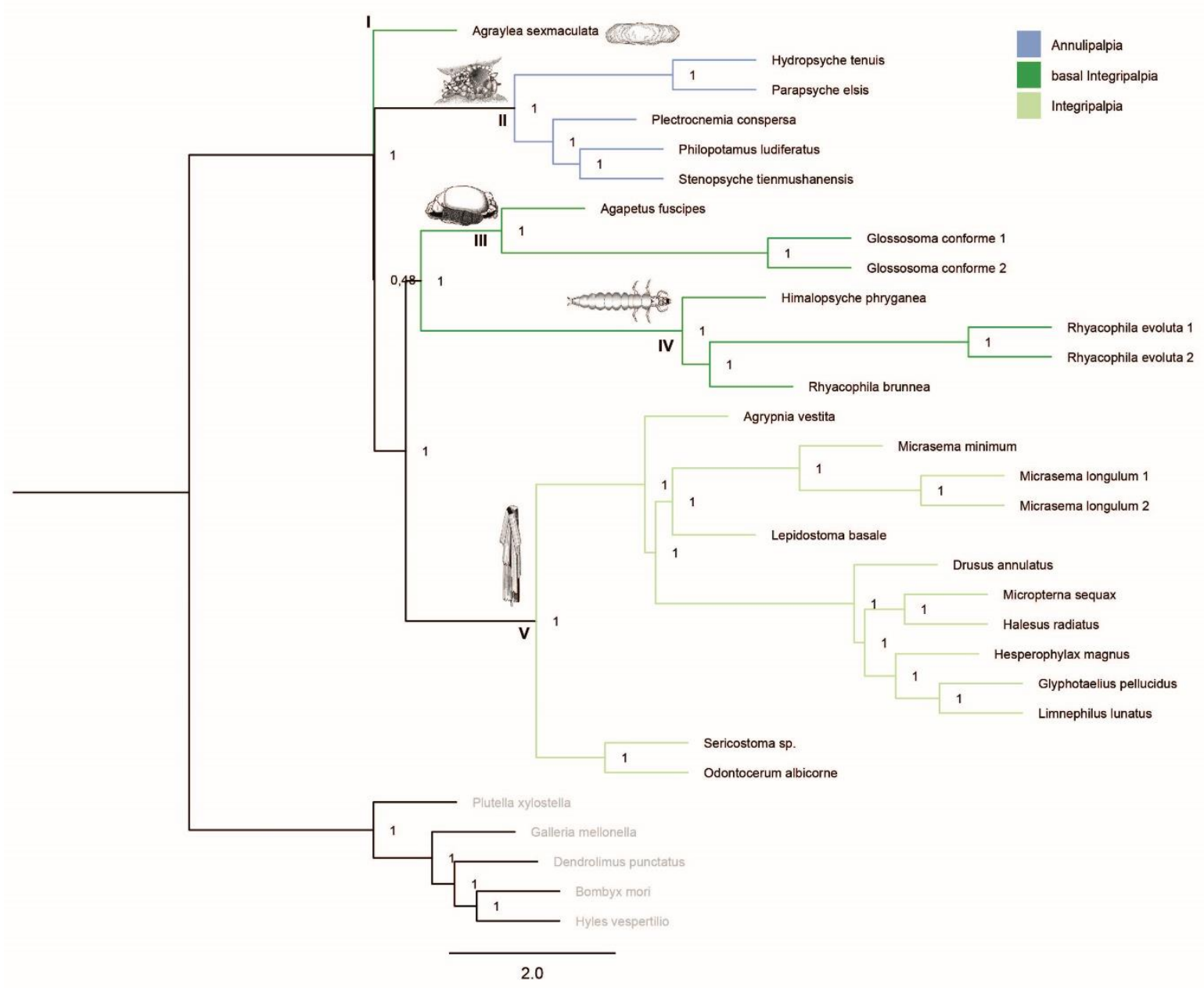

Fig. S1. Phylogenetic relationships derived from ASTRAL-III analyses using single BUSCO genes. Support values are given for each node. Trichoptera are divided into two suborders: Annulipalpia (II: blue) which consists of 'fixed retreat- and net-building' species and Intergripalpia (I, III, IV, V: green) which includes 'cocoon-making' (basal Integripalpia, clades I, III, IV, dark green) and 'case-building' (V: light green) caddisflies. 'Cocoon-makers' are divided into 'purse case'- (I), 'tortoise case-making' (III) and 'free-living' (IV) families. Illustrations represent an example of silk use in the respective clade. Taxa in grey (Lepidoptera) were used as outgroups. 


\section{Supplementary note 7: Genome size estimations and genome profiling}

\section{k-mer distribution-based method}

We conducted genome profiling (estimation of major genome characteristics such as size, heterozygosity, and repetitiveness) on the filtered short-read sequence data with GenomeScope 2.0 [23]. Before running GenomeScope 2.0, we counted k-mers with JELLYFISH v2.2.10 [24]. using jellyfish count -C -s 25556999998 -F 3 and a k-mer length of 21 (-m 21) as recommended for most genomes by the authors of GenomeScope2. A histogram of k-mer frequencies was produced with jellyfish histo. GenomeScope 2.0 was run with the exported k-mer count histogram within the online web tool (http://qb.cshl.edu/genomescope/genomescope2.0/) using the following parameters: Kmer length $=21$, Read length $=150$, Max kmer coverage $=10000$. For some species we ran the command-line version of Genomescope 2 with the option -1 to set the location of the first peak after correspondence with the Genomescope2 developer. Resulting GenomeScope profiles are available online and in the supplementary (see Additional File 1: Sup.4-Genomescope 2 Results). For three specimens the online interface version of Genomescope 2 had difficulties with finding the first peak with the default settings. After correspondence with the Genomescope 2 developer, we ran the command-line version of Genomescope 2 with the optional parameter -1 lambda to set the initial guess for the average k-mer coverage of the sequencing based on the results of the Genomescope 2 profile from the online version.

\section{Backmapping based approaches}

We mapped all trimmed and contamination filtered Illumina reads against the final genome assemblies using BWA-MEM v0.7.17-r1188 with the options -a and -c 10000. We used view $-1-b$ and sort -19 functions of SAMtools v1.9 to print alignments to standard output in BAM format and sort them by leftmost coordinates. We conducted genome size estimations using backmap.pl v0.3 [25] with the options -nq and the sorted .bam files resulting from the remapping step. The script uses BEDTools v2.27.1 [26] to generate a coverage histogram and R v3.5.1 (R Core Team, 2017; https://www.R-project.org/) to plot the coverage distribution. Assuming even sequencing coverage throughout the genome, backmap.pl estimates the genome size by dividing the number of total nucleotides which were mapped to the assembly by the maximum of the per-position coverage frequency distribution. For coverage distribution per position see Supplementary Figs. 21-44. Genome size estimates are given in Additional File 1: Sup.5-Backmap.pl Results. 


\section{Flow cytometry}

We estimated genome sizes (2C-values,[27]) for 29 of Trichoptera species (19 genera) by flow cytometry (FCM) using the Partec CyFlow Space (Partec, Münster, Germany) equipped with a green solid-state laser (Partec, $532 \mathrm{~nm}, 30 \mathrm{~mW}$ ). For sample preparation, we followed the two-step Otto protocol [28], with an internal standard Lycopersicon esculentum cv. Stupické polní tyčkové rané $(2 \mathrm{C}=1.96 \mathrm{pg}$; [29]). We mixed the whole or part of the caddisfly body with ca. $1 \mathrm{~cm}^{2}$ leaf of an internal reference standard and homogenized it with a razor blade in a Petri dish containing $1 \mathrm{ml}$ of ice-cold Otto I buffer $(0.1 \mathrm{M}$ citric acid, $0.5 \%$ Tween 20 ; [28]). We filtered the suspension through a 42- $\mu \mathrm{m}$ nylon mesh and incubated it for approximately $15 \mathrm{~min}$ at room temperature. The staining solution consisted of $1 \mathrm{ml}$ of Otto II buffer $\left(0.4 \mathrm{M} \mathrm{Na} \mathrm{HPO}_{4} \cdot 12 \mathrm{H}_{2} \mathrm{O}\right)$, $\beta$-mercaptoethanol (final concentration of $2 \mu \mathrm{l} / \mathrm{ml}$ ), intercalating fluorochrome propidium iodide (PI) and RNase IIA (both at final concentrations of $50 \mu \mathrm{g} / \mathrm{ml}$ ). We recorded fluorescence intensities of 10,000-20,000 particles (nuclei) for three to eleven replicates (different individuals). We calculated sample/standard ratios from the means of the sample and standard fluorescence histograms, and considered only histograms with coefficients of variation $<3.5 \%$ for the G0/G1 sample peak. For genome size calculation, we multiplied the sample/standard ratios with the genome size of the internal standard. For unit conversion, we used 1 pg DNA = 978 Mbp [29]. Genome size estimates are given in Additional File 1: Sup.6-FCM Results. 
bioRxiv preprint doi: https://doi org/10.1101/2021 05.10.443368; this version posted July 18, 2021. The copyright holder for this preprint (which was not certified by peer review) is the author/funder, who has granted bioRxiv a license to display the preprint in perpetuity. It is made available under aCC-BY-NC-ND 4.0 International license.

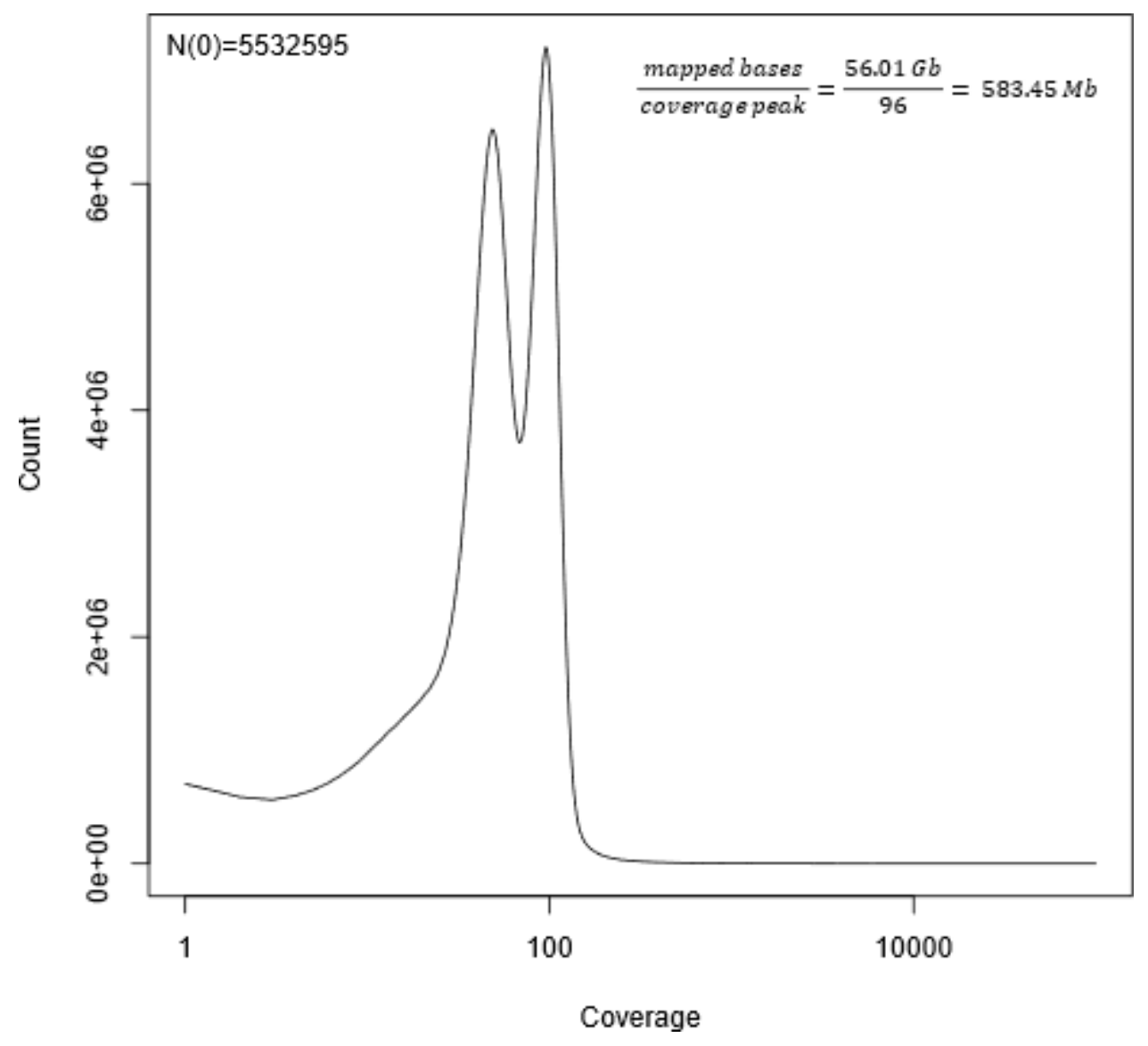

Fig. S49. Agapetus fuscipens: Coverage distribution per position and genome size estimate from backmap.pl. The x-axis is given in log-scale. For details, see Supplementary Note 5.

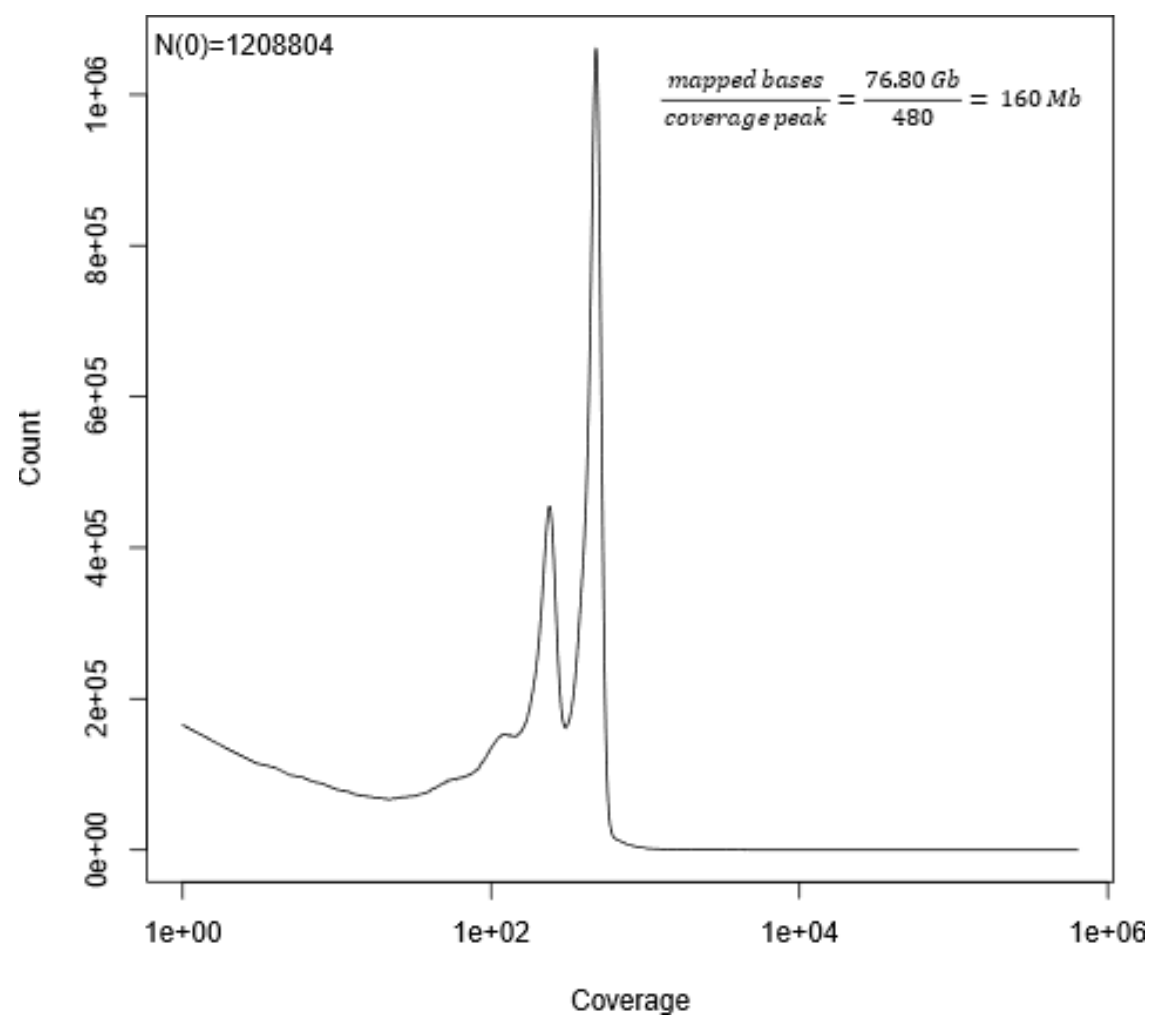


bioRxiv preprint doi: https://doi org/10.1101/2021.05.10.443368; this version posted July 18,2021 The copyright holder for this preprint (which was not certified by peer review) is the author/funder, who has granted bioRxiv a license to display the preprint in perpetuity. It is made available under aCC-BY-NC-ND 4.0 International license.

Fig. S50: Agraylea sexmaculata: Coverage distribution per position and genome size estimate from backmap.pl. The x-axis is given in log-scale. For details, see Supplementary Note 5.

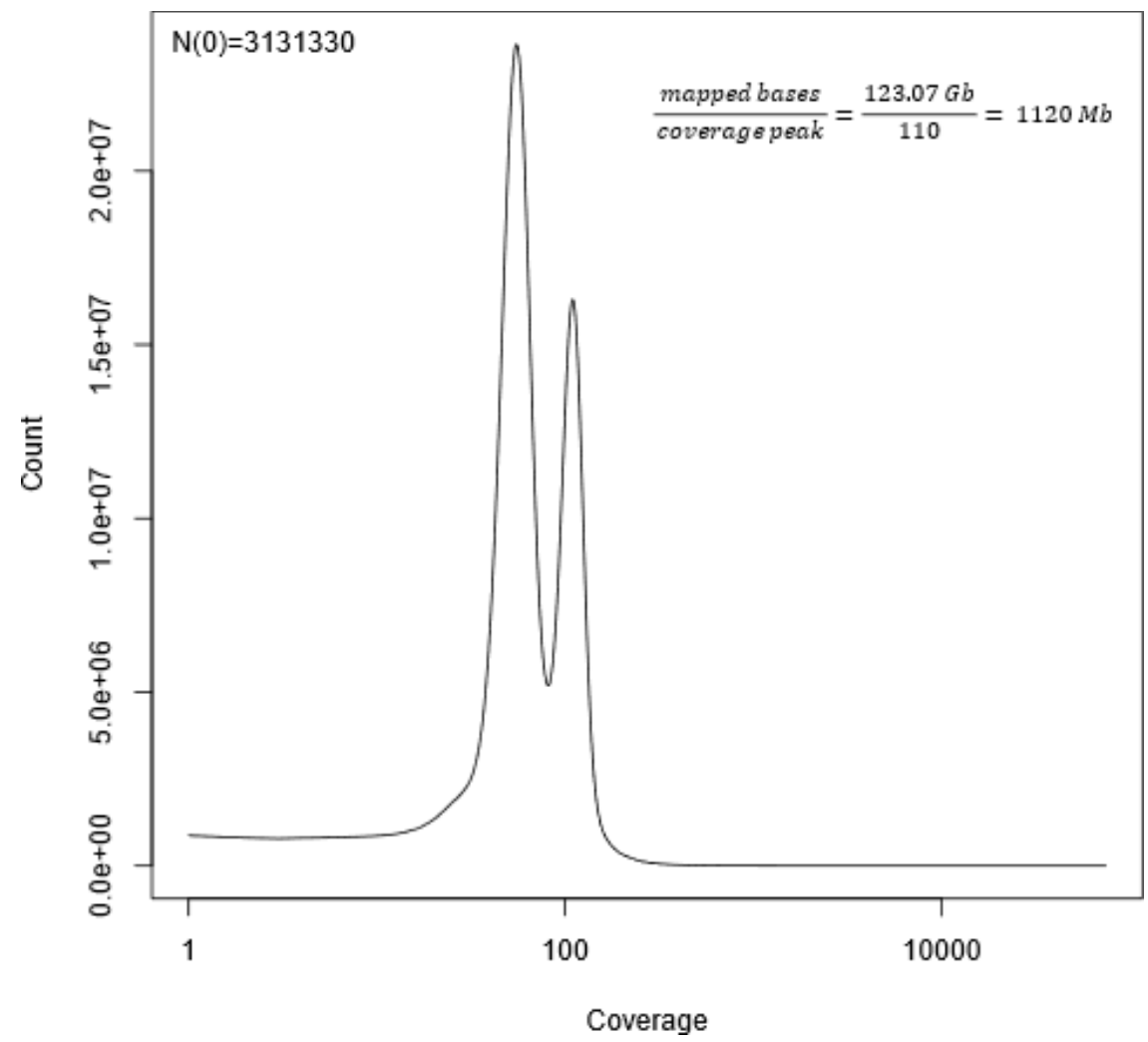

Fig. S51. Agrypnia vestita. Coverage distribution per position and genome size estimate from backmap.pl. The x-axis is given in log-scale. For details, see Supplementary Note 5.

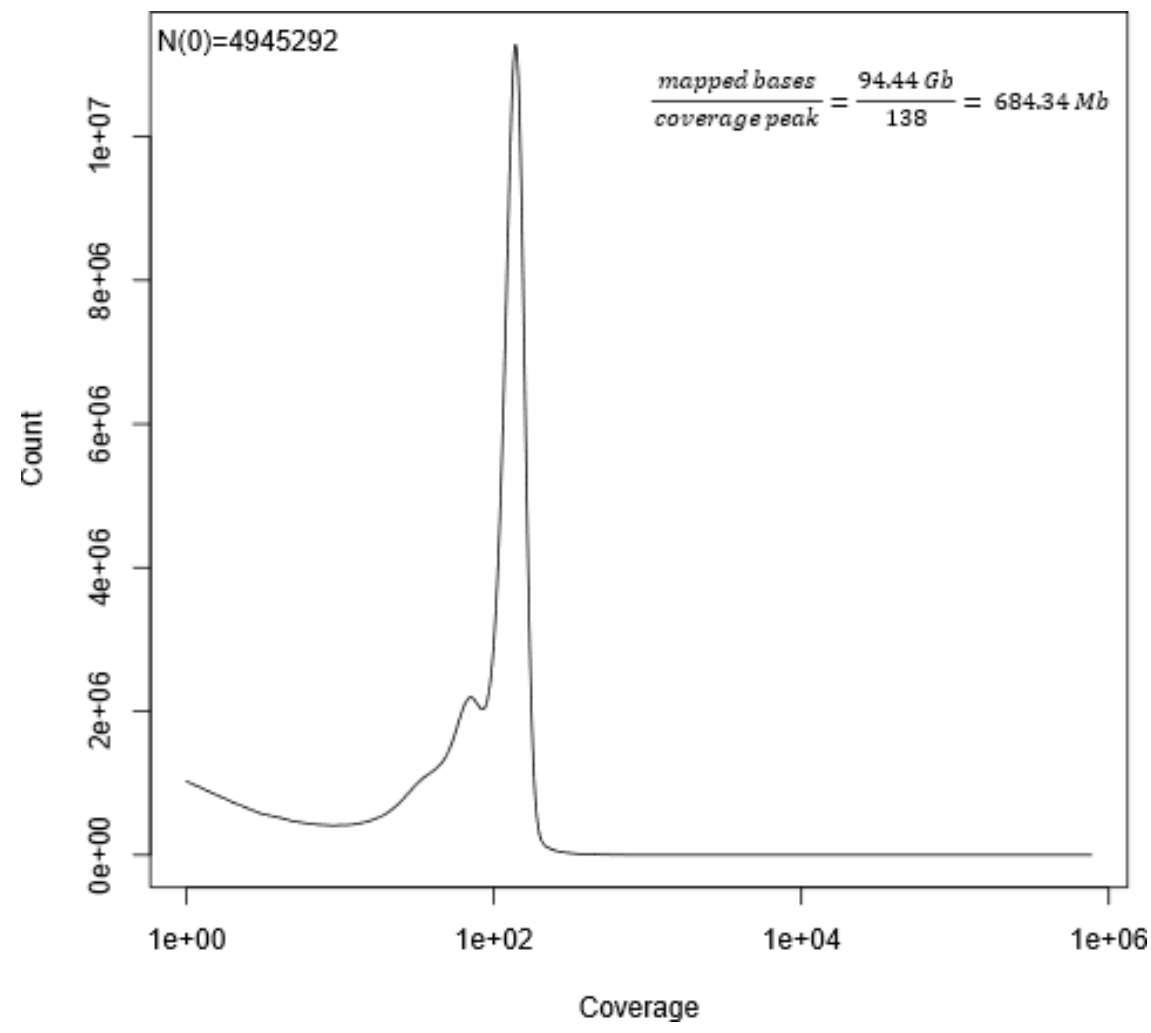


Fig. S52. Drusus annulatus: Coverage distribution per position and genome size estimate from backmap.pl. The $\mathrm{x}$-axis is given in log-scale. For details, see Supplementary Note 5.

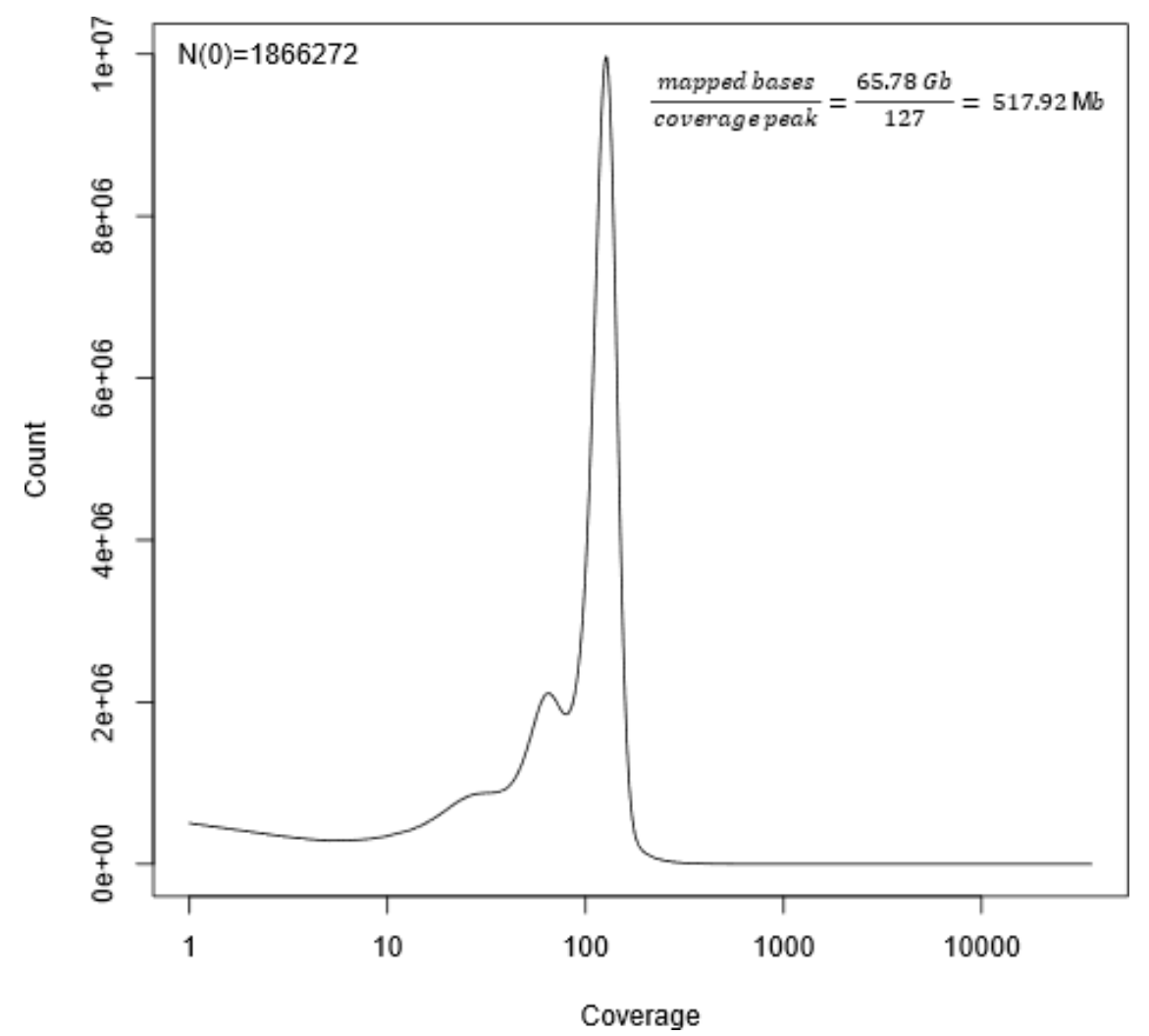

Fig. S53. Glossosoma conforme G1: Coverage distribution per position and genome size estimate from backmap.pl. The x-axis is given in log-scale. For details, see Supplementary Note 5.

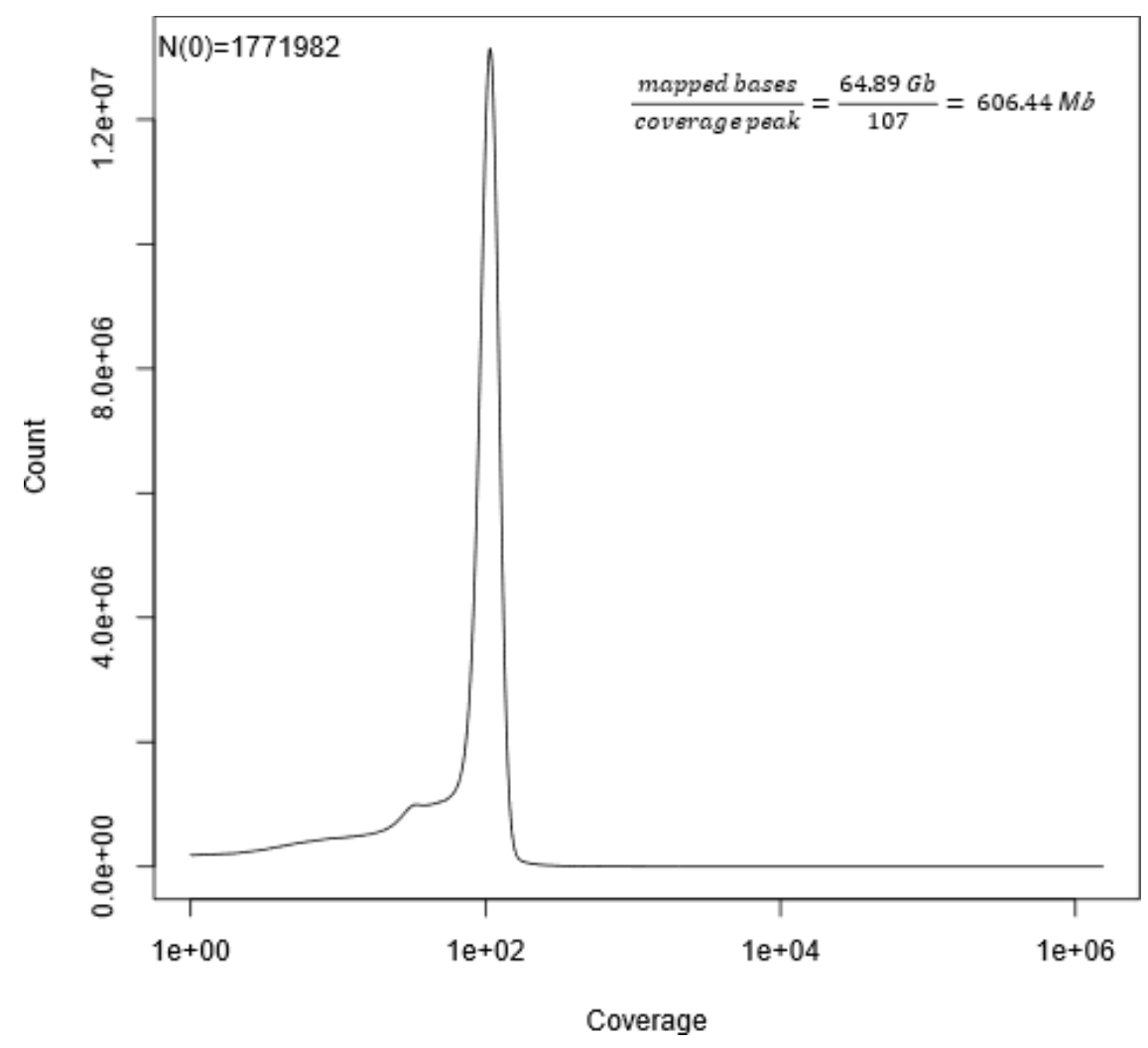

Fig. S54. Glossosoma conforme Glo: Coverage distribution per position and genome size estimate from backmap.pl. The x-axis is given in log-scale. For details, see Supplementary Note 5. 


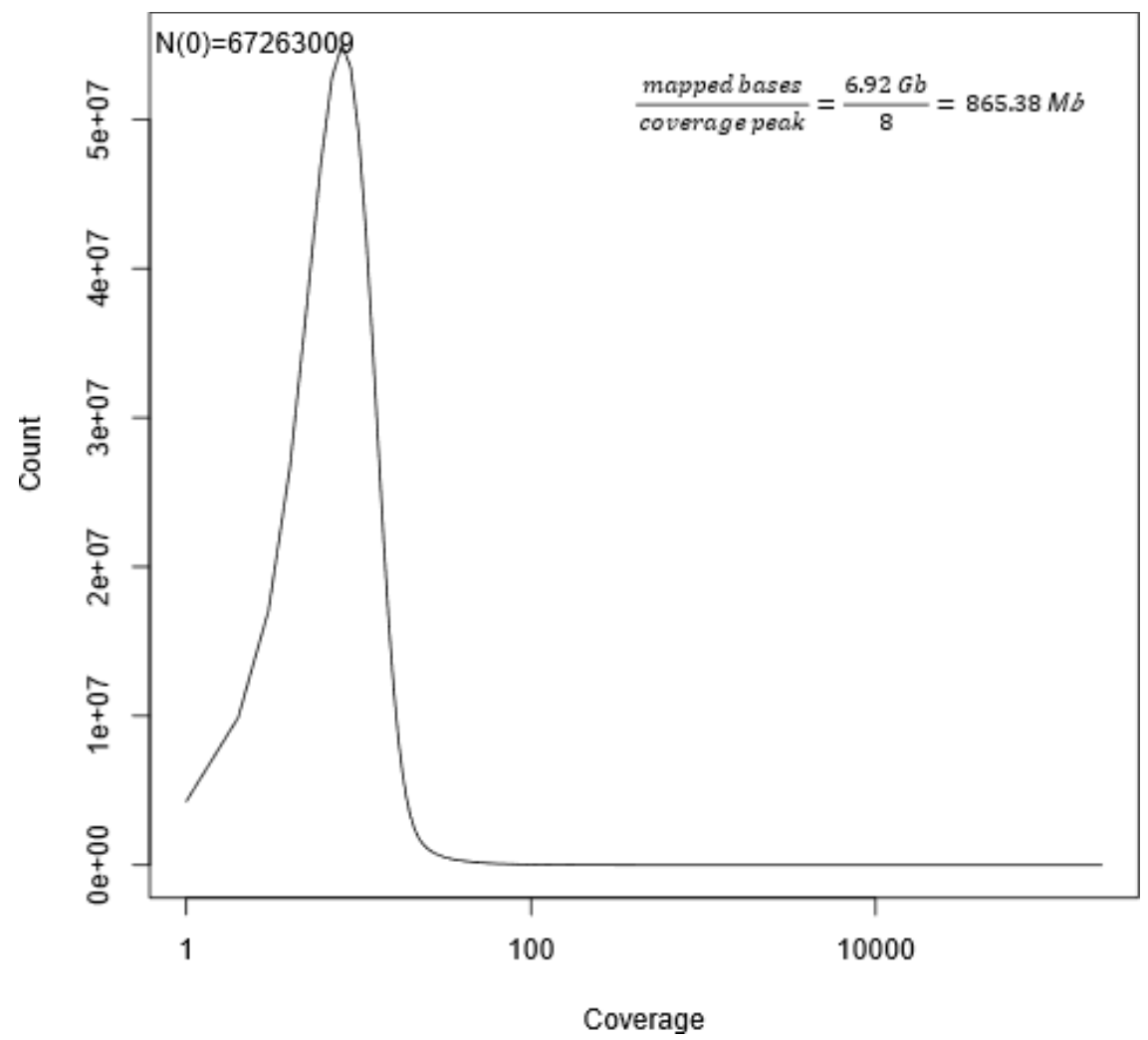

Fig. S55. Glyphotaelius pellucidula: Coverage distribution per position and genome size estimate from backmap.pl. The x-axis is given in log-scale. For details, see Supplementary Note 5.

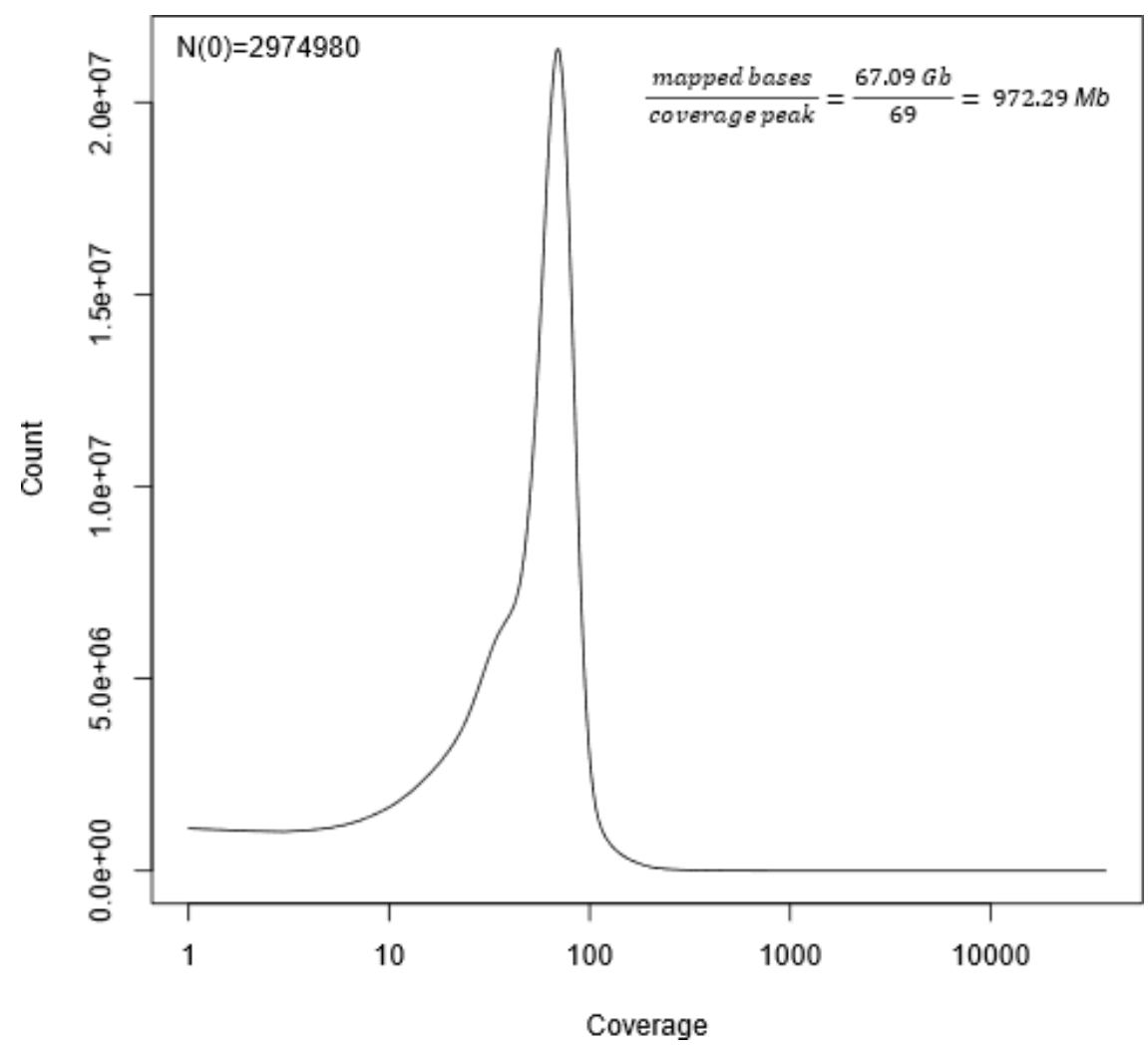

Fig. S56. Halesus radiatus. Coverage distribution per position and genome size estimate from backmap.pl. The x-axis is given in log-scale. For details, see Supplementary Note 5. 


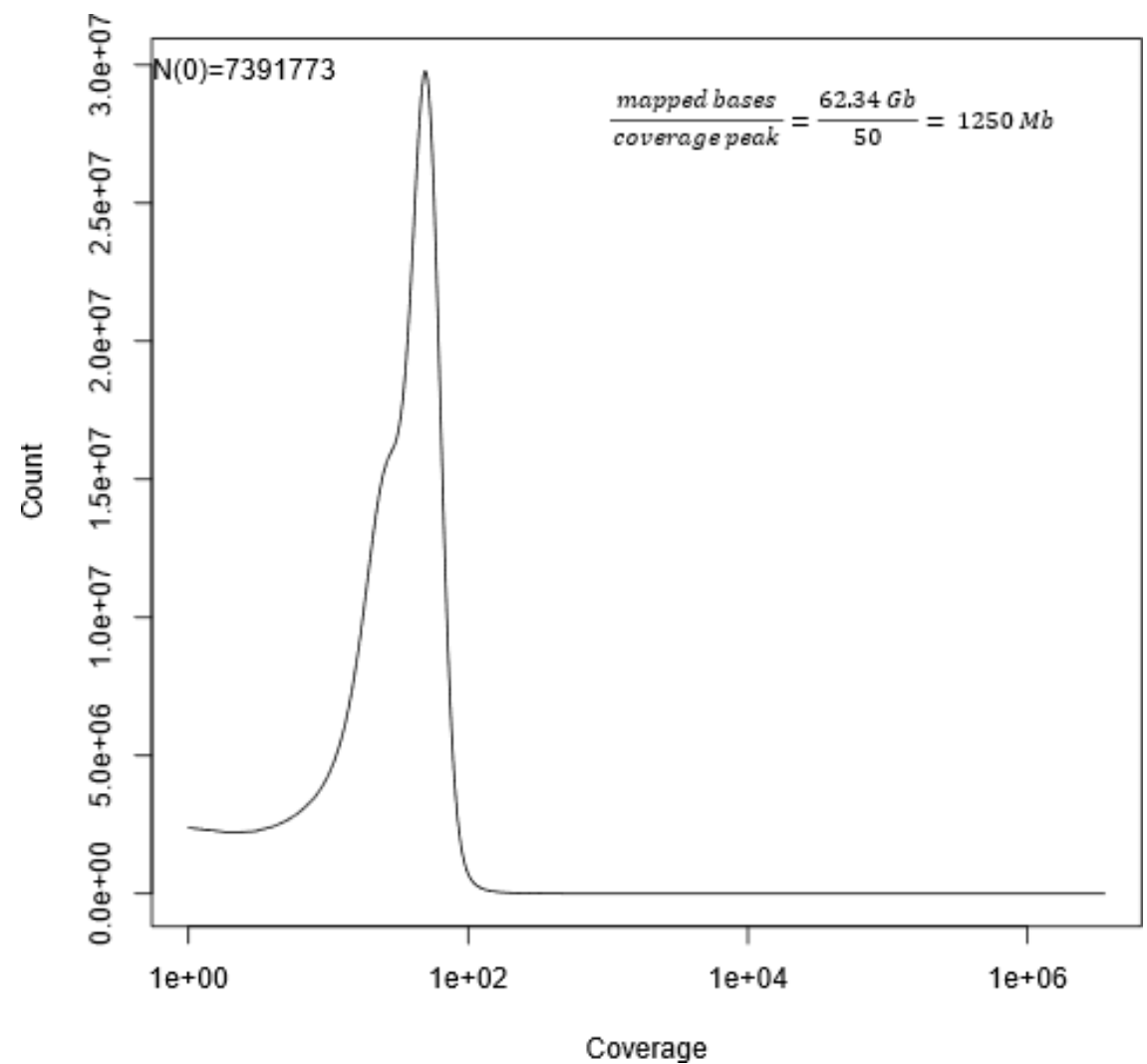

Fig. S57. Hesperophylax magnus: Coverage distribution per position and genome size estimate from backmap.pl. The x-axis is given in log-scale. For details, see Supplementary Note 5.

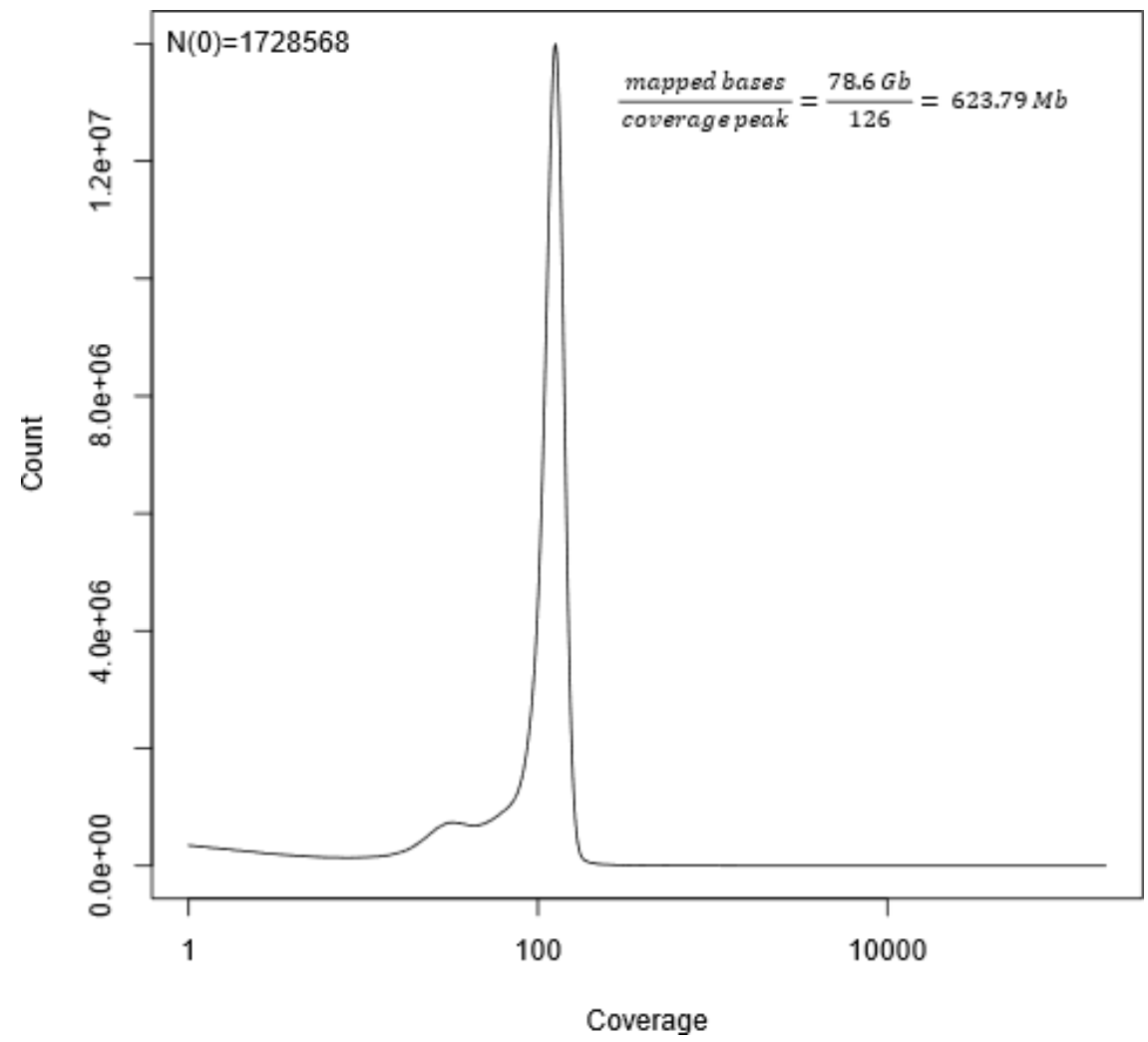

Fig. S58. Himalopsyche phryganeae: Coverage distribution per position and genome size estimate from backmap.pl. The x-axis is given in log-scale. For details, see Supplementary Note 5. 


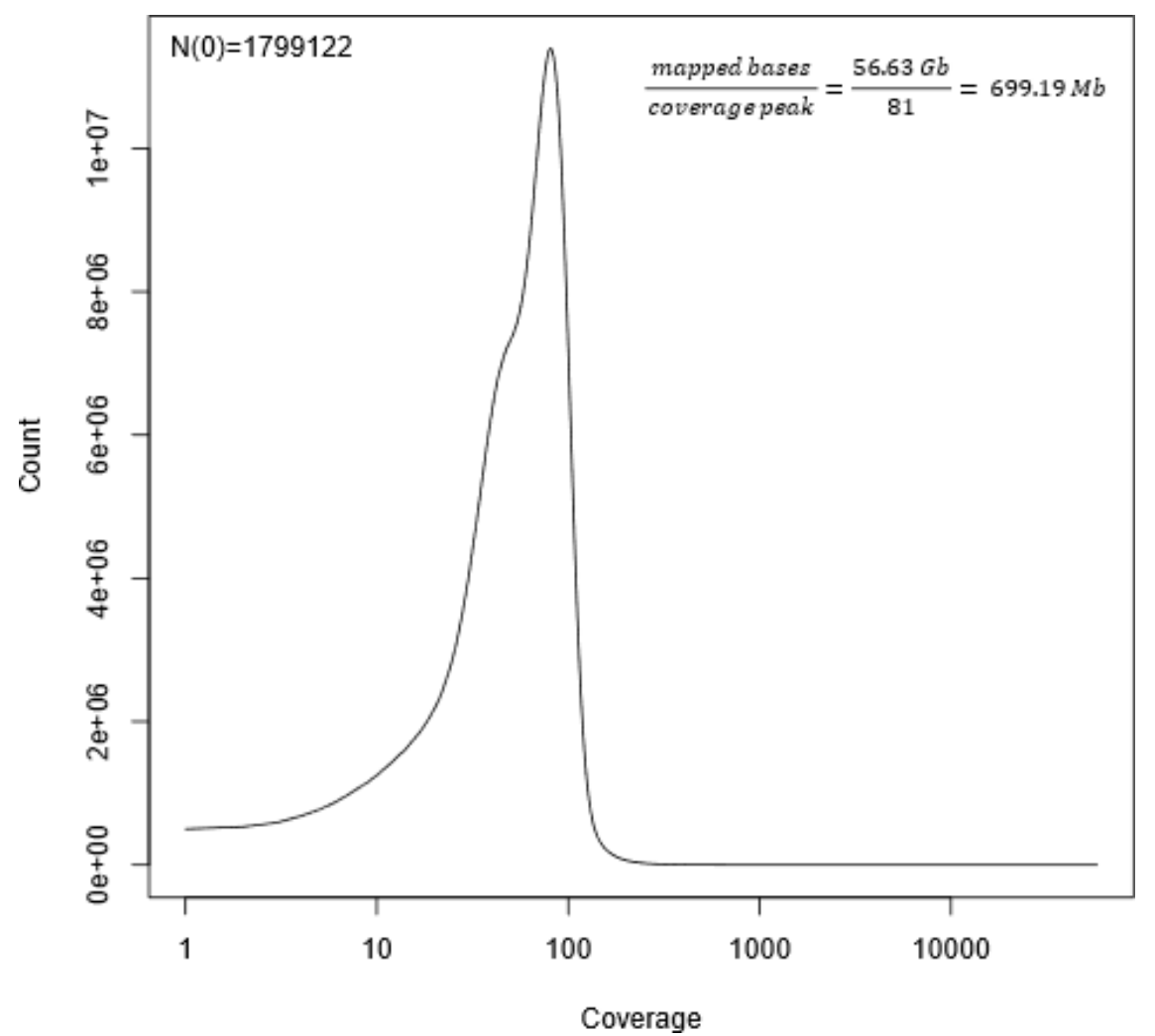

Fig. S59. Lepidostoma basale: Coverage distribution per position and genome size estimate from backmap.pl. The x-axis is given in log-scale. For details, see Supplementary Note 5.

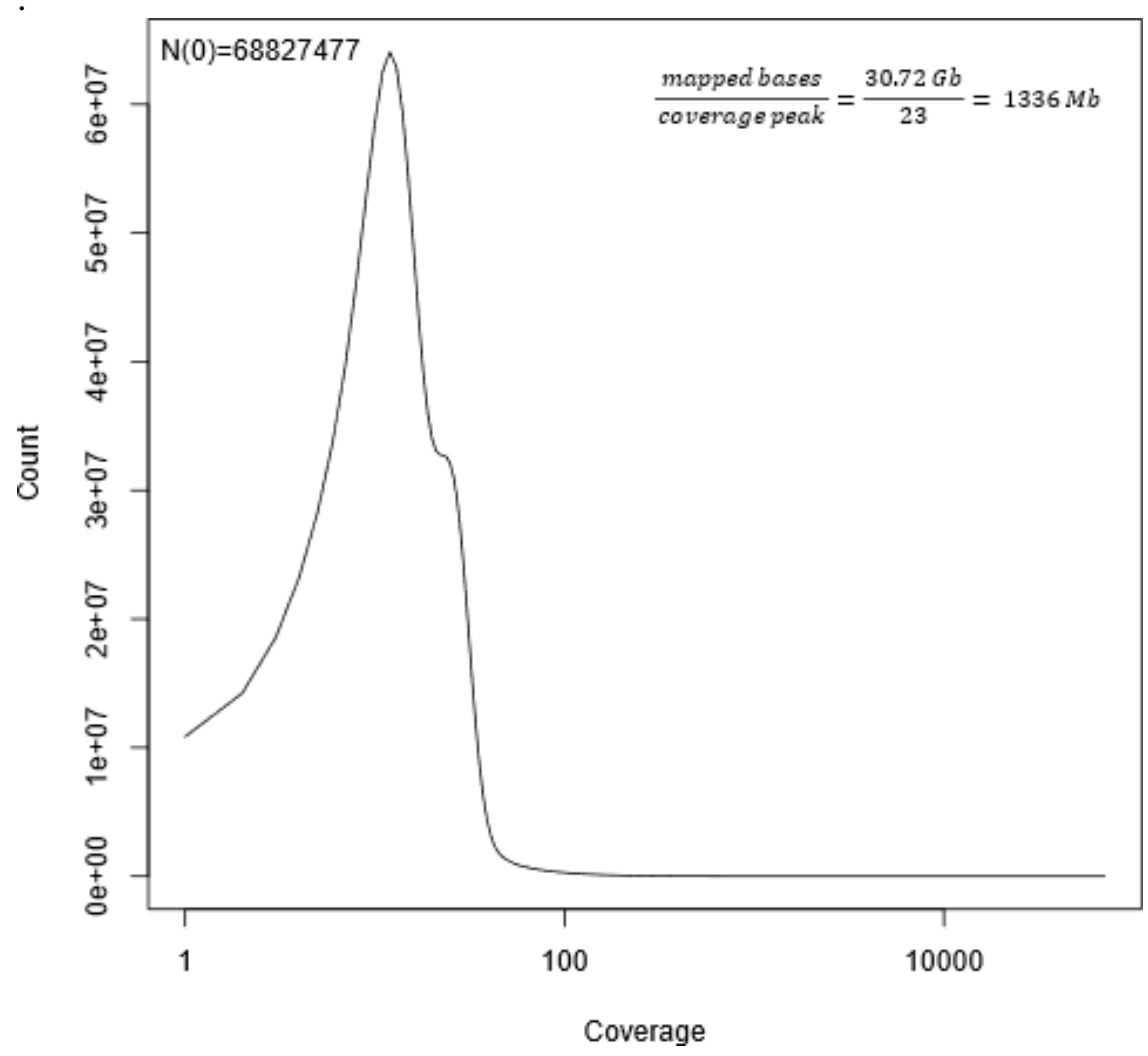

Fig. S60. Limnephilus lunatus: Coverage distribution per position and genome size estimate from backmap.pl. The $\mathrm{x}$-axis is given in log-scale. For details, see Supplementary Note 5 


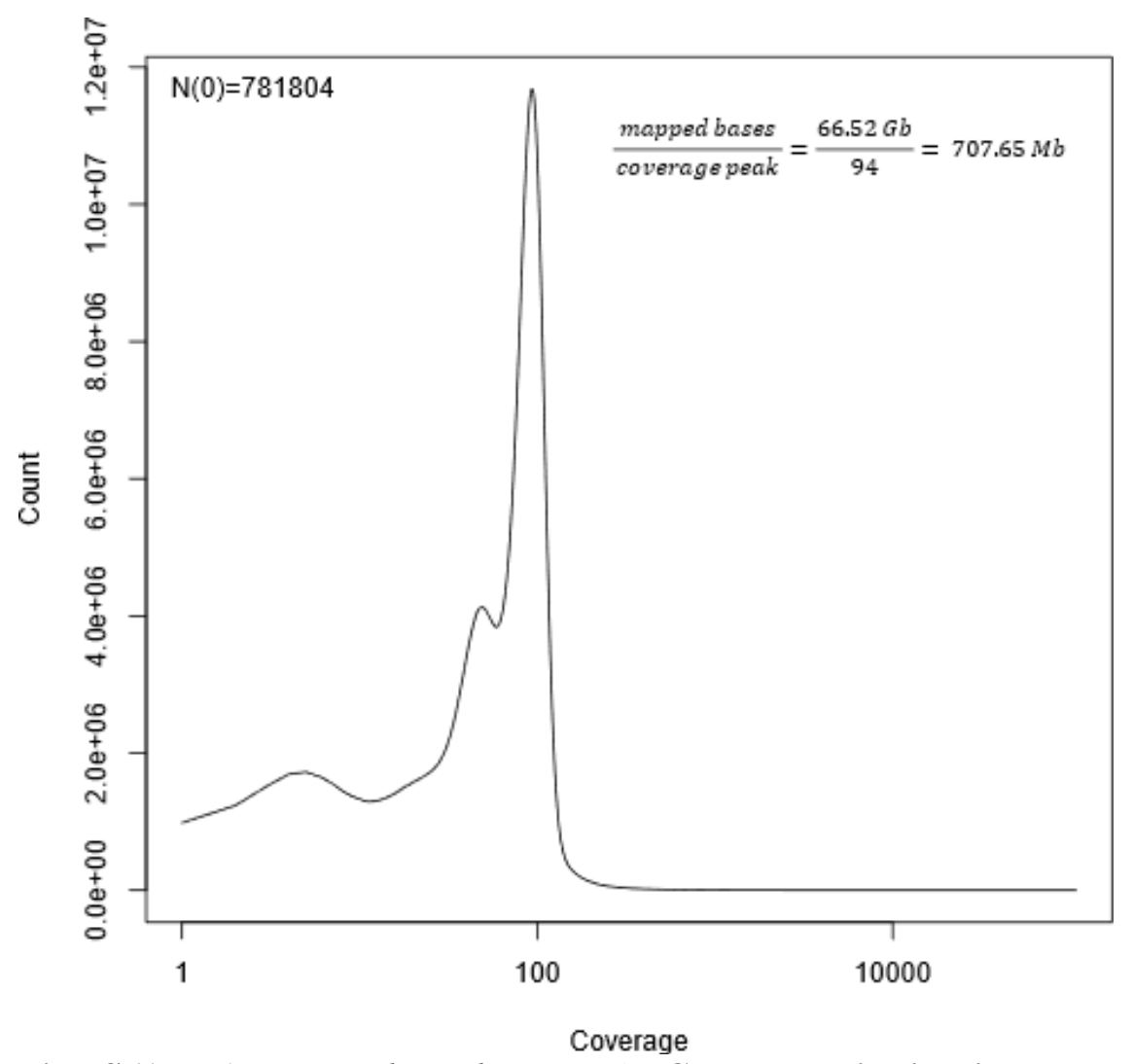

Fig. S61. Micrasema longulum ML1: Coverage distribution per position and genome size estimate from backmap.pl. The $\mathrm{x}$-axis is given in log-scale. For details, see Supplementary Note 5.

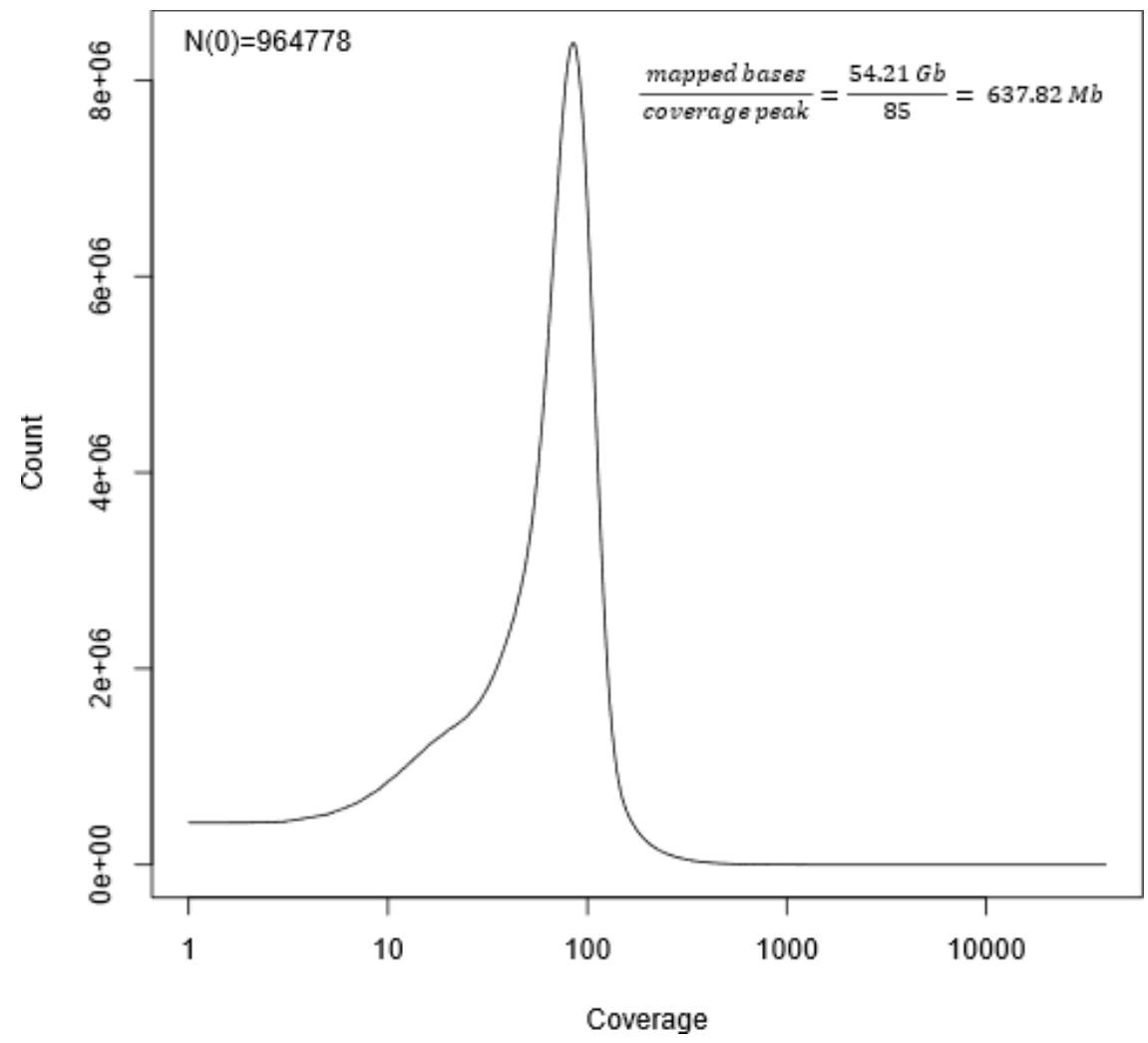

Fig. S62. Micrasema longulum ML3: Coverage distribution per position and genome size estimate from backmap.pl. The $\mathrm{x}$-axis is given in log-scale. For details, see Supplementary Note 5. 


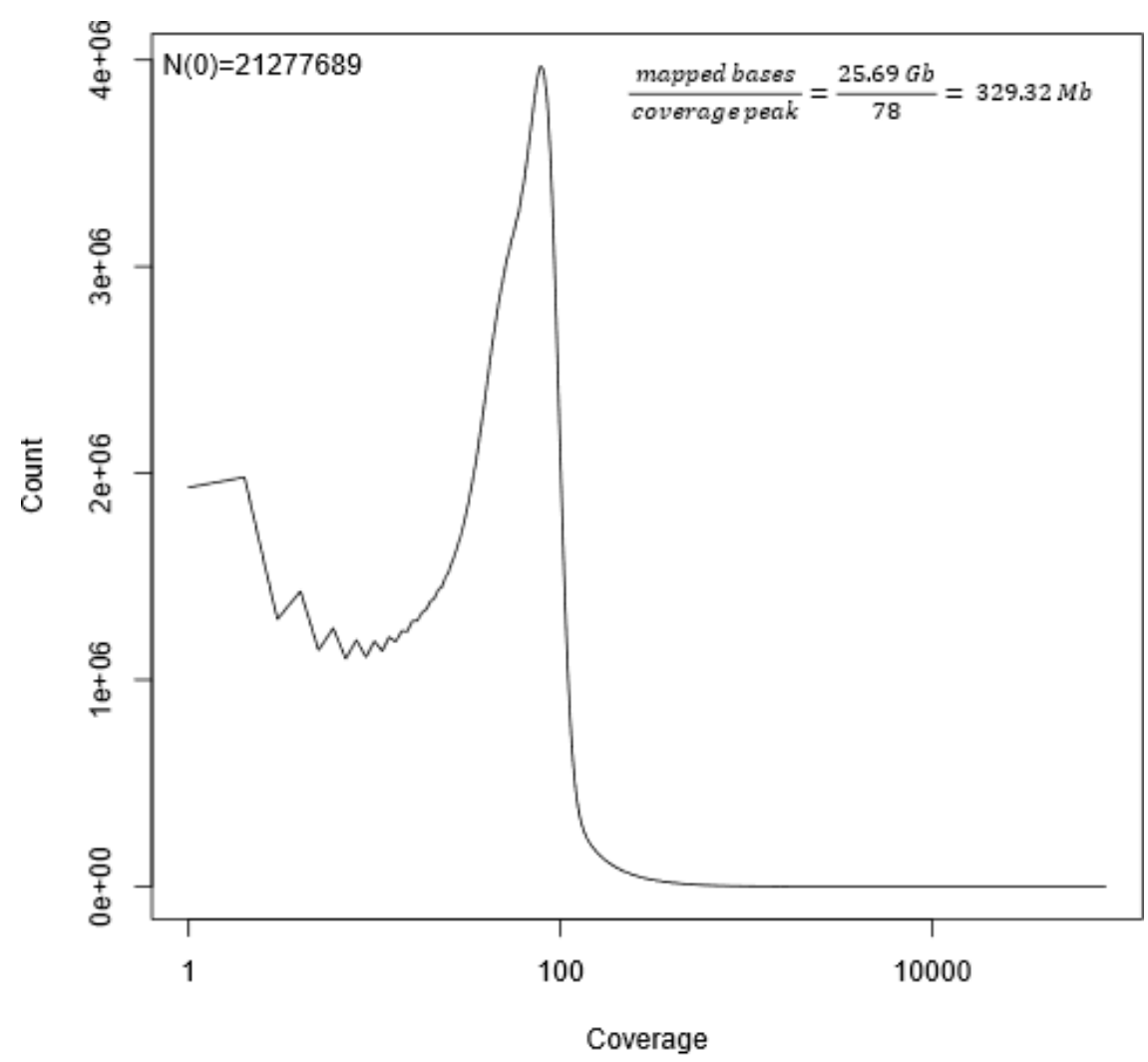

Fig. S63. Micrasema minimum: Coverage distribution per position and genome size estimate from backmap.pl. The x-axis is given in log-scale. For details, see Supplementary Note 5.

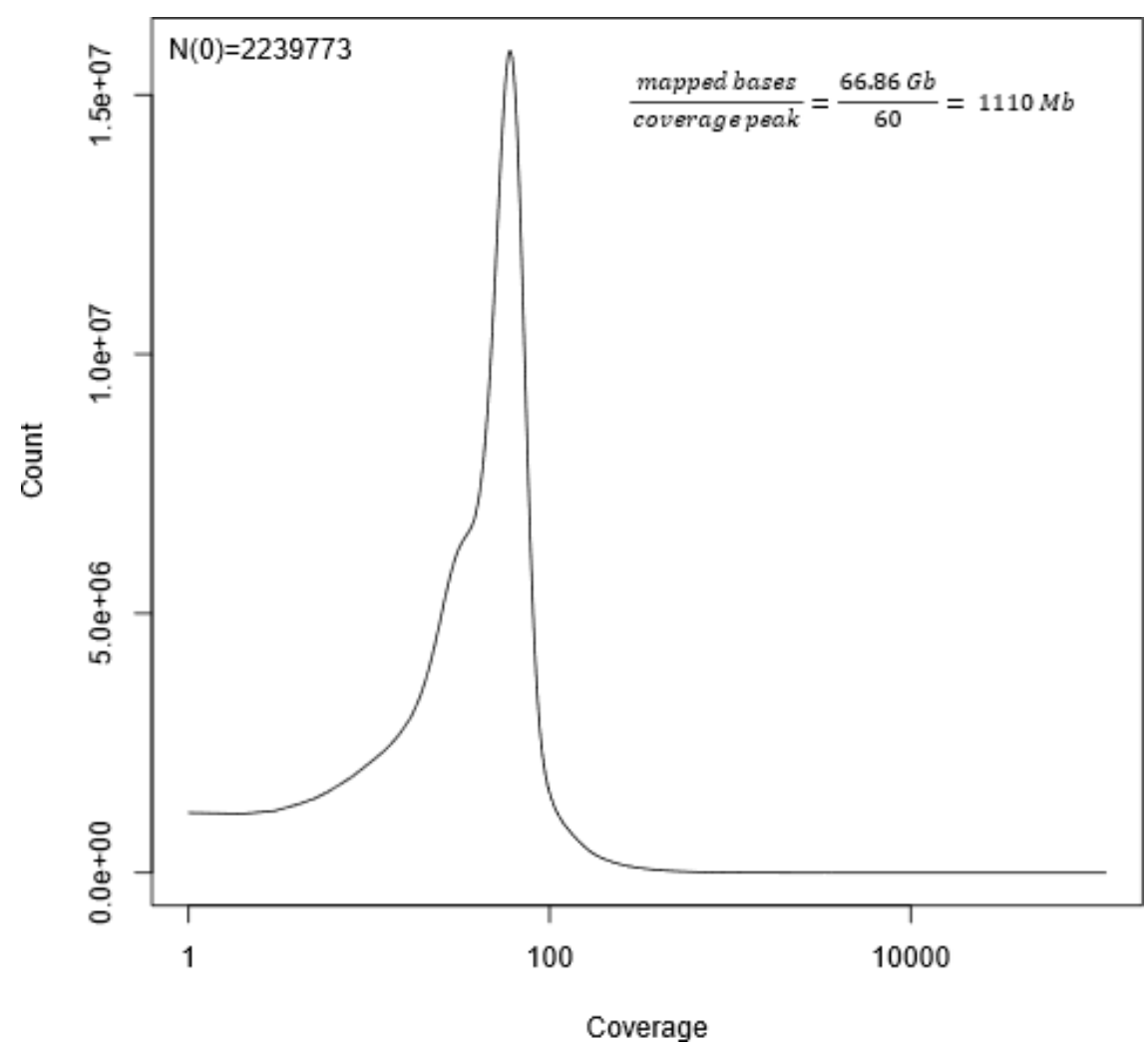

Fig. S64. Micropterna sequax: Coverage distribution per position and genome size estimate from backmap.pl. The x-axis is given in log-scale. For details, see Supplementary Note 5. 


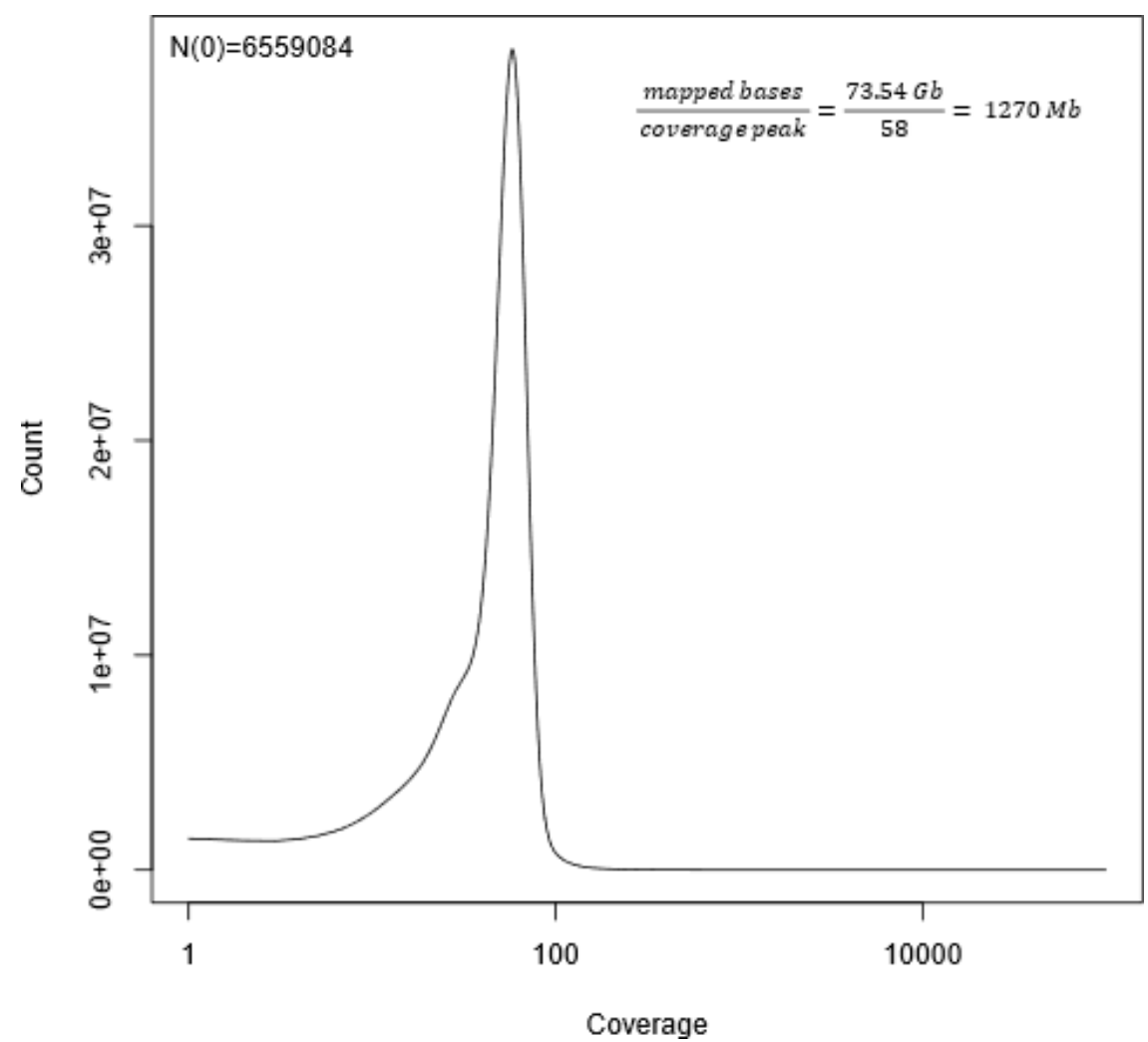

Fig. S65. Odontocerum albicorne: Coverage distribution per position and genome size estimate from backmap.pl. The x-axis is given in log-scale. For details, see Supplementary Note 5.

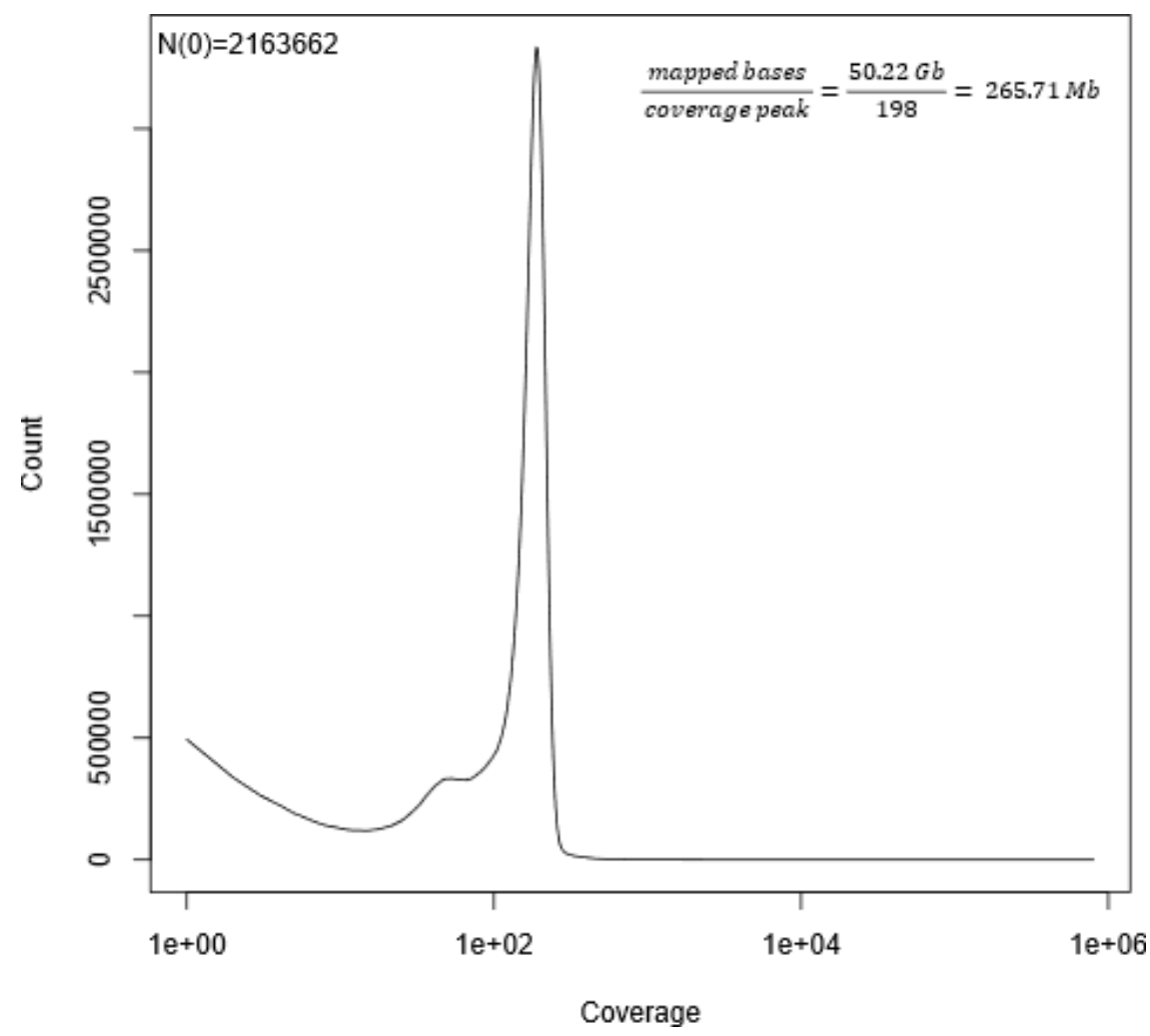

Fig. S66. Parapsyche elsis: Coverage distribution per position and genome size estimate from backmap.pl. The x-axis is given in log-scale. For details, see Supplementary Note 5. 


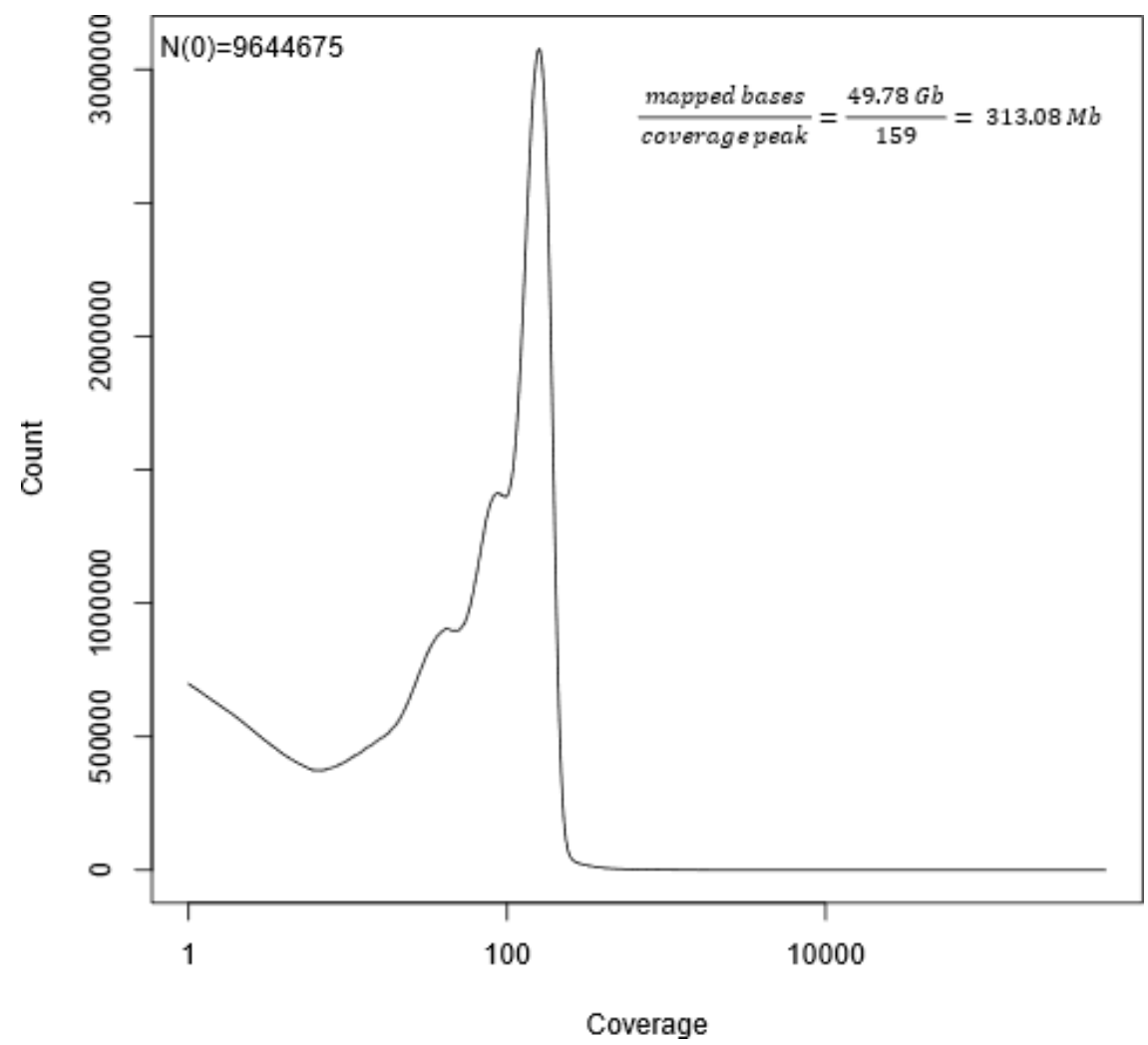

Fig. S67. Philopotamus ludificatus: Coverage distribution per position and genome size estimate from backmap.pl. The x-axis is given in log-scale. For details, see Supplementary Note 5.

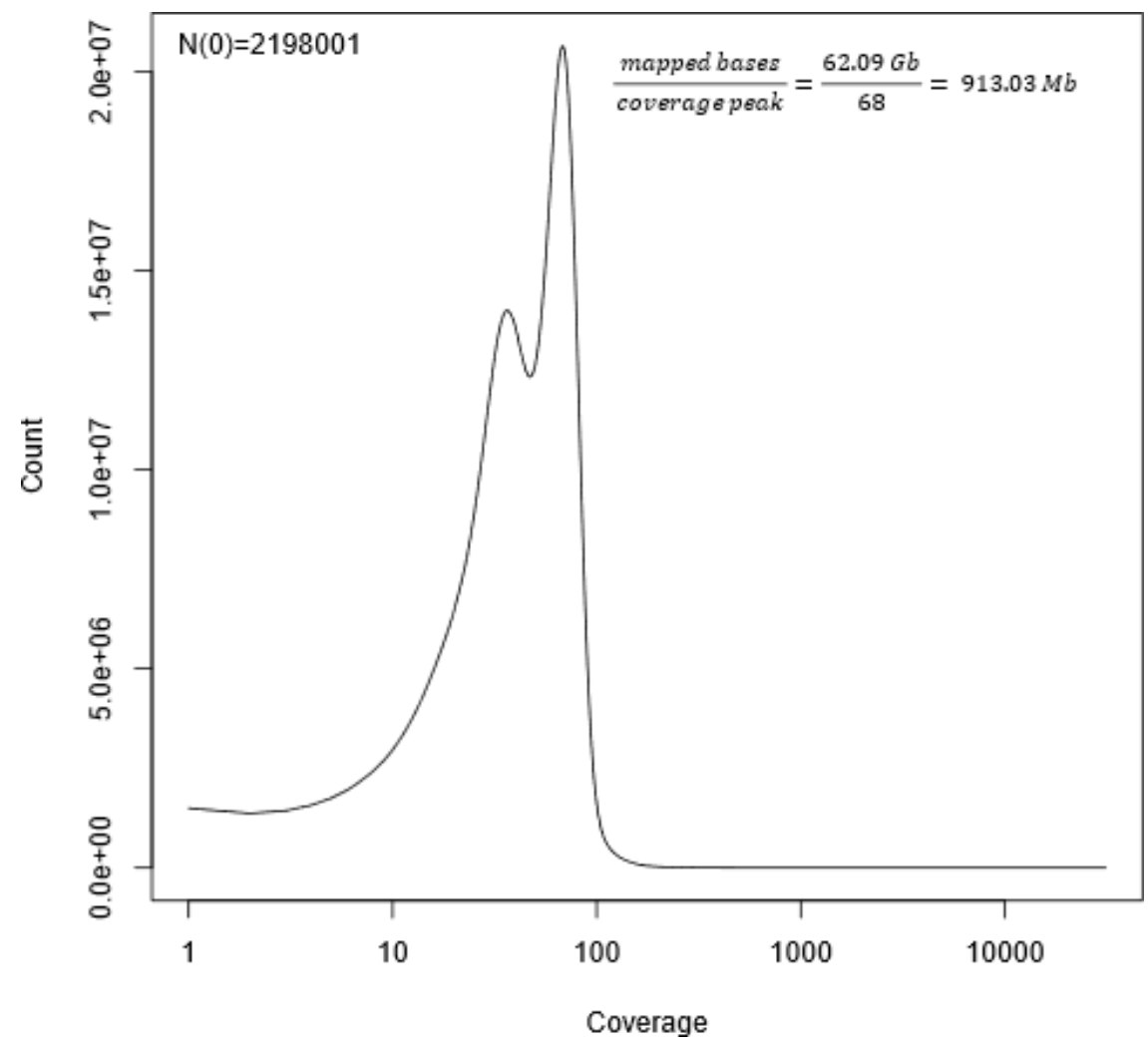

Fig. S68. Rhyacophila brunnea: Coverage distribution per position and genome size estimate from backmap.pl. The x-axis is given in log-scale. For details, see Supplementary Note 5. 


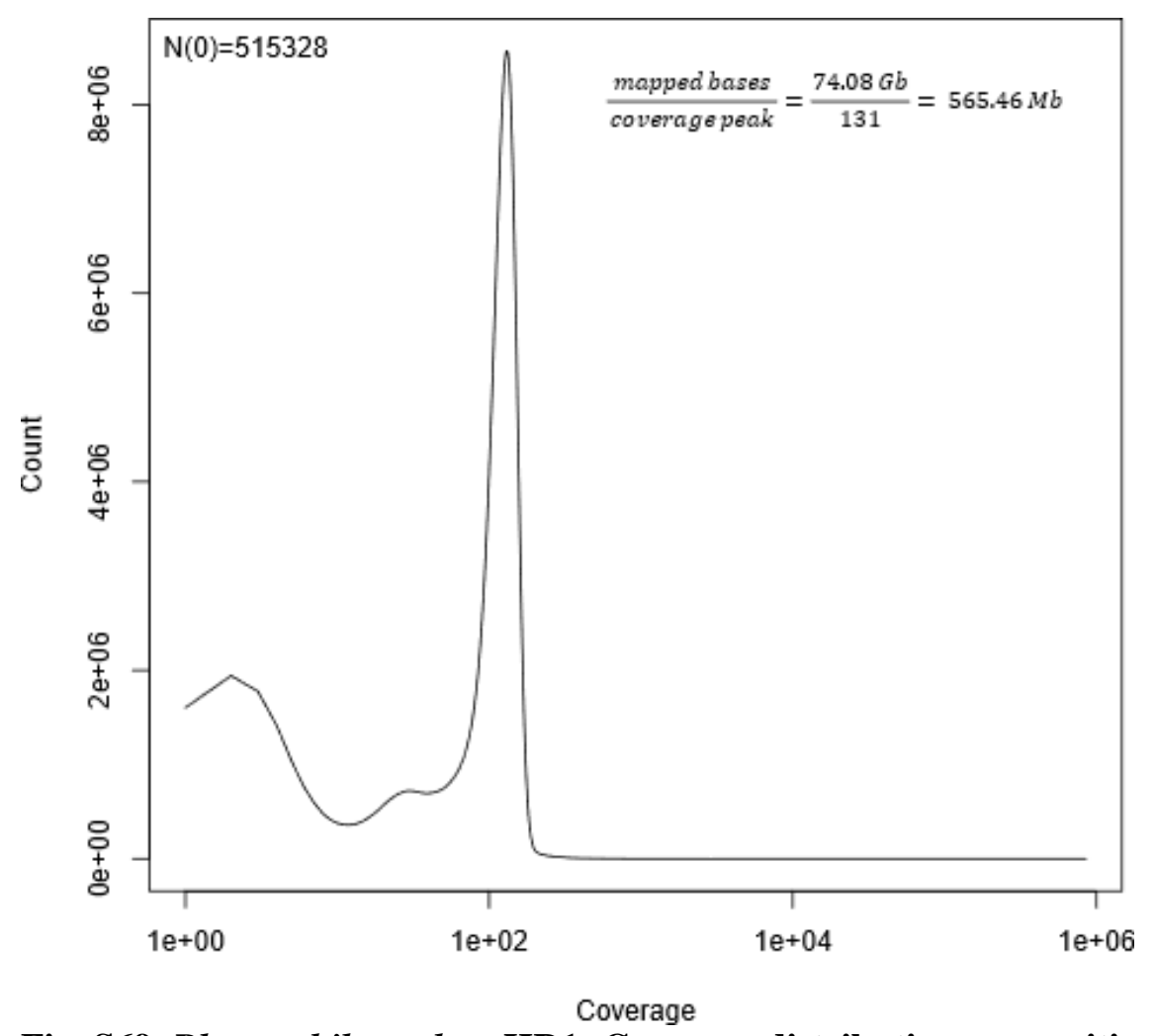

Fig. S69. Rhyacophila evoluta HR1: Coverage distribution per position and genome size estimate from backmap.pl. The x-axis is given in log-scale. For details, see Supplementary Note 5.

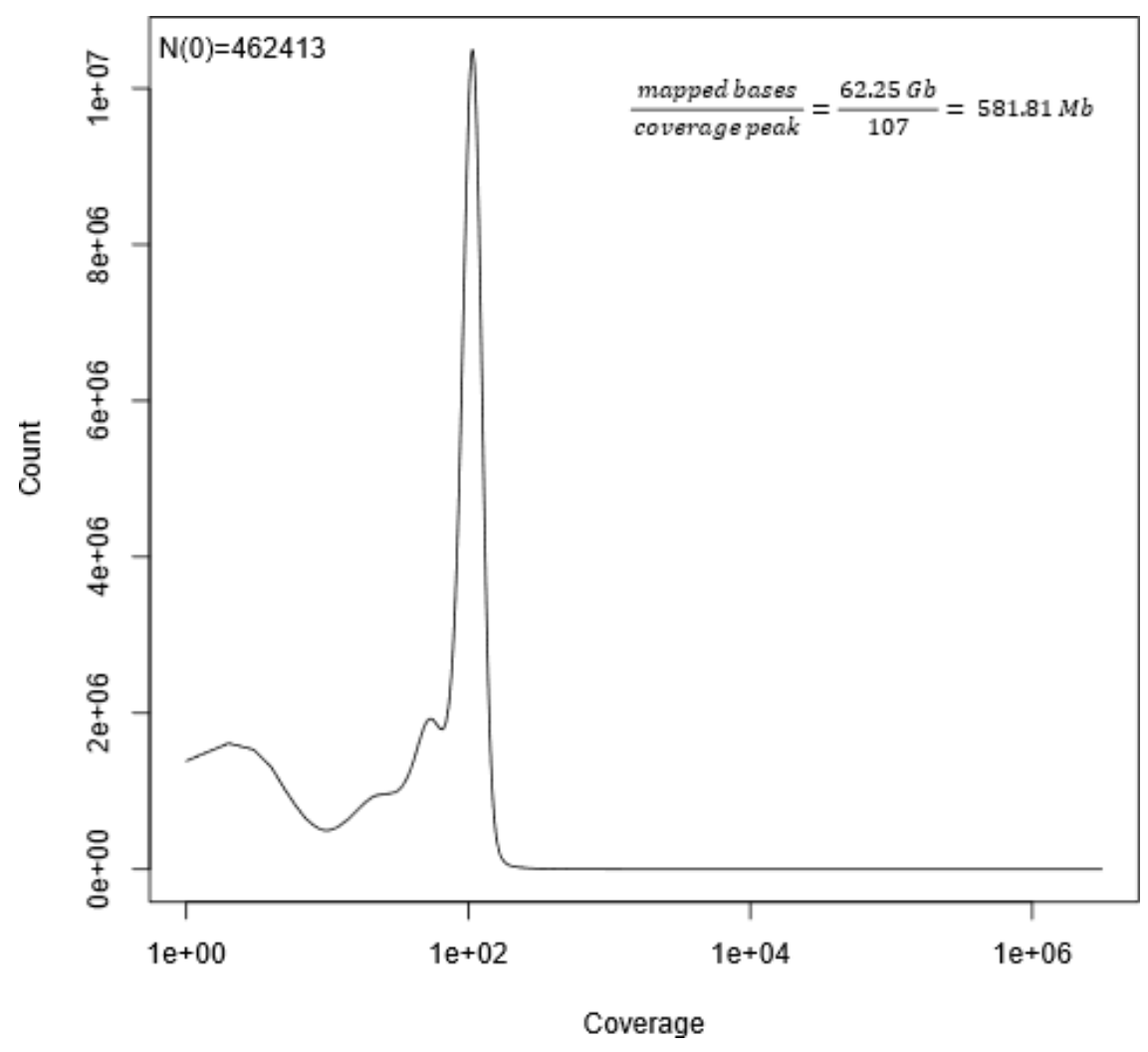

Fig. S70. Rhyacophila evoluta Rss1: Coverage distribution per position and genome size estimate from backmap.pl. The x-axis is given in log-scale. For details, see Supplementary Note 5. 


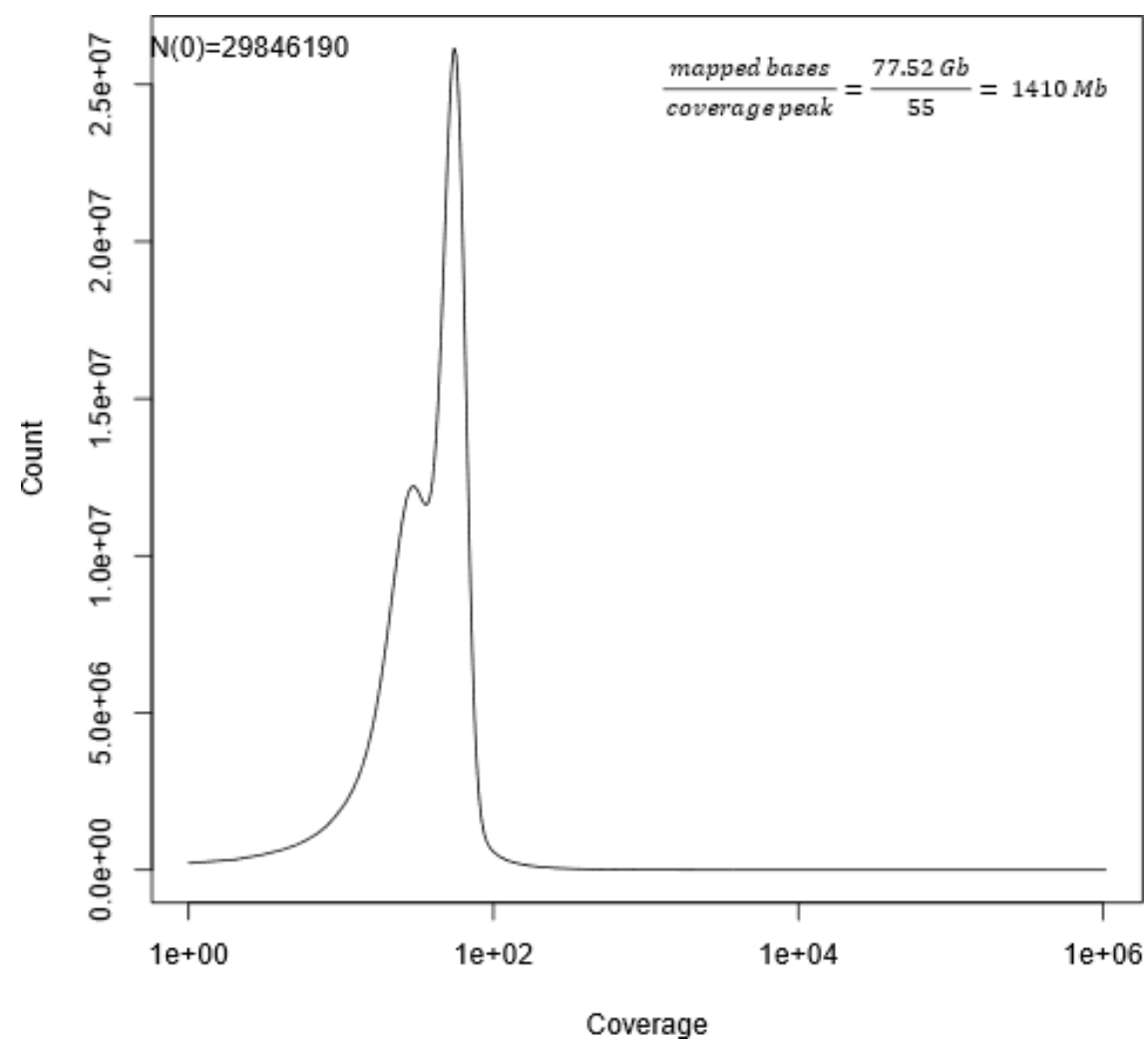

Fig. S71. Sericostoma sp.: Coverage distribution per position and genome size estimate from backmap.pl. The x-axis is given in log-scale. For details, see Supplementary Note 5.

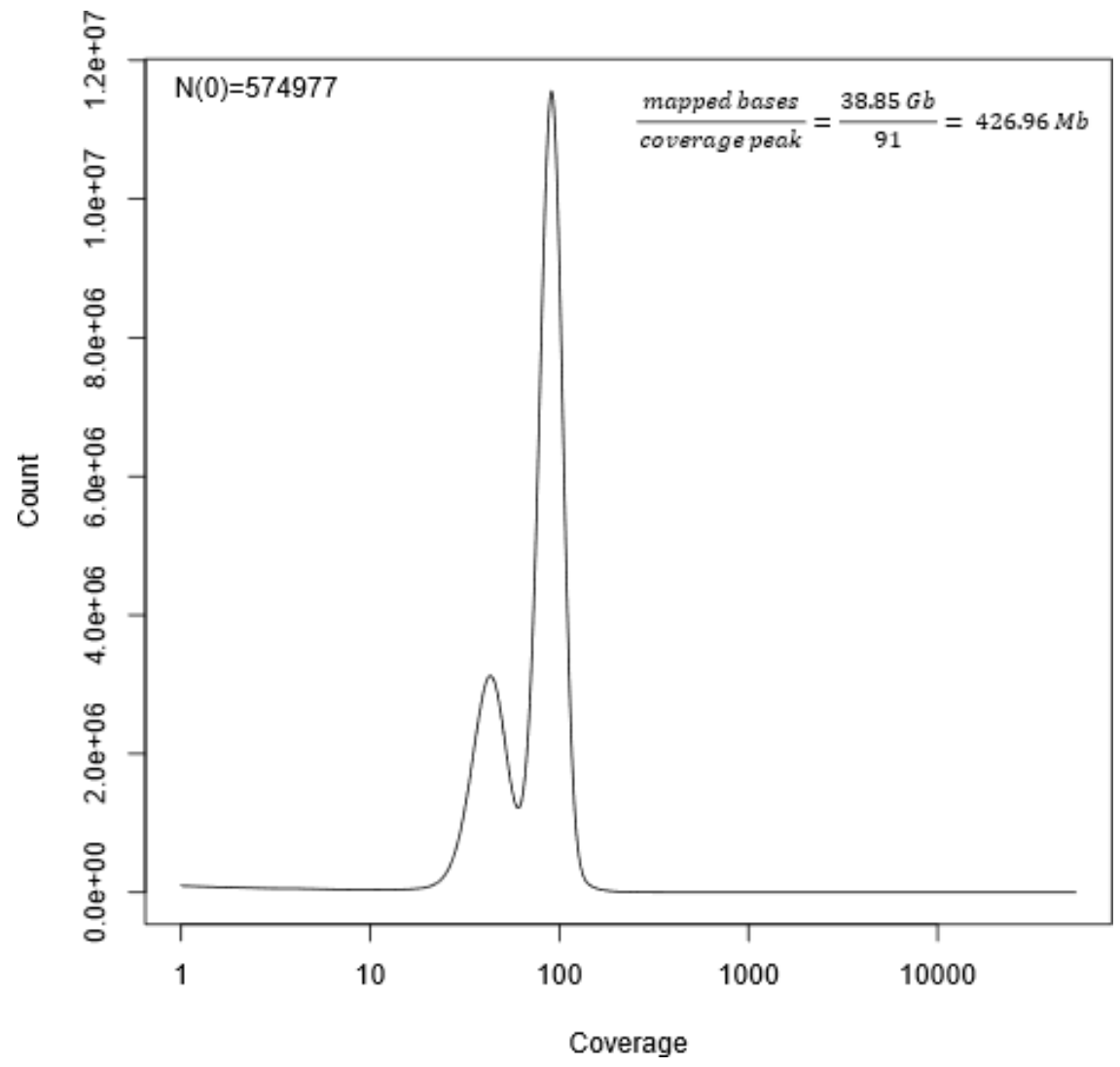

Fig. S72. Stenopsyche tienhuanesis: Coverage distribution per position and genome size estimate from backmap.pl. The x-axis is given in log-scale. For details, see Supplementary Note 5. 


\section{Supplementary note 8: Bland-Altman-Plots}

We assessed the comparability of agreement between the three quantitative methods of genome size measurement (Genomescope2, Backmap.pl and FCM; supplementary note 5) by conducting Bland-Altman-Plots using the function BlandAltmanLeh::bland.altman.plot in ggplot2 [30] in RStudio (RStudio Team (2020). RStudio: Integrated Development for R. RStudio, PBC, Boston, MA URL http://www.rstudio.com/;) as follows:

\#Bland-Altman-Plot: Genomescope2 vs. FCM

Genomescope2 <- c(222.82, 316.26, 463.24, 1103.37, 592.32, 918.70, 981.67, 642.96, $333.84,516.62,1238.19)$

FCM <- $\mathrm{c}(260.60,455.20,721.79,1616.01,840.20,1212.35,1434.71,663.60,588.81$, $651.30,1895.64)$

library(ggplot2)

BlandAltmanLeh::bland.altman.plot(Genomescope2， FCM, conf.int=.95, pch=19, main="Bland-Altman-Plot: Genomescope2 vs. FCM")

\#Bland-Altman-Plot: Genomescope2 vs. Backmap.pl

Genomescope 2<- c(232.92, 222.82, 316.26, 284.67, 389.48, 463.24, 495.47, 153.52, 1103.37, 592.32, 918.70, 1060.79, 1080.98, 981.67, 642.96, 333.84, 542.26, 931.69, 568.37, $770.82,516.62,1238.19)$

Backmap.pl <- c(265.71, 228.56, 364.91, 313.08, 426.96, 583.45, 562.18, 160.00, 1270.00, $684.34,972.29,1250.00,1230.00,1100.00,672.74,329.32,699.19,1120.00,623.79,913.03$, $573.64,1410.00)$

library(ggplot2)

BlandAltmanLeh::bland.altman.plot(Genomescope2, Backmap.pl, conf.int=.95, pch=19, main="Bland-Altman-Plot: Genomescope2 vs. Backmap.pl")

\#Bland-Altman-Plot: Backmap.pl vs. FCM

Backmap.pl<- c(228.56, 364.91, 583.45, 1270, 684.34, 865.38, 972.29, 1100, 672.74, 329.32, $573.635,1410)$

FCM <- c(260.60, 455.20, 721.79, 1616.01, 840.20, 1110.40, 1212.35, 1434.71, 663.60, $588.81,651.30,1895.64)$

library(ggplot2)

BlandAltmanLeh::bland.altman.plot(Backmap.pl, FCM, conf.int=.95, pch=19, main="BlandAltman-Plot: Backmap.pl vs. FCM") 
A

Bland-Altman-Plot: Genomescope2 vs, Backmap.pl

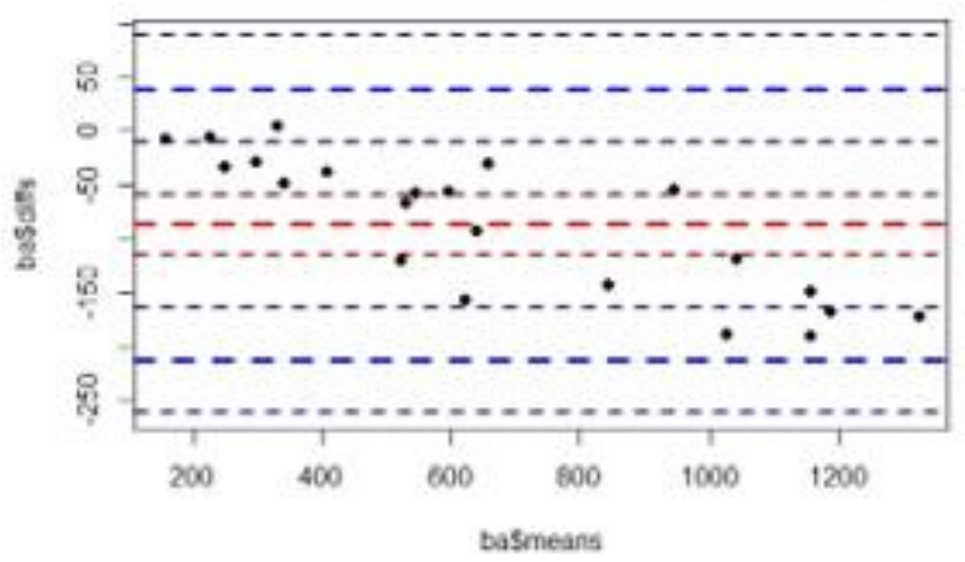

B

Bland-Aitman-Plot: Genomescope2 vs. FCM

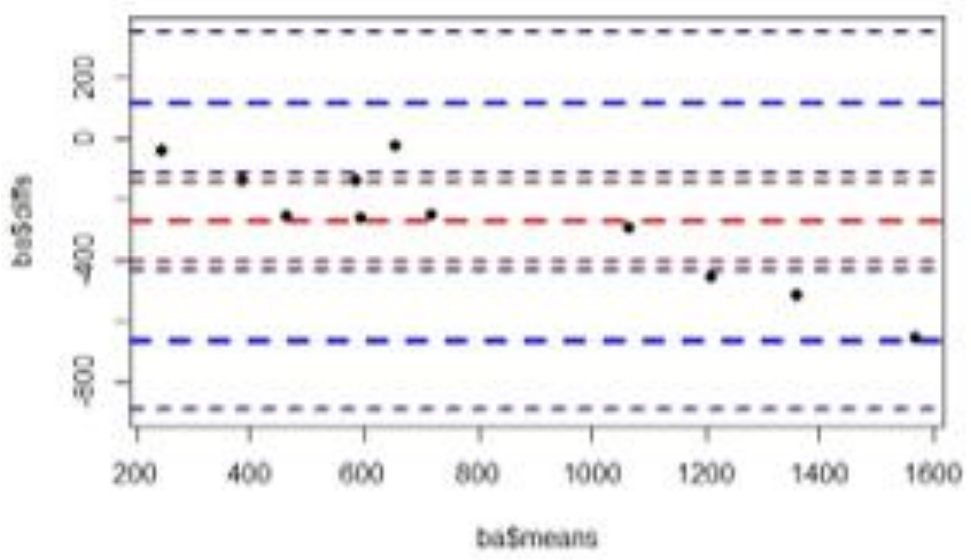

Bland-Altman-Plot: Backmap.pl vs. FCM

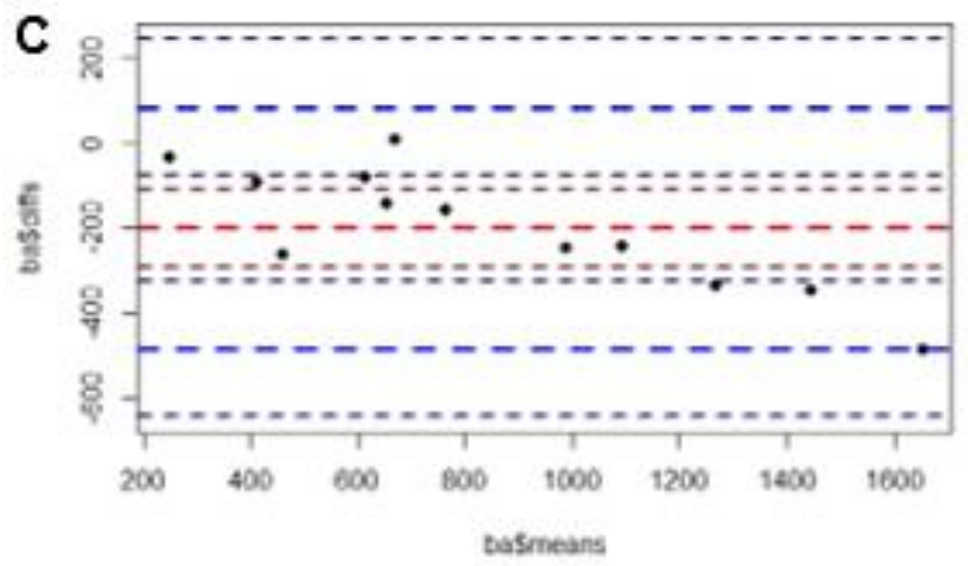

Fig. S73. Bland-Altman-Plots to test the comparability of agreement between the three quantitative methods of genome size measurement (Genomescope2, Backmap.pl and FCM; supplementary note 6). A: Genome size estimates obtained from Genomescope 2 were compared to the ones obtained from Backmap.pl; B:Genome size estimates obtained fromGenomescope 2 were compared to the ones obtained from FCM; C: Genome size estimates obtained from Backmap.pl were compared to the ones obtained from FCM. All three methods showed agreement. 


\section{Supplementary Note 9: Repeat abundance and classification based on reference-free analysis}

Our reference-free analysis of RE abundance (supplementary Fig. 2) showed results overall very consistent with our assembly-based approach, especially related to our major findings of LINE abundance and unclassified repeat abundance. This analysis also confirmed previous findings (Olsen et al. 2020) that satellite DNAs are not an abundant repeat class in trichopterans (average genome proportion $=1.56 \%$, $\mathrm{SD}=1.45 \%$ ). Four species [(Hydropsyche tenuis (HT), Hesperopylax magnus (HM), Limnephilus lunatus (LL), and Sericostoma sp. (SS)] had genomic proportions ranging from 3.0-5.1\% (whereas all trichopterans had $<1 \%$ in assembly-based estimates), but overall we do not find evidence that underestimates of satellite DNAs are a substantial source of error in our assembly-based repeat estimates. 
bioRxiv preprint doi: https://doi.org/10.1101/2021 05.10.443368; this version posted July 18, 2021. The copyright holder for this preprin (which was not certified by peer review) is the author/funder, who has granted bioRxiv a license to display the preprint in perpetuity. It is made available under aCC-BY-NC-ND 4.0 International license.

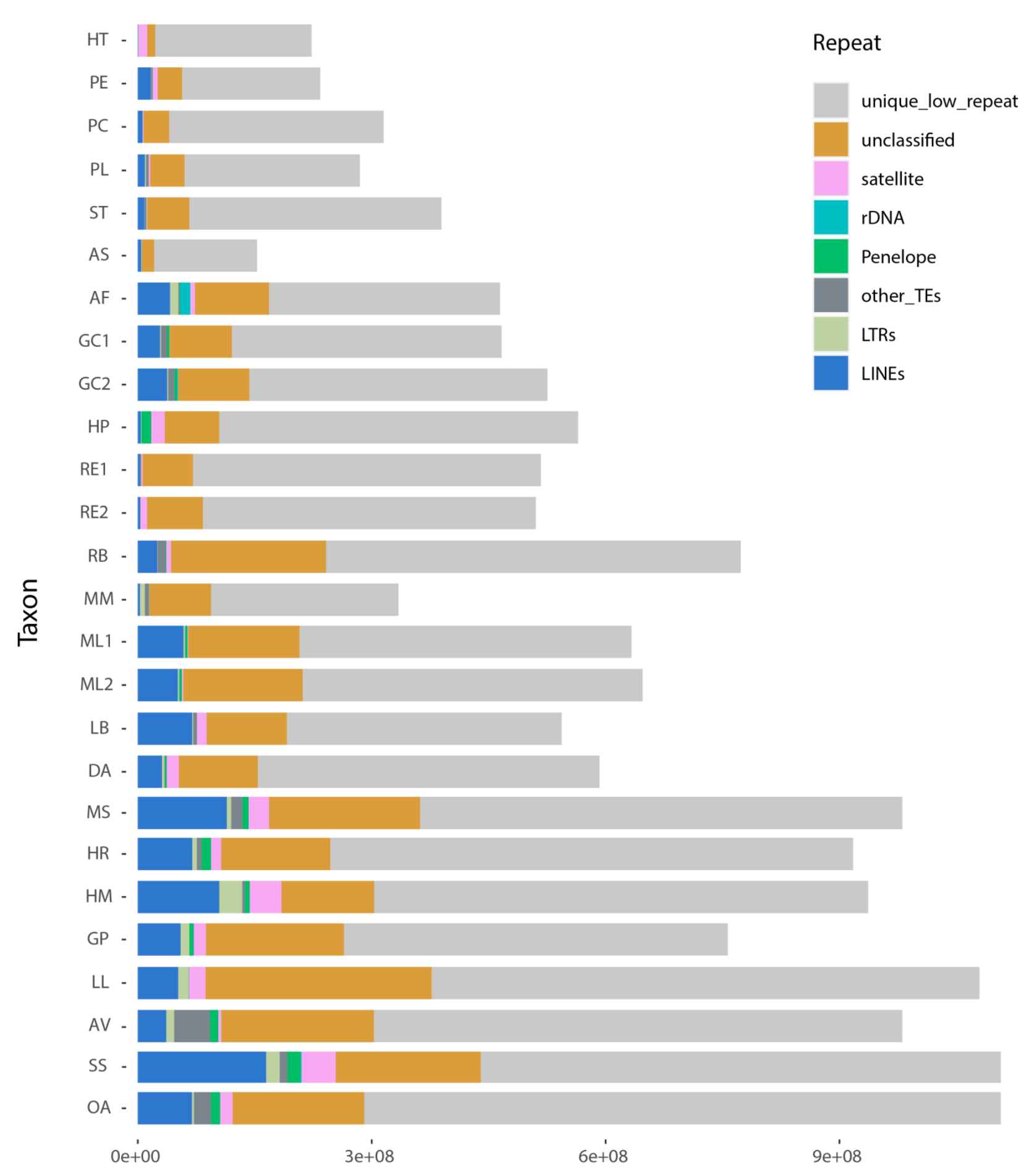

Reference-free Estimates of Repetitive Element Abundance

Estimated Assembly Size (bp)

Fig. S74. Repeat abundance summary from Repeat-Explorer 
bioRxiv preprint doi: https://doi.org/10.1101/2021.05.10.443368; this version posted July 18, 2021. The copyright holder for this preprint (which was not certified by peer review) is the author/funder, who has granted bioRxiv a license to display the preprint in perpetuity. It is made available under aCC-BY-NC-ND 4.0 International license.
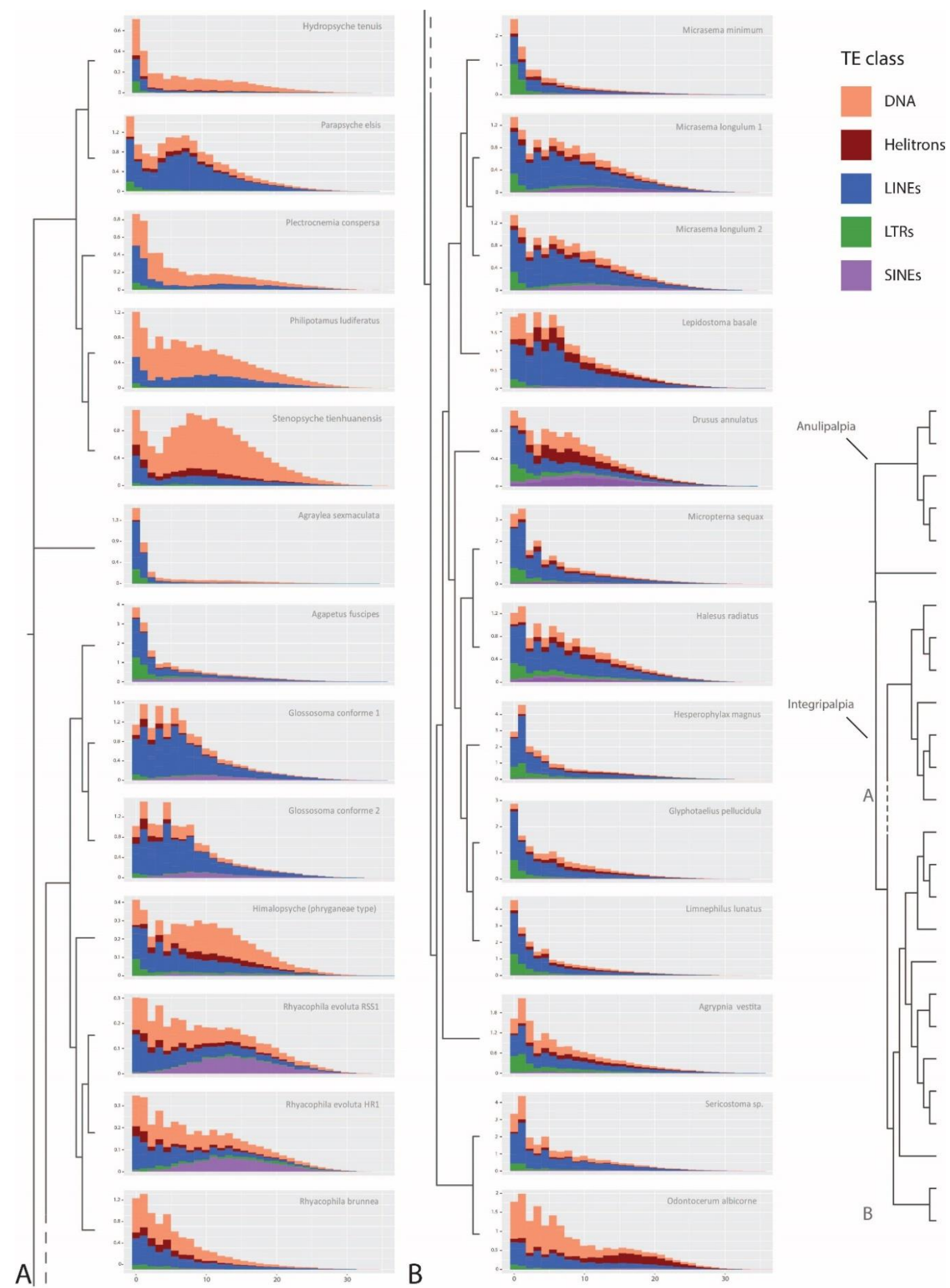

Fig. S75. Transposable element age distribution landscapes. The y-axis shows TE abundance as a proportion of the genome (e.g., $1.0=1 \%$ of the genome). The $\mathrm{x}$-axis shows sequence divergence relative to TE consensus sequences for major TE classes. TE classes with abundance skewed toward the left (i.e., low sequence divergence) are inferred to have a recent history of diversification relative to TE classes with right-skewed abundance. Plots were generated in dnaPipeTE [31]. For tip labels of the phylogenetic tree see Fig. 2. 


\section{Supplementary Note 10: TE sequence association with protein-coding genes}

During the early exploration of our sequence data we noted that copy number profiles of some BUSCO genes showed regions of unexpected high copy number with the frequency of such genes varying widely across species. Following this observation we analyzed repeat dynamics of all BUSCO genes for all species to quantify the abundance of repetitive BUSCOs across samples and test two alternative hypotheses that could account for the observed patterns: (1.) inflated copy-number of BUSCO gene fragments occur at sequences of repetitive elements (e.g., TEs) inserted into genes; (2.) inflated regions are BUSCO gene fragments that have proliferated throughout the genome (e.g., by hitch-hiking with TEs. This analysis also allowed us to quantify shifts in associations between TEs and genic regions across Trichoptera lineages with varying repeat abundance.

We tested for a general correlation between BUSCO repeat abundance and the abundance and major RE categories using Pearson's correlation in R v4.0.2. To gain more detailed insight, we generated copy number profiles of all Endopterygota BUSCO genes (OrthoDB v.9) for all study species using RepeatProfiler [32]. We quantified the abundance of BUSCOs with repetitive fragments by identifying BUSCO genes with coverage peak that exceeded $20 \mathrm{X}$ average coverage for all BUSCO genes in that species. Average coverage was calculated by averaging coverage depth of all BUSCO genes after excluding the top and bottom $15 \%$ when sorted by max coverage which eliminated 0-coverage and unexpectedly high-coverage BUSCOs from the calculation. After producing a BLAST database from each genome assembly using the application makeblastdb in ncbi-blast 2.10.0 [33] applying the parameters -dbtype nucl, -parse_seqids_blastdb, -blastdb_version5, we quantify the genomic abundance of bases in repetitive BUSCOs by using each repetitive BUSCO as a query in a BLAST (blastn) search against the genome assembly with the following settings: outfmt 6, max_target_seqs 50000. We allowed 50K hits based on the maximum coverage of repetitive BUSCOS observed in profiles. We used the perl script rmOutToGFF3.pl from RepeatMasker to convert the Repeatmasker OUT files from each Repeatmasker run to version 3 to gff files containing the RepeatMasker hints. We reclassified the repeats in the gff3 files with custom scripts, concatenated the two RepeatMasker runs of each species and sorted the resulting file using bedtools.

We used custom scripts to parse BLAST output, collapse hits with overlapping coordinates and extract coordinates of filtered hits. For each unique BLAST hit, we then asked whether it mapped to masked or unmasked coordinates in the assembly by cross-referencing the 
coordinates of BLAST hits against a gff file containing RepeatMasker annotations using the 'intersect' function in BEDTools. We also used custom scripts to calculate the total number of bases in filtered BLAST after subtracting the number of bases at the locus belonging to all 'complete' BUSCO genes, and to categorize BUSCO repeats based on their annotation status and repeat classification. We plotted the number of BUSCO repeats belonging to repetitive element categories (i.e., classes and subclasses) alongside plots of the relative genomic abundance of each respective category.

To test whether repetitive fragments are due to TE insertions or to proliferation of true BUSCO gene fragments we examined patterns of BUSCO gene structure in pairwise alignments of species in which one species has a repetitive fragment (i.e., the "inflated" species) and its counterpart does not (i.e., the "reference" species). To reduce the likelihood that indels due to sequence divergence (i.e., not due to REs) would complicate the analysis we conducted this test with three pairs of closely related species: Micrasema longulum and Micrasema minimum; Rhyacophila brunnea and Rhyacophila evoluta; and Hesperophylax magnus and Halesus radiatus. We predicted that if repetitive regions were due to $\mathrm{RE}$ sequence insertion (i.e., Hyp1 above) that inflated species would show indels at coordinates of repetitive fragments relative to reference species. If repetitive regions were due to proliferation of true BUSCO sequence (i.g., Hyp2 above) we predicted that alignments would be contiguous over the repetitive region. We further tested this prediction by taking the set of BUSCOs that are only repetitive in the inflated species and contrasted results of two BLAST searches followed by an intersect analysis. First, we used BLAST to compare the repetitive BUSCOs taken from the inflated species against the genome assembly of the inflated species and quantified the number of bases in hits that mapped to annotated repeats in the assembly. We then used BLAST to compare the same set of BUSCOs taken from the reference species against the inflated species and quantified the number of bases in hits that mapped to annotated repeats in the assembly. We predicted that if repetitive BUSCOs were due to TE insertions, that our first BLAST search would show a disproportionate number of hits that mapped to regions annotated as RE, and that when we repeated the search using orthologous BUSCOs taken from the reference sequences as queries, the number of hits belonging to annotated REs would drop substantially. We used the bedtools "intersect" function to determine the number of bases in BLAST hits that overlapped with RE annotations after merging duplicate coordinates in the BLAST output. 


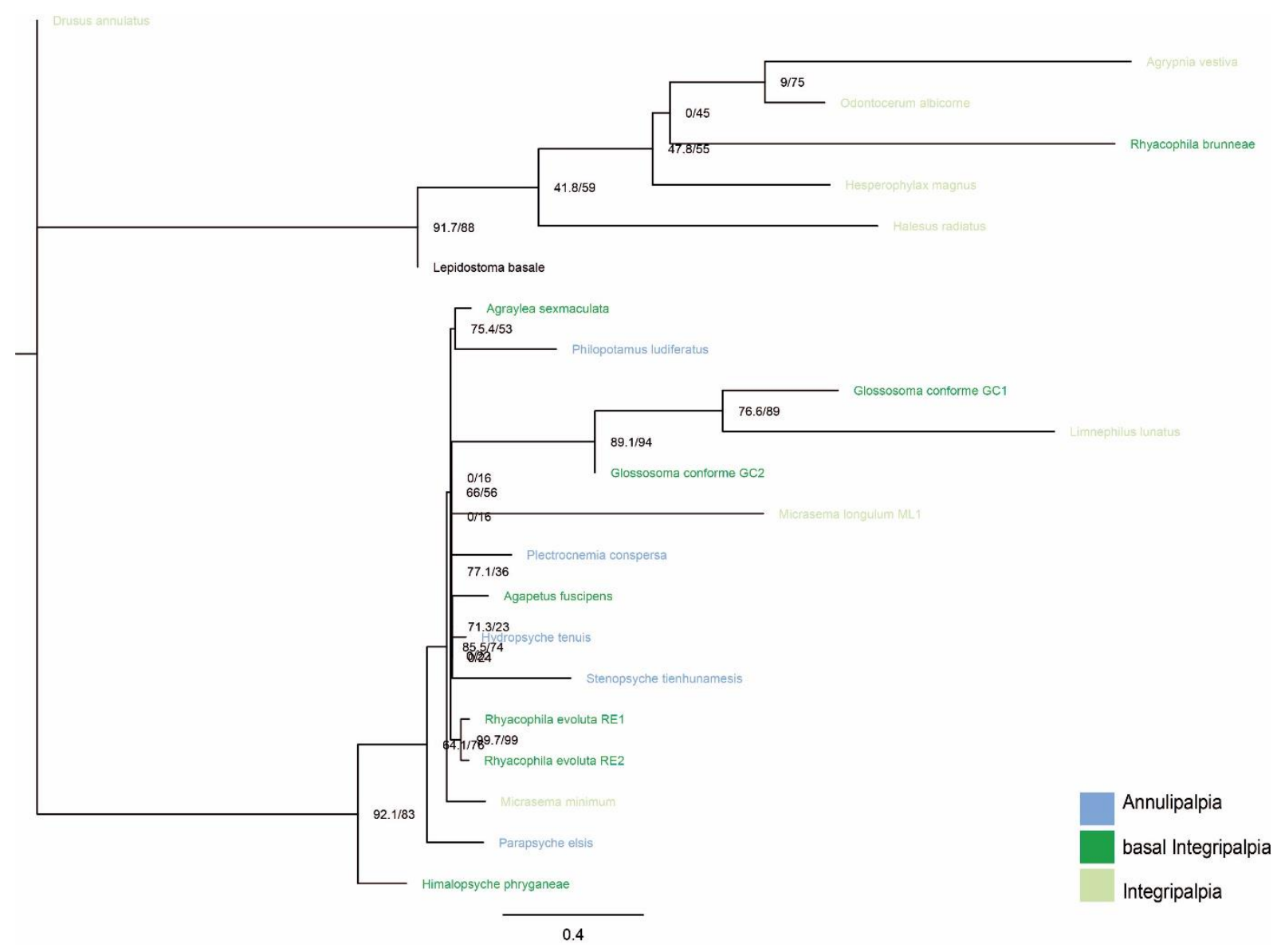

Fig. S76. Presence and absence of repetitive BUSCOs. We conducted a binary tree search using the presence/absence matrix of repetitive BUSCOs for each specimen, in which each of the $\sim 2000$ Endopterygota BUSCO genes were coded as 'repetitive' or 'non-repetitive' for 22 of the 26 study species (MS, ML2, GP, and were excluded due missing data) and analyzed as phylogenetic characters (Appendix 2). The overall lack of phylogenetic congruence with known phylogenetic relationships, especially in deep nodes, suggests high levels of homoplasy in the repetitive BUSCO data set. Some expected relationships are recovered with high support (e.g. both specimens of Rhyacophila evoluta and Glossosoma conforme are in well-supported clades, though the latter is interrupted by the placement of Limnephilus lunatus which occurs on a notably long branch). Several 'case-making' Integripalpia, including five of the six species with the most abundant repetitive BUSCOs (Fig. 4), also form a well-supported clade that generally mirrors phylogenetic relationships except for the placement of one basal Integripalpia (Rhyacophila brunnea, the basal Integripalpia with by far the most repetitive BUSCOs (Fig. 4)) on a long branch. Finding high levels of homoplasy in the repetitive BUSCO data set suggests the rate of evolution among repetitive BUSCOs is fast, a conclusion which is consistent with the results of TE landscape plots (Fig. S 4). 
Bases in Repetitive BUSCO BLAST hits x Genomic Abundance of Repeat Categories
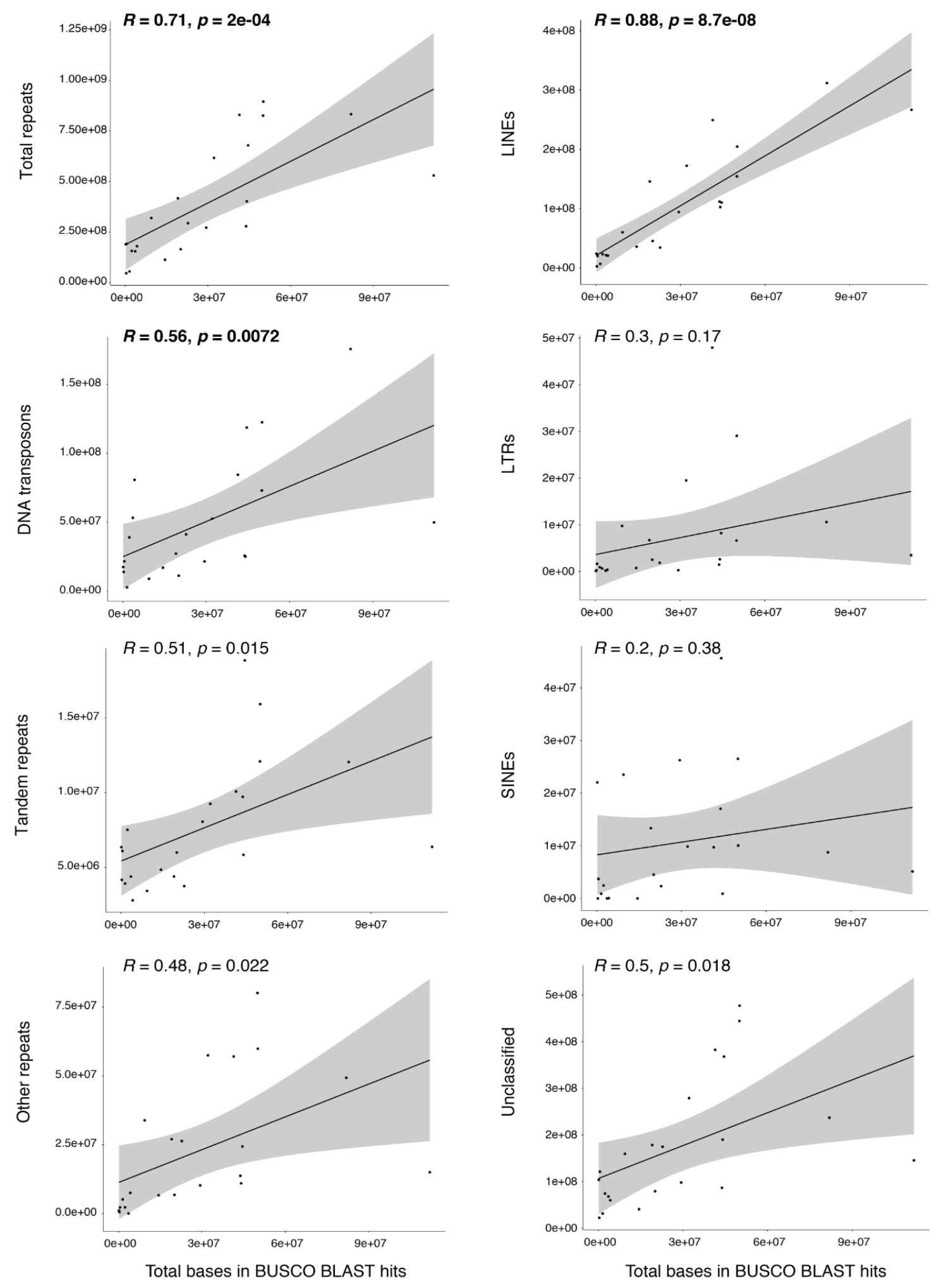

Fig. S77. Correlations between bases in repetitive BUSCO BLAST hits and genomic abundance of repeat categories. We investigated interactions between TEs and genic sequences by quantifying the abundance of repetitive sequences found within or adjacent to BUSCO genes. We found major expansion of repetitive BUSCO genes fragments that are significantly correlated with total repeat abundance, as well as the genomic proportion of LINEs and DNA transposons. 


\section{Supplementary Note 11:}

Because genome assemblies varied in contiguity, we conducted a variety of additional analyses to ensure that assembly quality is unlikely to cause artefacts during the analyses that would impact our conclusions. To test the robustness of our conclusions related to classification and abundance of transposable elements (TEs), we analyzed TE composition using both an assembly-based approach with RepeatMasker, as well as a short-read-based reference-free approach using RepeatExplorer2. We observe congruent patterns in the abundance of major repeat categories and unclassified repeat abundance with both methods (see Fig. S3 vs. Fig. 2 in main text). Another comparison that strengthens confidence in our TE-based analyses comes from the two species for which we included two replicates of conspecific individuals. Despite different assembly quality we observe high congruence in repeat annotation and abundance across replicate individuals (see Fig. S4 and Fig. 2 in main text: G. conforme 1 vs. G.conforme 2; M. longulum 1 vs. M. longulum 2).

Another area for which we considered the potential impact of assembly quality on our conclusion was the TE-gene association study. We quantified sequences that are incorrectly classified as BUSCOs, which we refer to as "repetitive BUSCOs". These repetitive BUSCOs are frequently associated with the presence of TE sequences occurring adjacent to BUSCO. One line of evidence that suggests assembly artefacts are not driving the pattern of increasing repetitive BUSCOs with increasing assembly size is the fact that in less contiguous assemblies we found notably fewer repetitive BUSCOs (including in replicate conspecifics with varying assembly quality), such that we could not justify including the four samples of lowest assembly quality in the full analysis. If assembly artefacts in low-quality assemblies were driving the abundance of repetitive BUSCOs we would have expected to find an increase of repetitive BUSCOs with decreasing assembly quality. To further test whether assembly artefacts might be driving the abundance of repetitive BUSCOs in more subtle ways, we 
mapped Nanopore reads back to an exemplary subset of repetitive BUSCOs to test whether junctions between repetitive BUSCOs and non-repetitive regions are embedded in full reads. For this purpose, we looked at repetitive BUSCOs from Hesperophylax magnus. More specifically, we extracted all Nanopore reads >= $10 \mathrm{kbp}$ sequenced of this specimen and mapped them back to the assembly of $H$. magnus. We converted the resulting sam file to a bam file with samtools and retained only reads which mapped in the alignment using samtools "view" -b -F 4. After sorting and indexing the sam file with samtools "sort" and "index" functions, the resulting bam file was imported to IGV together with the genome assembly. In IGV, we zoomed into the regions of interest (repetitive BUSCOs and flanking regions) which are given in Table S1. Figs. S1-S10 show A) the repetitive regions in the BUSCO gene with the flanking region and $\mathrm{B}$ ) repetitive regions in the BUSCO gene. Junctions between repetitive BUSCOs and non-repetitive regions are embedded in full reads and do not occur disproportionately at ends of reads. This test corroborates our conclusion that the TE sequences associated with "repetitive BUSCOs" do in fact represent valid TE-gene associations and not simply assembly artefacts.

\begin{tabular}{|l|l|l|l|}
\hline BUSCO & scaffold_extract & rep_scaff_start & rep_scaff_end \\
\hline EOG090R0A7C & >scaffold_868:201955-232310 & 220705 & 220814 \\
\hline EOG090R0A26 & >scaffold_89:2596962-2639655 & 2625525 & 2625615 \\
\hline EOG090R0AIP & >scaffold_6928:157581-209457 & 198718 & 199773 \\
\hline EOG090R0B6S & >scaffold_6701:1555973-1588111 & 1573592 & 1574053 \\
\hline
\end{tabular}




\begin{tabular}{|l|l|l|l|}
\hline EOG090R0BAL & >scaffold_1750:91532-114236 & 107561 & 107609 \\
\hline EOG090R0BV8 & >scaffold_5384:414318-454283 & 429002 & 429191 \\
\hline EOG090R0D3M & >scaffold_264:638549-690392 & 679193 & 679608 \\
\hline EOG090R0D5K & >scaffold_2906:96588-135291 & 125160 & 125249 \\
\hline EOG090R0DJA & >scaffold_5579:100801-141491 & 111993 & 112328 \\
\hline EOG090R0DQF & >scaffold_396:386030-431740 & 406547 & 406614 \\
\hline
\end{tabular}

Table S1: Ten BUSCOs of Hesperophylax magnus, their location in the genome and the start and end of the repetitive region.

Fig. S78: BUSCO EOG090R0A7C in IGV.

A: scaffold_868:201955-232310; B: scaffold_868:220705-220814 
bioRxiv preprint doi: https://doi org/10.1101/2021 05.10.443368. this version posted July 18,2021 . The copyright holder for this preprint (which was not certified by peer review) is the author/funder, who has granted bioRxiv a license to display the preprint in perpetuity. It is made available under aCC-BY-NC-ND 4.0 International license.

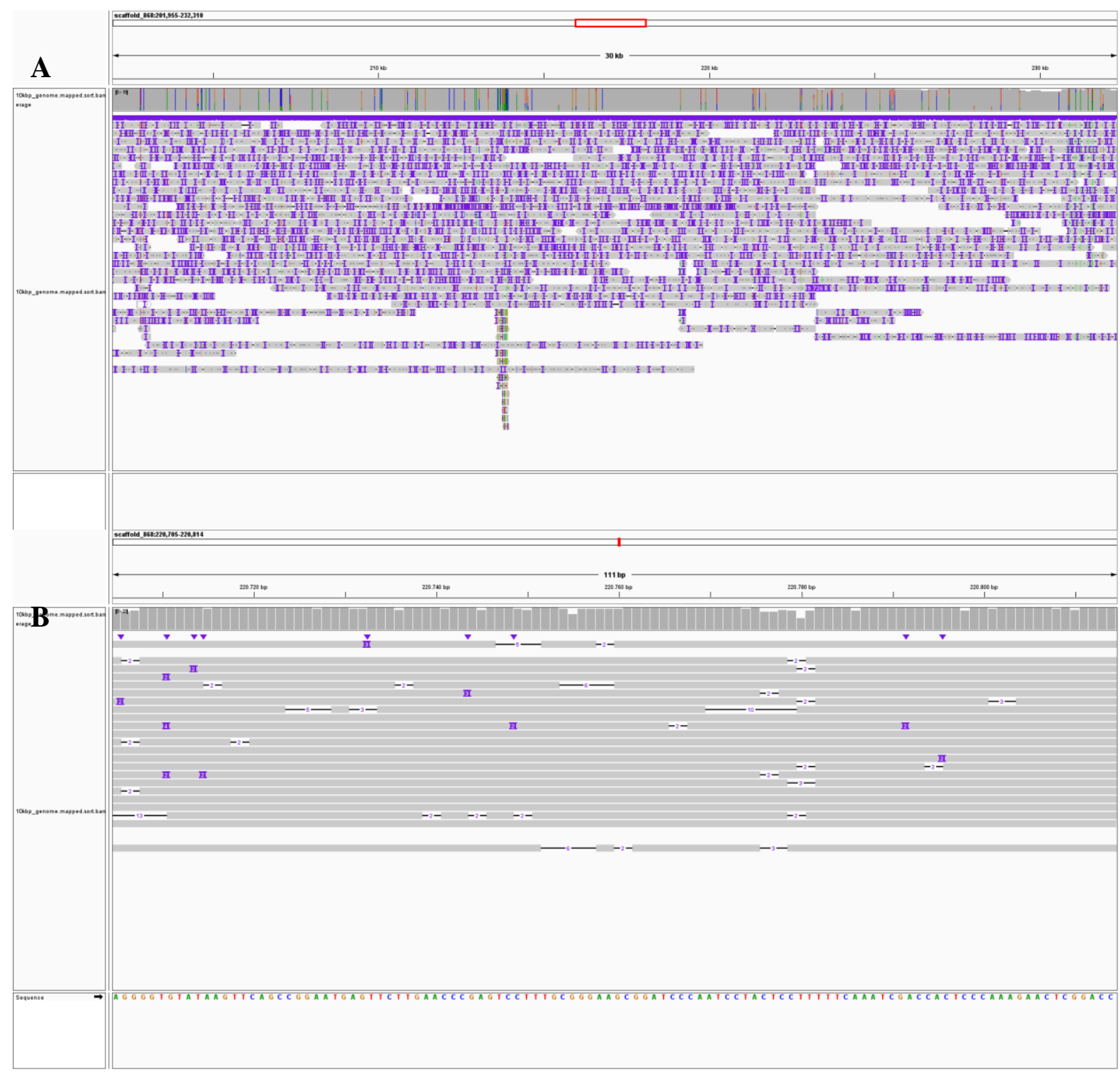

Fig. S79: BUSCO EOG090R0A26.

A: scaffold_89:2596962-2639655; B: scaffold_89: 2625525-2625615 
bioRxiv preprint doi: https://doi org/10.1101/2021 05.10.443368. this version posted July 18,2021 . The copyright holder for this preprint (which was not certified by peer review) is the author/funder, who has granted bioRxiv a license to display the preprint in perpetuity. It is made available under aCC-BY-NC-ND 4.0 International license.

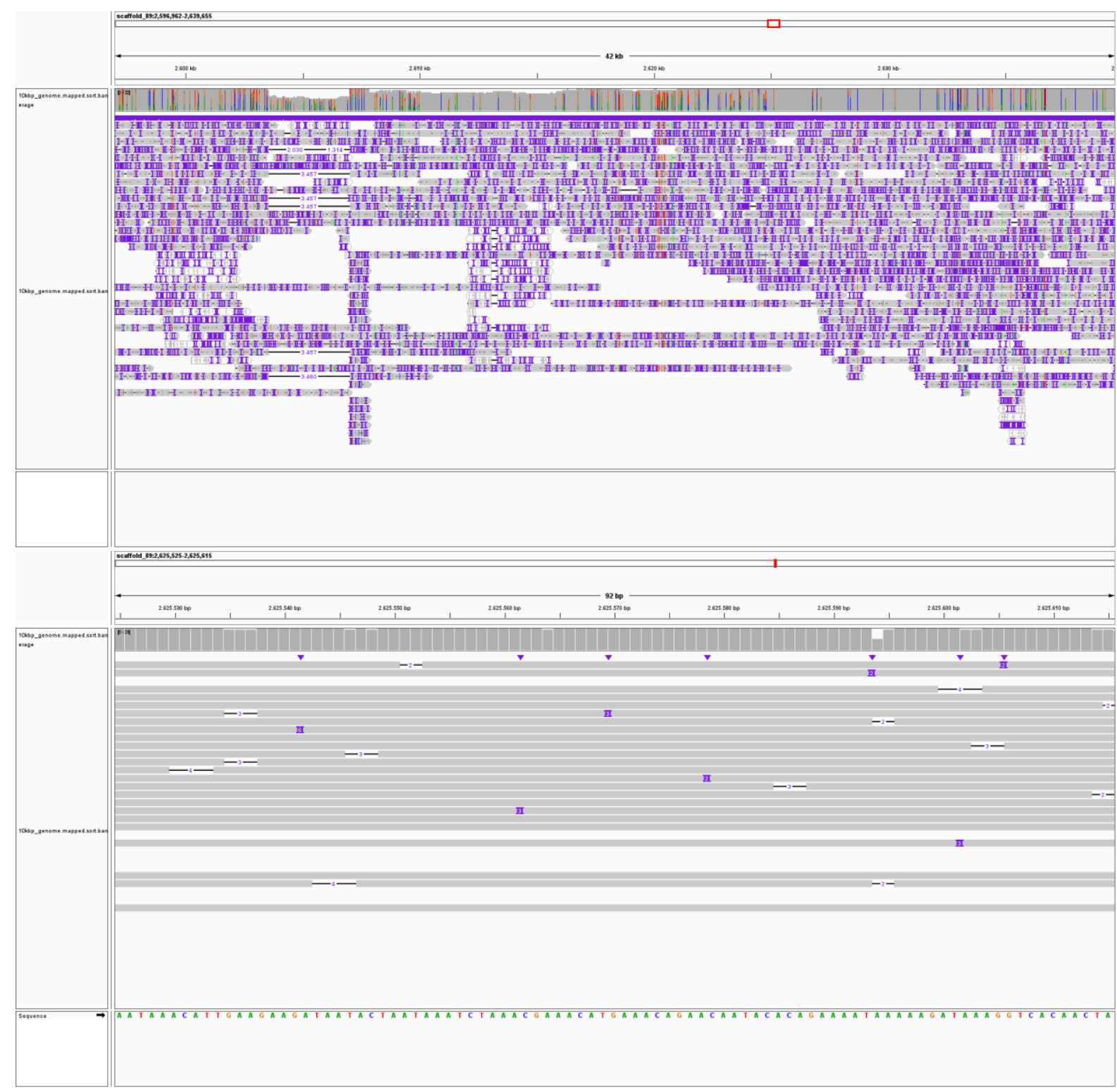

Fig. S80: BUSCO EOG090R0AIP in IGV.

A: scaffold_6928:157581-209457; B: scaffold_6928: 198718-199773 
bioRxiv preprint doi: https://doi org/10.1101/2021.05.10.443368. this version posted July 18,2021 . The copyright holder for this preprint (which was not certified by peer review) is the author/funder, who has granted bioRxiv a license to display the preprint in perpetuity. It is made available under aCC-BY-NC-ND 4.0 International license.

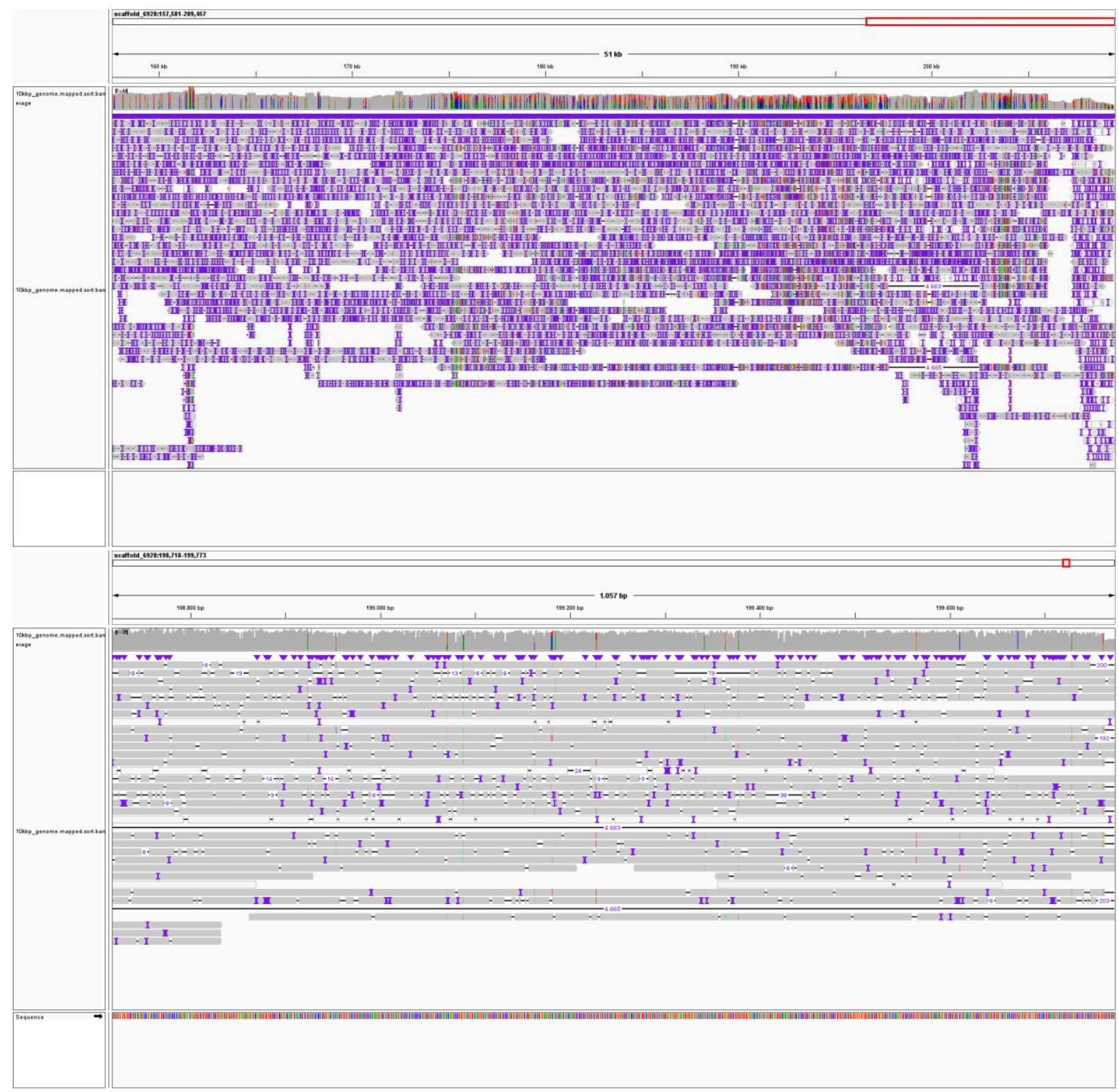

Fig. S81: BUSCO EOG090R0B6S in IGV.

A: scaffold_6701:1555973-1588111; B: scaffold_6701: 1573592-1574053 
bioRxiv preprint doi: https://doi org/10.1101/2021 05 10.443368. this version posted July 18,2021 . The copyright holder for this preprint (which was not certified by peer review) is the author/funder, who has granted bioRxiv a license to display the preprint in perpetuity. It is made available under aCC-BY-NC-ND 4.0 International license.

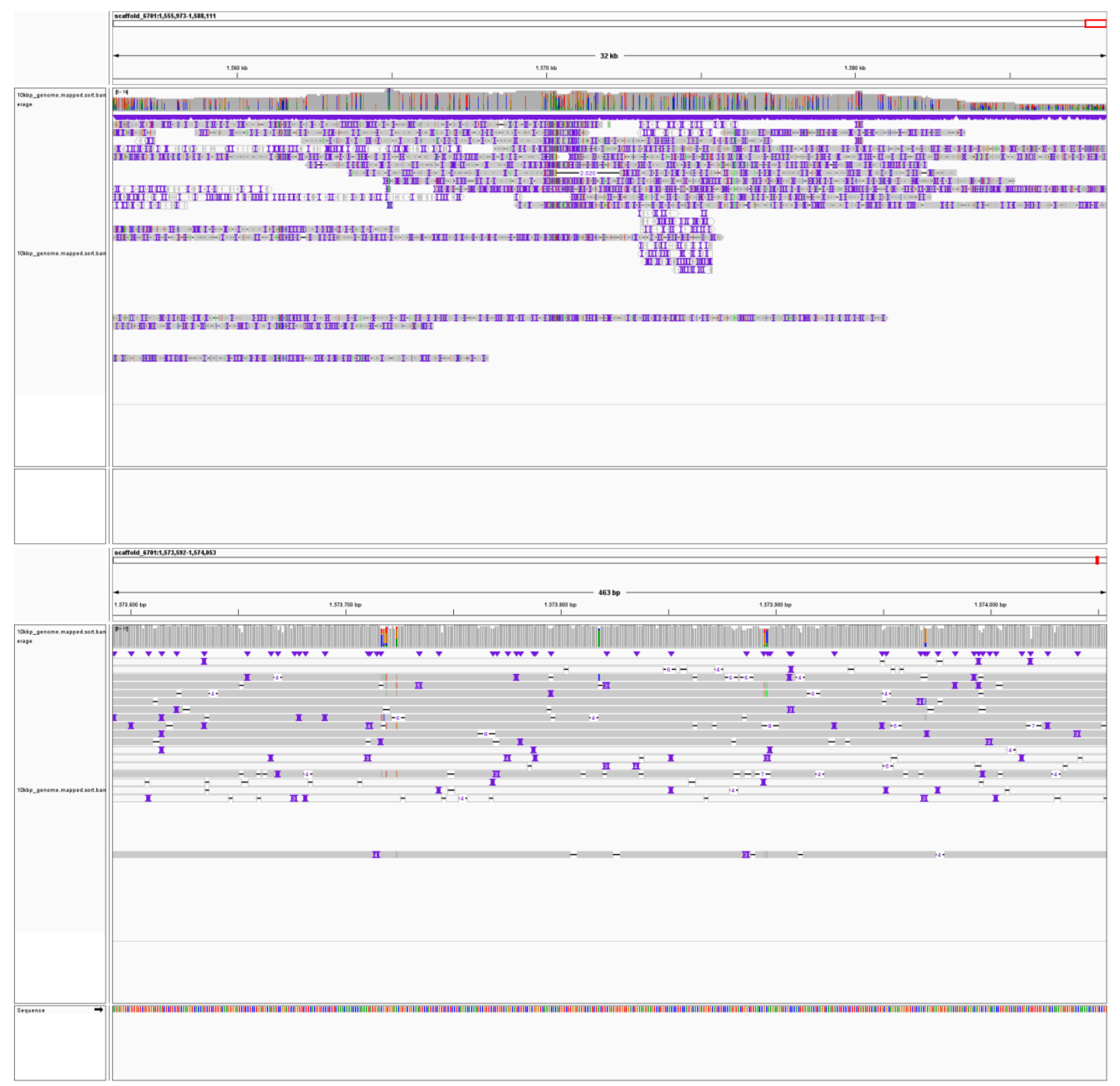

Fig. S82: BUSCO EOG090R0BAL in IGV.

A: scaffold_1750:91532-114236; B: scaffold_1750: 107561-107609 
bioRxiv preprint doi: $h$ ttps://doi. org/10.1101/2021.05.10.443368; this version posted July 18,2021 . The copyright holder for this preprint (which was not certified by peer review) is the author/funder, who has granted bioRxiv a license to display the preprint in perpetuity. It is made available under aCC-BY-NC-ND 4.0 International license.

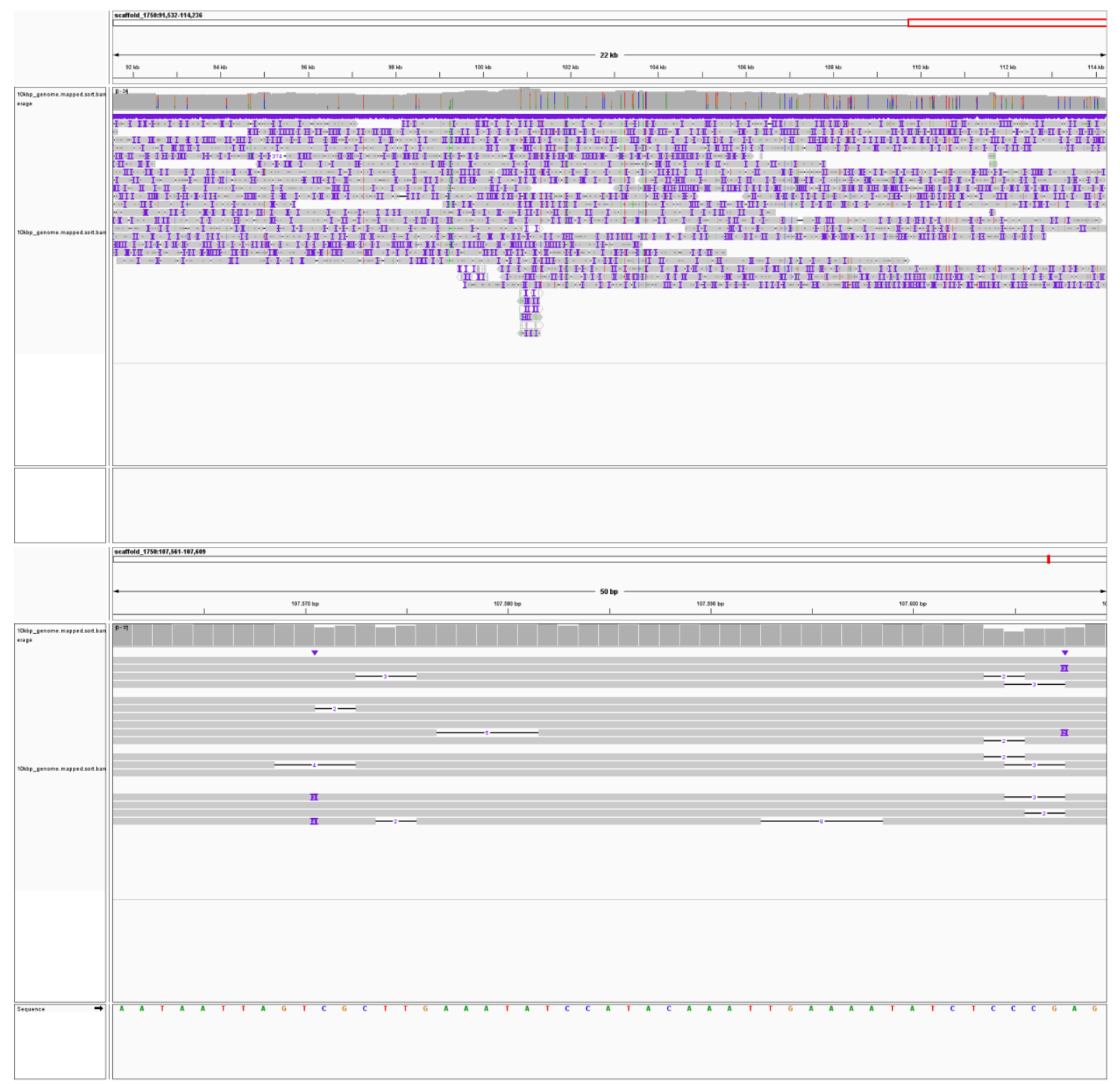

Fig. S83: BUSCO EOG090R0BV8 in IGV.

A: scaffold_5384:414318-454283; B: scaffold_5384: 429002-429191 
. 10.443368 ; this version posted July 18,2021 . The copyright holder for this preprint (which was not certified by peer review) is the author/funder, who has granted bioRxiv a license to display the preprint in perpetuity. It is made available under aCC-BY-NC-ND 4.0 International license.

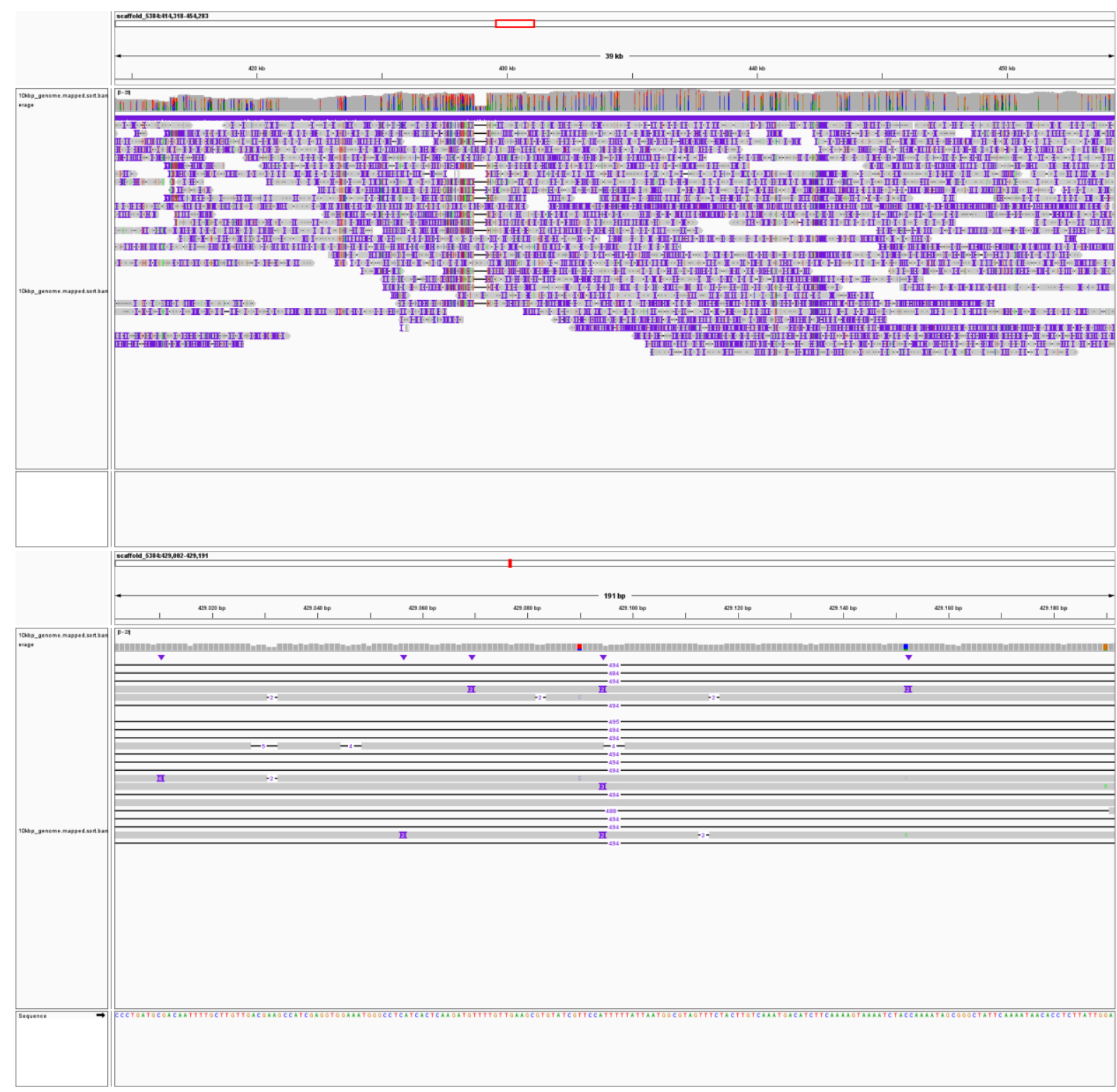

Fig. S84: BUSCO EOG090R0D3M in IGV.

A: scaffold_264:638549-690392; B: scaffold_264: 679193-679608 
bioRxiv preprint doi: https://doi org/101101/2021 05.10.443368; this version posted July 18,2021 . The copyright holder for this preprin (which was not certified by peer review) is the author/funder, who has granted bioRxiv a license to display the preprint in perpetuity. It is made available under aCC-BY-NC-ND 4.0 International license.

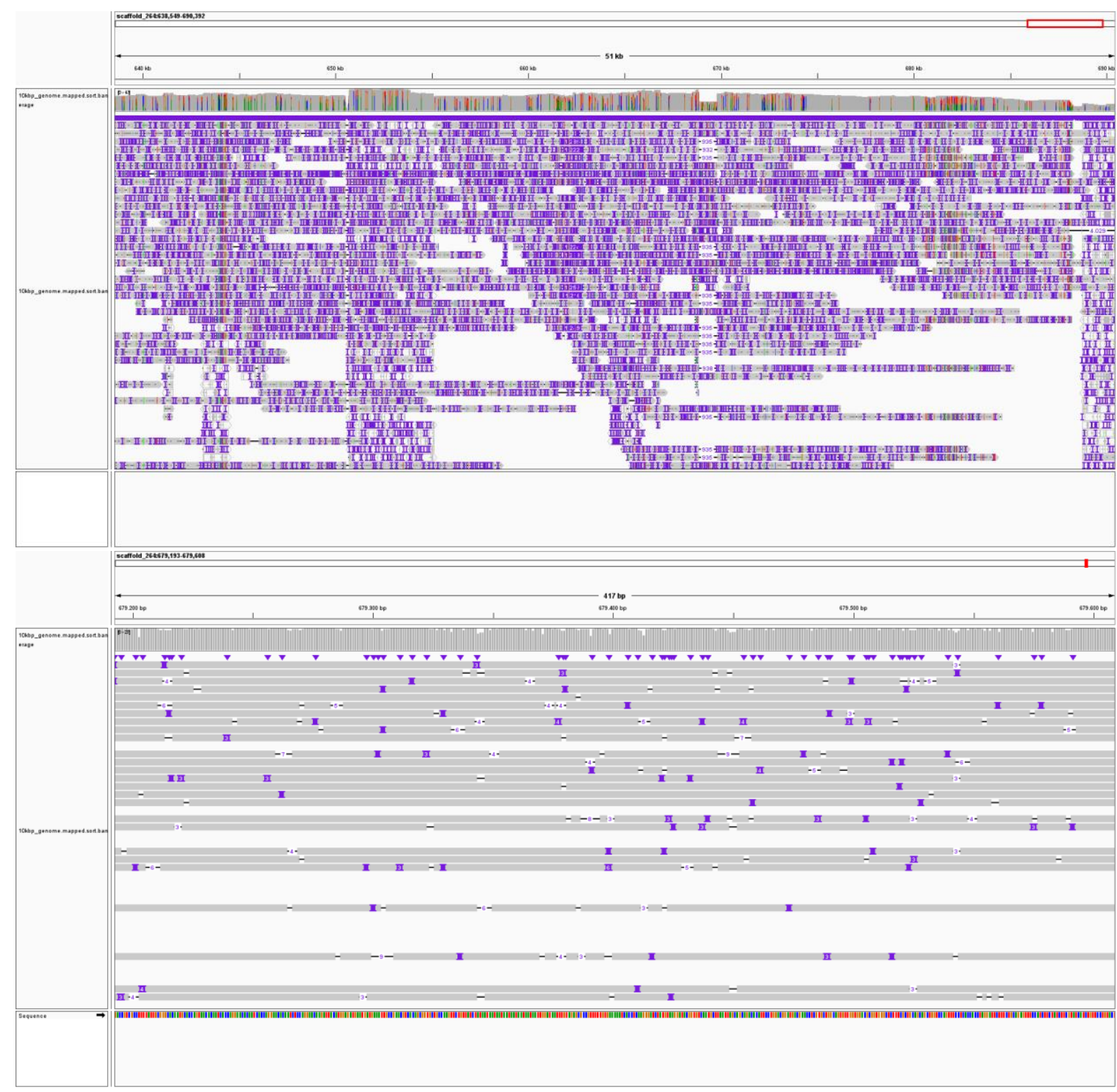

Fig. S85: BUSCO EOG090R0D5K in IGV.

A: scaffold_2906:96588-135291; B: scaffold_2906: 125160-125249 
bioRxiv preprint doi: https://doi org/10.1101/2021 05.10.443368. this version posted July 18, 2021. The copyright holder for this preprint (which was not certified by peer review) is the author/funder, who has granted bioRxiv a license to display the preprint in perpetuity. It is made available under aCC-BY-NC-ND 4.0 International license.

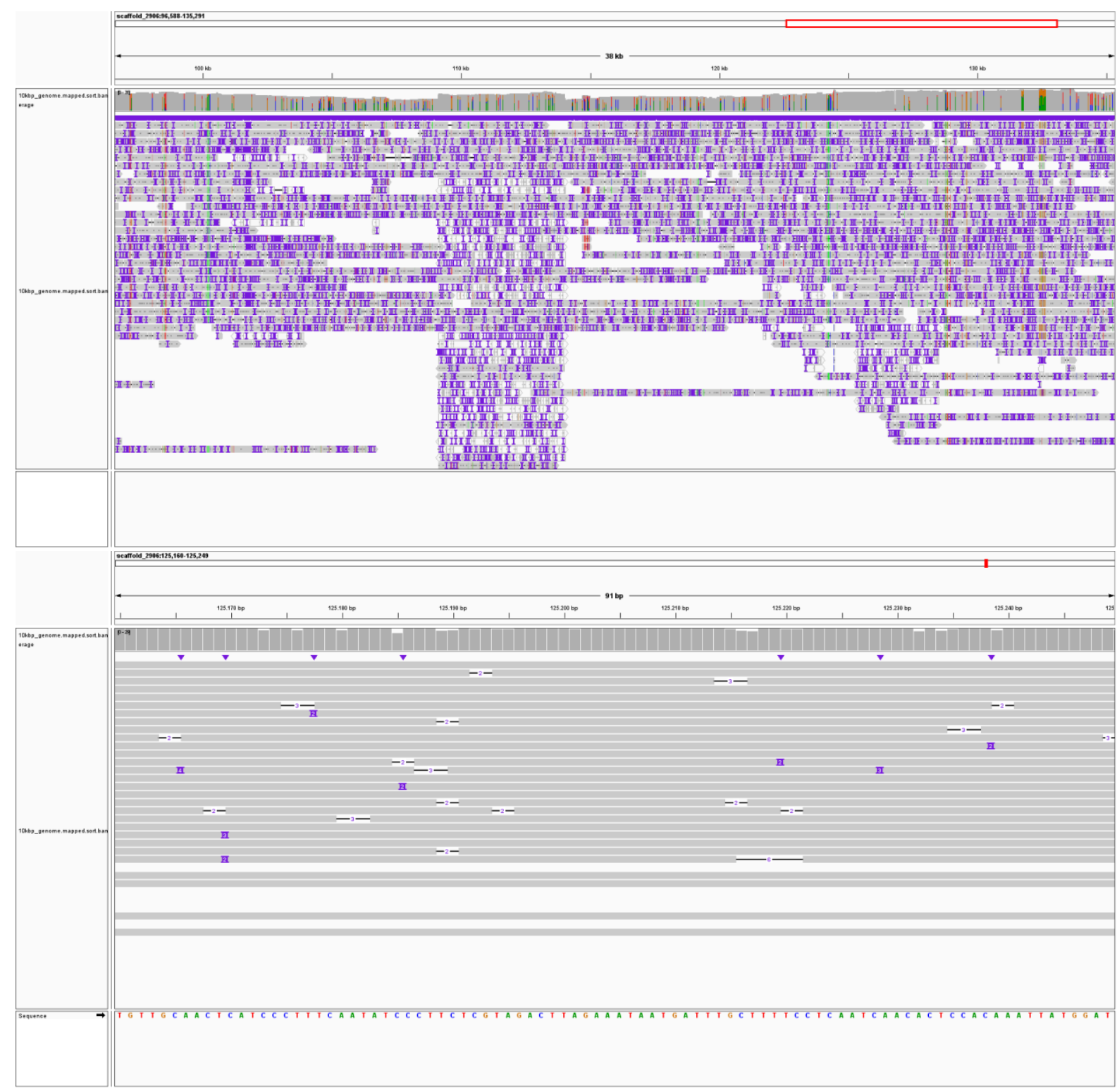

Fig. S86: BUSCO EOG090R0DJA in IGV.

A: scaffold_5579:100801-141491; B: scaffold_5579: 111993-112328 
bioRxiv preprint doi: https://doi org/10.1101/2021 05.10.443368. this version posted July 18,2021 . The copyright holder for this preprint (which was not certified by peer review) is the author/funder, who has granted bioRxiv a license to display the preprint in perpetuity. It is made available under aCC-BY-NC-ND 4.0 International license.

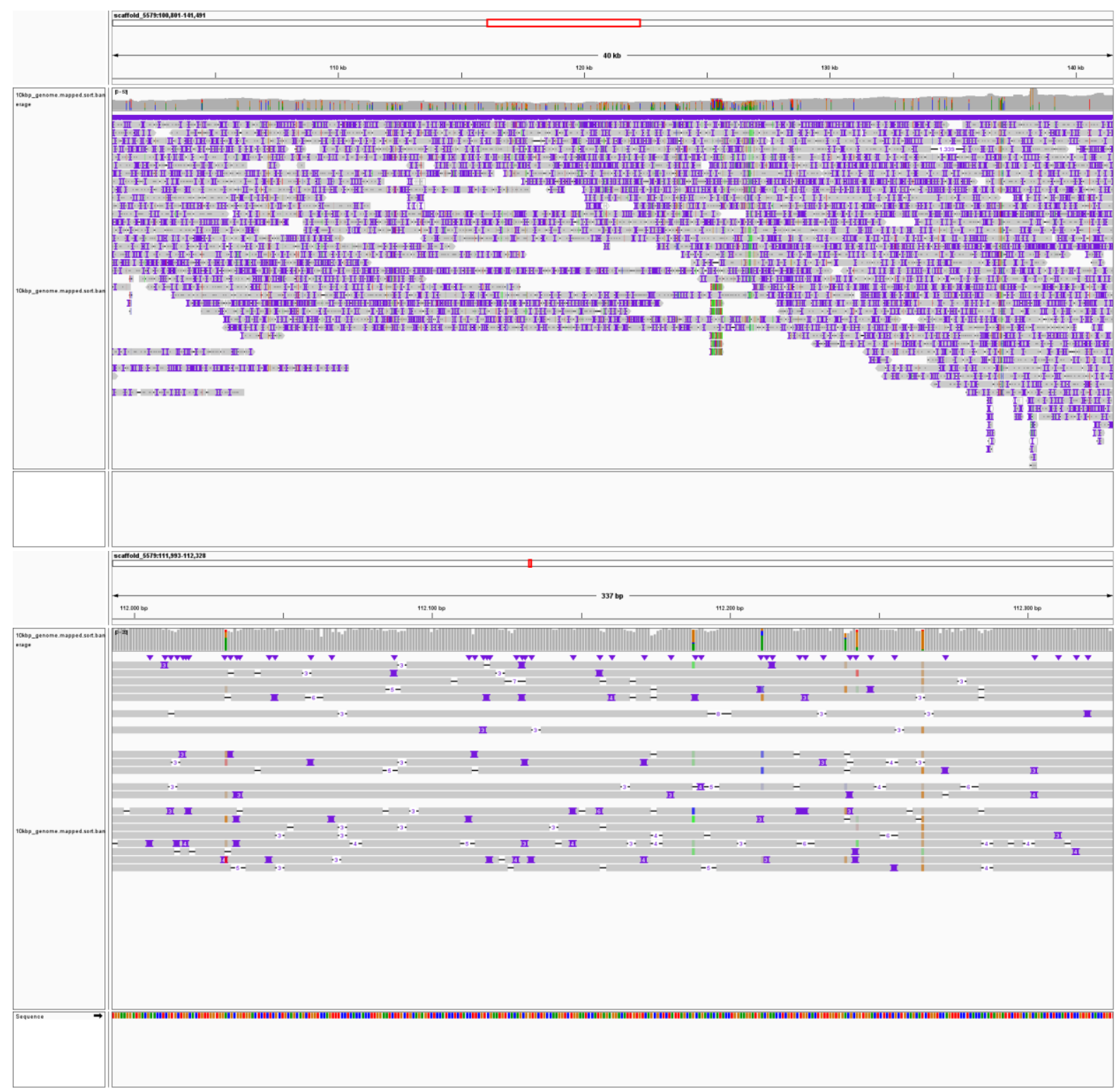


bioRxiv preprint doi: https://doi org/10.1101/2021.05.10.443368. this version posted July 18 2021. The copyright holder for this preprint (which was not certified by peer review) is the author/funder, who has granted bioRxiv a license to display the preprint in perpetuity. It is made available under aCC-BY-NC-ND 4.0 International license.

Fig. S87: BUSCO EOG090R0DQF in IGV.

A: scaffold_396:386030-431740; B: scaffold_396: 406547-406614

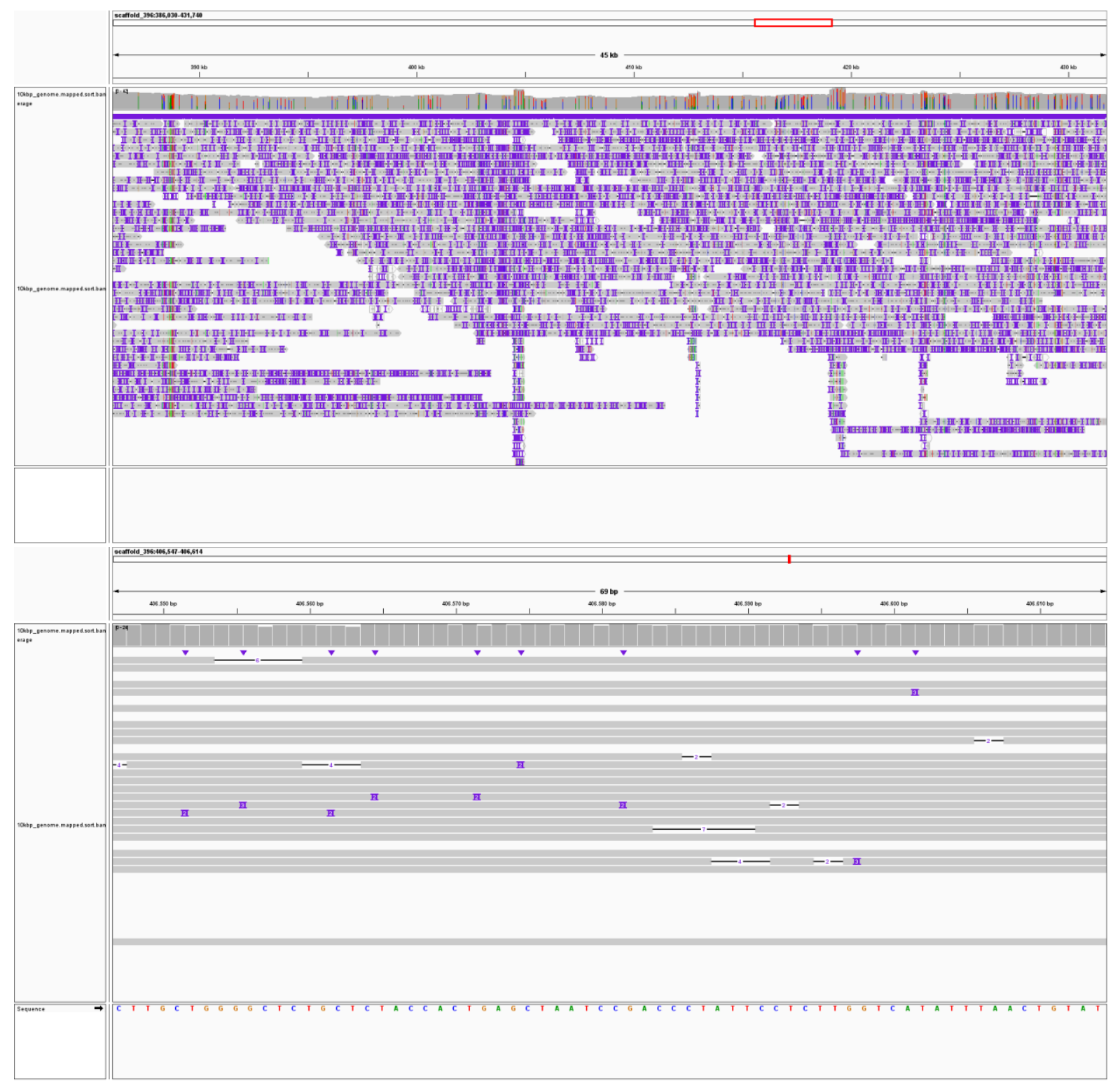


bioRxiv preprint doi: https://doi.org/10.1101/2021.05.10.443368; this version posted July 18, 2021. The copyright holder for this preprint (which was not certified by peer review) is the author/funder, who has granted bioRxiv a license to display the preprint in perpetuity. It is made available under aCC-BY-NC-ND 4.0 International license.

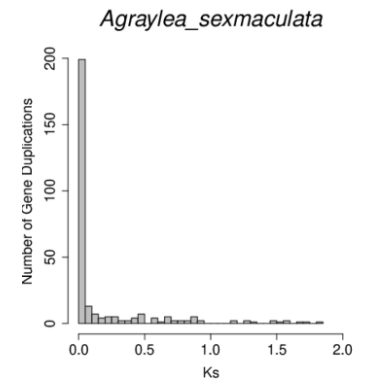

Himalopsyche_phryganea

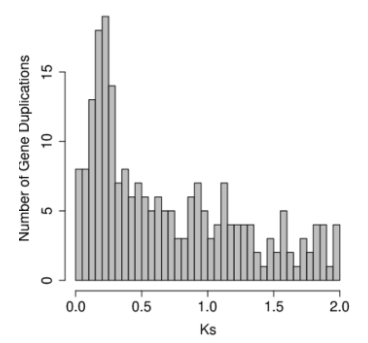

Micropterna_sequax
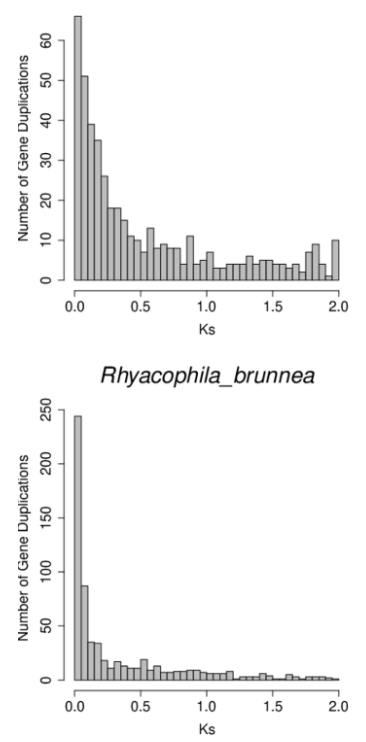

Hesperophylax_magnus

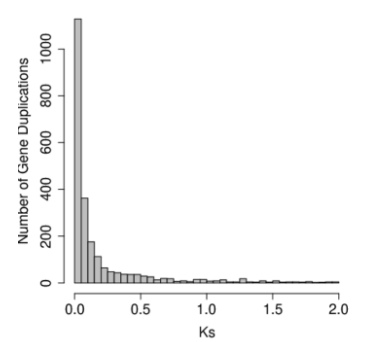

Drusus_anulatus

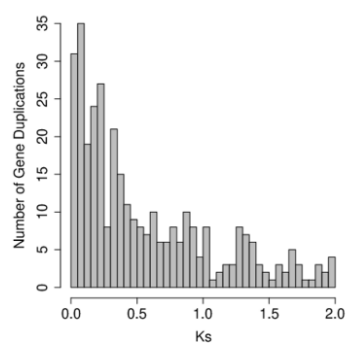

Lepidostoma_basale

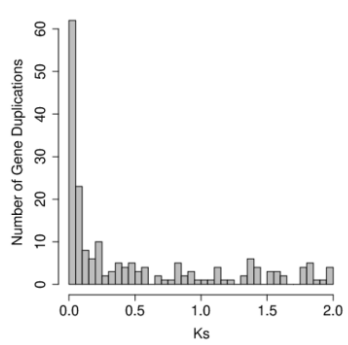

Odontocerum_albicorne

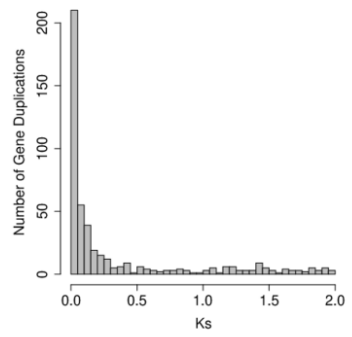

Rhyacophila_evoluta_HR1

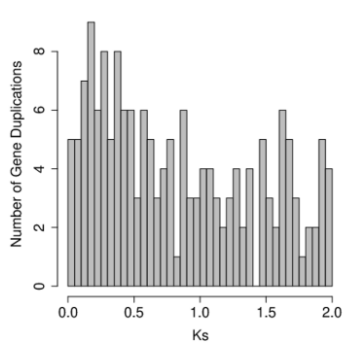

Hydropsche_tenuis

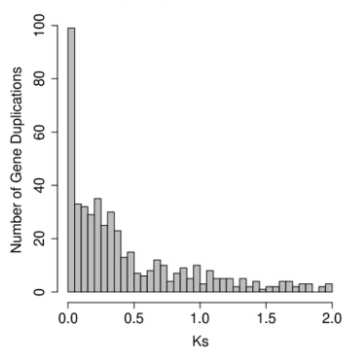

Glossosoma conforme

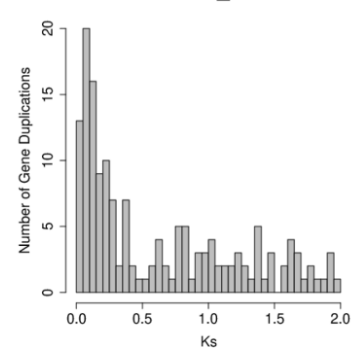

Micrasema_longulum

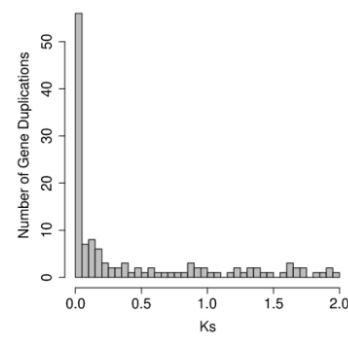

Parapysche_elsis

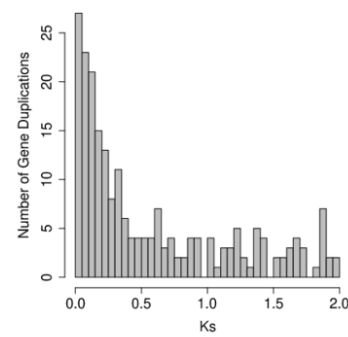

Rhyacophila_evoluta_Rss 1

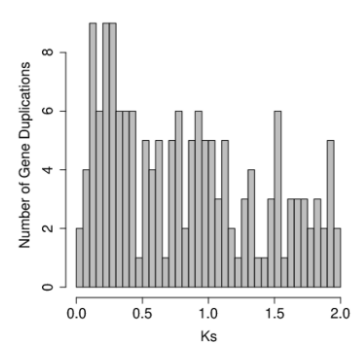

Plectrocnemia_conspersa

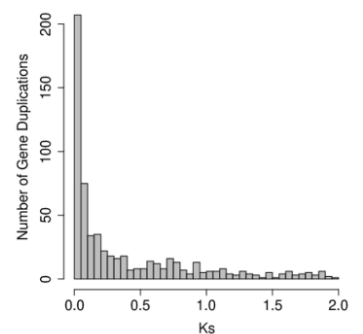

Halesus radiatus

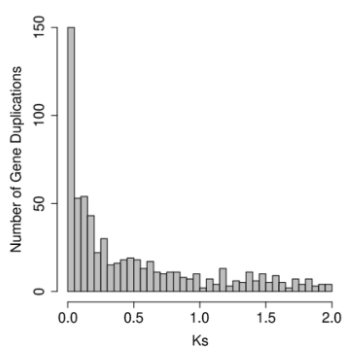

Micrasema_minimum

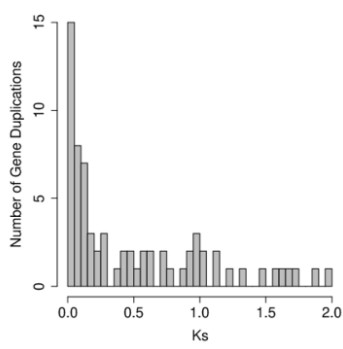

Philopotamus_ludiferatus

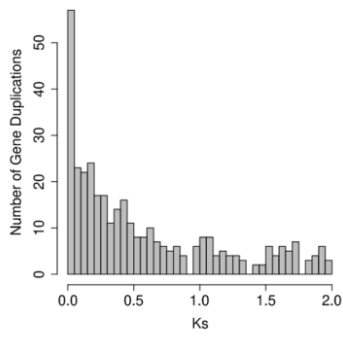

Agrypnia_vestita

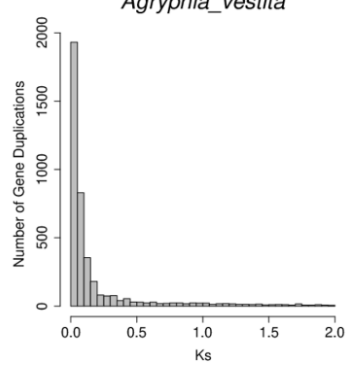

Stenopsyche_tienmushanensis

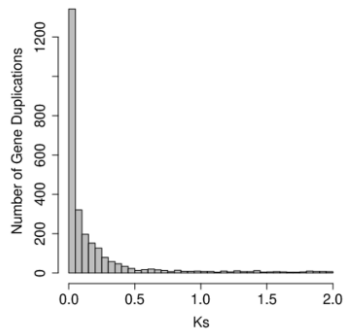

Fig. S88. Inference of WGDs from gene age distributions KS2 


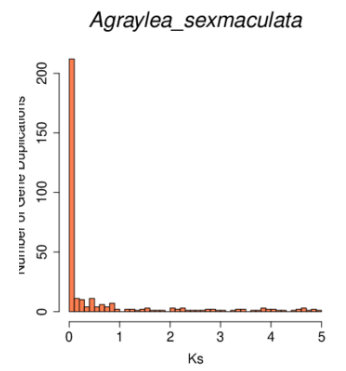

Himalopsyche_phryganea

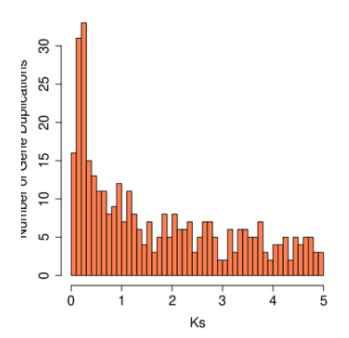

Micropterna_sequax

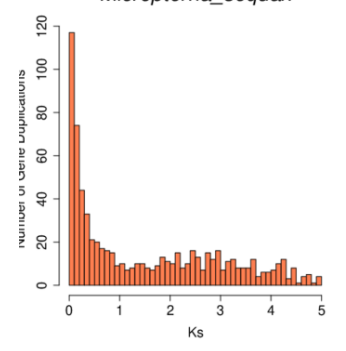

Rhyacophila_brunnea
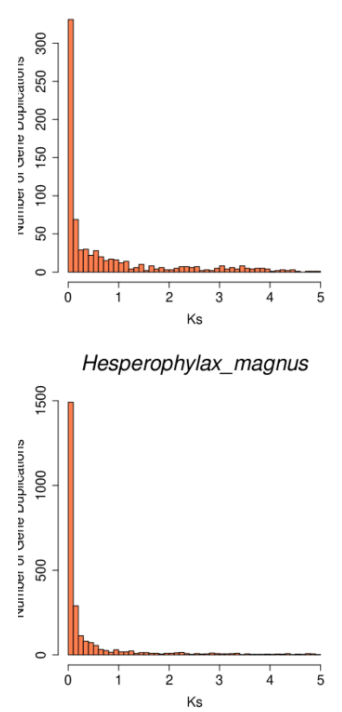

Drusus_anulatus

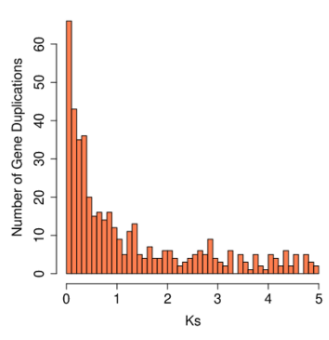

Lepidostoma_basale

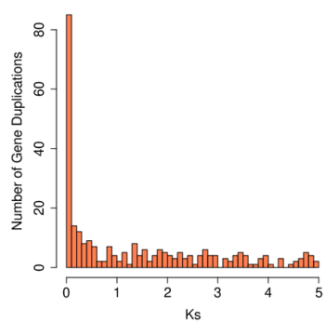

Odontocerum_albicorne

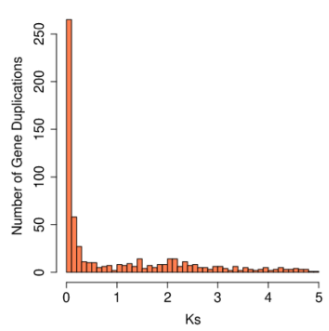

Rhyacophila_evoluta_HR1

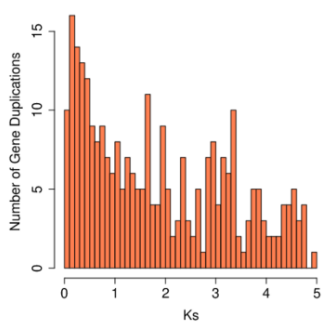

Hydropsche_tenuis

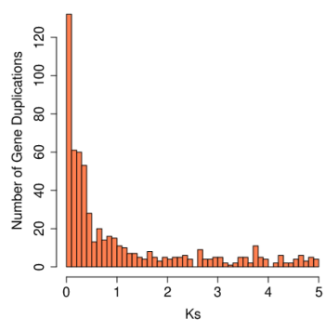

Glossosoma conforme

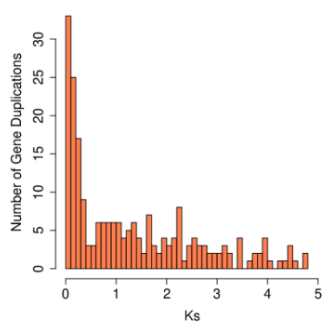

Micrasema_longulum

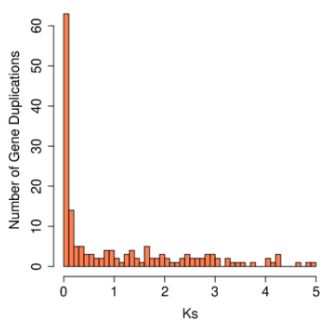

Parapysche_elsis

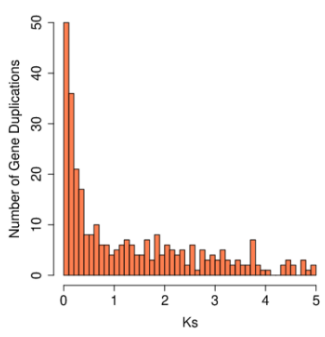

Rhyacophila_evoluta_Rss1

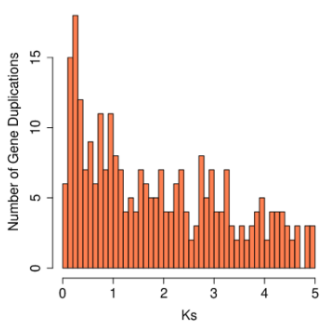

Plectrocnemia_conspersa

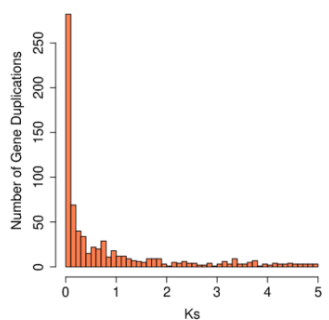

Halesus_radiatus

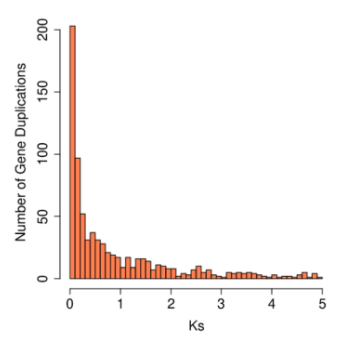

Micrasema_minimum

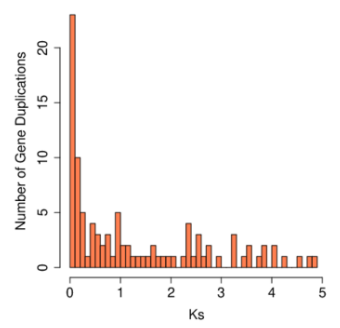

Philopotamus_ludiferatus

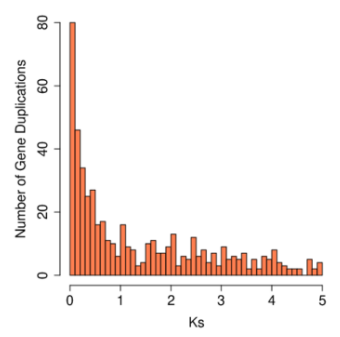

Agrypnia_vestita

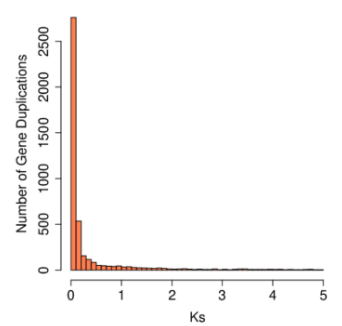

Stenopsyche_tienmushanensis

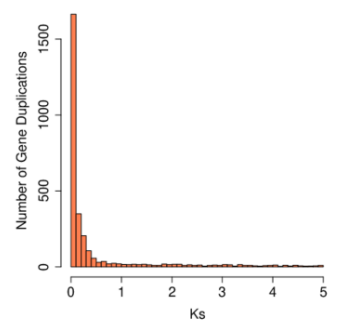

Fig. S89. Inference of WGDs from gene age distributions KS5

\section{References:}

1. Miller SA, Dykes DD, Polesky HF. A simple salting out procedure for extracting DNA from human nucleated cells. Nucleic Acids Res. 16:12151988; 
bioRxiv preprint doi: https://doi org/10.1101/2021.05.10.443368; this version posted July 18,2021 . The copyright holder for this preprin

2. Waldvogel A-M, Wieser A, Schell T, Patel S, Schmidt H, Hankeln T, et al.. The genomic footprint of climate adaptation in Chironomus riparius. Mol Ecol. 2018; doi:

$10.1111 / \mathrm{mec} .14543$.

3. Bolger AM, Lohse M, Usadel B. Trimmomatic: a flexible trimmer for Illumina sequence data. Bioinformatics. 2014; doi: 10.1093/bioinformatics/btu170.

4. Martin M. Cutadapt removes adapter sequences from high-throughput sequencing reads. EMBnet.journal. 2011; doi: 10.14806/ej.17.1.200.

5. Wood DE, Salzberg SL. Kraken: ultrafast metagenomic sequence classification using exact alignments. Genome Biol. 2014; doi: 10.1186/gb-2014-15-3-r46.

6. Wood DE, Lu J, Langmead B. Improved metagenomic analysis with Kraken 2. Genome Biol. 2019; doi: 10.1186/s13059-019-1891-0.

7. Loman NJ, Quinlan AR. Poretools: a toolkit for analyzing nanopore sequence data.

Bioinformatics. 2014; doi: 10.1093/bioinformatics/btu555.

8. Ruan J, Li H. Fast and accurate long-read assembly with wtdbg2. Nat Methods. Nature

Publishing Group; 2020; doi: 10.1038/s41592-019-0669-3.

9. Li H. Minimap2: pairwise alignment for nucleotide sequences. Bioinformatics. 2018; doi:

10.1093/bioinformatics/bty191.

10. Vaser R, Sovic I, Nagarajan N, Sikic M. Fast and accurate de novo genome assembly from long uncorrected reads. Genome Res. 2017; doi: 10.1101/gr.214270.116.

11. Loman NJ, Quick J, Simpson JT. A complete bacterial genome assembled de novo using only nanopore sequencing data. Nat Methods. Nature Publishing Group; 2015; doi:

10.1038/nmeth.3444.

12. Li H, Handsaker B, Wysoker A, Fennell T, Ruan J, Homer N, et al.. The Sequence Alignment/Map format and SAMtools. Bioinformatics. 2009; doi:

10.1093/bioinformatics/btp352.

13. Walker BJ, Abeel T, Shea T, Priest M, Abouelliel A, Sakthikumar S, et al.. Pilon: An Integrated Tool for Comprehensive Microbial Variant Detection and Genome Assembly Improvement. PLOS ONE. Public Library of Science; 2014; doi:

10.1371/journal.pone.0112963.

14. Roach MJ, Schmidt SA, Borneman AR. Purge Haplotigs: allelic contig reassignment for third-gen diploid genome assemblies. BMC Bioinformatics. 2018; doi: 10.1186/s 12859-0182485-7.

15. Antipov D, Korobeynikov A, McLean JS, Pevzner PA. hybridSPAdes: an algorithm for hybrid assembly of short and long reads. Bioinformatics. 2016; doi:

10.1093/bioinformatics/btv688.

16. Bankevich A, Nurk S, Antipov D, Gurevich AA, Dvorkin M, Kulikov AS, et al.. SPAdes: A New Genome Assembly Algorithm and Its Applications to Single-Cell Sequencing. $J$ Comput Biol. 2012; doi: 10.1089/cmb.2012.0021.

17. Laetsch DR, Blaxter ML. BlobTools: Interrogation of genome assemblies.

F1000Research. 2017; doi: 10.12688/f1000research.12232.1.

18. Li H. Aligning sequence reads, clone sequences and assembly contigs with BWA-MEM. ArXiv13033997 Q-Bio. 2013;

19. Wiggins GB, Wichard W. Phylogeny of Pupation in Trichoptera, with Proposals on the Origin and Higher Classification of the Order. J North Am Benthol Soc. [University of Chicago Press, Society for Freshwater Science]; 1989; doi: 10.2307/1467330.

20. : evolution and classification of Trichoptera. I. The groundplan of Trichoptera.

https://agris.fao.org/agris-search/search.do?recordID=US201301471380 Accessed 2021 May 9.

21. Thomas JA, Frandsen PB, Prendini E, Zhou X, Holzenthal RW. A multigene phylogeny and timeline for Trichoptera (Insecta). Syst Entomol. 2020; doi:

https://doi.org/10.1111/syen.12422. 
22. Ross HH. Evolution and classification of the mountain Caddis-flies. :21.

23. Ranallo-Benavidez TR, Jaron KS, Schatz MC. GenomeScope 2.0 and Smudgeplot for reference-free profiling of polyploid genomes. Nat Commun. 2020; doi: 10.1038/s41467-02014998-3.

24. Marçais G, Kingsford C. A fast, lock-free approach for efficient parallel counting of occurrences of k-mers. Bioinformatics. 2011; doi: 10.1093/bioinformatics/btr011. 25. Schell T, Feldmeyer B, Schmidt H, Greshake B, Tills O, Truebano M, et al.. An Annotated Draft Genome for Radix auricularia (Gastropoda, Mollusca). Genome Biol Evol. 2017; doi: 10.1093/gbe/evx032.

26. Quinlan AR, Hall IM. BEDTools: a flexible suite of utilities for comparing genomic features. Bioinforma Oxf Engl. 2010; doi: 10.1093/bioinformatics/btq033.

27. GREILHUBER J, DOLEŽEL J, LYSÁK MA, BENNETT MD. The Origin, Evolution and Proposed Stabilization of the Terms 'Genome Size' and 'C-Value' to Describe Nuclear DNA Contents. Ann Bot. 2005; doi: 10.1093/aob/mci019.

28. Otto F. DAPI staining of fixed cells for high-resolution flow cytometry of nuclear DNA. Methods Cell Biol. 1990; doi: 10.1016/s0091-679x(08)60516-6.

29. Dolezel J, Binarova P, Lucretti S. Analysis of Nuclear DNA content in plant cells by Flow cytometry. Biol Plant. 1989; doi: 10.1007/BF02907241.

30. Wickham H. ggplot2: Elegant Graphics for Data Analysis. 2nd ed. Springer International Publishing;

31. Goubert C, Modolo L, Vieira C, ValienteMoro C, Mavingui P, Boulesteix M. De Novo Assembly and Annotation of the Asian Tiger Mosquito (Aedes albopictus) Repeatome with dnaPipeTE from Raw Genomic Reads and Comparative Analysis with the Yellow Fever Mosquito (Aedes aegypti). Genome Biol Evol. 2015; doi: 10.1093/gbe/evv050.

32. Negm S, Greenberg A, Larracuente AM, Sproul JS. RepeatProfiler: a pipeline for visualization and comparative analysis of repetitive DNA profiles. bioRxiv. Cold Spring Harbor Laboratory; 2020; doi: 10.1101/2020.05.22.111252.

33. Altschul SF, Gish W, Miller W, Myers EW, Lipman DJ. Basic local alignment search tool. J Mol Biol. 1990; doi: 10.1016/S0022-2836(05)80360-2.

\section{Data S1. (separate file)}

Excel sheet with sampling information, assembly statistics, genome size measurements, Ks test

\section{Data S2. (separate file)}

Excel file with counts from intersect (TE-gene interactions) analysis 